\title{
LIDERAZGO EMOCIONAL: IMPACTO EN LOS COLABORADORES
}

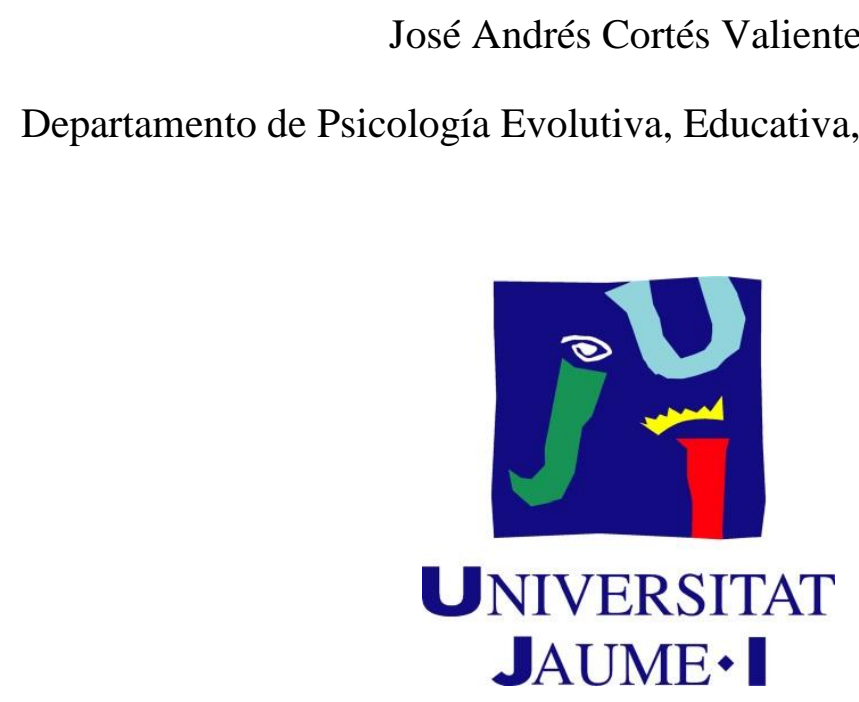

Castellón, 8 de Enero 2016

Directoras: Dra. Eva Cifre Gallego

Dra. María Vera Perea 


\section{Agradecimientos}

Se supone que en el momento de morir automáticamente perdemos 21 gramos que, según defienden algunas personas, corresponden a nuestra alma dejando atrás nuestro cuerpo. No sé si será así o no, pero puedo asegurar que con estas palabras se cierra un viaje llamado doctorado que emprendí, que nadie se asuste, hace más de 14 años. Puedo asegurar, que he puesto todo mi esfuerzo, ilusión, trabajo y pasión, en cada una de sus etapas y creo, sinceramente, que todo este equipaje pesa más que 21 gramos.

Esta Tesis refleja, a su manera, mi forma de entender la vida, la cual busca en todo momento el equilibrio entre lo emocional, y lo racional. Pero eso sí, siempre destacando el valor de seguir los impulsos emocionales que te hacen vibrar y sentir que estás en la dirección adecuada cuando no sabes qué hacer, ni dónde ir. A lo largo de mi vida, en el instante de escoger una alternativa u opción de cómo debía actuar y que puerta debía de abrir en busca de un camino, el criterio de elección se basaba según la vibración que producía cada una de ellas en mi interior. Ganaba la que me hacía sentir la pasión de vivir la experiencia. Me como la vida a bocados, por eso estoy en el Ecuador, persiguiendo el amor, cuando me di cuenta, que en él está la felicidad y el equilibrio espiritual.

Siempre la opción que vencía era la que la intuición me indicaba que era la correcta. De ahí que desde niño se me calificase de loco por escoger alternativas poco racionales y alejadas de los convencionalismos o, de lo que supone que “debería ser”. Y así empezó este viaje del doctorado con la elección del programa que quería seguir.

La decisión de seguir estudiando académicamente vino simplemente por ser fiel a uno de los valores que no voy a perder en mi vida, la integridad. Y es que como profesional que era del área de Recursos Humanos, no entendía que los asesoramientos y las consultorías que se hacían en el sector no tuviesen credibilidad y validez científica y académica. Sin eso, eres un vendedor de humo. El miedo de que mis actos como profesional y mis palabras fuesen cortinas de humo que los clientes compraban como novedad y novelería, me obligó a volver a estudiar un programa de corte más 
académico alejándome de lo más netamente empresarial. No había ningún impulso ni motivación, por otro lado respetable, de seguir una trayectoria como investigador en una universidad. Una vez que tuve claro que iba a estudiar el doctorado, allá creo que era el año 1999-2000, mis dos opciones eran: Valencia o Castellón. Yo había sido graduado de la Universidad de Valencia, y lo programas de doctorado que habían en psicología organizacional eran dirigidos por profesionales muy afamados y con una reputación ganada con mucho trabajo. Visité de nuevo mi ex universidad y me describieron el plan académico, los cursos, los procesos, y me abrieron las puertas administrativamente, eso sí, fríamente. Decidí visitar la Universidad Jaume I en Castellón. Nueva en muchas cosas en aquella época y sin mucho impacto en el medio en aquellos años. Allí me recibió la anterior catedrática, Rosa Grau. Me atendió muy afable, cordial, y me explicó las bondades del programa con un equipo joven vinculado a la Salud Psicosocial. Todo muy bonito, pero lo que me sorprendió fue como una señora catedrática, se levantase y me acompañase a la fotocopiadora para hacerme ella misma copias del programa. Ahí ya mi intuición sabía que iba a escoger Castellón. Si una catedrática te daba ese trato, ¿cómo no te lo iban a dar los profesores y tu futura directora de doctorado? Y efectivamente así sucedió años después. El trato que he recibido de mis profesoras y directoras desde entonces ha sido, una mezcla de profesionalidad y calidez humana, impagables. Gracias a ellas he conseguido llegar hasta aquí. Pero, debo ser justo y empezar a agradecer siguiendo un orden, pues muchas personas han compartido este peregrinaje.

En primer lugar, debo de dar gracias a mis padres, hermanas, y abuelos/as por enseñarme una marcada ética de trabajo basada en el esfuerzo. Los que nacemos en un entorno humilde no nos queda otra que trabajar con mucho sacrificio y dedicación. Mis padres nos educaron así, si algo quieres, algo tienes que hacer. El valor del esfuerzo. Y en esta parte no puedo olvidar a mi abuelo materno que me inculcó desde pequeño la semilla del aprendizaje constante, la curiosidad por conocer, y el amor por la lectura. Ahora mi familia está lejos, pero doy gracias por saber que los tengo ahí siempre que los necesito y siento la alegría de mis sobrinos; Anna, Teresa, Hugo y Aitana, son un regalo. Muchas 
gracias a mis dos hermanas $\mathrm{M}^{\mathrm{a}}$ Ángeles y Reme, espero que me sepan disculpar que la vida me ha llevado a gran distancia en kilómetros pero no de sentimientos vacíos. Sigo siendo el mismo desastre que siempre he sido pero sé que me vais a echar una mano para los líos que os meto. Ahora mi familia de Ecuador recibe mis gruñidos y mis malas formas, gracias también por intentar que mi estancia en Quito sea más fácil.

Debo de agradecer a mi maestro de EGB, Don Joaquín Estal. Te lo he dicho varias veces en persona y por escrito, si no es por la confianza y el camino que me abriste de superación y de esperanza cuando tenía 12 años, no creo que estuviese ahora aquí. No hay palabras de agradecimiento para ti, se quedan cortas. Cuando me preguntan qué cosas me enseñaste y me dicen, fue ¿sociales? ¿Inglés? ¿Matemáticas?, pues no. Lo que me enseñaste es que si crees en los demás, con sinceridad y amor, y les das una oportunidad, puedes ayudarles a cambiar su propio destino. No hay nada escrito.

Gracias Simón, eres un crack. La persona que me mostró, en vivo y en directo, lo que es realmente la capacidad de influenciar en los demás y que te sigan hasta la muerte. Siempre lo diré, aprendí contigo prácticamente todo lo que sé de cómo gestionar personas. Un verdadero mago en la utilización de las estrategias de influencia, y eso, que en tu vida has leído un libro de Yukl, ni un libro de liderazgo de ningún gurú. Si lo hubieses hecho, probablemente les hubieses corregido y ampliado con tus experiencias. Gracias maestro, un ejemplo también de superación.

Gracias a los compañeros de SGS-España, Carlos, Dulce, Silvia, Sandra, Ana, con vosotros aprendí realmente como se debe de trabajar con calidad y exigencia. Y gracias también, porque sé, que siempre vais a estar ahí como amigos. Es una alegría inmensa veros cuando regreso a España.

Gracias a los amigos nuevos del Ecuador por respetar y comprender mis aislamientos estos meses de tesis. Espero devolver el tiempo arrancado con creces a partir de ahora. Dejaré de ser ermitaño y contestar a vuestras invitaciones siempre con la famosa frase "estoy estudiando, no puedo”. Gracias a todos vosotros por los ánimos y poner cara de interesados cuando os contaba en las montañas andinas a $3.000 \mathrm{mts}$ de altura cómo demonios era posible que los líderes influyeran en 
lo mental de sus colaboradores. Recuerdo haciendo dibujos con un palo en Parque Metropolitano de los resultados de la tesis poseído por la pasión de la explicación tras correr 10 km por la montaña, ¿qué estaríais pensando vosotros de todo eso?

En este punto, hay que agradecer a los jefes que tengo por darme tiempo y apoyo de todo tipo para realizar esta tesis. Es muy raro ver que un Rector que, ante las responsabilidades de gestión asociadas a mi puesto, me facilitase tiempo para poder acabar la tesis. Y no es peloterio, o como se dice en el Ecuador, "hacer cepillo”. Ernesto Flores eres un excelente jefe en el Instituto Tecnológico Superior Cordillera que destacas por tu faceta humana. Una muestra que se puede unir resultados con la buena gestión de personas. Ese es el camino que has aprendido y espero acompañarte en esa senda. Sólo puedo estar agradecido por el trato y confianza que me ha dado desde que entre en el instituto. Si no es por el tiempo que se me concedió, no sé cómo podría haber terminado esta tesis. De igual modo, mis respetos y agradecimiento al ideólogo-educador y humanista Cristóbal Flores por contagiarme de su amor por intentar ofrecer la mejor educación a las personas más desfavorecidas. Podemos discutir, pero esa misión y visión fundacional organizacional la llevo en mis entrañas. Hermoso el querer dar oportunidades de calidad educativa a personas con recursos bajos, así era yo. No hay peor cosa que ser un adulto sin memoria de lo que fue y vivió de niño.

Y ya vamos cerrando el viaje. Eva y María, mis directoras. Tengo muy claro que sin vosotras dos no hubiese sido posible acabar lo que se inició hace tanto tiempo atrás. Cada una me habéis hecho mejor y gracias a vosotras mis graves limitaciones se han ido subsanando. Muchísimas gracias, por el apoyo emocional, por los rollos burocráticos que me superan a $10.000 \mathrm{~km}$ de distancia, y por exigirme cuando era necesario. Gracias Eva pues desde un principio siempre has estado ahí, y ya son años. Gracias en especial María por vivir y empatizar conmigo este viaje como si fuese el tuyo, no tiene precio ese nivel de involucración personal que has tenido conmigo. ¡Vaya tela! Y la leche, ese nivel técnico que tienes en tus correcciones ha hecho que mejorase cada día, eso sí, sacándome la madre. 
Por último, ni un millón de vidas hay espacio sufriente para decirte lo que te quiero y lo agradecido que estoy al universo por despertar cada día y sentir los latidos de tu corazón a mi lado. Belén, tu eres la razón y el por qué. Gracias por tu paciencia, tu energía positiva, tu apoyo incondicional, tu amor, por creer en mí y en nosotros. Cuando surgía el desaliento aparecía tu sonrisa, cuando aparecía el cansancio me dabas tu mano, cuando había frustración me dabas un abrazo. Y es que mi fuerza interior no es nada sin el equilibrio que me da tu maravillosa compañía. Gracias compañera de sueños hechos realidad.

Ya echaré de menos tu pregunta,

Cosi, y hoy, ¿cuántas hojas has escrito?

Pronto seremos tres, y espero que Pau sea cómo tú., pues como dice Calle 13, ¡¡No hay nadie como tú, mi amor!!

Para ti Belén... 


\section{Tabla de contenidos}

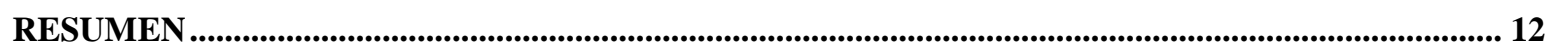

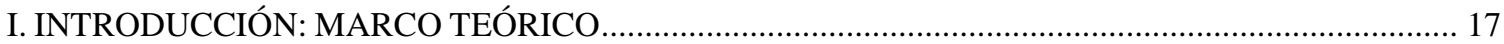

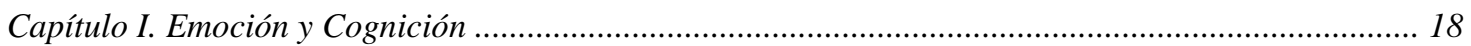

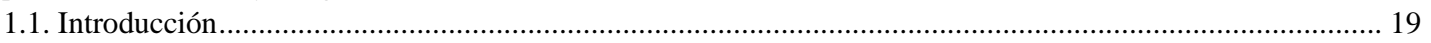

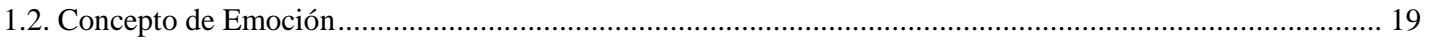

1.3. Evolución Histórica del Estudio Científico de la Emoción.......................................................................... 23

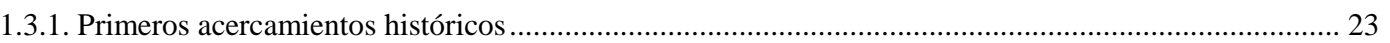

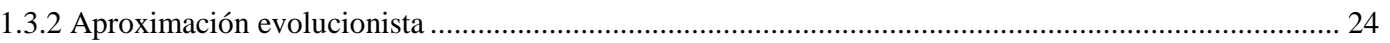

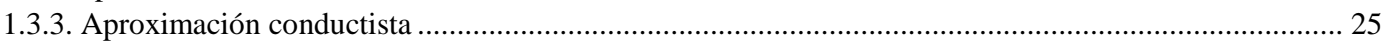

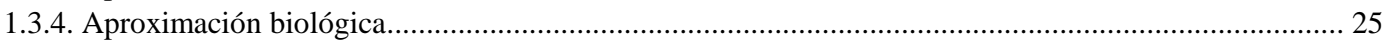

1.3.4.1. James-Lange. Teoría Periférica de la emoción.......................................................................... 25

1.3.4.2. Teoría de la Activación en las Emociones ................................................................................ 27

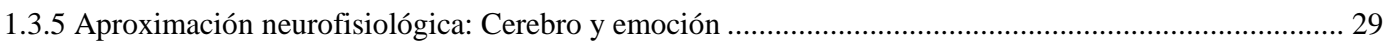

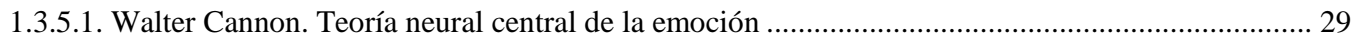

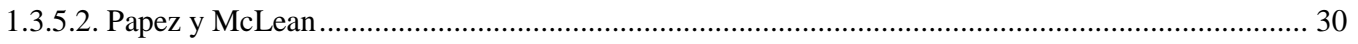

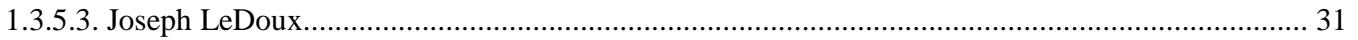

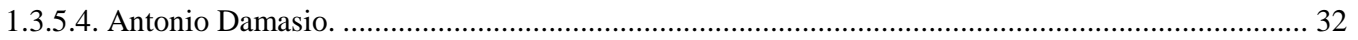

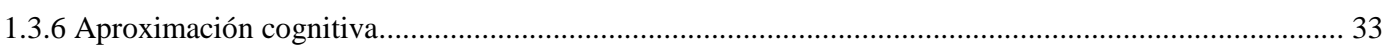

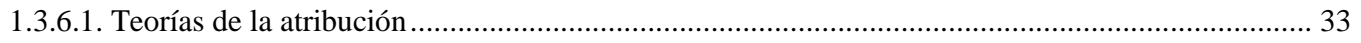

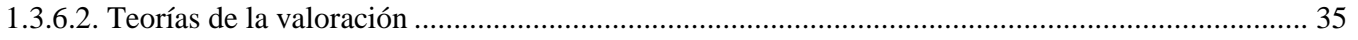

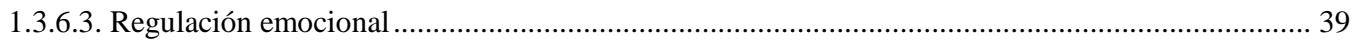

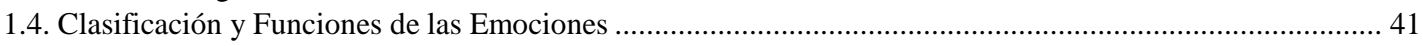

1.4.1. Clasificación de las emociones. .................................................................................................... 41

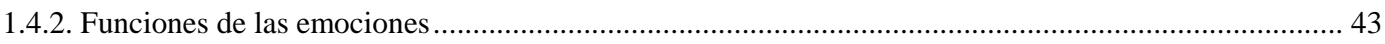

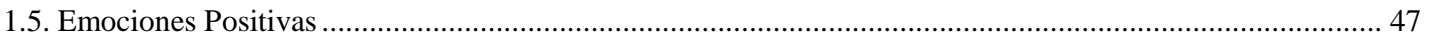

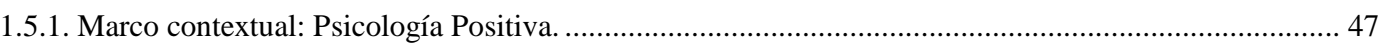

1.5.2. Teoría de la Ampliación y Recursos: Broaden-and-Build Theory ............................................................ 50

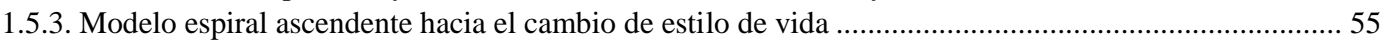

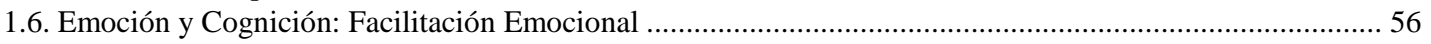

1.6.1. Anatomía de la emoción y cognición............................................................................................ 57

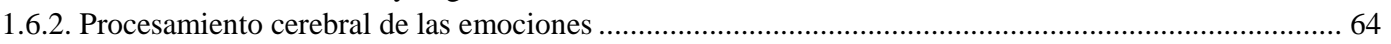

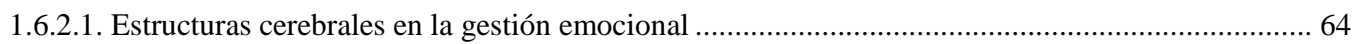

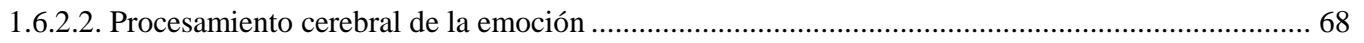

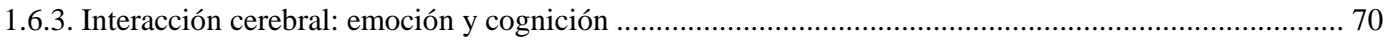

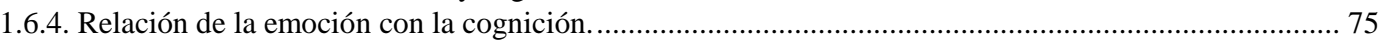

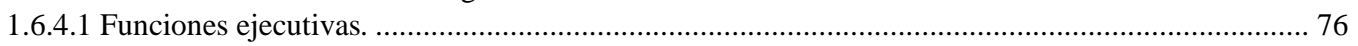

1.6.4.2. Impacto de las emociones en las funciones ejecutivas ............................................................... 79

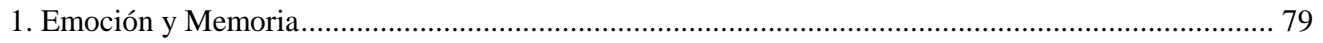

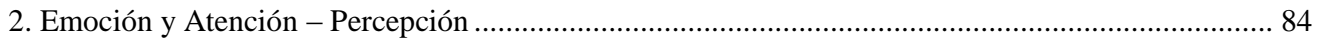

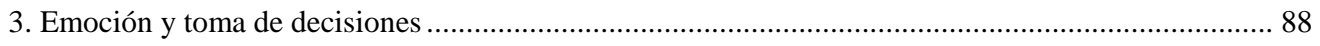

4. Emoción, flexibilidad cognitiva y creatividad...................................................................................... 96

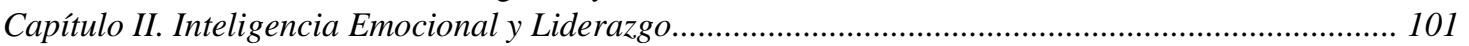

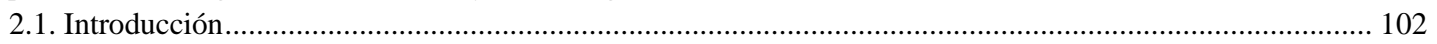

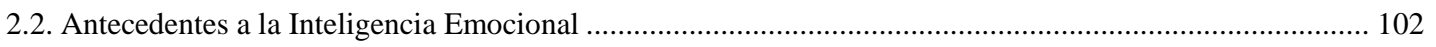

2.3. Evolución del Constructo de Inteligencia Emocional ............................................................................... 106

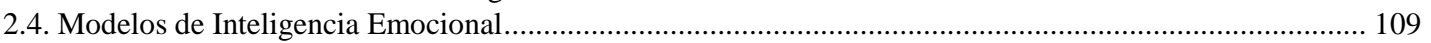

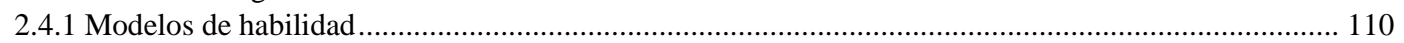

2.4.1.1. Modelo de las cuatro ramas de Mayer y Salovey (1997) …………………………………...... 110

2.4.1.2. Propuesta Ampliación del Modelo de las Cuatro Ramas .................................................................. 114

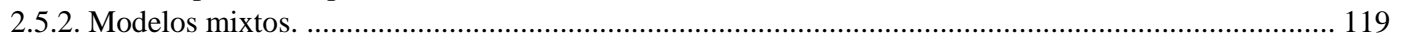

2.5.2.1. Modelo de competencias (Goleman, Boyatzis y McKee, 2002).................................................. 119

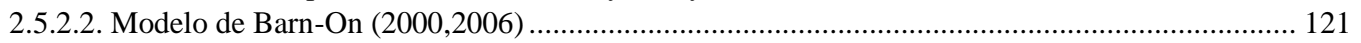

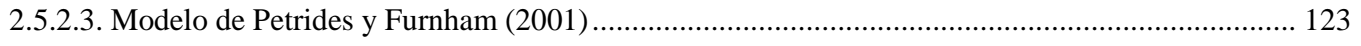


2.6. Instrumentos de Evaluación de la Inteligencia Emocional......................................................................... 126

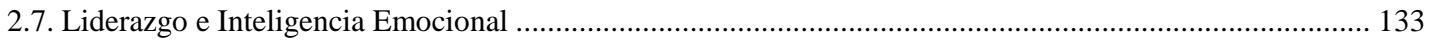

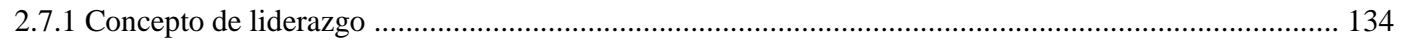

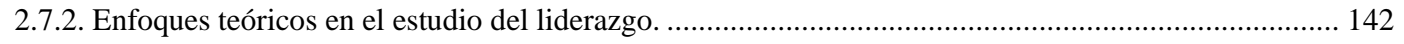

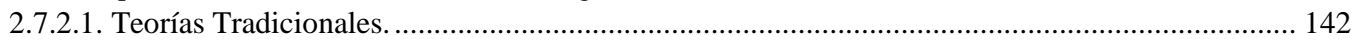

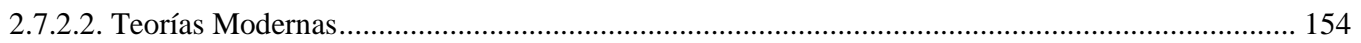

2.8. Influencia de la inteligencia emocional en el liderazgo .................................................................. 175

2.8.1. Primera cuestión: Importancia de la inteligencia emocional en los líderes ...................................... 175

2.8.2 Segunda cuestión: Impacto de la inteligencia emocional de los/as líderes en los/as colaboradores/as. 178

Capítulo III. Comprensión Emocional............................................................................... 191

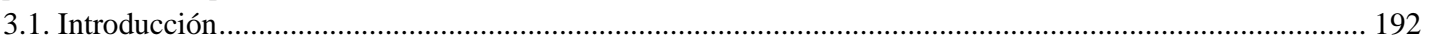

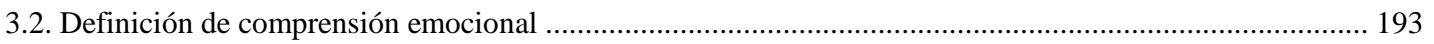

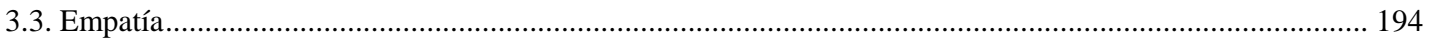

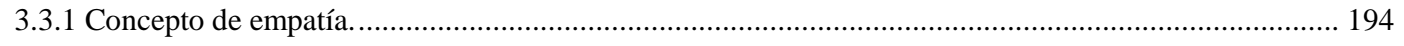

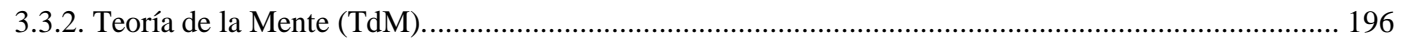

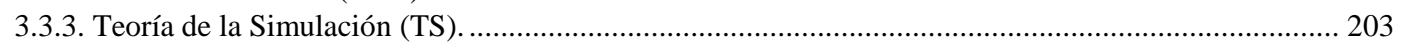

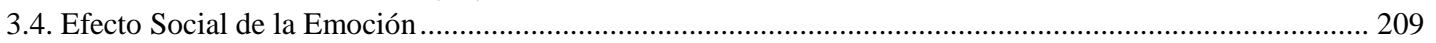

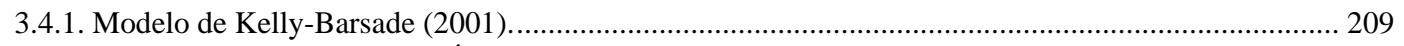

3.4.2. Modelo EASI: Universidad Ámsterdam (Van Kleef, 2009) .......................................................... 210

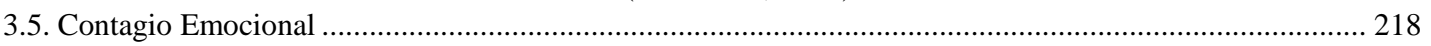

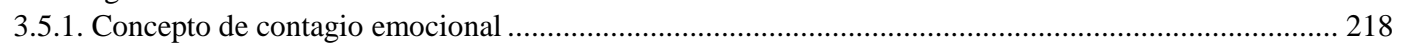

3.5.2. ¿Cómo se produce el contagio emocional? ......................................................................... 221

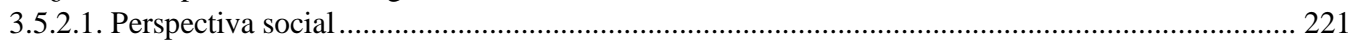

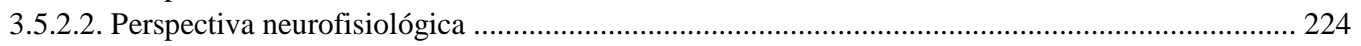

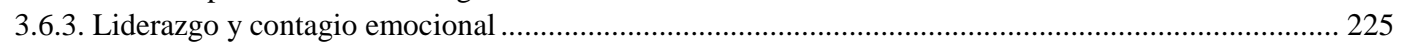

Capítulo 4. Engagement, Vigor, y su influencia en el liderazgo........................................................... 233

4.1. Marco contextual: Psicología Positiva aplicada al contexto organizacional ............................................ 234

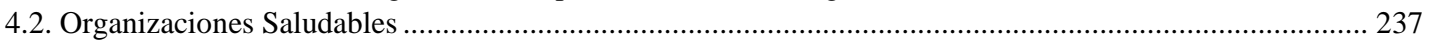

4.2.1. Recursos y prácticas organizacionales saludables.................................................................. 239

4.2.2. Colaboradores/as y grupos de trabajo saludables................................................................... 243

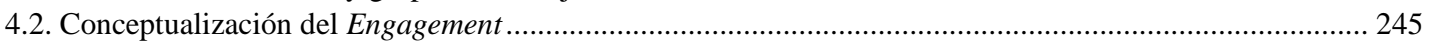

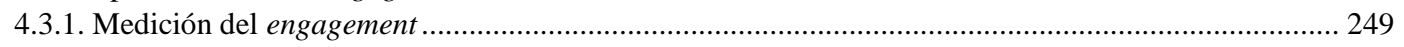

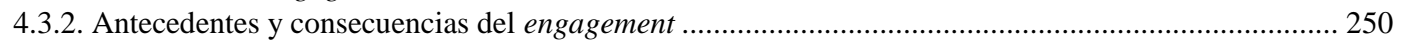

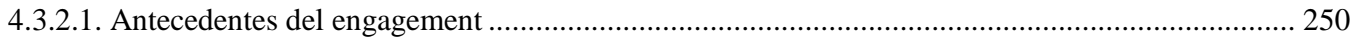

4.3.2.2. Consecuencias en el contexto laboral del engagement ............................................................. 251

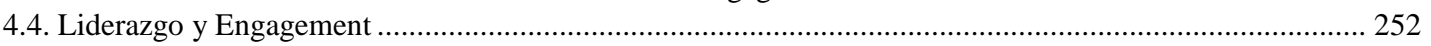

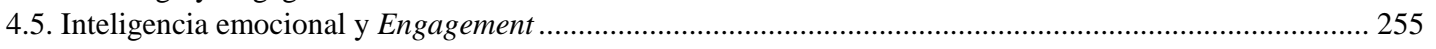

4.6. Conceptualización Multidimensional del Vigor ............................................................................... 256

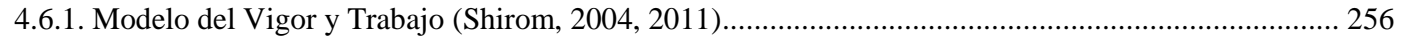

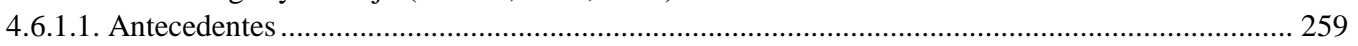

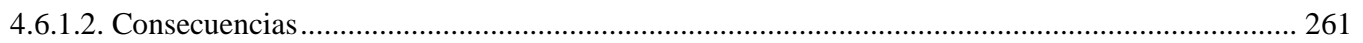

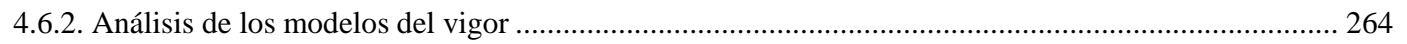

4.7. Liderazgo y vigor: Integración de modelos ...................................................................................... 266

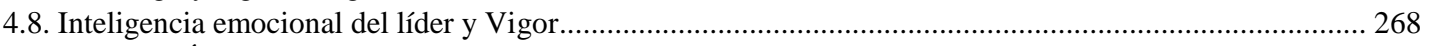

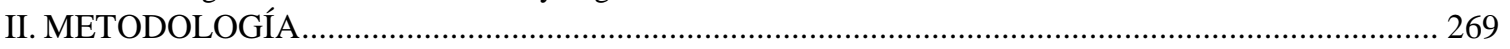

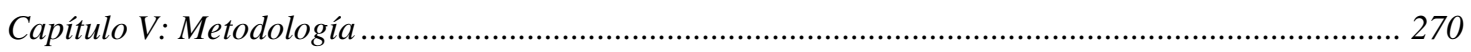

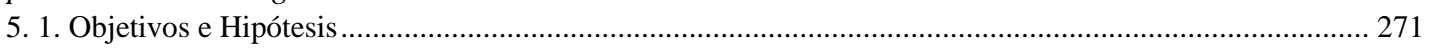

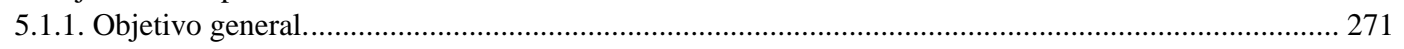

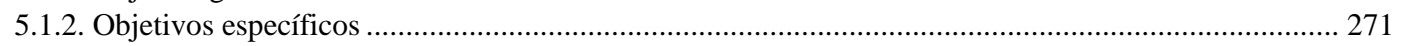

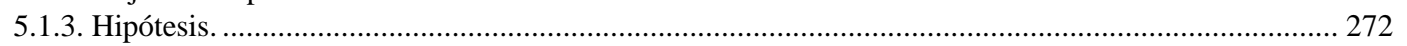

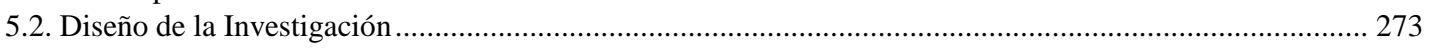

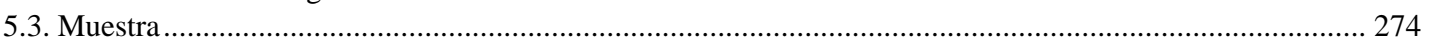

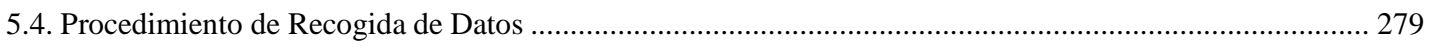

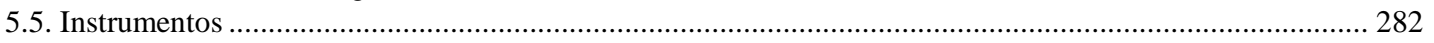

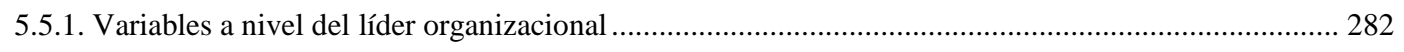

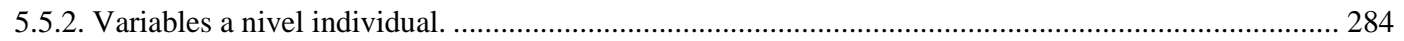




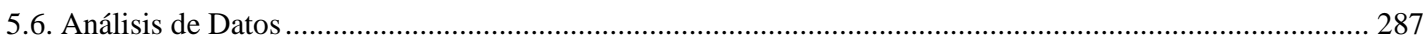

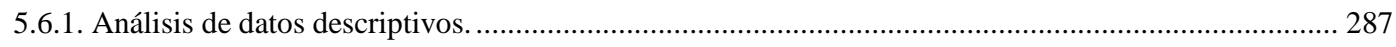

5.6.2. Análisis de datos multinivel para la comprobación de las hipótesis............................................... 289

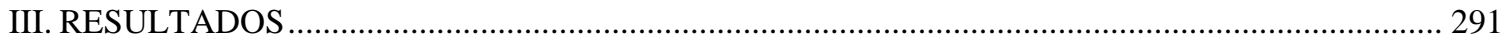

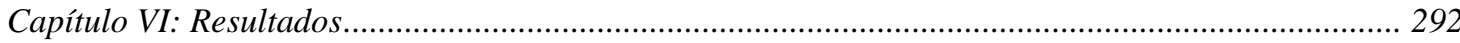

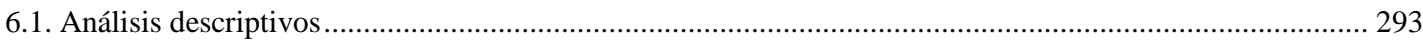

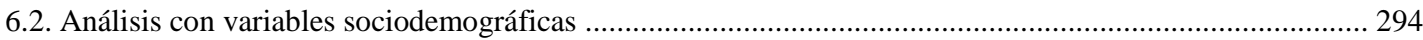

6.3. Análisis Multinivel para la Comprobación de las Hipótesis ......................................................................299

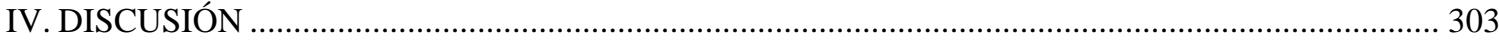

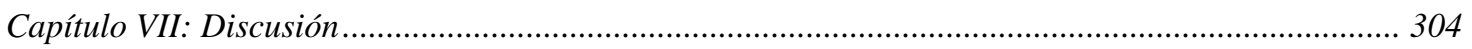

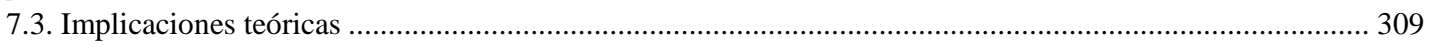

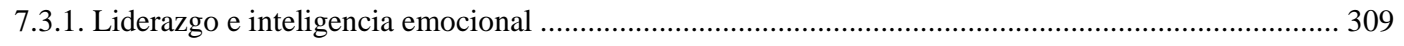

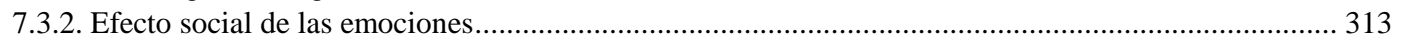

7.3.3. Inteligencia Emocional: Comprensión y Facilitación emocional ....................................................... 314

7.3.4. Diferencias individuales y Vigor de los colaboradores/as....................................................... 319

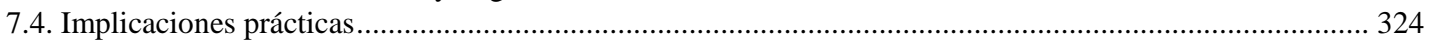

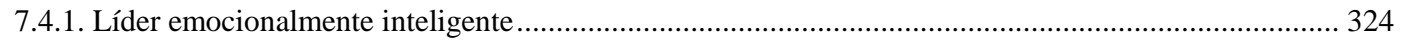

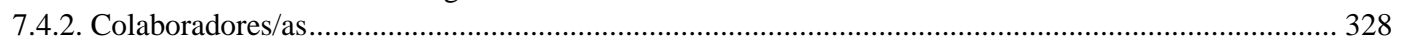

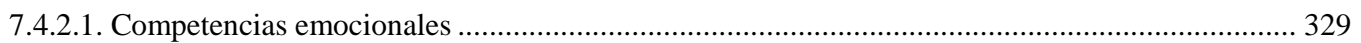

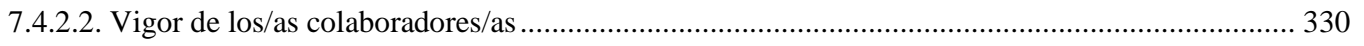

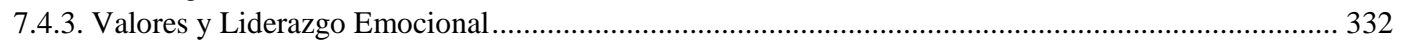

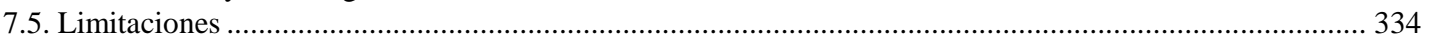

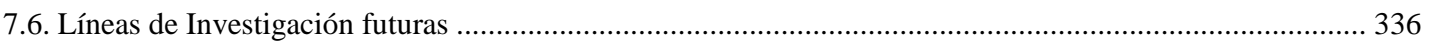

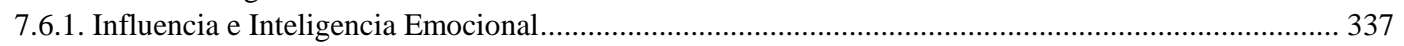

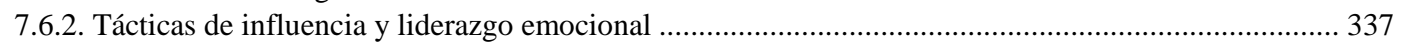

7.6.3. Emociones positivas y negativas en el contagio y facilitación $\quad$ emocional ................................... 339

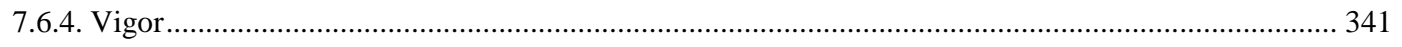

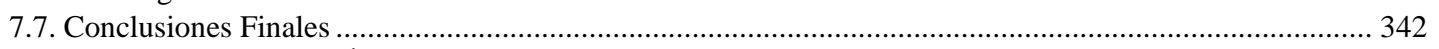

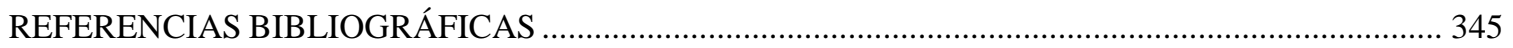




\section{Resumen}

La presente Tesis se enmarca dentro del interés profesional sobre qué aspectos se vuelven esenciales en el proceso de influencia que se establece entre el/la líder y sus colaboradores/as. Durante mis años de experiencia en el mundo organizacional en diferentes roles, Director de Formación, Director de Evaluación y Acreditación, y Coach ejecutivo, he apreciado cómo ciertos lideres establecían fuertes conexiones con sus colaboradores/as de forma intuitiva, casi natural. Gracias a los conocimientos adquiridos, a través de la combinación de una extensa experiencia profesional y de un labrado transcurrir por las diferentes etapas que han configurado este proceso como doctorando, he podido comprobar como estos/as líderes disponían de una serie de herramientas y habilidades emocionales, muchas veces sin saberlo, que les hacían distintos/as. Influían de una manera sobre sus colaboradores/as que hacían que éstos/as les siguiesen sin dudar, y, sobre todo, esta influencia les hacía mejorar en su puesto de trabajo. Yo mismo recibí esta influencia en su momento.

Estas habilidades emocionales se agrupan en el constructo de inteligencia emocional de Mayer y Salovey (1997) compuesto de cuatro factores: percepción, comprensión, facilitación, y manejo emocional. Aunque, cómo se describirá en la última sección, consideramos la alternativa de ampliar el modelo con otra habilidad como es la de influencia emocional, tal y como argumenta Côté, y Hideg (2011).

En definitiva, mi empeño era conocer la importancia de lo emocional en la relación líder-colaborador y darle evidencia empírica a lo que defiendo a capa y espada como profesional como un credo particular, y es que, para ser un líder eficaz y desarrollar a nuestros/as colaboradores/as, es necesario disponer de una alta inteligencia emocional. Al mismo tiempo, la intención clara y manifiesta como profesional e investigador, era 
revalorizar las emociones humanas en su comparación frente al valor positivo que se otorga a la cognición. Eso sí, no una defensa a ultranza de lo emocional, ni de las emociones positivas por encima de lo cognitivo o de las emociones negativas. Se plantea la necesidad que en el proceso de liderar personas se integren los factores emocionales con los cognitivos valorándolos y otorgándoles la misma importancia. De igual manera se sugiere que se debe ampliar el estudio del papel tanto de las emociones positivas como de las negativas, así como su aplicabilidad práctica.

En esta Tesis se intenta aportar un paso más en el estudio de las emociones y su influencia social en el trabajo ya que el problema central que trata de responder, es si es posible que exista una relación entre la inteligencia emocional del/la líder y las competencias mentales de sus colaboradores/as. De ahí que se denomine este tipo de liderazgo, liderazgo emocional, pero eso sí, sin el ánimo de pretender inundar de etiquetas pretenciosas, ya que, y éste fue un excelente debate con las directoras de esta Tesis, considero que el liderazgo emocional es en realidad un conjunto de herramientas dentro de un modelo más amplio de actuación como líder que debe estar dirigido por fuertes valores éticos.

La idea inicial central de conocer cómo se relaciona la inteligencia emocional de los/as líderes con las competencias mentales de sus colaboradores/as, se expandió hacia el interés investigativo por averiguar si en esta relación multinivel el vigor que sentían los colaboradores/as modulaba o mediaba entre ambos constructos. Creo, que una de las tendencias futuras dentro del estudio del engagament será conocer cómo funciona el vigor como constructo independiente y analizar cómo influye en diversos aspectos organizacionales y de salud. Finalmente, para acabar de situar el verdadero papel de la 
dimensión emocional en el estudio científico del liderazgo, se analizó como las competencias emocionales de los colaboradores/as se relacionan con sus propias competencias mentales.

Con este conjunto de propuestas investigativas la Tesis que se presenta sigue un orden tradicional en su estructura. Se compone de cuatro grandes apartados: I. Introducción: Marco Teórico; II. Metodología, III. Resultados, IV. Discusión.

La primera parte consta de cuatro capítulos que pretenden explicar las bases teóricas y el estado del arte de las variables de estudio. En el capítulo I se presentan las ideas conceptuales de cómo la emoción y la cognición están estrechamente relacionadas. Se destacará la importancia del factor emocional en el funcionamiento de las funciones ejecutivas de orden superior, y se mostrará como ambos constructos no pueden funcionar por separado. En este capítulo se recogerán las diversas investigaciones y teorías que demuestran como la emoción tiene un rol transcendental en el funcionamiento cognitivo, es decir, de lo que se denomina facilitación emocional.

En el Capítulo II se describe la evolución del constructo de inteligencia emocional, así como los diversos modelos de inteligencia emocional existentes siendo nuestra apuesta por el de Mayer y Salovey (1997). De igual modo se describen las investigaciones que relacionan la inteligencia emocional con varios outputs en el contexto laboral. Para finalmente, exponer las bases conceptuales por las cuales el liderazgo se entiende hoy en día como un proceso de influencia entre el/la líder y sus colaboradores/as, así como las investigaciones que muestran la relación existente entre el liderazgo y la inteligencia emocional.

El Capítulo III tiene como objetivo resolver la incógnita de cómo se produce la influencia emocional del/la líder a los colaboradores/as. Para ello se profundiza en el estudio 
de las teorías desarrolladas hasta la fecha que explican la comprensión emocional. Esta habilidad emocional tiene una dimensión social (interpersonal) por la cual entendemos y comprendemos las emociones de los/as demás y los comportamientos que se derivan de las mismas. Así mismo, se recogen las diversas teorías e investigaciones que explican cómo se produce en los/as colaboradores/es el contagio emocional de las emociones de su líder y que consecuencias provoca en el contexto laboral.

Cerrando esta parte teórica se desarrolla el Capítulo IV, que tiene como objetivo principal describir la conceptualización del vigor en sus diversas aproximaciones, bien dentro del constructo del engagament o como constructo independiente, y su influencia en el proceso de liderazgo.

La segunda parte II Metodología de la Tesis recoge los objetivos y las hipótesis a demostrar. Se describen las variables de estudio y los instrumentos utilizados en su evaluación, así como el procedimiento manejado en la recogida de información. Cabe recalcar que es una investigación que se ha realizado en el contexto de América Latina, más concretamente en tres empresas de la ciudad de Quito-Ecuador. Es una de las investigaciones de carácter multinivel pionera en este contexto, dónde uno de los aspectos a tener en cuenta es que los instrumentos utilizados para medir las variables objeto de estudio (inteligencia emocional de los líderes, y engagament-vigor, competencias emocionales y mentales de los colaboradores/as) están basados en muestras españolas. No obstante, este hecho no impide que este trabajo signifique una pequeña aportación para contrarrestar la escasez de investigación psicológica que existe en Ecuador.

En la sección IV: Resultados se exponen los resultados obtenidos en los diferentes análisis realizados dentro del modelo multinivel planteado que confirman las hipótesis 
inicialmente planteadas. Por un lado, se describen los resultados del Nivel Inter (lídercolaborador/a), y por otro los resultados a Nivel Intra (colaborador/a-colaborador/a). Finalmente, en la última parte V: Discusión que recoge el capítulo VII, se describen y se discuten los resultados obtenidos. Se realiza una enumeración de las diversas implicaciones teóricas-prácticas que pueden ser derivadas tanto a académicos/as como a profesionales interesados/as en conocer y profundizar en los aspectos emocionales que aparecen en el proceso del liderazgo. Se expondrán las limitaciones del estudio buscando que nuevas investigaciones las superen y mejoren. Por último, no se quería dejar pasar la ocasión para señalar el principio y la meta que debe de cubrir todo proceso de influencia del/la líder sobre sus colaboradores/as, es decir, la relevancia de los valores y la ética en el uso de las habilidades emocionales. Considero que, siendo fundamental el uso de la inteligencia emocional a la hora de liderar y desarrollar personas, esta habilidad que nos transforma en líderes emocionalmente inteligentes, debe de estar guiada por un liderazgo ético que ponga límites razonables al poder de influenciar sobre los demás. La habilidad de impactar sobre otros/as a través del dominio de las estrategias de influencia emocionales debe estar supeditado a la ética. 


\section{INTRODUCCIÓN: MARCO TEÓRICO}




\section{Capítulo I. Emoción y Cognición}

"Si quieres construir un barco, no empieces por buscar madera, cortar tablas o distribuir el trabajo, sino que primero has de evocar en los hombres el anhelo del mar libre y ancho". Antoine De Saint Exupery

"El corazón tiene razones que la razón ignora" Pascal 


\subsection{Introducción}

El objetivo central de este primer capítulo es mostrar la relación funcional que existe entre la emoción y la cognición. Se destacará la relación e importancia de los aspectos emocionales en el funcionamiento cognitivo, así como en el de las funciones mentales ejecutivas de orden superior. Para ello, se realizará una revisión teórica de lo que es emoción y las teorías más importantes que intentan explicarla, para a continuación, describir cómo se produce la interacción entre emoción y cognición. El objetivo inicial es sentar las bases teóricas de cómo la emoción juega un papel importante y transcendental en el razonamiento cognitivo humano. Esta función de la emoción que facilita el funcionamiento y desarrollo de aspectos cognitivos, como: atención, percepción, memoria, toma de decisiones creatividad y flexibilidad, es una habilidad emocional dentro del modelo de inteligencia emocional de Mayer y Salovey (1997) en el que se apoya esta Tesis, denominada facilitación emocional. Con ello, se romperá la visión tradicional de menospreciar las emociones y ponerlas en un segundo plano con respecto a la cognición, ya que ambas, funcionan en sincronía para poder ofrecer respuestas de ajuste más eficaces al entorno, a nosotros mismos, y a las personas con las que nos rodeamos.

\subsection{Concepto de Emoción}

La disparidad conceptual sobre qué es la emoción, impregna su estudio y análisis e impide que exista una uniformidad en su definición. Esta diversidad conceptual es debida a que en cada época de la historia, desde los griegos a la actualidad, las escuelas y las tendencias sociopolíticas y filosóficas que dominaban cada momento histórico marcaban como debía de explicarse. Igualmente, desde la psicología tampoco ha habido una claridad 
de términos ya que cada una de las subespecialidades que la integran han aportado su punto de vista desde su particular objeto de estudio. Los psicólogos del desarrollo se han centrado en delimitar los cambios emocionales que se producen en las diversas etapas de la vida de las personas, así como de destacar el rol que desempeñan en el apego y en el temperamento; desde la psicología social se pone el énfasis en la importancia de la comunicación de la expresión emocional y en la gestión emocional en diferentes contextos; los psicólogos cognitivos se centran en el estudio de la relación entre emoción y cognición; la psicología clínica está encontrando la forma de facilitar solución a los distintos trastornos derivados de la vivencia de experiencias emocionales; por último, la aparición de las neurociencias ha provocado el interés por conocer el funcionamiento del proceso emocional en el sistema nervioso central, el efecto de las hormonas y el papel de los neurotransmisores en la comunicación y codificación de la información de los estímulos emocionales (Palmero, Guerrero, Gómez y Carpi, 2006).

Ante esta heterogeneidad de aproximaciones sobre un mismo campo de estudio, tal y como señala Mandler $(1975,1984)$, intentar establecer una definición consensuada de la emoción es prácticamente imposible. Esta dificultad afecta a la generación de una teoría general de la emoción (Scherer, 2000).

La tendencia actual es considerar a la emoción como un proceso afectivo de respuesta del ser humano. Al recibir del entorno un estímulo se provoca en el sujeto una valoración subjetiva y cognitiva de la experiencia que está viviendo así como cambios neurofisiológicos que le impulsan al movimiento y a la acción, siendo su fin último facilitar la adaptación al entorno. La emoción es un proceso afectivo, pero como tal, hay que evitar confundirla con otros procesos afectivos que normalmente aparecen en la literatura 
científica y en el uso coloquial del público no especializado. Convencionalmente se suele confundir con el afecto, con el humor y sobre todo con el sentimiento. Siguiendo a Palmero et al. (2006) es conveniente realizar las siguientes puntualizaciones al respecto:

- Afecto: De los tres conceptos, es el que tiene una dimensión más general. Se relaciona con la valencia positiva-negativa e intensidad baja-alta.

"El afecto tiene que ver con la preferencia; permite el conocimiento del valor que tienen para el sujeto las distintas situaciones a las que se enfrenta. Existe una tendencia innata hacia el afecto positivo, de tal suerte que la meta de un sujeto es obtener placer. Podríamos decir que el afecto representa la esencia de la conducta, entendida ésta en la formulación más elemental de aproximarse a lo que gusta, gratifica o satisface, y de alejarse de aquello que proporciona las consecuencias opuestas" (Palmero et al., 2006, p. 17).

- Humor: Es una forma específica dentro del conjunto de los procesos afectivos. Implica la existencia de tono e intensidad. El humor, además, manifiesta la existencia de un conjunto de creencias acerca de la probabilidad que tiene el sujeto de experimentar placer o dolor en el futuro. Un humor concreto puede durar varios días, variando según lo haga la expectativa de futuro del sujeto. En comparación con el afecto, tiene una duración más breve, pero, relacionado con la emoción, suele ser más duradero (Palmero, et al., 2006).

- $\quad$ Sentimiento: Se refiere a la toma de conciencia de la emoción que se está produciendo. Teniendo en cuenta que la emoción es un proceso, el sentimiento sería la fase final dónde se adquiere conciencia de la emoción que se está experimentado como respuesta a un estímulo. Esta dimensión subjetiva de la 
emoción se le denomina sentimiento. El sentimiento es la experiencia vivida de la emoción y si adquiere como vivencia una duración más larga en el tiempo que cuando se extiende pasa a convertirse en humor.

Teniendo en cuenta estas diferencias, se propone la siguiente definición de emoción y que va a ser la utilizada en la presente Tesis doctoral como referencia teórica:

“Las emociones son procesos episódicos que, elicitados por la presencia de algún estímulo o situación interna o externa, que ha sido evaluada y valorada como potencialmente capaz de producir un desequilibrio en el organismo, dan lugar a una serie de cambios o respuestas en los planos subjetivo, cognitivo, fisiológico y motor expresivo; cambios que están íntimamente relacionados con el mantenimiento del equilibrio, esto es: con la adaptación de un organismo a las condiciones específicas del medio ambiente” (Palmero, et al., 2006, p.21). Por lo tanto, la emoción es un proceso en el que interviene tres dimensiones multidimensionales que ponen en marcha tres sistemas de respuesta: cognitivo/subjetivo, conductual/expresivo y fisiológico/adaptativo (Choriz, 2005). A continuación, se recogen las diferentes corrientes históricas que se han centrado en el estudio de la emoción humana. 


\subsection{Evolución Histórica del Estudio Científico de la Emoción}

\subsubsection{Primeros acercamientos históricos}

Hasta el XIX las emociones no se escaparon de la atención de la tradición filosófica, teológica y antropológica, iniciándose su tratamiento científico a través de los esfuerzos del psicólogo William James.

Tal y como señala Damasio (1999), a lo largo de la historia las emociones no han recibido el mismo interés por parte de la ciencia en contraposición a otros procesos psicofisiológicos. Posiblemente, esta apatía por el estudio de las emociones puede estar marcada por una gran tradición filosófica que formulaba teorías identificando las emociones como pasiones que causaban enfermedad del alma y que incluso se las calificaba como moralmente reprochables. Tanto en la Grecia clásica, con autores como Platón, o en la edad media, se asociaba las emociones con las pasiones, reforzando la idea que la desmesura pasional provocaba conductas amorales. Posteriormente, en el Renacimiento y en siglos sucesivos, empieza a aparecer otro concepto, el de afecto, dejando la palabra emoción para sentimientos más intensos y exacerbados. No obstante, se apodera en el imaginario colectivo la dualidad mente $=$ razón y corazón $=$ pasión, lo que provocará que el afecto, lo emotivo se asociase a una experiencia pasional del corazón. Finalmente, y ya en el S. XIX, se inicia el estudio de la emoción como objeto de análisis de la psicología alejado de las consideraciones filosóficas anteriores.

En la revisión histórica del estudio científico de la emoción realizado se han tenido en cuenta las aportaciones más importantes dentro de las diferentes aproximaciones, a saber: evolucionista, conductista, biológica, neurociencia (con la integración fisiológica cerebroemoción) y por última, la cognitiva. 


\subsubsection{Aproximación evolucionista}

Esta aproximación surge con el tratado original de Darwin: "The Expression of the Emotions in Man and Animals" (1872) en el cual se enfatiza la similitud entre la emoción humana y la animal. Esta aproximación presenta a la emoción como un facilitador de la conducta humana. Se establecen tres principios básicos de la emoción en la teoría de Darwin:

a) Hábitos asociados a la utilidad; las emociones, en un primer momento, fueron aprendidas pero seguidamente se convirtieron en un rasgo heredado y transmitido de generación a generación.

b) Antítesis: emociones distintas como el amor o el odio provocan al mismo tiempo conductas contrapuestas.

c) Acción directa del sistema nervioso excitado. El vacío en la categorización de algunas emociones hizo que Darwin asumiese que si se da una excitación apropiada, el sistema nervioso responde generando movimientos expresivos. Según este principio, la descarga neural puede afectar directamente a la musculatura expresiva asociada a la emoción (Choriz, 1995). Las tres acciones más importantes son los reflejos, hábitos, e instintos.

Bajo estos principios, se establece y, así es recogido por autores posteriores como Izard (1977) y Ekman (1981), que las emociones son reacciones universales innatas que permiten la adaptación al medio y por tanto mejoran las posibilidades de supervivencia. Dentro de esta línea de pensamiento, Ekman es considerado uno de los investigadores centrales en el análisis de las expresiones emocionales. Afirma que tanto las emociones y sus expresiones son innatas pero que gracias al factor de aprendizaje que se da través del 
ambiente pueden ser modeladas para ayudar a la especie a adaptarse al entorno (Ekman, 1981).

\subsubsection{Aproximación conductista}

Siguiendo los conceptos tradicionales del conductismo, el estudio de la emoción se centró en la conducta emocional como una respuesta que se podía observar y, por tanto, medir. De entre los autores de esta aproximación destacan las aportaciones de Wundt y Watson. Para Wundt (1920), las emociones son un conjunto de sentimientos cargados de intensidad que no se podrían analizar. Watson (1928) en la misma línea, considera que las emociones son simples reacciones corporales a estímulos específicos en las que la experiencia consciente no es relevante Según Watson, reaccionamos ante estímulos provocando distintas conductas y emociones de las cuáles considera como básicas a la ira, miedo, y al amor. En definitiva, el conductismo analiza la función de la conducta final que se deriva del proceso emocional sin profundizar más allá. Por tanto, no le interesa cómo se operativiza las emociones y si existe un procesamiento del estímulo que provoque la respuesta emocional.

\subsubsection{Aproximación biológica}

\subsubsection{James-Lange. Teoría Periférica de la emoción}

William James psicólogo, pionero en diversas áreas, inició desde la psicología el estudio moderno de las emociones. Recogió las ideas anteriores de un fisiólogo danés, Carl G. Lange, para elaborar un modelo de referencia actual conocido como el de James-Lange (James, 1884). El modelo enfatiza la importancia de los cambios que se producen fuera del sistema 
nervioso central para explicar el proceso emocional, de ahí que reciba también el sobrenombre de Teoría Periférica de la emoción.

La idea central inicial es que la emoción se origina en la percepción de los cambios somáticos que se producen como respuesta a un estímulo. Estos cambios somáticos acontecen fuera del sistema nervioso central. Según James (1884) para que surja una emoción primero debe de existir una respuesta fisiológica, bien sea motora o vegetativa, para posteriormente realizar una evaluación cognitiva que hace que surja la emoción.

La diferencia entre James y Lange es que James posteriormente hizo hincapié en que para que se provoque la experiencia emocional es necesario que se dé un feedback tras recibir la información fisiológica a modo de valoración subjetiva (Mayor, 1998). Por el contrario, Lange no da significación a que exista factor mental-psicológico en la experiencia emocional, se centra en los cambios corporales y especialmente los viscerales quedando la emoción constreñida a un trastorno vasomotor.

En conclusión el esquema (ver Figura 1.1) del proceso emocional bajo la visión de James que influye al resto de investigadores actuales sería el siguiente:

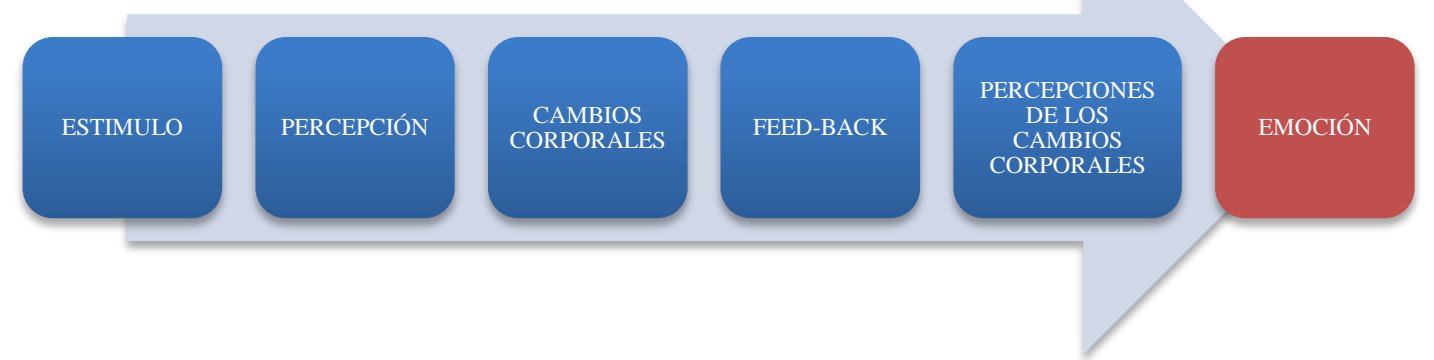

Figura 1.1: Proceso Emocional según W. James. Adaptado de Mayor, Sospeña, (1994). La obra de William James y su teoría de las emociones en las ciencias sociales. VII Symposium de la Sociedad Española de Historia de la Psicología (S.E.H.P.). Murcia, 14 al 16 de abril. 
La perspectiva de James actualmente está teniendo una gran acogida en las teorías que aúnan el estudio de la neurología y la psicología buscando la conexión entre emoción, la cognición y el sustrato neurofisiológico. De entre los diferentes autores herederos de la tradición de James que se destacan en la actualidad se encuentra el neurólogo portugués Antonio Damasio autor de la teoría de los Marcadores Somáticos (1996).

\subsubsection{Teoría de la Activación en las Emociones}

Elisabeth Duffy (1934) fue la primera investigadora en usar el término de activación o "arousal" para referirse a los cambios fisiológicos periféricos asociados a estímulos emocionales. Para esta autora, era importante registrar estos cambios ya que con ello se podría medir el nivel de activación. El concepto de activación periférica o "arousal” se despliega en una única dimensión de activación general del organismo en un continuo que va desde el sueño a la excitación extrema. A través de este continuo se pueden producir cambios de activación que pueden ser medidos utilizando diversos indicadores somáticos.

Posteriormente Lindsey (1951), en el recién inaugurado campo del estudio de la activación en la psicología, establece una línea de conexión entre los fenómenos psicológicos y el registro de la actividad electroencefálica. Esta teoría fue contemporánea a la aparición de nuevas herramientas de medición fisiológicas lo que provoco un interés inusitado del estudio de los procesos internos y su registro fisiológico. Defendía que los estados psicológicos caracterizados por la máxima vigilia, la máxima excitación, estado de alerta y alta emoción se corresponden con los ritmos electroencefálicos caracterizados por la mayor frecuencia o ciclos por segundo. Se centraba en que toda la información somática 
y sensorial era recogida por la formación reticular mesencefálica y por ello se podía explicar cualquier conducta posterior. Hay que tener en cuenta que en aquella época se estaba empezando a realizar investigaciones que apuntaban que la formación reticular era una estructura cerebral que guiaba la activación emocional. Por tanto, Lindsey se basaba en el estudio de la relación activación-emoción a través de las mediciones que se recogían en el electroencefalograma (EEG). La activación se veía como sinónimo de desincronización electrocortical. La baja activación aparecería en las situaciones de nula o mínima emoción, y la máxima activación en las situaciones de máxima excitación emocional. Lindsey argumenta, y nótese la semejanza con la Ley de Yerkes y Dodson (1908) sobre ansiedad, rendimiento y su funcionamiento como $\mathbf{U}$ invertida, que conforme se incrementa la activación lo hace también el rendimiento, pero una vez se ha superado un punto de activación máximo se produce progresivamente una disminución o empeoramiento del mismo (Palmero, 1996).

Hebb y Malmo compartieron argumentos sobre la activación ya que la consideraron inespecífica, unidimensional y unidireccional. El primero defendía que la activación ante un estímulo era producto de una estimulación inespecífica que genera la excitación de una serie de neuronas (asambleas neurales) que provocan la ejecución de un patrón de conductas (Hebb, 1955). Por otro lado, Malmo teorizó sobre la activación desde el estudio de la motivación, y en línea con los anteriores, describió que el rendimiento se incrementa a medida que se incrementa el nivel de activación (Malmo 1958, 1959). Las ideas de estos autores que explicaban el proceso emocional centrándose en la activación de la formación reticular mesencefálica dejaron de tener su relevancia ya que no pudieron dar respuesta al fraccionamiento direccional y a la influencia inconsciente. Al mismo tiempo, se descubrió 
que en la activación y desactivación de la formación reticular confluyen varios sistemas como son el dopaminérgico, noradrenérgico, serotoninérgico y colinérgico que no se habían tenido en cuenta, por lo que había que integrar nuevos conceptos (Roselló, 1996).

\subsubsection{Aproximación neurofisiológica: Cerebro y emoción}

\subsubsection{Walter Cannon. Teoría neural central de la emoción}

En contraposición a la teoría de James, surgió una corriente alternativa crítica encabezada por Walter Cannon que situaba la respuesta emocional en el sistema nervioso central demostrando que los cambios corporales que se producen ante ciertas situaciones en las vísceras no logran explicar, en su totalidad, algo tan complejo como la variedad emocional (Roselló y Revert, 2008). Para este autor, el sistema periférico, tal y como argumentaba James, no era la explicación del proceso emocional. Cannon, en contraposición a James, argumenta que la activación que se produce con las emociones se deriva de un conjunto de acontecimientos escalonados que tienen su precursor en un estímulo ambiental sobre los receptores (Palmero, 1996). Éstos transmiten la estimulación a través del tálamo hasta la corteza cerebral. El proceso se repite en el sentido inverso ya que la corteza responde estimulando nuevamente al tálamo que responderá con patrones particulares. Con Cannon se inicia la búsqueda de una explicación desde la psicología de las emociones en las respuestas que se dan a nivel central, es decir, en la actividad neuronal, y en concreto en las neuronas talámicas. Es por esto, que su teoría se le conoce también con el nombre de Teoría Neural Central de la Emoción. Siguiendo a Roselló y Revert (2008) la réplica de Cannon a James dio pie a las propuestas que reivindicaban la actividad neural (y, por extensión, la cognición) como condición necesaria y suficiente para 
la existencia de la emoción, mientras que las teorías periféricas entendían la emoción como la percepción de la actividad somática y vegetativa.

\subsubsection{Papez y McLean}

Estos dos autores iniciaron el proceso de búsqueda de la localización en el cerebro de las estructuras neurológicas que son el motor del funcionamiento de la emoción. Papez (1937), recogiendo las aportaciones anteriores de Paul Broca y de Christofredo Jakob, introdujo la idea que existía un circuito al se llamó "circuito de Papez" por el que trascurría el proceso emocional a través del sistema límbico. Este conjunto de estructuras cerebrales pasaron a configurar la denominación de "cerebro emocional"

Tal idea fue adaptada y ampliada veinte años más tarde por Paul McLean que recogió todas las ideas de sus predecesores y desarrolló una teoría global sobre el cerebro emocional que combinaba la importancia del hipotálamo en la expresión emocional y la importancia de la corteza cerebral en la experiencia emocional. Estableció las estructuras del sistema límbico que incluía partes del hipotálamo, del área septal, el núcleo accumbens, las áreas neocorticales y la amígdala. De igual modo, defendió la teoría filogenética del cerebro ternario, por la que existen tres cerebros según su nivel de desarrollo evolutivo. El cerebro reptil es el primero en desarrollarse siendo el responsable de las respuestas automáticas necesarias para la supervivencia. Seguidamente, aparece el cerebro mamífero antiguo o paleomamífero que se encarga de conservar a la especie y en el que se incluye partes cerebrales entre las que se destacan las que modulan y direccionan las emociones humanas, denominado también, cerebro visceral o emocional. Por último, aparece el cerebro mamífero nuevo o neomamífero que sólo está en los primates y en los hombres ya 
que en él se encuentra la neocorteza cerebral dónde se concentran las funciones cognitivas superiores. Estos tres cerebros funcionaban de manera autónoma e independiente entre ellos Belmonte, (2007).

El error de estos autores era considerar la existencia de unas zonas específicas por dónde transcurre la emoción denominado sistema límbico y que sólo ellas configuraban el cerebro visceral. Actualmente, ya no se acepta la idea que el proceso emocional se localice en una única estructura cerebral única ya que se ha observado que es muy dificultoso concretar la delimitación del mismo cerebro visceral, existiendo además, una clara superposición entre estructuras cerebrales que, tal y cómo veremos a continuación, provocan la interacción entre cognición y emoción.

\subsubsection{Joseph LeDoux}

Este autor se centró en el estudio específico de la emoción del miedo. Defendió la idea que la gestión emocional se producía en el sistema límbico en interrelación con la corteza cerebral. Destacó la importancia de la amígdala como centro de evaluación de la información emocional configurando la idea de un cerebro emocional interconectado. Demostró que existen vías que trasmiten la información sensorial desde el tálamo a la amígdala sin que intervengan estructuras corticales por lo que se desprende que existe un análisis emocional previo al procesamiento cognitivo. LeDoux (1999) consideró que en la amígdala se producía una evaluación emocional inconsciente a la persona que está recibiendo la estimulación emocional. Su teoría será ampliada en la sección posterior dónde se analizará con mayor detalle la interacción neurológica entre emoción y cognición, junto 
a las investigaciones de Damasio. El objetivo será intentar esclarecer las bases neurofisiológicas de la habilidad emocional denominada facilitación emocional, por la cual, a través de las emociones se facilita el pensamiento superior cognitivo.

\subsubsection{Antonio Damasio.}

Este neurocientífico realizó diversas aportaciones al estudio de las emociones rompiendo con el dualismo cartesiano caracterizado por la asunción que la razón estaba separada de la emoción. La idea novedosa que ofreció Damasio fue defender que las emociones intervienen en el proceso de toma de decisiones racionales. Para ello definió la teoría de los marcadores somáticos por la que cuando nos vemos sometidos a una toma decisiones nuestro cuerpo experimenta un sentimiento del que muchas veces nos somos conscientes. Este marcador somático o sentimiento es grabado en nuestro cerebro. Ante la toma de decisiones que nos enfrentamos permite eliminar opciones posibles que en experiencias anteriores no han resultado positivas.

De esta manera, los marcadores somáticos son un caso especial de sentimientos generados a partir de emociones secundarias que han sido conectados, mediante aprendizaje, a resultados futuros predecibles de determinados supuestos (Damasio, 1996).

Damasio defendió la idea de la interconexión de la racionalidad y de la emoción ya que ambas comparten estructuras neuronales. Además la cognición es influenciada también por la segregación de hormonas cuando se produce una respuesta emocional. La corteza cerebral recibe información de las regiones sensoriales que procesan imágenes de los estímulos que recibimos. Igualmente, recibe información de la bioquímica de nuestro cuerpo quedando registrado en nuestra memoria interna lo que hemos sentido cuando nos 
hemos visto enfrentados a un proceso de toma de decisiones. El marcador somático desprende una señal en forma de sentimiento que puede ser positiva o negativa. En el caso de ser negativo se genera una alarma interna de peligro, y en el caso de ser positivo se convierte en un incentivador a una opción de respuesta. De esta manera, gracias al marcador somático, podemos reducir las alternativas en la toma de decisiones. El marcador somático tiene dos vías de acción: una consciente y la otra inconsciente; esta segunda vía es la que ha venido a denominarse como intuición (Damasio, 1996). Sin duda, este autor fue uno de los precursores de la línea de investigación de la facilitación emocional, que es uno de los ejes de la presente investigación, ya que el argumento principal de esta habilidad emocional es que la gestión de la información emocional que recibimos permite mejorar el procesamiento cognitivo.

\subsubsection{Aproximación cognitiva}

Para esta corriente de pensamiento la emoción es una consecuencia de los procesos cognitivos que incluye la evaluación cognitiva de la situación que provoca la emoción. En este apartado, ante la profusión de corrientes y puntos de vista diversos, se recogen las teorías y autores agrupados en los postulados teóricos de mayor repercusión.

\subsubsection{Teorías de la atribución}

Las teorías de atribución tratan de explicar cómo surge la emoción teniendo en cuenta el procesamiento de la información tras recibir una estimulación. Estas teorías se basan en la existencia de la activación fisiológica, pero su foco de interés no se centra en el análisis 
de la misma, sino en los procesos cognitivos que son los que explicarán el sentimiento emocional concreto que resulta en cada caso. Los mayores representantes de esta corriente son:

\section{a.1. Schachter y Singer: Teoría Bifactorial.}

En 1962 dentro del paradigma cognitivista que arrancaba con fuerza en aquellos años, se publicó un artículo revolucionario de Schachter y Singer (1962) en la revista Psychological Review. El artículo introducía la explicación cognitiva de la aparición de las emociones. Estos autores construyeron la Teoría Bifactorial que tenía como principal postulado la combinación entre la activación fisiológica y la generación de etiquetas cognitivas. Para que surja la emoción humana es necesario que se produzca previamente una activación fisiológica que determina la intensidad de la emoción. Acompañando a esta estimulación aparece un mecanismo de valoración cognitiva que intenta dar una explicación a la estimulación recibida. Independientemente de las críticas metodológicas

que acogió el experimento en el que se basaron los autores; (Marshall y Zimbardo, 1979) se inició el camino a la explicación cognitivista de la emoción.

\section{a.2. Valins: Teoría del Feedback Falso.}

Para este autor la activación es sólo una fuente de información y no se puede considerar como una parte transcendental para el funcionamiento emocional del ser humano. La creencia de estar activado podría ser suficiente para que un individuo experimente una emoción. La teoría de Valins (1966) se basó en un experimento en el que se ofreció feedback falso a estudiantes universitarios sobre la frecuencia de sus latidos de corazón ante los estímulos de diapositivas de mujeres que estaban visualizando. La información falsa sobre esta frecuencia influenciaba en la valoración de los estímulos que 
estaban percibiendo. Valins concluyó que las percepciones de los cambios, independientemente de si son cambios internos verdaderos o no, influyen en la clasificación de las diapositivas en base a su atractivo.

a.3. Teoría de la Evaluación-Discrepancia de Mandler.

Mandler (1984) enuncia en su Teoría de la Evaluación-Discrepancia que la activación por sí sola no produce una emoción, ya que es necesario una evaluación de la situación. Esta activación o arousal provoca una discrepancia interna en el sujeto cuando no encaja con sus esquemas mentales, y determina la intensidad de la experiencia emocional del sujeto. Tras esta activación, que bien puede ser causada por una discrepancia entre la percepción, la acción o el pensamiento, o por estímulos diversos, se produce una valoración cognitiva (appraisal) que puede dar como resultado una nueva conciencia de la activación como del proceso de valoración resultante que puede modificar de nuevo la experiencia emocional vivida. Una vez se adquiere conciencia, a partir del arousal y la interpretación cognitiva (y de su interacción recíproca), se produce la experiencia emocional (Roselló y Revert, 2008).

\subsubsection{Teorías de la valoración}

La perspectiva cognitiva en el estudio de la emoción entiende que la activación de una respuesta emocional está vinculada básicamente a los procesos de valoración. Las distintas teorías de la valoración se centran en el hecho de cómo las emociones son evocadas y se diferencian en base a evaluaciones subjetivas de las personas o a valoraciones de relevancia personal de la situación, o del objeto. (Scherer, 2000). 
Según Frijda (1993), la valoración hace referencia a la estimación que hace un individuo de su interacción con el ambiente en términos de bienestar, equilibrio, y estabilidad. Estas valoraciones no son necesariamente conscientes y se consideran los antecedentes de las emociones.

\section{b.1. Teoría de Arnold: Valoración cognitiva.}

Esta autora estableció (Arnold, 1960) uno de los modelos teóricos de mayor impacto en la tradición cognitivista del estudio de la emoción. Desde un punto de vista hedónico, lo primero que sucede cuando percibimos un estímulo es que le otorgamos una valoración intuitiva, positiva o negativa, que dependiendo de la misma induce a actuar de una manera u otra. En el caso que se produzca una acción significativa tras un juicio apreciativo se produce una experiencia intensa que se denomina sentimiento. El proceso sería el siguiente: en primer lugar se produce una valoración espontánea de la situación percibida que es seguida finalmente por una acción tendencial que se siente como emoción. La activación y los cambios físicos que se producen pueden a su vez hacer que la persona actúe de acuerdo a la emoción que está sintiendo.

\section{b.2. Lazarus: Teoría Cognitiva-Motivacional-Relacional.}

Este autor, colaborador de las ideas de Arnold, fortalece el concepto de valoración cognitiva. Lazarus defiende que en lugar de producirse una valoración dicotómica (bueno/malo) lo que acontece es una valoración primaria que determina la emoción posterior. Es decir, evaluaciones de amenaza conducen a emociones de miedo, evaluaciones de situaciones cómicas a la emoción de alegría, y así sucesivamente. Cada emoción tendría como antesala un tipo concreto de valoración, una predisposición particular a la acción entendido como activador motivacional y una expresión específica (Lazarus, 1984,1991). 
Las valoraciones y, en consecuencia las emociones que se derivan de las mismas, acontecen dependiendo del conocimiento emocional específico de cada persona. De la misma manera, esta individualidad también se aprecia en los diversos comportamientos de afrontamiento o “coping” que manifiesta la persona para hacer frente las situaciones cotidianas que vive.

En los primeros años su postura sobre la importancia de la evaluación cognitiva se manifestaba en la incorporación del concepto de appraisal (valoración cognitiva) al estudio de la emoción ya que logró demostrar que las emociones y los efectos del estrés no dependían directamente de las características objetivas de los eventos estimulantes o de la situación contextual dónde se encontraba el sujeto, sino del análisis, de la evaluación de los mismos que realizaban los sujetos (León, 2000). Posteriormente, Lazarus (2001) reformuló su idea original e incluyó la idea de núcleos temáticos por la cual se relacionaba a una emoción con una valoración inicial primaria de componentes y subcomponentes que afectan a la congruencia de una valoración específica de la emoción percibida por la persona para, a continuación, realizar una análisis más complejo generando un "núcleo temático" que construye un significado global a la persona combinando factores motivacionales, relacionales y afectivos.

Desde una perspectiva aplicada, la consideración de Lazarus de la valoración cognitiva y de las estrategias de afrontamiento con un componente emocional ha tenido una implicación directa en la intervención de trastornos como el estrés (Lazarus y Folkman, 1984). Lazarus tuvo como principal opositor de sus planteamientos cognitivistas a Robert Zajonc. Entre ambos se produjo un periodo de discusión, con continuas réplicas y contrarréplicas, que se extendió desde los años 70 hasta la primera mitad de la década de la 
década del 80. Para Zajonc la emoción podría aparecer sin que existiese cognición ya que era un fenómeno separable y parcialmente independiente de la cognición (Zajonc, 1984)

b.3. Scherer: Teoría de las Comprobaciones Secuenciales para la Diferenciación de las Emociones.

Para este autor la emoción es un proceso complejo, dinámico y formado por varios componentes que propician la adaptación (Scherer, 2000, 2001). Los cinco componentes que describe son: componente cognitivo, eferencias periféricas, carácter motivacional, expresión motora y el sentimental, el cual sirve para visualizar la interacción entre la persona y el ambiente.

En primer lugar, el componente cognitivo está vinculado al procesamiento de la información como sistema de funcionamiento, su substrato orgánico es el sistema nervioso central, y cumple la función fundamental en el proceso emocional de la evaluación de los eventos, objetos o situaciones que se presentan al organismo. En segundo lugar, las eferencias periféricas ejecutan una función de regulación de sistemas orgánicos, dependiendo del sistema nervioso central, del sistema nervioso autónomo y del sistema neuroendocrino. En tercer lugar, el carácter motivacional y, de acuerdo a un funcionamiento de tipo ejecutivo vinculado al sistema nervioso central, prepara y dirige la acción. En cuarto lugar, la expresión motora que informa sobre la reacción y las intenciones conductuales. En quinto y último lugar, el sentimiento subjetivo que sirve, desde el sistema nervioso central, para monitorizar el estado interno del organismo y la interacción que éste ha tenido con el ambiente (Pérez, y Redondo, 2006).

Este enfoque teórico precisa que para poder explicar y entender la emoción es necesario tener en cuenta cada uno de sus componentes ya que los diferentes episodios 
emocionales es la respuesta combinada del organismo a una secuencia interrelacionada de valoración en cada uno de los componentes anteriormente descritos del estímulo recibido.

\subsubsection{Regulación emocional}

En la actualidad una de las tendencias en el estudio de las emociones que se están desarrollando con mayor énfasis dentro de la perspectiva cognitiva y del procesamiento emocional es la de la regulación emocional. Siguiendo a Mestre y Guil (2012), la aproximación que se está imponiendo actualmente es la que considera la regulación de las emociones como un conjunto de procesos cognitivos y conductuales por el cual el sujeto influye en las emociones que tiene, cuando las tiene, y en cómo experimenta y expresa sus emociones (Gross y Barret, 2011). Para Mestre y Guil (2012) la regulación emocional contempla dos dimensiones clásicas en la literatura investigadora: la primera es la de arousal, y la segunda es cómo valoramos los procesos afectivos que están implicados. Esta propuesta se apuntala como base teórica en el Modelo Circumplejo del Afecto (Rusell, 1980), y que posteriormente fue representado gráficamente, tal y cómo se recoge en la Figura 1.2. 


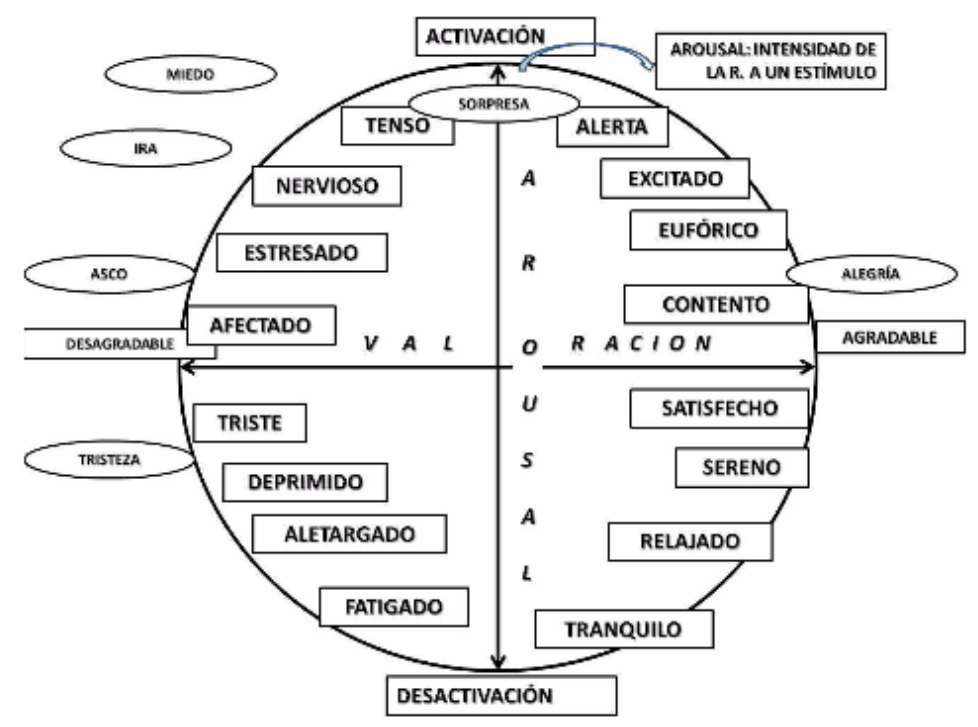

Figura 1.2: Modelo Circumplejo del afecto, adaptación de las revisiones de Posner, Russell, y Peterson (2005).

Dependiendo del nivel de arousal o activación y de la magnitud de la valoración que hace el sujeto se obtiene un estado afectivo u otro. La regulación emocional efectiva se relaciona con los estados emocionales representados en este círculo con la activación del sistema nervioso simpático (SNS) y del sistema nervioso parasimpático (SNP). La activación del SNS produce estados afectivos del $0^{\circ}$ a $90^{\circ}$, y la activación del SNP la aparición de estados positivos del cuadrante del $270^{\circ}$ a $360^{\circ}$. Estos resultados sólo se producen siempre y cuando exista una búsqueda individual de la valoración positiva de la situación. La regulación emocional tiene como objetivo ser el instrumento por el cual se produzcan respuestas adaptativas a las diversas situaciones a las que nos vemos enfrentados mejorando nuestra adaptación y el bienestar a través de la regulación positiva emocional. 


\subsection{Clasificación y Funciones de las Emociones}

\subsubsection{Clasificación de las emociones.}

Existen dos grandes enfoques a la hora de establecer la taxonomía y clasificación de las emociones. El primer enfoque se denomina dimensional y considera a la emoción como una entidad inespecífica y no discreta. Se caracteriza por situar a cada tipo de emoción dentro de un factor compuesto por dimensiones combinadas. Estos factores y las dimensiones asociadas en un intervalo son: 1) valencia afectiva (agradable-desagradable), 2) activación (calma-entusiasmo) y 3) control (controlador de la experiencia-contralado por la experiencia (Belmonte, 2013). Según Bradley y Lan (2000), y Gray (2001), citados en Fernández (2012), el arousal (activación) y la valencia afectiva (nivel de valoración) son las dimensiones más utilizadas en la investigación.

El segundo enfoque se encuadra en lo que se ha venido a denominar enfoque discreto por el cual se entienden las emociones como respuestas básicas afectivas con rasgos diferenciados que son comunes a todos los seres humanos independientemente de su cultura y contexto (Ekman, 1984, 1992; Izard, 1991). Esta conceptualización de la emoción se encuadra dentro de la tradición evolucionista iniciada con Darwin ya que considera que como especie, el ser humano dispone de una serie de emociones básicas que le han permitido mayores posibilidades de adaptación al medio en aras de perpetuarse. Por tanto, estas emociones básicas, o primarias, son mecanismos con una clara función adaptativa y con un componente biológico y genético que determinan la expresión emocional posterior (Choriz, 1995). Son emociones que se encuentran de forma natural y generalizada en todas las culturas por lo que se supone que son fruto de la evolución aunque todavía no se haya podido concretar para cada una de ellas las estructuras especificas cerebrales que serían su 
base neurológica. Dentro de las investigaciones que avalan este enfoque, se encuentran los estudios iniciados por Ekman (1972) que descubrió, analizando distintas culturas, que existían patrones de expresiones faciales comunes para seis emociones básicas, a saber, alegría, miedo, ira, sorpresa, asco y tristeza.

Posteriormente, Ekman (1999) incluyó una serie de emociones que denominó secundarias que no estaban necesariamente codificadas en músculos faciales entre las cuales se encuentran: diversión, desprecio o desdén, complacencia o contento, bochorno, entusiasmo o excitación, culpa, orgullo, alivio, satisfacción, placer sensorial, vergüenza, ira o rabia, repugnancia, repulsa, asco o repulsión, miedo o temor, felicidad, sorpresa y tristeza. Estas emociones secundarias no se relación con un origen filogénetico-ontogénetico sino más bien con el aprendizaje después de nacer que se desarrolla en una cultura determinada a través de la maduración de las habilidades cognitivas en interacción con el medio.

Dentro de este enfoque, diversos autores han ofrecido sus aportes de cuáles son las emociones básicas, en la Tabla 1.1 se ofrece el resumen de algunas de las más importantes.

Tabla 1.1: Emociones básicas

\begin{tabular}{|c|c|}
\hline AUTOR & EMOCIONES BÁSICAS \\
\hline Arnold (1960) & $\begin{array}{l}\text { Amor, aversión, desaliento, desesperación, } \\
\text { esperanza, ira, miedo, odio, tristeza y valor }\end{array}$ \\
\hline Plutchik (1980) & $\begin{array}{l}\text { Aceptación, alegría, expectación, ira, miedo, asco, } \\
\text { sorpresa y tristeza }\end{array}$ \\
\hline $\begin{array}{l}\text { Ekman, Friesen y Ellsworth } \\
\text { (1982) }\end{array}$ & Ira, alegría, miedo, asco, sorpresa y tristeza \\
\hline Panksepp (1982) & Miedo, furia, pánico y expectativa \\
\hline Izard (1991) & $\begin{array}{l}\text { Alegría, ansiedad, culpa, desprecio, asco, } \\
\text { excitación, ira, miedo, sorpresa y vergüenza }\end{array}$ \\
\hline Gross, Levenson (1995) & $\begin{array}{l}\text { Alegría, miedo, ira, asco, tristeza, sorpresa y } \\
\text { bienestar }\end{array}$ \\
\hline
\end{tabular}




\subsubsection{Funciones de las emociones}

Las emociones son imprescindibles en nuestro quehacer diario y por tanto, en la interrelación con los demás. Las emociones se vinculan a nuestra toma de decisiones pudiendo inclusive a través del contagio emocional llegar a influenciar en las personas que nos rodean. Independientemente de la clasificación que se siga todas las emociones tienen utilidad, incluso las que consideramos negativas como la ira, el miedo, o la tristeza. Choriz (2005) explica que las emociones tienen tres funciones principales: 1) función adaptativa,

2) función social, y 3) función motivacional. Veamos con más detenimiento cada una de ellas:

\section{Función adaptativa.}

Las emociones preparan al sujeto para que realice de una forma eficiente el comportamiento de adaptación que le exige el medio y las condiciones ambientales. Activan la energía y los recursos necesarios para poner en marcha la conducta de evitación o acercamiento hacia un objetivo determinado. Para Darwin (1872), que fue el precursor de la visión filogenética de las emociones, la emoción tiene como fin facilitar la conducta apropiada, lo que es básico en el proceso de adaptación. Con gran aceptación posterior Plutchik (1980) proporcionó una combinación de emociones básicas asociadas a su función respectiva (ver Tabla 1.2.). Por ejemplo, la emoción de miedo ante una situación de peligro como un terremoto es la respuesta lógica que determina que nos pongamos a cubierto y poder salvarnos. De ahí que las emociones tengan un claro componente adaptativo al orientarnos y prepararnos hacia la conducta más apropiada. 
Tabla 1.2: Funciones de las emociones (Plutchik, 1980). Tomado de Choriz (2005)

\begin{tabular}{cc}
\hline LENGUAJE SUBJETIVO & LENGUAJE FUNCIONAL \\
\hline Miedo & Protección \\
Ira & Destrucción \\
Alegría & Reproducción \\
Tristeza & Reintegración \\
Confianza & Afiliación \\
Asco & Rechazo \\
Anticipación & Exploración \\
Sorpresa & Exploración \\
& \\
\hline
\end{tabular}

En aquellas ocasiones con cierta gravedad (ej. atentados, guerras, etc.) las emociones facilitan respuestas adaptativas de gran intensidad y provocan cambios internos para poder contrarrestar la situación que se está viviendo (Mestre y Guil, 2012). El problema surge cuando estos cambios si se mantienen con alta frecuencia, intensidad y duración, pueden ocasionar que las mismas emociones que inicialmente han intentado proteger a la persona, ahora se vuelvan en factores de riesgo para la salud (Palmero y Fernández Abascal, 1998).

\section{Funciones sociales.}

La idea inicial que contextualiza este tipo de funciones es que las personas son seres sociales por lo que le es indispensable vivir en sociedad para cubrir sus necesidades, como por ejemplo, de interrelación personal, identificación y comunicación. Para ello, y bajo cada cultura, los grupos se alinean a los valores predominantes en cada sociedad y es necesario que cada individuo muestre un comportamiento afiliativo para poder integrarse en el grupo. Desde un punto de vista de función social las emociones permiten identificar las oportunidades y problemas que aparecen coordinando las acciones de los individuos que pertenecen a un grupo o desean integrarse al mismo (Keltner y Haidt, 2001). 
Las emociones y su expresión se hacen imprescindibles para comportarnos en sociedad ya que permite dar a conocer a los demás como nos sentimos, así como, percibir y comprender como se sienten los demás, y de ahí establecer un feedback emocional y comportamental. Sin la expresividad emocional no se podría establecer procesos de comunicación sociales y familiares de calidad. Por tanto, la expresión emocional puede considerarse como una serie de estímulos ejecutivos que facilitan la realización de conductas sociales (Fernández-Abascal y Jiménez, 2000). En este sentido las emociones positivas inciden en la generación de vínculos sociales y relaciones interpersonales saludables. Desde niños, ya en la relación madre-bebé la expresión emocional se establece como vinculo de comunicación entre ambos. A través de las emociones podemos conocer cómo se sienten los demás y por tanto actuar en base a la comprensión de la emoción que están sintiendo y expresan los demás, es decir, se establece un lazo de empatía entre las personas. La imposibilidad de identificar las emociones de los demás se denomina alexitimia. Esta enfermedad hace referencia a la dificultad que tienen algunas personas para identificar y expresar sus emociones (Sifneos, 1973), provocando consecuencias negativas tanto para el funcionamiento psicológico como biológico (Taylor, Bagby y Parker, 1997). Por ejemplo, se ha comprobado que las personas con mayor nivel de alexitimia mantienen un estilo de vida menos saludable y perciben mayor sintomatología cardiovascular. Igualmente estas personas con mayor nivel de alexitimia, a diferencia de las que presentaban niveles bajos, señalaban un estado de ánimo más depresivo, mayor hostilidad y un nivel de rumiación más alto (Rueda y Pérez-García, 2007).

La habilidad para poder leer en los demás la emoción que está sintiendo es básica en nuestra experiencia humana ya que permite anticipar una respuesta o inhibirla al 
comprender el estado emocional de las personas con las que convivimos. Sin una correcta comprensión de las emociones de los demás se hace dificultoso mantener de una forma sostenida en el tiempo relaciones sociales de calidad. Desde un punto de vista de la psicología positiva, Algoe, Haldt, y Gable (2008) se propone que las personas que expresan gratitud hacia otras, conlleva a la construcción de una relación de alta calidad entre quien se muestra agradecido y quien recibe este agradecimiento. En esta línea de trabajo Lambert, Clark, Durtschi, Fincham, y Graham (2010) mostraron en uno de sus estudios que, en la relación de pareja, cuando se expresa gratitud se mejora la percepción de la intensidad de la misma. En el ámbito laboral esta habilidad emocional permite la construcción de una red facilitadora de apoyo social que contrarresta los estresores y exigencias diarias.

\section{Función Motivacional.}

La emoción tiene la capacidad de dirigir y dar intensidad a la actividad que se está realizando. Tal y como afirma Choriz (2005) la emoción da energía a la conducta motivada, por lo que una conducta con una buena carga emocional se va a realizar de una forma más vigorosa. La emoción puede provocar que se realice una actividad, e inclusive la direcciona regulando la intensidad de su ejecución en busca de la meta establecida. Toda conducta motivada provoca una reacción emocional, y al mismo tiempo, la emoción facilita que surjan unas conductas motivadas y no otras (Choriz, 2005). 


\subsection{Emociones Positivas}

\subsubsection{Marco contextual: Psicología Positiva.}

Antes de entrar en la cuestión más particular de las emociones positivas es necesario describir el contexto de la psicología positiva en cual se ha desarrollado su estudio en la última década.

Tradicionalmente la psicología ha centrado su foco de interés en el estudio de los aspectos negativos del ser humano hasta que surgió un nuevo movimiento a finales de los años 90 liderado por el psicólogo norteamericano Martin Seligman. En 1998, como presidente de la American Psychological Association (APA), señaló que una de las directrices básicas para el desarrollo de la psicología es ir hacia una psicología más positiva. Seguidamente, recogió en un número especial de la revista American Psychologist (Seligman, y Csikszentmihalyi, 2000) una serie de artículos científicos relacionados con la motivación intrínseca, la felicidad, la sabiduría, el talento, la sabiduría, la creatividad y el desarrollo humano. Esta publicación se constituyó como el lanzamiento científico de la Psicología Positiva (Castro, 2010). Por tanto, la Psicología Positiva nació como respuesta alternativa al funcionamiento clásico de la psicología que hasta ese momento se había centrado en aspectos patológicos del ser humano y su rehabilitación (Gancedo, 2009). El principio inicial de la Psicología Positiva es que, aun cuando la desaparición de los trastornos psicológicos puede conllevar a reducir el sufrimiento de las personas, no necesariamente significa que exista un mayor bienestar psicológico. Tradiciones anteriores recogían esta fundamentación siendo el aporte de la Psicología Positiva dotarle de análisis y método científico para unificar su implantación a través de un objetivo común para la investigación, intervención y formación profesional. (Castro, 2010). Tal y como describe 
Prada (2010) la Psicología Positiva se puede definir como el estudio científico de las experiencias positivas y los rasgos individuales positivos, además de las instituciones que facilitan su desarrollo. Desde un plano individual la Psicología Positiva intenta establecer un itinerario hacia la vida plena y el bienestar. Para ello, según Seligman (2011), existen cinco caminos que hay que seguir para alcanzar esta plenitud.

El primero de ellos es cultivar las emociones positivas para disponer de una vida agradable, pleasant life. Esta visión hedonista consiste en dotar a nuestras vidas de momentos placenteros que nos generen emociones positivas. Estos momentos del presente se pueden alcanzar con técnicas como el savoring y el mindfulnes. El savoring o saborear la situación que se está viviendo consiste en disfrutar de los pequeños momentos que nos da la vida como puede ser una buena película, comida, o el sexo. El mindfulness puede entenderse como atención y conciencia plena, como presencia atenta y reflexiva a lo que sucede en el momento actual. Pretende que la persona se centre en el momento de un modo activo, procurando no interferir ni valorar lo que se siente o se percibe en cada momento (Vallejo, 2006). Esta vía para alcanzar el bienestar tiene dos grandes limitaciones: la primera que nuestra carga genética y nuestra personalidad condiciona el nivel de emocionalidad entre un 40 a un 50\%; la segunda, es que nos acostumbramos a las emociones positivas, en lo que se denomina adaptación hedónica o habituación, y ya no nos proporcionan placer una vez alcanzamos un nivel de habituación determinado.

Para completar esta vía hedónica Seligman, plantea la segunda ruta que consiste en cultivar la entrega, el compromiso por lo que se hace, engagement life, que lleva a que vivamos experiencias positivas mientras realizamos una tarea. Es decir, se experimenta flow, definido como aquella experiencia óptima extremadamente disfrutada en la que se 
experimenta total concentración y disfrute con un alto interés por la actividad (Csikszentmihalyi, 1996).

En tercer lugar, y dejando de lado una perspectiva hedónica, aparece la búsqueda del sentido de lo que hacemos, o vida con significado (meaningful life). Es dar un paso más y consiste en la aplicación de las fortalezas personales para ayudar a los demás y acompañarlos para que puedan liberar su potencial.

El cuarto sería la importancia de alcanzar los logros por su valor intrínseco, que es disfrutar del proceso y no de las consecuencias de aquellas metas que nos proponemos. Y, por último, describe las relaciones sociales, la vida social, donde es fundamental disponer de relaciones interpersonales de calidad (Seligman, 2011).

Dentro de este contexto de la Psicología Positiva surge el interés por el estudio de las emociones positivas en contraposición a la postura clásica que se centraba en el análisis e impacto de las emociones negativas en el ser humano. Si se repasa las investigaciones sobre emociones nos encontramos como las emociones negativas han sido objeto de estudio preferente por encima de las positivas debido, entre otras causas, por que tradicionalmente existen identificadas mayor número de emociones negativas. Tan sólo hay que observar las diferentes taxonomías expuestas anteriormente de emociones básicas y nos encontramos que existen más emociones negativas que positivas. Una de las explicaciones de esta diferencia presupone que esto es debido a que la selección natural configura emociones sólo para situaciones que contienen amenazas y oportunidades, por lo que existen más emociones negativas ya que se producen más amenazas que oportunidades. (Fredrickson, 2001). Además, desde un punto de vista de análisis de consecuencias, el precio de no dar una respuesta eficiente guiada por una emoción ante una amenaza puede ser la muerte; en 
cambio esto no sucede con una mala decisión orientada por una emoción positiva. De igual manera, la psicología se centró en las emociones negativas porque era clara su asociación a las patologías físicas y psicológicas que intentaba resolver, como celos, envidias, violencia, ansiedad, disfunciones sexuales. Sin embargo, la investigación y experimentación de las emociones y afectos positivos es fundamental en nuestra esencia como seres humanos aportando beneficios a nuestra calidad de vida (Fredrickson, 2003a).

No hay que caer en el error de desprestigiar las emociones negativas con la aparición de esta nueva línea de trabajo que está impregnando al estudio emocional, ya que las personas con predominio de emociones negativas tienen un razonamiento más crítico, están muy capacidades para tomar decisiones difíciles y tienen una tendencia a ver la realidad más nítida. Por lo tanto, en ciertas ocasiones disponer de emociones negativas es eficiente como puede ser el caso de una toma de decisiones sobre inversiones presupuestarias tras un análisis de costos e ingresos.

\subsubsection{Teoría de la Ampliación y Recursos: Broaden-and-Build Theory}

\section{(Fredrickson, 2001).}

Fredrickson (2001) propuso un modelo teórico modelo denominado de Ampliación y Construcción de Emociones Positivas (Broaden-and-Build Theory) cuyo enunciado teórico defiende que las emociones positivas y los estados afectivos relacionados con ellas se vinculan a una ampliación de la atención, la cognición, la acción, y a una mejora de los recursos físicos, intelectuales y sociales de la persona (Fredrickson, 2001). Es decir, las emociones positivas, si bien son diferentes entre sí, lo que provocan es una ampliación de los reportorios de pensamiento de la acción y crecimiento personal (ver Figura 1.3). 


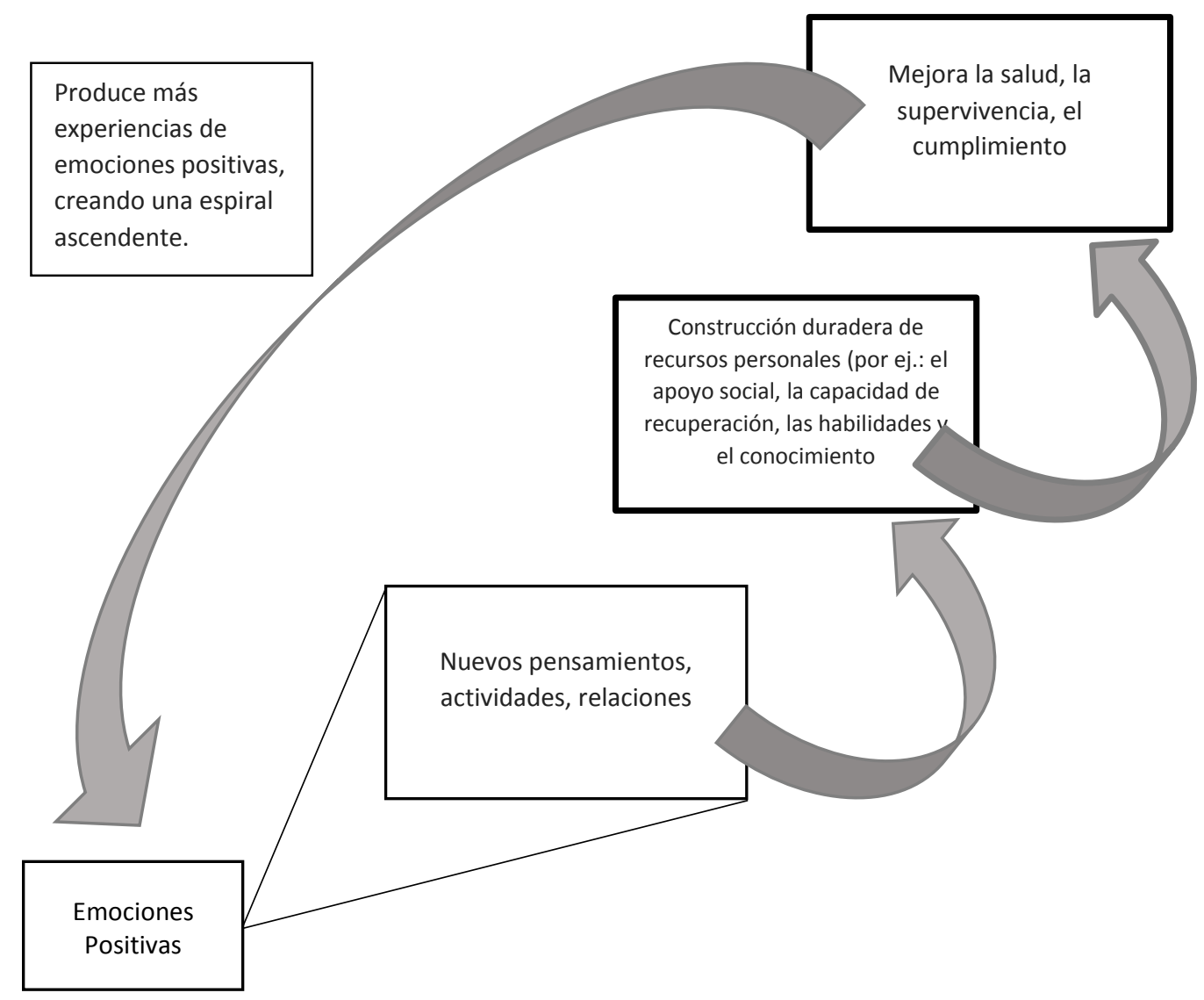

Figura 1.3: The Broaden and Build Theory of Positive Emotions. Adaptada de Fredrickson y Cohn (2008)

Fredrickson detalla que, a diferencia de las negativas, las emociones positivas no tienen una puesta en escena tan inmediata, ya que no se asocian a la necesidad de responder rápidamente por las consecuencias de una respuesta tardía, como puede ser la presión de responder ante un accidente de tráfico, robo, o un desastre natural. Es decir, no provocan una tendencia a una acción predominantemente física, sino que por el contrario provocan en las personas una serie de respuestas mucho más variadas, y sobre todo cambios cognitivos que posteriormente pueden llevar a variaciones físicas. Para la autora, las emociones positivas generan nuevas tendencias de pensamiento y acción construyendo nuevos 
recursos personales, por lo que una función nueva que se le da a las emociones es el crecimiento y ampliación de recursos personales tales como, los físicos, intelectuales y sociales. Para esta investigadora las diez emociones positivas más comunes son (Fredrickson, 2005): Alegría, Gratitud, Serenidad, Interés, Esperanza, Orgullo, Diversión, Inspiración, Asombro, y Amor.

Experimentar emociones positivas nos prepara de una forma más estable y duradera para las posibles complicaciones que pueden acontecer en un futuro cercano. De igual forma complementa el sentido evolutivo de las emociones positivas explicando que probablemente los antepasados que experimentaron más emociones positivas resultaron con mejores recursos personales para contrarrestar con mayores garantías de éxito las diversas amenazas que les cernían. Gracias a esta práctica tenían más posibilidades de sobrevivir, por lo que fue probable que el incremento de mayores alternativas de supervivencia permitiera incrementar las posibilidades de reproducción y probablemente esta tendencia de acción se incorporó a nuestro kit de supervivencia transcendiendo de generación a generación. Las emociones pasaron así, al reportorio hereditario de nuestra especie proporcionando a nuestros ancestros mayores recursos personales (Fredrickson, 2003b).

Según Fredrickson (2013b), las dos hipótesis principales de su teoría son:

a) Ampliación: Las emociones positivas, en relación con las emociones negativas y los estados neutrales, son capaces de ampliar la variedad de pensamientos, acciones y percepciones que espontáneamente vienen a la mente. Esta hipótesis inicial, según reconoce y cita la propia autora, tiene su base en las investigaciones de Alice Isen y sus colaboradores, por las cuales se concluye que aquellas personas que experimentan emociones positivas muestran 
patrones de pensamiento inusuales (Isen, Johnson, Mertz, y Robinson, 1985), son flexibles (Isen y Daubman, 1984), creativos (Isen, Daubman, y Nowicki, 1987), integradores (Isen, Rosenzweig, y Young, 1991), y abiertos a la información (Estrada, Isen, y Young, 1994).

b) Construcción: La argumentación central es que las emociones amplían la variedad de pensamientos, acciones y percepciones que vienen espontáneamente a la mente. Según las evidencias encontradas (Fredrickson, Cohn, Coffey, Pek, y Finkel, 2008) las emociones positivas generan recursos personales, psicológicos, personales, cognitivos y físicos incrementándose al mismo tiempo el bienestar subjetivo.

A continuación, y a modo síntesis, (ver Tabla 1.3.) se recogen algunas de las investigaciones que avalan cada una de estos dos efectos que configuran el modelo de Fredrickson (2013b): 
Tabla 1.3: Investigaciones Efectos Emociones Positivas Elaboración propia a partir

de Fredrickson (2013b)

\begin{tabular}{|c|c|c|}
\hline $\begin{array}{l}\text { FACTOR } \\
\text { MODELO }\end{array}$ & $\begin{array}{c}\text { EFECTO DE LA } \\
\text { EMOCIÓN POSITIVA EN }\end{array}$ & AUTORES INVESTIGACIÓN \\
\hline \multirow[t]{12}{*}{ 1.Construcción } & Resiliencia & Block y Kreven (1996) \\
\hline & Ansiedad & Turgade y Fredrickson(2004) \\
\hline & Atención & Basso $(1992,1996)$ \\
\hline & & Fredrickson y Branigan,2005) \\
\hline & Atención visual & Wadlinger and Issacowitz (2006) \\
\hline & Social-Confianza & Dunn y Schweitzer (2005) \\
\hline & Social-Compasión & Nelson (2009) \\
\hline & Social-Comprensión & Waugh y Fredrickson (2006) \\
\hline & Creatividad & Isen (1985) \\
\hline & Activación Hipocampo & Schimitz, De Rosa, y Anderson (2009) \\
\hline & Comportamiento físico & Gross, Crane, y Fredrickson (2012) \\
\hline & Cognición & Johnson (2010) \\
\hline \multirow[t]{10}{*}{ 2. Ampliación } & Resiliencia & Fredrickson al (2003) \\
\hline & Ingenio & Lyubomirsky, King, y Diener (2005) \\
\hline & Funcionamiento Óptimo & Mauss et al. (2011) \\
\hline & Satisfacción con la vida & Cohn et al. (2009) \\
\hline & $\begin{array}{l}\text { Sacar beneficio incluso de la } \\
\text { adversidad }\end{array}$ & Hart, Vella, y Mohr (2008) \\
\hline & $\begin{array}{l}\text { Capacidad de afrontar los } \\
\text { problemas con otra percepción }\end{array}$ & Fredrickson y Joiner (2002) \\
\hline & $\begin{array}{l}\text { Motivación Intrínseca, } \\
\text { autoeficacia, recursos } \\
\text { organizacionales }\end{array}$ & Salanova, Bakker y Llorens (2006) \\
\hline & $\begin{array}{l}\text { Recursos personales y } \\
\text { cognitivos }\end{array}$ & Catalino y Fredrickson(2011) \\
\hline & $\begin{array}{l}\text { Contagio emocional y } \\
\text { desempeño laboral }\end{array}$ & $\begin{array}{l}\text { Carsol, Kacmar, Zivnuska, Fergurson, } \\
\text { y Whtttn (2011) }\end{array}$ \\
\hline & $\begin{array}{l}\text { TonoVagal y Bienestar } \\
\text { (espiral) }\end{array}$ & Kok y Fredrickson(2010) \\
\hline
\end{tabular}




\subsubsection{Modelo espiral ascendente hacia el cambio de estilo de vida (Fredrickson,}

2013b).

Fredrickson completa su desarrollo teórico con su última aportación del Modelo Espiral hacia el Cambio de Vida. Este modelo tiene como objetivo estudiar como las emociones positivas pueden alterar los sistemas corporales de las personas, y cómo funciona la motivación no consciente que aparece adherida a los comportamientos que refuerzan el cambio de estilo de vida (Fredrickson, 2013b). La idea que emerge en esta nueva teoría es que las emociones positivas movilizan una serie de motivaciones no conscientes que impulsan nuevos comportamientos. Estos comportamientos hacen que nos sintamos bien incrementando nuestros recursos personales, y al mismo tiempo, al sentirnos bien, se refuerza la motivación inicial no consciente volviéndose a reiniciar el bucle.

En la Figura 1.4 se representa el modelo y su funcionamiento en espiral. En la medida en que un nuevo comportamiento de bienestar evoca emociones positivas se producen los siguientes efectos:

a) Motivos no conscientes asociados a los nuevos comportamientos y que empujan hacia arriba provocando nuevos comportamientos (bucle interior)

b) Aumento en los recursos biológicos y psicológicos que impulsan el rendimiento de la persona (bucle exterior, y al mismo tiempo internamente potencia el mantener los comportamientos derivados de las emociones positivas reforzándolas a que se sigan desarrollando. 


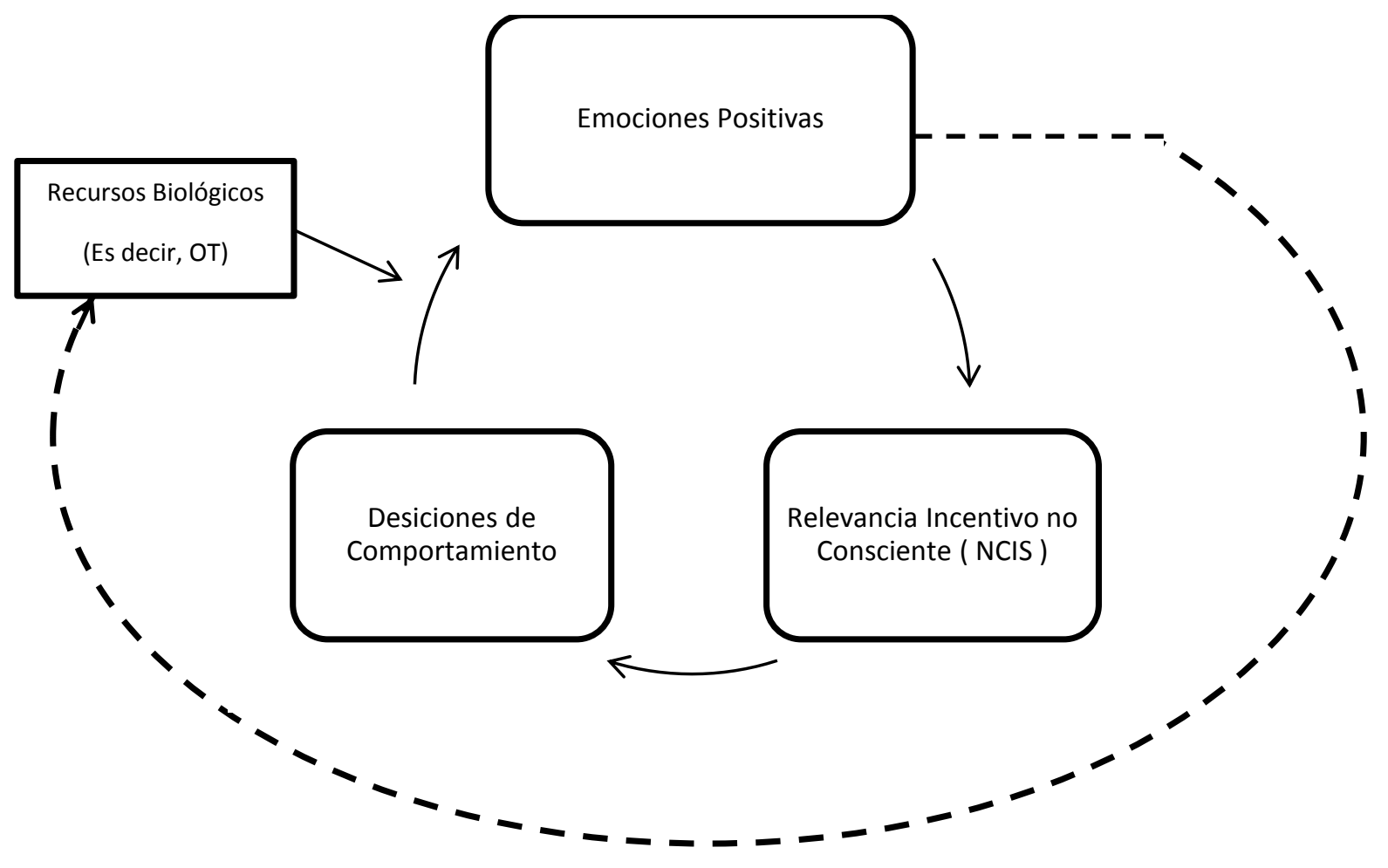

Figura 1.4: Modelo Espiral hacia el Cambio de estilo de Vida (Adaptada de Fredrickson, 2013b)

Actualmente se están desarrollando diversos proyectos de investigación longitudinal para corroborar el modelo (Fredrickson, 2013b).

\subsection{Emoción y Cognición: Facilitación Emocional}

La dicotomía entre emoción y cognición ha sido una de las grandes discusiones filosóficas, biológicas, psicológicas y neurofisiológicas que ha provocado una visión enfrentada y contrapuesta de estos dos componentes del ser humano. En esta división, tal y como se ha señalado anteriormente, la emoción se asociaba a la idea de corazón, de pasión, y quedaba relegada a un segundo plano frente la racionalidad. A continuación se revisan las investigaciones que apuntan a lo contrario y destacan la importancia de las emociones en el 
plano cognitivo, tema principal, por otra parte, de esta tesis doctoral. Para ello, es necesario explicar brevemente la composición anatómica de las áreas del sistema nervioso central y del cerebro que intervienen en el procesamiento emocional y cognitivo. Posteriormente se identificarán y se describirán las estructuras cerebrales que subyacen en el procesamiento emocional y su interacción con los aspectos cognitivos. Finalmente, tras definir cuáles son las funciones ejecutivas de orden superior cognitivo, se recogerán algunas de las investigaciones recientes que las relacionan con la gestión e información emocional.

\subsubsection{Anatomía de la emoción y cognición.}

El Sistema Nervioso Central (SNC) se compone del encéfalo (cerebro, cerebelo, tronco encefálico) y de la medula espinal. El SNC se divide en tres subsistemas principales:

a) La vía sensitiva, que transmite señales desde las terminaciones nerviosas sensitivas periféricas hacia casi todas las partes de médula espinal, tallo cerebral, cerebelo y cerebro.

b) La vía motora, que lleva señales nerviosas que se originan en todas las áreas centrales del SN hacia los músculos y las glándulas de todo el cuerpo

c) El sistema de integración (sistema cortical) que analiza la información sensitiva, almacena en la memoria y utiliza la información para efectuar las reacciones apropiadas.

Las reacciones nerviosas más simples se integran en la médula espinal y las más complejas, como el control de la postura, regulación de las funciones cardíacas y respiratorias, se integran en el tallo cerebral. Y las funciones como los procesos del pensamiento, memoria y almacenamiento, actividades motoras complejas, se integran en la 
corteza cerebral. Aunque como componente del SNC, el cerebro hay que entenderlo como un sistema interconectado entre sí por varios subsistemas compuesto por billones de neuronas dónde cada una de ellas significa un promedio de más de diez mil conexiones que las comunican con otras tantas neuronas configurando una red de conectividad funcional y comunicativa extremadamente compleja.

Para proceder a una descripción anatómica del cerebro se seguirá el trabajo de MacLean (1970) que recogiendo las investigaciones previas de Papez (1937) plantea una composición evolutiva del cerebro que da lugar a lo que se define como cerebro triuno (ver Figura 1.5).

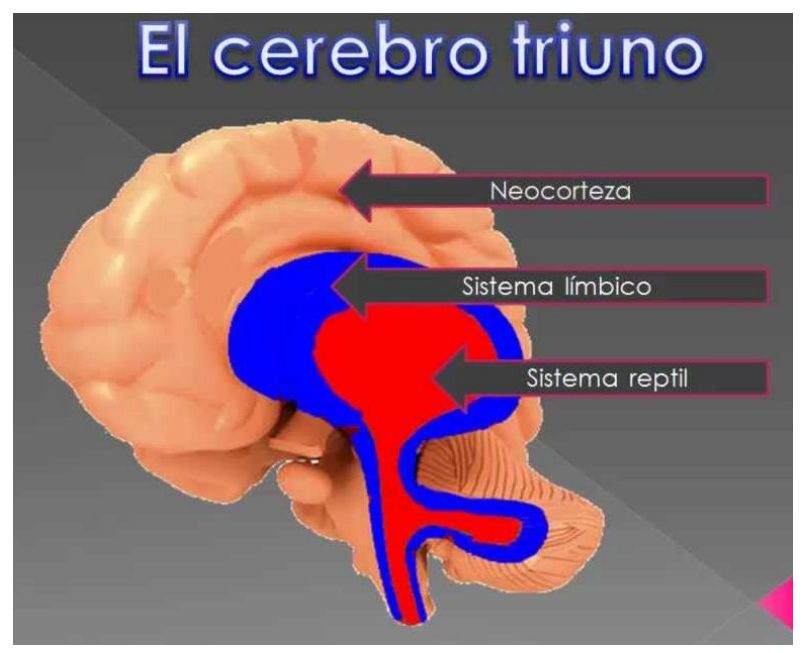

Figura 1.5: Recuperado de https://filosofiaymente.wordpress.com/2015/03/03/teoriadel cerebro-triuno/

A lo largo del proceso evolutivo el cerebro se ha ido desarrollando a través de la generación de tres capas o cerebros distintos. Cada capa nueva que se iba creando suponía un incremento en las capacidades cognitivas así como de complejidad funcional. Según esta 
secuencia del desarrollo evolutivo cerebral de MacLean (1970) existen tres cerebros (ver Figura 1.6).

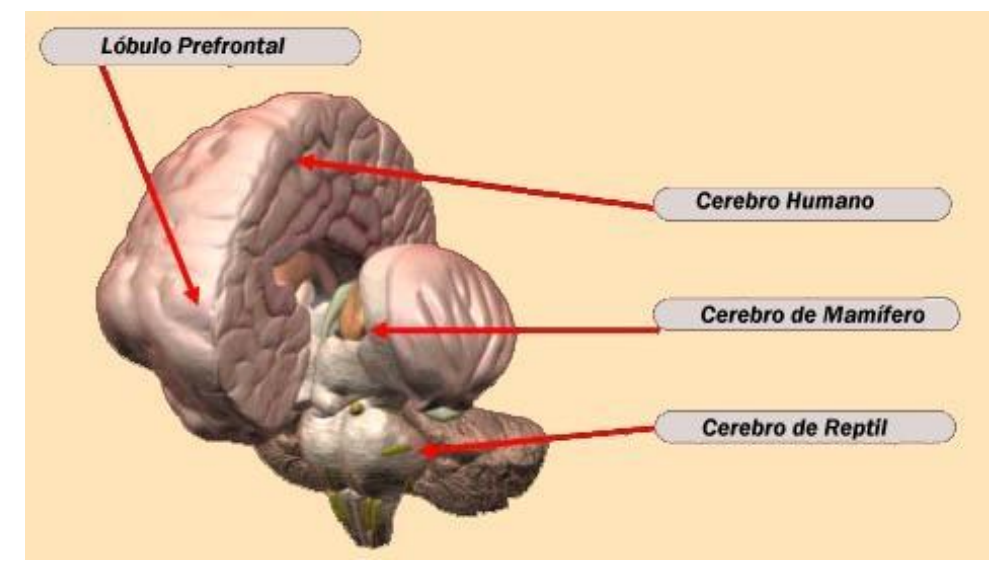

Figura 1.6: Recuperado de https://sites.google.com/site/cerebrohumanoycalculoracional/algunos-nombres/paulmaclean-cerebrotriuno

\section{Cerebro Reptiliano:}

Se compone del tronco cerebral y el cerebelo. Responde a los instintos siendo el más primitivo en su aparición. Se responsabiliza de las funciones básicas del organismo que incluye el mantenimiento, control del ritmo cardiaco. Estas funciones vitales son comunes a todas las especies. El tronco cerebral también controla los estados de sueño y vigilia mientras tanto el cerebelo se encarga de la coordinación del movimiento corporal y la priopercepción. De igual manera se ha encontrado evidencia que está relacionado con el neocortex para la planificación de la conducta intencional (Glover, 2004).

\section{Cerebro límbico o emocional (Mesencéfalo).}

Esta parte del cerebro comprende las estructuras que componen el sistema límbico de las cuales destacan, la amígdala, los cuerpos mamilares del hipotálamo, el hipocampo, el fornix, la corteza de del cíngulo tálamo, el septum, y el bulbo olfatorio (Pinel, 2001). Las 
funciones básicas de esta parte del cerebro son luchar, huir, alimentarse, y tener relaciones sexuales. Se denomina cerebro emocional, gestionando gran parte de nuestros estados emocionales, la memoria emocional y las respuestas primarias emocionales, así como de la regulación a través del mesencéfalo y el hipotálamo de los estados internos, controlando químicamente el ambiente interno del cuerpo.

\section{$\underline{\text { 3. Cerebro Neocortex }}$}

El neocórtex es último cerebro en surgir en el proceso evolutivo apareciendo recientemente (según nuestra historia como especie hace 60.000.000 años) siendo la zona responsable de las funciones superiores (Berubé, 1991) tales como razonar, planificar, aprender, recordar, crear, analizar, dominio del lenguajes, entre otras. Permite relacionarnos con el exterior y en base a las experiencias pasadas selecciona o modifica la conducta manifestada anteriormente para obtener una respuesta correcta incluyendo el proceso de regulación emocional en las nuevas situaciones que se presentan. El neocortex se divide en dos mitades, el hemisferio izquierdo (HI) y el hemisferio derecho (HD) unidos y comunicados por un grueso puente de fibras nerviosas denominado cuerpo calloso. La especialización de funciones de cada uno de los hemisferios y su prevalencia se ha denominado lateralización cerebral. En su análisis para ver cómo influyen los dos hemisferios en la percepción emocional se determinan dos grandes modelos, el de la predominancia del hemisferio derecho (HD) y el de las valencias (Mozaz, Mestre y Núñez, en Mestre y Fernández Berrocal, 2007). El HD adquiere dominancia sobre el HI en la percepción facial de las emociones ya que se ha comprobado que desempeña un papel crucial en la percepción emocional, el procesamiento emocional e incluso el procesamiento de palabras de contenido afectivo (LeDoux, 1999). Según Martínez-Selva, Navarro, 
Bechara y Román, (2006) el HD está más implicado en las funciones emocionales, en la conciencia y en el mapa o referencia subjetiva de los estados corporales y en la comprensión neurocognitiva de la información somática. El deterioro de la percepción de la emoción resultante de daños en el HD no se limita a la emoción transmitida a través del canal facial: daños hemisferio derecho también compromete la percepción de palabras emocionales (Borod, Cicero, Obler, Welkowitz, Erhan, Santschi y Whalen (1998), y deteriora la capacidad de interpretar la prosodia emocional (Tucker, Watson, y Heilman, 1997).

Consistentemente, las lesiones en el HD provocan que se tenga mayores problemas en la percepción y comprensión del significado de la expresión facial o de la prosodia de pacientes con lesiones en el HI (Browers, Bauer, Coslett y Heilman, 1985; Ahern, 1994,). Más recientemente Bourne y Watling, (2015) han evidenciado que para procesar las expresiones de las emociones se depende del procesamiento de la información emocional facial en el HD. Los datos clínicos recogidos anteriormente implican claramente un papel dominante en el HD de la percepción y del procesamiento general de la emoción. Con respecto al modelo de valencias (positivo-negativo) la hipótesis central es que el HD se responsabiliza de las emociones negativas y el $\mathrm{HI}$ de las positivas. A lo largo de la última década han aparecido investigaciones a favor y en contra de esta hipótesis aunque la tendencia generalizada es que se ha podido evidenciar la emotividad negativa en el HD existen opiniones contrapuestas. A favor de esta hipótesis nos encontramos con la investigación de Jansari, Tranel y Adolph (2000) por la cual a los sujetos experimentales se les expuso imágenes de caras normales emparejadas con imágenes de caras con expresiones emocionales positivas y negativas de (felicidad, sorpresa, asco, miedo, ira o tristeza). 
Encontraron un efecto sorprendente ya que los sujetos discriminaron mejor las emociones negativas cuando la cara con la emoción negativa estaba a la izquierda de la cara neutral. Por el contrario, cuando tenían que discriminar expresiones positivas, los sujetos tuvieron un mejor desempeño cuando la cara emocional estaba a la derecha. No obstante hay que tener en cuenta las investigaciones que han demostrado el papel de estructuras del HI en la percepción de estímulos que provocaban emociones negativas (Tamietto, Latini, De Gelder y Geminiani, 2006). Actualmente, una línea de investigación que intenta dar una respuesta uniforme ante los resultados contradictorios expuestos se centra en el estudio de la interacción entre los dos hemisferios, así como, a nivel intra, del análisis de las estructuras internas de cada uno de ellos y su correlación específica con el funcionamiento neurológico emocional. Sin duda, hace falta seguir investigando y tal vez ampliar a una búsqueda de un modelo mixto dónde se tengan en cuenta otras variables y que, posiblemente, conduzca a admitir que se da una colaboración entre ambos hemisferios para procesar cada emoción al margen de la valencia de los estímulos (Palmero, 1996).

Para finalizar la composición estructural del neocortex hay que tener en cuenta que los dos hemisferios se subdividen en cuatro regiones separadas que se denominan lóbulos:

- Lóbulos Occipitales: Responsables del manejo de la información visual

- Lóbulos Parietales: Relacionados con la sensación y percepción táctil, también coordinan algunas funciones del lenguaje

- Lóbulos Temporales: Responsable de la percepción y procesamiento de los estímulos auditivos

- Lóbulos Frontales: La parte del cerebro que regula la acción intencional de nuestra conducta incluyendo la respuesta psicomotriz. Fue la última región en aparecer en 
nuestro cerebro y es la que dota al ser humano de aspectos diferenciadores del resto de especies como el lenguaje, la percepción y, sobre todo, cómo se va a explicar seguidamente, la recepción de la información que generan las emociones para dotarles un significado y proceder a responder en consecuencia.

Hasta hace poco tiempo atrás el interés científico en el estudio neurofisiológico de las emociones se centraba en el sistema límbico. Si bien es cierto que su importancia anatómica y neurológica en esta gestión es innegable, la aparición de las nuevas técnicas de visualización de la actividad cerebral como la Tomografía Computarizada (TC), las imágenes de Resonancia Magnética (IRM), la Tomografía Cerebral de Emisión de Positrones (TEP), la Tomografía de Emisión de un Fotón Único (TEFU), las Imágenes de Resonancia Magnética funcional (IRMf) (Power, y Dalgleish,1999; Drevets y Raichle, 1998) junto a investigaciones pioneras como LeDoux $(1999,2000)$ y Damasio, 1996) han permitido describir las diferentes interacciones cerebrales que existen en diferentes niveles cerebrales para el proceso emocional, por lo que es imposible negar que el proceso emocional transcurre por múltiples circuitos cerebrales estando integrados en diferentes niveles de procesamiento que incluye el neocortex (Gray, 2004).

Tomando en consideración lo expuesto anteriormente se puede concluir que el cerebro humano funciona como un sistema compuesto por distintos niveles, y subsistemas interconectados, y que, a pesar de existir una especialización de algunas de sus funciones en localizaciones específicas, es imposible realizar un análisis segmentado anatómico de la emoción sin tener en cuenta las diversas zonas, incluyendo el neocortex, que intervienen en la gestión emocional. En la siguiente sección se revisarán las investigaciones que desde un 
punto de vista neurofisiológico describen la interacción entre las estructuras cerebrales que protagonizan la interconectividad e integración entre la emoción y la cognición.

\subsubsection{Procesamiento cerebral de las emociones}

En primer lugar se identifican las estructuras cerebrales especializadas en la gestión de las emociones y seguidamente se describe cómo se produce el procesamiento cerebral de la información emocional.

\subsubsection{Estructuras cerebrales en la gestión emocional}

\section{$\underline{\text { Sistema Límbico }}$}

El sistema límbico debe su nombre a Paul Broca (1878). Broca denominó Grand lobe limbique-gran lóbulo marginal a la estructura que recogía los bordes replegados hacia dentro de la corteza cerebral configurando un óvalo hacía delante (Wicht, 2012). Inicialmente también era denominado rinencéfalo ya que se pensaba erróneamente que estaba muy vinculado a la percepción olfativa. Aunque algunos autores (ej. Siegel, 2015) afirman la complejidad de determinar las zonas específicas que componen el sistema límbico. A continuación se destacan las más importantes y su función en la gestión emocional. 
Tabla 1.3: Sistema límbico y funcionalidad emocional. Elaborado a partir de Belmonte (2013)

$\begin{array}{ll}\text { Amígdala } & \begin{array}{l}\text { Media y controla la actividad emocional principalmente de las } \\ \text { emociones de miedo, ira, y agresión así como la identificación del } \\ \text { peligro } \\ \text { Considerada como una estructura esencial para el procesamiento } \\ \text { emocional de las señales sensoriales, ya que recibe proyecciones de } \\ \text { todas las áreas de asociación sensorial. Es esta convergencia de } \\ \text { proyecciones anatómicas la que sitúa a la amígdala como la } \\ \text { estructura responsable para la formación de asociaciones entre los } \\ \text { estímulos y el refuerzo o el castigo (Jones y Mishkin, 1972; Rolls, }\end{array} \\ \text { 1986). } \\ \text { Hipocampo } & \begin{array}{l}\text { Controla la memoria (sobre todo a largo plazo) y manejo del espacio } \\ \text { Tálamo }\end{array} \\ \text { Tallo encefálico } & \begin{array}{l}\text { La formación emocional por su conexión con el córtex prefrontal } \\ \text { reacciones emocionales que preparan para dar respuesta activa de } \\ \text { alertas que permiten la supervivencia ante estímulos amenazadores. } \\ \text { Mantiene el ciclo del sueño. }\end{array} \\ \text { Área ventral } & \text { Su estimulación produce sensaciones placenteras } \\ \text { tegmental } & \text { Responsable de sensaciones placenteras } \\ \text { Septum } & \end{array}$

En el sistema límbico existen dos grandes circuitos de comunicación cerebral de los cuales se desprende diferentes vías que conectan sus estructuras internas con el resto de áreas cerebrales incluyendo zonas de la corteza cerebral situadas en el neocortex

\section{Circuito de Papez}

Este circuito se consideraba como el centro del procesamiento cerebral de las emociones localizado en el centro del sistema límbico. Aunque investigaciones posteriores han dejado la idea que este circuito sea el único centro del control y gestión de las emociones, sí que es cierto que existe anatómicamente en el sistema límbico y debido a ello provocó la idea inicial de la existencia de una interacción anatómica de regiones cerebrales profundas y primitivas, con la corteza cerebral. Tal y como recoge Palmero (1998), para Papez la emoción esta mediada por las conexiones cortico-hipotalámicas e implica la 
expresión conductual y la experiencia subjetiva que denomina sentimiento. Tras llegar al tálamo, las aferencias sensoriales se dividen en tres rutas: hacia la corteza cerebral (corriente de pensamiento), hacia los ganglios basales (corriente de movimiento) y, por último, hacia el hipotálamo (corriente de sentimiento). Del circuito de Papez se desprenden tres vías:

a) Circunvolución del hipocampo. Esta vía conecta directamente el hipotálamo con la corteza cerebral y se produce constantemente un flujo de comunicación y combinación de señales nerviosas en ambos sentidos.

b) La segunda vía pasa por el trígono cerebral. Desde allí salen fibras nerviosas para las regiones de la parte anterior del hipotálamo que es el inicio de los sentimientos de alegría y desgracia.

A través de estas dos vías se produce una clara unión entre cognición y emoción y viceversa.

c) La tercera vía también pasa por el trígono cerebral en dirección al septum pellucidum y a los ganglios basales que controlan el movimiento.

Este circuito, tal y como describe Wicht (2012), es el centro anatómico del sistema límbico sobre el que se reúnen otros grupos de células nerviosas dispuestas en capas de cebollas, comunicadas entre sí, permitiendo un flujo constante de comunicación por varias vías que se conectan con la zona de la corteza cerebral que se encarga de las funciones cognitivas siendo la más importante la entrada y salida de información a través de la circunvolución del hipocampo.

\section{Circuito Límbico: Cuerpo Amigdalino.}


La amígdala está especializada en el procesamiento de las emociones, especialmente las negativas como la ira o la repulsión. Sobre todo se ha investigado la amígdala con la relación con la emoción del miedo a través de las investigaciones de LeDoux (1993,1999, 2007). En un primer nivel, en el interior del sistema límbico, la amígdala se conecta con estructuras del propio sistema que se vinculan con la percepción de los olores que se perciben influyendo en la posterior emoción que se produce directamente en el mismo sistema límbico. La amígdala además se conecta en dos direcciones con la corteza cerebral, por un lado remite fibras nerviosas al circuito de Papez (a través de la circunvolución del hipotálamo) y en segundo lugar se conecta con los centros motores de la corteza (ver Figura 1.7)

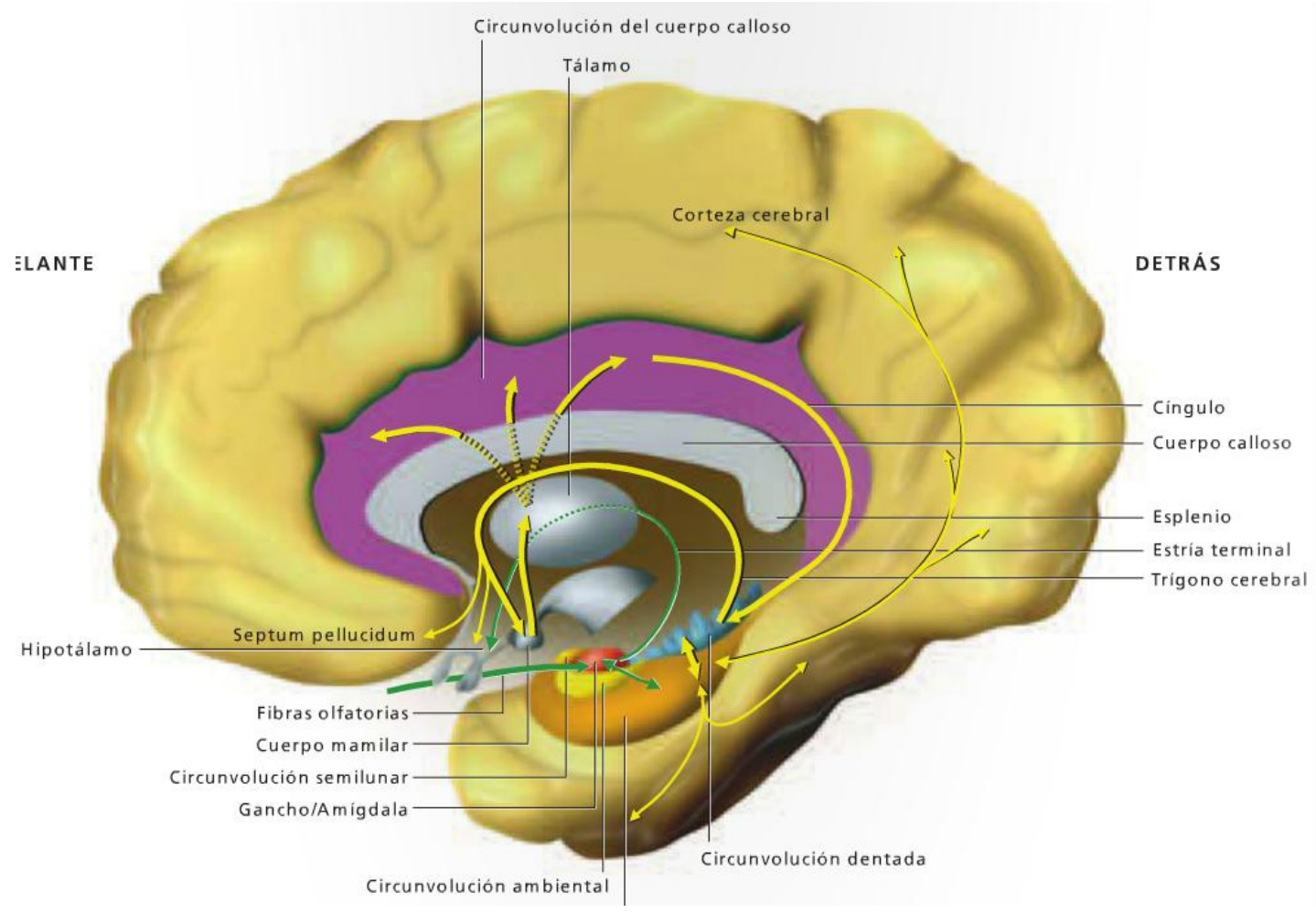

Figura 1.7: Circuitos de comunicación sistema límbico (Wicht, 2012) 


\subsubsection{Procesamiento cerebral de la emoción}

Con respecto al funcionamiento y procesamiento de las emociones una de las teorías sobre cómo se produce el procesamiento cerebral emocional que más respaldo ha tenido es la ofrecida por Joseph LeDoux a través de sus investigaciones pioneras sobre el miedo y el rol de la amígdala en su activación. Este autor se ha convertido en referencia obligada a través de la publicación de su libro "El cerebro emocional” (1999) así como la aparición de algunos de sus estudios en la referencias neuropsicológicas que aportó Daniel Goleman en sus muy conocidas publicaciones sobre la inteligencia emocional (1995, 1998). Para LeDoux existen dos vías de procesamiento cerebral de los estímulos que provocan la emoción humana. La primera vía denominada vía implícita o talámico-límbica transmite la información sensorial desde el tálamo a la amígdala sin intervención de los sistemas corticales más complejos, lo que demuestra que se produce un procesamiento emocional precognitivo ya que en la amígdala, según el autor, se evidencia una función de valoración de los estímulos emocionalmente relevantes para el organismo. Este camino es el corto, el “atajo cerebral” que se pone en funcionamiento (recordemos que el autor está especializado en el estudio de la emoción del miedo) cuando nos enfrentamos a un estímulo amenazador dónde no cabe el tiempo de un procesamiento complejo en la corteza cerebral, activando en la amígdala el mecanismo de activación de miedo-respuesta. Esta secuencia de trabajo sin una experiencia consciente de lo que comprende el estímulo es la forma rápida de una respuesta corporal. La segunda vía se denomina vía corticolímbica o explicita (mecanismo hipocampico) que conecta la estimulación exterior con el tálamo, la corteza prefrontal, la amígdala, el hipocampo y el hipotálamo compuesta por un gran número de sinapsis neuronal. Esta vía es más larga ya que conlleva un análisis de la información más 
elaborado, a nivel temporal es más lenta pero facilita una información mucha más completa del estímulo sensorial. Esta vía recoge la información visual y transcurre desde los centros de relevo a la corteza occipital y parietal (información viso-espacial), a zonas temporales (información verbal) y parietal (información somática), integrándose el recuerdo de la emoción percibida en el hipocampo (ver Figura 1.8).

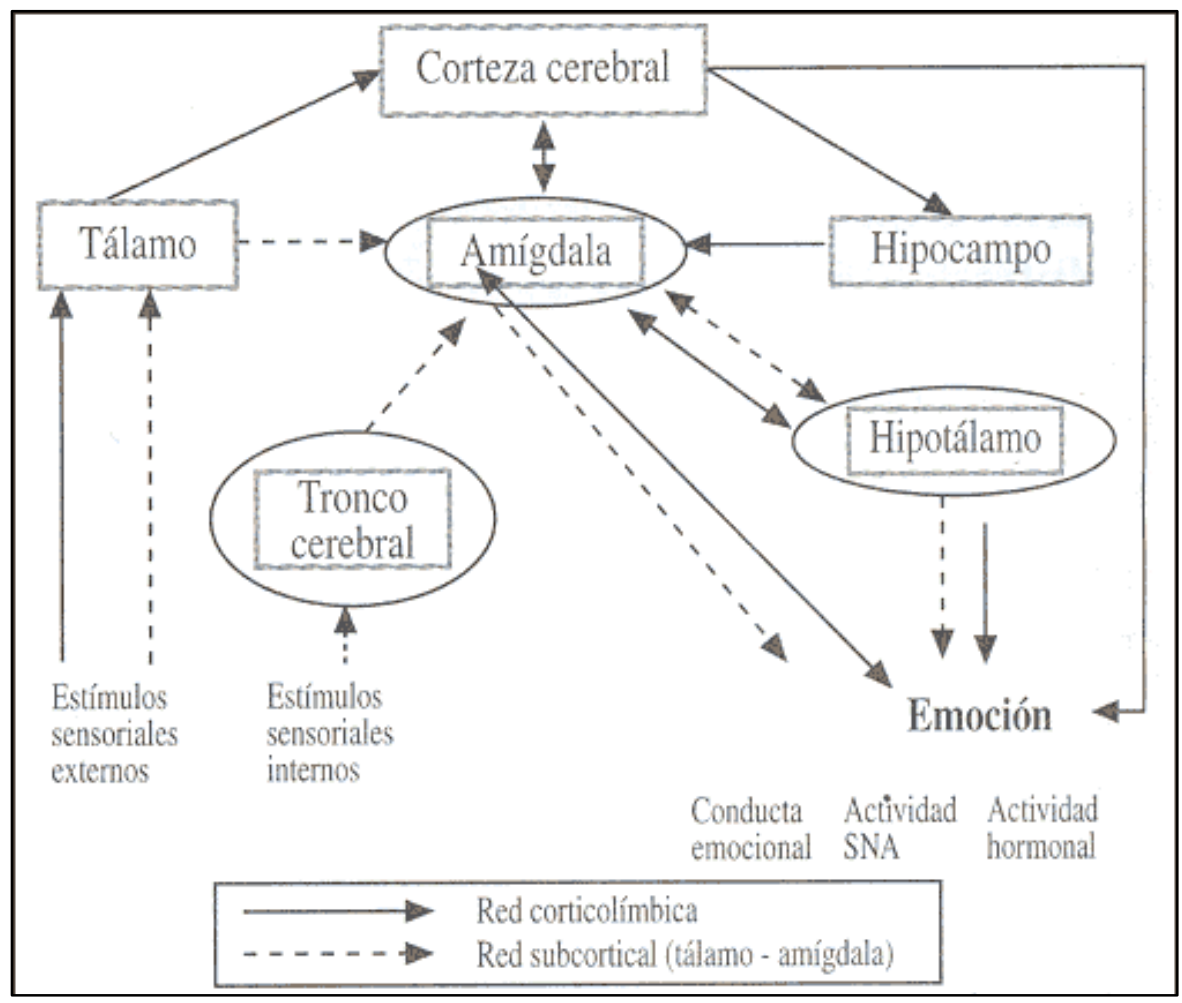

Figura 1.8: Representación vías neuronales de la emoción, según LeDoux (Ballesteros, 1998).

Basándose en este modelo de funcionamiento de dos vías, De Gelder (2006) postula que los estímulos (caras) de bajo nivel (de corte inconsciente) activan su recepción en el cuerpo amigdalino, mientras que los estímulos que se reciben de una forma más consciente ponen en funcionamiento la vía cortico-límbica y posteriormente activan al núcleo amigdalino. 
LeDoux afirma que para entender el funcionamiento emocional hay que explicarlo desde una postura integradora que incluso incluya en la explicación los circuitos neuronales que unen emoción, motivación y esfuerzo (2008,2012).

\subsubsection{Interacción cerebral: emoción y cognición}

A continuación, se recogen diversas investigaciones que resumen ${ }^{1}$ cómo ante la exposición de estímulos emocionales se produce la activación de regiones del sistema límbico que al mismo tiempo influyen en zonas específicas y localizadas del neocortex. Estas investigaciones demuestran la interacción anatómica a través de la activación sincrónica de diferentes regiones cerebrales para recoger, procesar, expresar y regular la información emocional (ver Tabla 1.5)

Tabla 1.5. Interacción actividad límbica y actividad en el neocortex.

\begin{tabular}{|c|c|c|c|}
\hline Factor Emocional & $\begin{array}{l}\text { Área de Activación } \\
\text { del Sistema } \\
\text { Límbico }\end{array}$ & $\begin{array}{l}\text { Área de Activación } \\
\text { en la corteza } \\
\text { cerebral }\end{array}$ & Investigación en: \\
\hline $\begin{array}{l}\text { Expresión } \\
\text { emocional }\end{array}$ & $\begin{array}{l}\text { Regiones } \\
\text { Temporales (incluye } \\
\text { la amígdala) }\end{array}$ & $\begin{array}{l}\text { Córtex occipital } \\
\text { Corteza prefrontal } \\
\text { inferior } \\
\text { Lóbulo parietal } \\
\text { derecho }\end{array}$ & $\begin{array}{l}\text { Kolb y Whishaw } \\
\text { (2006) }\end{array}$ \\
\hline $\begin{array}{l}\text { Respuesta a } \\
\text { expresiones } \\
\text { emocionales } \\
\text { negativas }\end{array}$ & Amígdala izquierda & Corteza prefrontal & $\begin{array}{l}\text { Carretié; López- } \\
\text { Martín, y Albert } \\
\text { (2010) }\end{array}$ \\
\hline $\begin{array}{l}\text { Respuesta a } \\
\text { expresiones }\end{array}$ & Amígdala & Córtex estriado & De Gelder (2006) \\
\hline
\end{tabular}

\footnotetext{
${ }^{1}$ Para esta revisión se ha seguido la obra Manual de Inteligencia Emocional (2007) cuyos coordinadores fueron José Miguel Mestre Navas y Pablo Fernández Berrocal (Editorial Pirámide).
} 


\begin{tabular}{|c|c|c|c|}
\hline $\begin{array}{l}\text { emocionales } \\
\text { negativas }\end{array}$ & & & \\
\hline Ira & Amígdala & $\begin{array}{l}\text { Corteza } \\
\text { Orbitofrontal }\end{array}$ & $\begin{array}{l}\text { Palmero y } \\
\text { Fernández Abascal } \\
(2002),\end{array}$ \\
\hline Asco & Ganglios Basales & Corteza Cingulada & $\begin{array}{l}\text { Rizzolatti y } \\
\text { Sinigaglia (2006) }\end{array}$ \\
\hline Miedo & Amígdala & $\begin{array}{l}\text { Corteza } \\
\text { Orbitofrontal }\end{array}$ & Davidson (2002) \\
\hline $\begin{array}{l}\text { Respuesta } \\
\text { emocional a } \\
\text { expresiones faciales }\end{array}$ & Amígdala & $\begin{array}{l}\text { Corteza } \\
\text { Orbitofrontal }\end{array}$ & \\
\hline $\begin{array}{l}\text { Comunicación } \\
\text { emocional } \\
\text { modulando los } \\
\text { componentes } \\
\text { emocionales de la } \\
\text { voz }\end{array}$ & $\begin{array}{l}\text { Hipocampo, } \\
\text { Amígdala }\end{array}$ & $\begin{array}{l}\text { Región medial de la } \\
\text { corteza frontal }\end{array}$ & McLean (1985) \\
\hline $\begin{array}{l}\text { Facilitación } \\
\text { emocional- } \\
\text { Tendencia de } \\
\text { aproximación a un } \\
\text { estímulo } \\
\text { (aprendizaje por } \\
\text { refuerzo positivo) }\end{array}$ & $\begin{array}{l}\text { Núcleo Accumbens } \\
\text { (Ganglios Basales ) }\end{array}$ & $\begin{array}{l}\text { Corteza prefrontal } \\
\text { izquierda }\end{array}$ & Davidson (2004) \\
\hline $\begin{array}{l}\text { Atención de } \\
\text { estímulos } \\
\text { emocionales }\end{array}$ & Amígdala & Neocortex & Phelps (2006) \\
\hline $\begin{array}{l}\text { Trastorno Obsesivo } \\
\text { Compulsivo- } \\
\text { Imposición de } \\
\text { rutinas fijas y } \\
\text { rígidas }\end{array}$ & Sistema Límbico & $\begin{array}{l}\text { Corteza } \\
\text { Orbitofrontal } \\
\text { Dorsolateral y } \\
\text { lateral }\end{array}$ & Golberg, 2001 \\
\hline Toma de decisiones & Sistema Límbico & Córtex Prefrontal & Damasio (1996) \\
\hline $\begin{array}{l}\text { Autoconciencia } \\
\text { emocional }\end{array}$ & $\begin{array}{l}\text { Cíngulo, Amígdala } \\
\text { Estructura } \\
\text { Paralímbica (ínsula) }\end{array}$ & $\begin{array}{l}\text { Córtex prefrontal } \\
\text { medial en conexión } \\
\text { con el córtex } \\
\text { cingular y el } \\
\text { Orbitofrontal }\end{array}$ & $\begin{array}{l}\text { Phillips, Drevets, } \\
\text { Rauch, y Lane } \\
\text { (2003) }\end{array}$ \\
\hline Toma de decisiones & Amígdala & $\begin{array}{l}\text { Córtex prefrontal } \\
\text { ventromedial, } \\
\text { regiones insulares }\end{array}$ & $\begin{array}{l}\text { Bechara, Damasio, } \\
\text { y Damasio (2003) }\end{array}$ \\
\hline
\end{tabular}


A estas investigaciones hay que añadir el extenso cuerpo de evidencias y hallazgos científicos que corroboran como lesiones cerebrales en la corteza cerebral afectan al funcionamiento emocional propio y en la sociedad. De igual modo, se ha podido comprobar que los niveles de asimetría funcional de la corteza prefrontal tiene una marcada influencia en el estilo afectivo humano (Silva, 2008).

Incluso, y sin caer en la facilidad de la moda y tendencia actual de mostrar, sin razón de uso, neuroimagenes del cerebro por doquier, se puede apreciar en la Figura 1.9, como a la hora de procesar un estímulo que desencadena una respuesta emocional se activa tanto zonas del sistema límbico como de la corteza cerebral. En este caso la neuroimagen mostrada pertenece a la investigación realizada por Schaefer, Larson, Davidson, y Coan (2014) dónde se puede apreciar que, ante la exposición de estímulos amenazantes a los sujetos experimentales que sufren de miedo fóbico, se les activan tanto zonas centrales del sistema límbico como del neocórtex (ver Figura 1.9).

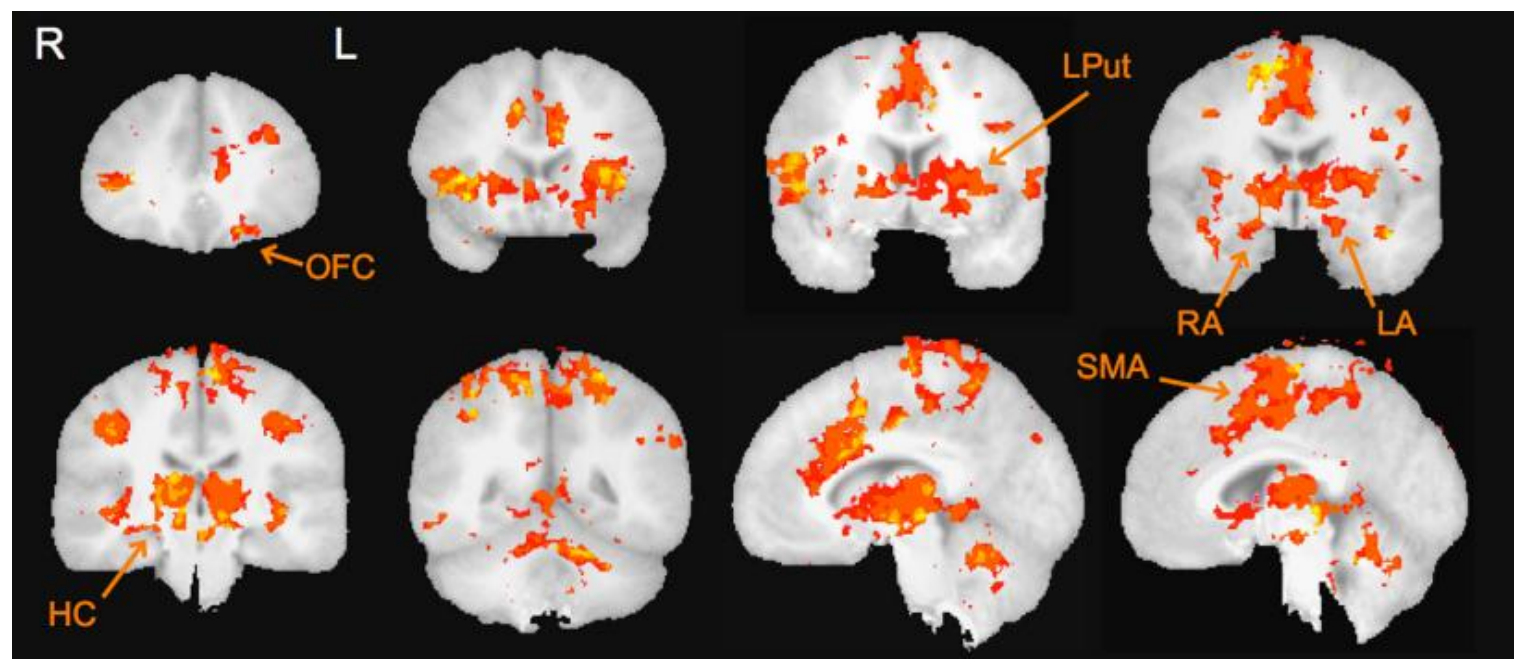

Figura 1.9: Activación combinada de estructuras del sistema límbico y de la corteza cerebral.HC: Hipocampo; OFC: Córtex Orbitofrontal, LPut: Putamen Izquierdo, RA: Amígdala Derecha, LA: Amígdala Izquierda, SMA: Área Suplementaria Motora (Schaefer, Larson, Davidson, y Coan, 2014) 
Con el objetivo de ofrecer la neuroanatomía del funcionamiento cerebral de la emoción, Silva (2008) realizó una revisión de los hallazgos y evidencias encontradas, concluyendo que las regiones cerebrales más importantes en la organización y procesamiento de la respuesta emocional humana son la amígdala, la corteza cingulada anterior, y la corteza prefrontal. El autor concluyó que es imposible hablar de una zona especializada en la gestión emocional. Incluso rechaza la denominación de un "cerebro emocional", ya que en realidad todo el cerebro se dedica en mayor o menor medida a la gestión de las emociones. Las evidencias halladas dibujan la idea que la respuesta emocional humana se distribuye y representa en múltiples regiones de la corteza y de las estructuras subcorticales.

Para finalizar, dentro de las teorías que intentan explicar la importancia de la integración e interacción entre emoción y cognición, se encuentra la popular teoría del Marcador Somático de Antonio Damasio (1996). Siguiendo a Guil en Mestre y Fernández Berrocal (2007) esta teoría, basada en los preceptos anteriores de James-Lange, recoge la distinción de lo que es emoción y lo que es sentimiento. Para Damasio, la emoción es una repuesta fisiológica, química y neuronal cuya función es contribuir al mantenimiento de la vida en un organismo, proporcionando conductas adaptativas que repercuten en mantener una situación de eficiencia homeostática. Por el contrario, el sentimiento es la interpretación que el cerebro hace del estado corporal y de sus señales fisiológicas. El marcador somático se ha generado de forma evolutiva en un largo aprendizaje evolutivo que permite al cerebro reconocer sensaciones que ya ha vivido anteriormente y que le facilita la toma de decisiones ante nuevos estímulos que se presentan. Nuestro organismo ha ido acumulando gran cantidad de asociaciones entre estimulo/situación y estado 
somático que son almacenadas en nuestra corteza prefrontal. Por tanto, cuando acontece una situación novedosa se compara con algún registro anterior para poder ofrecer una respuesta positiva o negativa en base al resultado obtenido en la experiencia ya vivida. $\mathrm{Si}$ en el pasado el resultado de la experiencia similar fue positivo, el marcador somático tenderá a promover a la acción en la nueva situación; si en cambio, si el resultado anterior fue negativo, se paralizará la acción.

Los marcadores somáticos influyen en el proceso de toma de decisiones permitiendo reducir las alternativas posibles de respuesta haciendo más eficiente el proceso de razonamiento. El funcionamiento de los marcadores somáticos se produce en dos etapas: en primer lugar se asocian las respuestas a las emociones primarias (comparte clasificación con Ekman), y posteriormente a través del aprendizaje en sociedad aparecen las emociones sociales que también son influenciadas por la valoración del sujeto. En la corteza prefrontal se realiza una función de regulación de la conducta en base a la información emocional recogida permitiéndonos un ajuste tanto intra como interpersonal. La crítica que algunos autores como Palmero le realizan es que este autor no acaba de explicar el funcionamiento de las emociones sociales y de la representación que la persona realiza de sus propios estados emocionales; no sólo se debe de tener en cuenta el objeto como el estímulo que provoca el sentimiento posterior, sino, por ejemplo, ¿qué bienestar proporciona el procesamiento de la información de lo que se está percibiendo? Se hace complicado sentir vergüenza o culpa sin una representación previa o valoración no sólo del objeto sino de las situaciones complejas que dan lugar a estas emociones. La teoría de Damasio ha sido llevada inclusive a la generación de simuladores y programación informática que han validado a nivel de simulación de software los mecanismos dinámicos del funcionamiento 
de la emoción, sentimiento y conciencia (Bosse, Jonker, y Treur, 2008). En el siguiente apartado se retomará este postulado teórico centrándonos en la importancia de la emoción en la toma de decisiones como un factor que demuestra como las emociones facilitan un proceso cognitivo superior como es el de la toma de decisiones.

\subsubsection{Relación de la emoción con la cognición.}

Tal y cómo se ha mencionado, una de las funciones que se le atribuyen recientemente a las emociones es su capacidad para desarrollar el procesamiento cognitivo (Fredrickson, 2001), y tal y cómo afirma Norman (2004) gracias a "las emociones somos más inteligentes”. En este sentido nos adentramos en el campo de la facilitación emocional.

El concepto de facilitación emocional que se va a utilizar en esta Tesis doctoral se enmarca como uno de los factores que componen el modelo de habilidad de inteligencia emocional de Mayer, Salovey y Caruso (1999, 2000, 2002). Se define como la habilidad para generar, usar, y sentir la emoción como competencia necesaria para comunicar sentimientos, o mejorar diversos procesos cognitivos. Es decir, gracias a las emociones y la información emocional que generan, se puede mejorar y desarrollar el procesamiento cognitivo. Por ejemplo, según Mayer y Salovey (2007) el tener un tipo de estado de ánimo adecuado o inadecuado afecta al pensamiento y a nuestro procesamiento de la información de cara a tomar la decisión más adecuada y resolver los problemas que nos acontecen.

Seguidamente, con el fin de concretar con mayor exactitud esta vía de interacción entre lo emocional y lo cognitivo, se dividirá la cognición en las diversas funciones ejecutivas que se consideran más importantes a la hora de regular la conducta humana y 
cuya ejecución se asocia a las zonas de cerebro de mayor desarrollo y complejidad, para posteriormente identificar como la emoción se relaciona con cada una de ellas.

\subsubsection{Funciones ejecutivas.}

Derivado de la aparición de las neurociencias y de las investigaciones que en las últimas décadas se han realizado sobre el funcionamiento del cerebro (y específicamente la corteza frontal), se ha abierto el campo de estudio de las funciones ejecutivas que regulan la conducta humana y que gobiernan operaciones específicas como la memorización, metacognición, aprendizaje y resolución de problemas (Tirapu, García, Luna, Roig, y Pelegrín, 2008).

Las funciones ejecutivas son un conjunto de habilidades implicadas en la generación, la supervisión, la regulación, la ejecución y el reajuste de conductas adecuadas para alcanzar objetivos complejos, especialmente aquellos que requieren un abordaje novedoso y creativo (Gilbert y Burgess, 2008). Para algunos autores las funciones ejecutivas abarcan la flexibilidad mental y las conductas mentales (Ardila, 2008). A su vez, Sholberg y Mateer (1998) consideran que las funciones ejecutivas incluyen una serie de procesos cognitivos, entre los que destacan la anticipación, elección de objetivos, planificación, selección de la conducta, autorregulación, autocontrol y uso de retroalimentación (feedback). Tal y como afirma Tirapu et al. (2008) es un constructo que está siendo muy complicado poder limitar su configuración, así como mostrar modelos conceptuales que agrupen y definan con homogeneidad cómo se articulan estas funciones ejecutivas siendo muy complejo conocer que habilidad fundamental las pueda explicar. 
Ardila y Ostrosky-Solís (2008) realizaron una división de las funciones ejecutivas en metacognitivas, o aquellas que recogen las neurociencias en general, y en segundo lugar, las que se dedican a la coordinación de la cognición y emoción/motivación (emocionales), es decir, las que se dedican a satisfacer las necesidades biológicas de acuerdo a las condiciones existentes. Estos autores realizaron una revisión del desarrollo histórico de las funciones ejecutivas concluyendo que la gran mayoría de investigaciones se han centrado en el análisis de las funciones metacognitivas dejando de la lado las funciones de coordinación entre cognición y emoción, apuntando además, que las estrategias de evaluación de las funciones ejecutivas presentan limitaciones importantes en su validez ecológica. En este mismo sentido, Verdejo-García y Bechara (2010) afirman que existe una relativa escasez de pruebas para medir los aspectos ejecutivos relacionados con la motivación y la emoción y la necesidad de mejorar tanto la validez interna, (en relación con el constructo), como la validez ecológica (en relación con el funcionamiento diario) de las pruebas actuales. Según estos investigadores, las aproximaciones que recogen los modelos teóricos que intentan explicar el funcionamiento ejecutivo se sintetizan en cuatro grupos: 1) Modelos de procesamiento múltiple basados en la noción de modulación jerárquica arriba-abajo (top-down); 2) Modelos de integración temporal orientada a la acción relacionados con el constructo de memoria de trabajo; 3) Modelos que asumen que las funciones ejecutivas contienen representaciones específicas relacionadas con secuencias de acción orientadas a objetivos; y 4) Modelos que abordan aspectos específicos del funcionamiento ejecutivo soslayados por los modelos previos.

Aunque es complejo y controvertido esclarecer cuales son los componentes principales de las funciones ejecutivas, los autores revisaron los diferentes estudios que 
combinaban las dos metodologías que a su criterio son las correctas para el estudio de las

funciones ejecutivas, a saber, análisis factorial y el estudio con neuroimagenes de lesiones cerebrales y su impacto en la conducta, para establecer los siguientes componentes de las funciones ejecutivas (ver Tabla 1.6).

Tabla 1.6: Interacción actividad límbica y actividad en el neocortex. Elaborado a partir de Verdejo-García y Bechara (2010)

\section{Componentes}

Actualización: Actualización y monitorización de contenidos en la memoria de trabajo
Inhibición. Cancelación de respuestas automatizadas, predominantes o guiadas por recompensas inminentes que son inapropiadas para las demandas actuales
Bases Neuronales

-Corteza prefrontal lateral/dorsolateral izquierda

-Corteza parietal
-Corteza cingulada anterior -Giro frontal inferior derecho -Área pre-suplementaria -Núcleo estriado

\section{Medidas neuropsicológicas}

- Escala de memoria de trabajo

(Escalas Wechsler). _N-back -Generación aleatoria -Fluidez verbal (FAS, Animales) $y$ de figuras (RFFT)

Razonamiento analógico (Semejanzas - Escalas Wechsler)...

- Test de Inteligencia (p.e., Matrices de Raven).

- Tareas de inhibición motora: Stroop, Stop-Signal, Go/No Go, CPT, Test de los Cinco Dígitos. -- Tareas de inhibición afectiva: Test de descuento asociado a la demora
- Polo frontal -Corteza prefrontal o medial inferior -Corteza orbitofrontal lateral -Núcleo estriado

- Polo frontal. - Corteza prefrontal dorsolateral derecha

- Corteza cingulada posterior.
Test de Clasificación de Tarjetas de Wisconsin.

-Test de categorías

-Test de Trazado

- Test de "reserval learning"

- Torres de Hanoi/ Londres

- Laberintos de Porteus.

- Seis Elementos (BADS).

- Mapa del Zoo (BADS).

- Test de Aplicación de Estrategias. 
Toma de decisiones: Habilidad para seleccionar la opción más ventajosa para el organismo entre un rango de alternativas disponibles
- Corteza prefrontal ventromedial. - Ínsula.

- Amígdala/ Núcleo estriado anterior.
- Iowa Gambling Task.

- Cambridge Gamble Task (CANTAB).

- Tarea de Recolección de Información (CANTAB). - Juego del dado.

- Tarea de Ganancias con Riesgo.

Las funciones ejecutivas permiten ejecutar la conducta deseable en pro de alcanzar un objetivo y para ello, desde una visión integradora, es necesaria la codificación de la información emocional. Las interacciones emoción-cognición ocurren en múltiples niveles de procesamiento, y a través de diferentes tipos de circunstancias emocionales y tareas cognitivas. En este punto es necesario revisar cómo la emoción tiene un impacto directo en las funciones ejecutivas y permite una ampliación de las habilidades cognitivas del ser humano. Para ello, se recogen algunas de las investigaciones que describen la interacción de las emociones en algunas de las funciones ejecutivas más importantes como atenciónpercepción, memoria, toma de decisiones, flexibilidad-creatividad, y regulación emocional.

\subsubsection{Impacto de las emociones en las funciones ejecutivas}

\section{Emoción y Memoria}

La memoria es el proceso por el que la información adquirida se convierte en conocimiento que se almacena para utilizarlo posteriormente cuando sea preciso. Se caracteriza por adquisición, almacenamiento y reposición de la información y las experiencias previas aprendidas, ingresadas por alguna vía sensorial y que es fundamental para que se produzca un aprendizaje efectivo (Solís, López-Hernández, 2009). También se puede denominar como memoria al almacenamiento de la información que estuvo acompañada por factores activadores o estresantes a través de los cuales pudo fijarse con 
mayor facilidad y en forma más duradera (Erk, von Kalckreuth y Walter, 2010; Schwabe, Nader y Pruessner, 2013). Aunque existen varias taxonomías para clasificar a los diferentes tipos de memoria, existe un consenso a la hora de aplicar la siguiente diferenciación:

\section{1) Memoria a Largo Plazo.}

Este tipo de memoria retiene información durante un tiempo variable: desde minutos hasta tiempos ilimitados (Solís y Hernández, 2009). La información que percibe, procesa y almacena es semántica cuando el material es verbal y por el contrario es visual cuando hay que procesar información de figuras o gráficos. Se compone de la memoria declarativa o explícita y memoria no declarativa, implícita o procedimental.

\section{2) Memoria a Corto Plazo.}

Dentro de este tipo de memoria se encuentra la memoria de trabajo en la que interviene la corteza prefrontal que, como se ha señalado anteriormente, es el centro de las funciones metacognitivas. Este tipo de memoria permite la integración de percepciones instantáneas que se producen en intervalos breves y combinarlas con recuerdos de acontecimientos pasados. Es imprescindible para la reflexión y la resolución de problemas o para realizar una actividad cotidiana.

Por otro lado, la introducción del estudio de las emociones y su relación con la memoria provocó la aparición del concepto de memoria emocional. Bajo esta denominación se entiende el resultado del almacenamiento de la información que ha estado acompañada por factores activadores o estresantes a través de los cuales pudo fijarse con 
mayor facilidad y en forma más duradera (Erk, von Kalckreuth y Walter, 2010; Schwabe, Nader y Pruessner, 2013).

La emoción y su relación con la memoria han sido estudiadas teniendo en cuenta tres indicadores: a) La cantidad de eventos recordados, b) La intensidad subjetiva o calidad del recuerdo sobre esos hechos, y c) la cantidad de detalles precisos que se recuerdan de tales eventos (Kensinger y Schacter, 2008).

Con respecto a la cantidad de eventos recordados se han encontrado resultados que apuntan que tendemos a recordar más los eventos con carga emocional, bien sea positiva o negativa, que los que no la tienen y son considerados neutros (Buchanan y Adolphs, 2002). Estos resultados se replican incluso utilizando una variedad de estímulos a recordar que incluyen palabras frases, imágenes y presentaciones de diapositivas narradas (Bradley y Lang 2000; Cahill y McGaugh, 1995; Kensinger y Schacter, 2008).

En relación a la calidad del recuerdo que provocan los contenidos emocionales positivos y negativos, los resultados que se encuentran en la literatura (véase Kensinger y Schacter, 2008) son contradictorios. Por ejemplo, Ochsner (2000) reporta una serie de experimentos en los que se demuestra que los participantes tienen mejor memoria para los estímulos negativos que para los positivos. Incluso encontró que las personas expresan mayores niveles de confianza para sus recuerdos de estímulos negativos que para los de estímulos positivos. Bless y Schwarz (1999) presentan resultados en los que las personas recuerdan más los estímulos positivos que los negativos, aunque los reportes para los primeros van acompañados de menor certidumbre que para los segundos. Este efecto de dirección dual es tan consistente, que incluso puede mantenerse en personas que por decisión propia se centran más en la información positiva que en la negativa. A través del 
estudio de la activación cerebral por neuroimagenes (Erk, Kiefer, Groethe, Wunderlich, Spitzer, y Walter, 2003) se ha apreciado que el recuerdo que estimula emociones positivas activa el hipocampo, estructura vinculada al aprendizaje, mientras que en casos de estimulación del recuerdo a través de emociones negativas se produce una activación de la amígdala que permitirá una posterior respuesta adaptativa de rápida ejecución. Como se aprecia en la imagen (ver Figura 1.9) los estímulos emocionales elicitan diferentes partes del cerebro, dónde es relevante apreciar como las emociones positivas activan el hipocampo que está muy vinculado a la memoria.

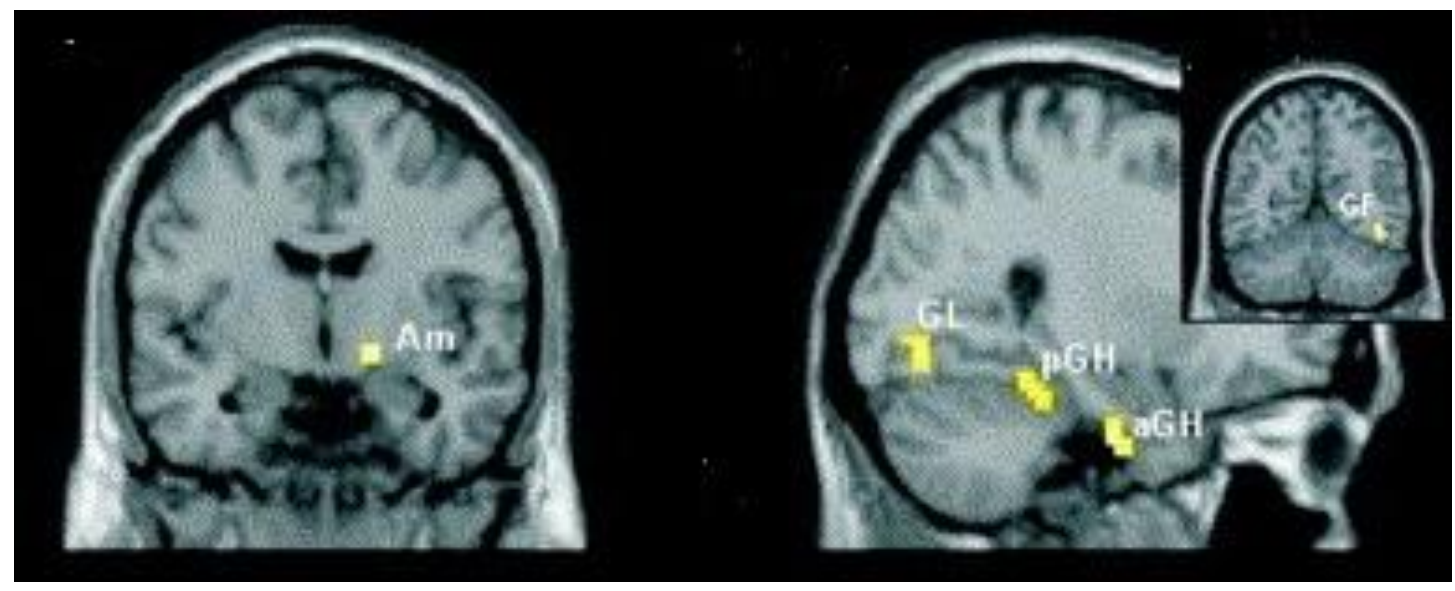

Figura 1.9: Activación cerebral de la memoria según tipo de estímulo (Erk et al., 2003). En la imagen de la izquierda activación de la amígdala (AM) al recordar un estímulo con valencia negativa. A la derecha, al procesar un recuerdo con valencia positiva se activa el hipocampo (pGH, aGH).

Al mismo tiempo que numerosas investigaciones apoyan la hipótesis que se recuerda más aquella información que es provocada por estímulos con carga emocional positiva o negativa que neutros, cabe comentar que este recuerdo también puede ser producto del estado emocional, estado de ánimo o afectivo, en el que se encuentra la persona en el momento en que tiene que procesar la información que recibe del ambiente. 
La inducción de estados de ánimo positivo y negativos puede conducir a provocar lo que se denominan falsas memorias también referidas como falsos recuerdos, que son reportes memorísticos que difieren parcial o totalmente de la realidad que fue experimentada (Mojardín-Heráldez, Elizalde-Monjardín, Rodelo-Morales, González-Oceguera, y Urquidez, 2010).

Los experimentos realizados sobre qué estado de ánimo, de valencia positiva o negativa, influye con mayor fuerza en el recuerdo y en las falsas memorias, ofrecen resultados contradictorios. Por un lado aparecen experimentos que evidencian que cuando las personas están bajo estados emocionales positivos (ej. alegres) tienden a reportar más falsas memorias que cuando están bajo estados emocionales negativos (ej. Tristes) (Storbeck y Clore, 2005). Según estos autores, es porque las personas en estados emocionales positivos dependen más de contenidos de significado (gist) y de la heurística para recuperar los eventos o material aprendido, en tanto que las personas con estado de ánimo negativo tienden más a centrarse en los detalles específicos(vebatim) de la información. En esta línea, y más recientemente, Mojardin Heráldez, Elizalde-Monjardín, Rodelo-Morales, González-Oceguera, y Urquidez, (2010) han replicado éstos resultados. Por el contrario, cuando se utiliza la técnica sobre memoria autobiográfica y se les solicita a los participantes que recuerden acontecimientos de su vida, los resultados varían. Schaefer y Philippot (2005) reportaron experimentos en los que pidieron a los participantes que memorizaran información previa clasificada con valencia positiva, negativa y neutra, para luego solicitarles realizar una prueba de recuerdo libre. Durante la prueba, los participantes respondieron el Cuestionario de Características de Memoria (Johnson Foley, Suengas, y Raye, 1998), en el que al reportar cada reactivo recordado tuvieron que enlistar la 
información de contexto, de relación semántica e información temporal de cada uno. Lo que encontraron fue que los participantes proveyeron mayor cantidad de asociaciones para los reactivos positivos que para los negativos. Es decir, la memoria para reactivos positivos ofreció mucho más detalles de conexión semántica que la memoria para reactivos negativos.

Por todo lo visto anteriormente se puede concluir que la memoria se encuentra directamente relacionada con la emoción. La carga emocional del estímulo independientemente que sea positiva o negativa influye directamente con más fuerza en el recuerdo que si este fuese percibido como neutro. De igual modo, el estado emocional (positivo o negativo) también condiciona el recuerdo. Finalmente, es de destacar que con referencia al recurso derivado de la estimulación con emociones positivas se ha evidenciado que se activan zonas cerebrales que tienen una funcionalidad específica en el aprendizaje como es el hipocampo. Si se toma al aprendizaje humano como un proceso de construcción y de desarrollo se traza un paralelismo fisiológico de corroboración con las investigaciones mostradas de Erk et al. (2003) y con la Teoría de la Ampliación y Construcción sobre el efecto de las emociones positivas que defiende Fredrickson.

\section{Emoción y Atención-Percepción}

La atención puede definirse como un mecanismo central de control del procesamiento de información, que actúa de acuerdo con los objetivos del organismo activando e inhibiendo procesos, y que puede orientarse hacia los sentidos, las estructuras de conocimiento en memoria y los sistemas de respuesta. Además, se admite la posibilidad 
de que este mecanismo muestre características estructurales diferentes cuando actúa sobre los sentidos, las estructuras de conocimiento en memoria o los sistemas de respuesta (Posner y Dehaene, 1994; Tudela, 1992).

La atención es una activación generalizada que permite la selección de determinadas entradas sensoriales de entre otras muchas que compiten entre sí. Dicha activación ocurre en regiones corticales del cerebro hacia el sistema de activación reticular del tronco encefálico (Rosenzweig y Leiman, 1992). Se pueden distinguir diferentes tipos de atención. La atención focalizada implica concentrarse en un determinado estímulo; la atención selectiva requiere la concentración en un estímulo o información mientras se inhiben las respuestas a otros estímulos distractores; la atención mantenida o sostenida consiste en la persistencia y el mantenimiento de la atención durante la ejecución de una tarea. Dentro de la atención selectiva incluso se aprecian dos tipos de atención que intentan establecer un camino a la hora de priorizar y modular el número de estímulos a los que se ve el cerebro expuesto. Por un lado se encuentra la atención endógena que también se llama de arriba abajo (up-down) que se produce de forma voluntaria, iniciado por los estados internos y las expectativas conscientes que provoca un objeto o situación específica (Posner, Snyder y Davidson, 1980). En sentido inverso nos encontramos con la atención exógena denominada de abajo-arriba (bottom-up) provocada por las respuestas reflejas, automáticas a los estímulos recibidos con insumos sensoriales de bajo nivel (Wolfe y Horowitz, 2004). Además, las propiedades físicas de bajo nivel como la intensidad del estímulo, color o tamaño pueden desencadenar un proceso involuntario que no es procesado por la corteza cerebral en un primer momento. 
Los estímulos son procesados por un mecanismo de análisis de relevancia con un umbral crítico para pasar a ser procesados. Si no se supera este umbral por el detector de relevancia se predetermina que no sucede nada y se produce una ceguera intencional de la información que se está percibiendo. Los factores por los que se atraviesa este umbral mínimo para poner este mecanismo de atención inconsciente dependen del propio estímulo (Comptom, 2003) así como de las características individuales de la persona como la ansiedad (Bishop, Duncan, Brett y Lawrence, 2004). Por ejemplo, en las personas diagnosticadas con trastorno de ansiedad se aprecia que se centran con mayor énfasis en los estímulos negativos, por lo que el estado emocional que sienten provoca que se centren en aspectos negativos del ambiente. De igual modo sucede con las personas que padecen de estrés postraumático, déficit de atención y fibromialgia dónde hay una atención permanente más a lo negativo que a otros estímulos. Por último, el nivel de concentración en la tarea que se esté llevando provoca que si éste es muy elevado sea más complicado estar atentos a cambios que se estén dando simultáneamente en el ambiente (Carretié, 2012).

Con respecto al estímulo, se han encontrado que varios estímulos emocionales como expresiones faciales de enojo, serpientes, bebes o palabras con carga emocional son procesados de forma preferente por los mecanismos cerebrales de la atención (Brosch, Sander, Pourtois, y Scherer, 2008; Öhman, Flykt, y Esteves, 2001). La explicación de esta priorización se basa en el trabajo en conjunto que la emoción y la atención realizan para establecer priorizaciones en nuestras percepciones del ambiente, lo que permite la supervivencia como especie al realizar un análisis sobre que objetos, y/o situaciones nos son beneficiosas o dañinas. Se ha sugerido que los circuitos neuronales dedicados a esta funcionalidad pueden estar al servicio de un tipo de atención, denominada atención 
emocional (Vuilleumier, 2005; Vuilleumier y Brosch, 2009) dónde el papel de la amígdala es fundamental.

Por otro lado, para Fenske y Raymond (2006) los procesos de atención selectiva y la emoción operan juntos en la priorización de los pensamientos y acciones. Hay abundantes pruebas que sugieren que los estímulos emocionalmente sobresalientes y los estados afectivos pueden determinar cómo la atención visual se centra en ellos (Compton, 2003). En este sentido las investigaciones analizadas concuerdan en determinar que los estímulos con carga emocional, sea positiva o negativa, son más rápidos en ser percibidos poniendo a funcionar la atención selectiva hacia ellos, que los estímulos que son neutros. La base del por qué sucede esto es la capacidad limitada que tiene el cerebro de procesar toda la estimulación ambiental. Las evidencias encontradas apuntan a la dirección que los estímulos negativos que inicialmente se reciben son percibidos y codificados de una forma más rápida.

En una de las investigaciones realizadas por Lundqvist y Öhman (2005) mostraron a los participantes estímulos de rostros neutros y amables. A las imágenes de rostros amables les añadieron una característica amenazante y pudieron comprobar como la atención selectiva de los participantes se centraba inicialmente en ésta última. De igual forma, utilizando parecida metodología de imágenes dividió a 20 participantes en tres grupos con tres condiciones distintas basadas en imágenes de gestos de las manos (imagen de gesto neutra, imagen de gesto de la mano amenazante, y gesto de la mano aprobatorio), para posteriormente medir su registro atencional cerebral con potenciales relacionados con el evento (ERPs). El resultado obtenido fue que los gestos con valencia negativa son más potentes en las medidas obtenidas de ERPs que los gestos de aprobación positivos. 
En el caso de la atención exógena, estudios neurofisiológicos revelan que la amígdala se activa cuando se muestra a los sujetos experimentales estímulos negativos. Siguiendo a LeDoux (2000), esto se debe a que es necesario una respuesta de supervivencia rápida, sin procesamiento elaborado de la información; por ello la información amenazante, negativa es recogida en primera instancia por la amígdala que seguidamente envía mensajes de alerta para proceder a emitir una respuesta básica de lucha o huida. Como describen Brosch, Pourtois, Sander, y Vuilleumier (2011), tanto la atención endógena y exógena, implican principalmente las redes de los lóbulos parietales, de la corteza cerebral por lo que de nuevo se aprecia el funcionamiento en red del cerebro entre emoción y cognición.

En vista de lo anteriormente descrito se podría afirmar que la emoción influye en la atención y en la percepción de los inputs que nos rodean ya que por un lado, la valencia emocional del estímulo, y por otro, el estado emotivo interno en el que nos encontremos, hacen que la atención y la percepción, se focalicen en un tipo de estímulos dejando de lado al resto.

\section{Emoción y toma de decisiones}

La toma de decisiones ha sido comprendida tradicionalmente como un proceso cognitivo mediante el cual se evalúan las diversas alternativas de acción y se estiman las consecuencias más positivas (Medin, Ross y Markman, 2005). Tomar decisiones requiere de la participación de las funciones ejecutivas por ser éstas las encargadas de iniciar, supervisar, controlar y evaluar la conducta (Salvador, Mestas, Gordillo, Arana, Meilán, Pérez y Carro, 2010). Históricamente, el estudio de la toma de decisiones se ha analizado 
desde un punto de vista únicamente racional, quedando relegado, hasta hace bien poco, el papel de la emoción en este proceso. Hoy en día se observa en diferentes investigaciones que la toma de decisiones no es un terreno exclusivo de la racionalidad, sino que nuestros estados emocionales, las experiencias parecidas vividas directamente u observadas de los demás, influyen con mucha fuerza en el tipo de decisiones que tomamos. Tal y cómo afirman Martínez-Selva, Sánchez-Navarro, Bechara y Román (2006):

"Las emociones guían la toma de decisiones, simplificando y acelerando el proceso, reduciendo la complejidad de la decisión y atenuando el posible conflicto entre opciones similares". (Martínez-Selva, et al., p.411)

A continuación, se agruparán las diferentes investigaciones que analizan la relación de la emoción y toma de decisiones.

El primer grupo se centra en el estudio del impacto de las emociones, según su valencia (positiva, negativa, neutra) en la toma de decisiones (Bradburn, 1969; Frijda, 1993). Las emociones positivas aumentarían el acceso de la información congruente con el estado anímico, lo que le permite a la persona utilizar de forma más efectiva el conocimiento tácito, que reconozca más fácilmente dilemas sociales y morales y que los interprete adecuadamente (Haviland-Jones y Kahlbaugh, 2000). Los trabajos pioneros de Estrada, Isen y Young (1994) demostraron que a médicos que se les indujeron emociones positivas eran capaces de estructurar la información sobre los casos clínicos de forma más eficiente, e incluso iban más allá de los diagnósticos anteriores y generaron mayor creatividad en su pensamiento. Un aspecto a tener en cuenta es el estado afectivo de los sujetos antes de la toma de decisiones y las emociones positivas o negativas que perciben. Bajo la influencia de emociones positivas los sujetos en laboratorio no usan la información 
para modificar su estado de ánimo positivo, por lo que los sujetos con emociones positivas sobrevaloran resultados positivos (Kahn e Isen, 1993), subestiman los negativos (Nygren, Isen, Taylor y Dulin 1996; Wright y Bower, 1992) y utilizan un pensamiento más estereotipado que aquellos con ánimo neutral (Luce, Bettman y Payne, 1997).

Los resultados en el caso de las emociones negativas nos son homogéneos. Se observa la tendencia a realizar evaluaciones de las situaciones más realistas, menos influenciado por el contexto, así como uso de estereotipos. Las personas bajo la influencia de las emociones negativas tienden a aumentar su capacidad de razonamiento deductivo, analítico, concreto y focalizado, lo que complica que puedan tener en cuenta otras variables; por el contrario el uso de la memoria es más efectivo (Schwarz, 2000). El segundo grupo de investigaciones se agrupan en torno a la idea de que las emociones de similar valencia no afectan de igual manera en la toma de decisiones. La idea central se basa en la Teoría de Apreciación Cognitiva que toma el afecto como información. (Fridja, 1986; Keltner, Ellsworth y Edwards, 1993; Lerner, Golberg y Tetlock, 1998; Weiner, Graham y Chandler, 1982). Según esta teoría, cada emoción se compone de una estructura propia que determina dimensiones cognitivas únicas y diferenciadoras. En esta línea Lerner y Keltner (2000) (véase Bedregal, 2010), demostraron que dos emociones negativas como miedo y rabia afectaban a la asunción de riesgos de forma diferente.

El tercer grupo de investigaciones se basan en el peso de la emoción sobre la toma de decisiones. De forma que el efecto de las emociones sobre las decisiones que tomamos es distinto dependiendo del nivel de importancia o relevancia a que le adjudiquemos a la decisión a tomar. Cuanto más nos afecte a nivel personal la decisión, más influencia de los aspectos emocionales Pham, (1998). Greene y Haidt (2002), basados en los trabajos 
recientes sobre psicología moral de Haidt (2001), propusieron que algunos juicios morales, los que se denominarían personales, estaban altamente influidos por respuestas socioemocionales, mientras que aquellos juicios morales impersonales estaban menos influidos por estos aspectos y más por procesos puramente "racionales". Greene, Sommerville, Nystrom, Darley y Cohen (2001) encontraron que las regiones cerebrales asociadas con las emociones y la cognición social presentan más actividad en la resolución de dilemas personales, en comparación con la resolución de dilemas impersonales que se caracterizan por una mayor actividad en áreas asociadas con la memoria de trabajo y otros procesos cognitivos. Greene et al. (2001) también encontraron que frente a dilemas personales difíciles se activan más aquellas áreas relacionadas con procesamiento de conflictos que frente a dilemas personales fáciles.

Para completar las investigaciones que relacionan emoción y toma de decisiones, se retoma la teoría de Damasio y su hipótesis sobre el rol de la emoción en las situaciones que planteen una toma de decisiones, así como una aproximación reciente sobre la toma de decisiones en el ámbito social del grupo investigadores de la Universidad de Ámsterdam (Emotions as Social Information-EASI).

\section{Teoría neurofisiológica de Damasio: Hipótesis de los marcadores somáticos}

Esta teoría ya comentada anteriormente se desarrolló al amparo de la investigación neurofisiológica con personas que tenían lesiones regiones de la corteza cerebral (córtex orbifrontal) así como de la amígdala. El resultado observado es que mostraban graves dificultades para tomar decisiones adecuadas. Damasio (1996) propuso la Hipótesis del Marcador Somático para explicar cómo se produce la toma decisiones destacando el papel 
transcendental de la emoción en este proceso ejecutivo. La argumentación central de la hipótesis es que los procesos de toma de decisiones dependen de manera fundamental de los mecanismos neurales que regulan la homeostasis, las emociones y los sentimientos. Este autor observó la incapacidad que tenían las personas con lesiones en el córtex orbifrontal y drogadictos para una correcta toma decisiones. Para ello aplicaba la tarea de apuestas de IOWA (IOWA-Gambling Task) y posteriormente medía la actividad corporal a través de la respuesta conductancia cutánea. Para Damasio, esta incapacidad a la hora decidir era debido a que no eran capaces de poner en marcha un mecanismo emocional derivado de los sentimientos que denominó marcador somático. Este marcador somático es una señal que se genera a partir de procesos de autorregulación y homeóstasis provocando modificaciones fisiológicas en el propio cuerpo y en las regiones cerebrales que están implicadas en la representación de estados emocionales (Márquez, Salguero, Paíno y Alameda, 2013).

Los marcadores somáticos pueden generarse a partir de dos tipos de eventos: inductores primarios e inductores secundarios. Los inductores primarios son estímulos que de modo innato o a través del aprendizaje han sido asociados con estados placenteros o aversivos. Cuando uno de estos estímulos está presente en el entorno inmediato se genera de manera necesaria y automática una respuesta emocional. Por otro lado, los inductores secundarios son entidades generadas a partir del recuerdo personal o hipotético de un evento emocional, es decir, recordar o imaginar la situación que produce placer o aversión (Bechara, Damasio y Damasio, 2003).

Durante la evaluación de que decisión tomar, los marcadores somáticos pueden ser elicitados por inductores primarios o secundarios. Una vez generados, los marcadores 
somáticos intervienen en dos procesos: primero, la inducción de un sentimiento, positivo o negativo, y segundo, la guía del proceso de decisión hacia una de las opciones posible. Cuando nos enfrentamos ante una situación en la cual debemos de seleccionar entre varias opciones, se produce una anticipación de los resultados probables basada en el recuerdo somático (marcador somático) de las consecuencias de haber tomado una alternativa igual o parecida acontecida en situaciones anteriores. El marcador somático es la respuesta emocional ante el proceso de toma de decisiones. Esta respuesta incluso se ha podido producir de forma inconsciente guiándonos a una respuesta conductual sin ser conscientes del proceso. Se produce por tanto un aprendizaje emocional en la toma de decisiones ya que la capacidad de percibir y utilizar la información de las emociones que sentimos nos facultará a un mecanismo más adecuado de elección de la mejor alternativa. Por tanto, los marcadores somáticos apoyan los procesos cognitivos, permiten una conducta social apropiada, contribuyen a la toma de decisiones ventajosas -mediante la inhibición de la tendencia a buscar el refuerzo inmediato- y facilitan la representación de escenarios futuros en la memoria de trabajo. El marcador somático facilita y agiliza la toma de decisiones, especialmente en la conducta social, donde pueden darse situaciones de mayor incertidumbre.

La hipótesis del marcador somático ha recibido críticas que se centran en la utilización del IOWA-Task Gambling como instrumento eficaz para dar validez a la teoría. Más concretamente, se describen dificultades en sus instrucciones y clasificación de los estímulos, en la previsibilidad de la prueba, así como en lo confuso de la interpretación de los datos (León, Martínez, Cruz y Hernández, 2011). Así mismo, se han revisado la causa posible de los resultados diferenciales encontrados entre pacientes con lesión cerebral en la 
corteza ventromedial y población normal. Según una hipótesis alternativa (cognitiva/moral) a los resultados obtenidos las personas con lesión que realizan la prueba tienen que decidir mazos de cartas con conceptos como "bueno", "malo", "debido" o "indebido" y lo que sucede es que los pacientes no saben lo que es prudencial o moralmente bueno o malo. Sus juicios no tienen el carácter prescriptivo o motivante que debieran tener. Una cognición moral debe incluir esos aspectos para ser propiamente cognición moral. Por ello, para varios autores, los pacientes posiblemente respondan al azar (Rosas, Caviedes, Arcienagas y Arcienagas, 2013).

Sin duda el debate está servido, lo que nadie pone en duda es el peso de la emoción en la toma de decisiones aunque, como resaltan numerosos autores, hay que seguir avanzando en investigar cómo se produce el funcionamiento de interacción entre ambas.

\section{Emotions as Social Information-EASI: Toma de decisiones sociales}

Por último, se recoge una posición teórica que aporta una visión diferenciadora, complementaría y necesaria, del resto anteriormente comentadas, ya que no se centra en la importancia de la valencia de la emoción, ni del funcionamiento neurofisiológico entre emoción y toma decisiones, sino que subraya el efecto de las emociones discretas en el comportamiento de la persona en su toma de decisiones sociales. Esta aproximación enfocada en el estudio del efecto interpersonal de las emociones está basada en el modelo de la emoción como información social (Emotions as Social Information-EASI, Van Kleef, 2008, 2009). Esta teoría postula que para entender cómo influyen las emociones discretas (o secundarias) en las toma de decisiones sociales es necesario analizar cómo se produce la interacción entre las personas. Es decir, los autores se concentran en la 
necesidad de estudiar los efectos de la emoción en una persona y como afecta al comportamiento de la otra en la interacción que se dé entre ambos a la hora de tomar una decisión social. Las dos grandes ideas teóricas sobre la toma de decisiones sociales son, en primer lugar, que las personas en situaciones ambiguas utilizan las emociones de los demás para dar construcción a la realidad a la que se enfrentan, y en segundo lugar, los efectos de la influencia de las emociones de los demás dependen si la situación tiene un trasfondo cooperativo o competitivo. Dentro de este enunciado teórico se destaca la trascendental importancia del contexto para definir el tipo de efecto que puede tener una emoción. Las mismas emociones pueden tener efectos completamente diferentes dependiendo de si son expresadas en un entorno predominantemente cooperativo o competitivo. Investigaciones recientes muestran que en ambientes cooperativos predominan mayores niveles de confianza y benevolencia y una mayor motivación a trabajar juntos; por el contrario ambientes competitivos normalmente generan desconfianza, las motivaciones más egoístas, y comportamiento estratégico (De Dreu, Beersma, Steinel y Van Kleef, 2007). A esta teoría, y a su modelo, nos volveremos a referir en la sección que se describa el contagio como un mecanismo fundamental en el efecto social de las emociones.

En base al avance científico en el estudio de la emoción y de la toma de decisiones, se observa como ambos procesos interaccionan entre sí. Por lo cual, se rompe el mito que la función ejecutiva de la toma de decisiones es terreno exclusivo de la racionalidad. Tal y como se ha explicado, las emociones influyen directamente en nuestra toma de decisiones Aunque en la actualidad no hay consenso entre las distintas posturas de los mecanismos de influencia entre ambas, sí que se puede afirmar que existe una clara influencia ente ambos 
procesos e inclusive existe base neurológica compartida cuando tenemos que elegir entre diferentes elecciones para decidir qué decisión tomamos.

\section{Emoción, flexibilidad cognitiva y creatividad.}

La flexibilidad cognitiva es definida como la capacidad de un sujeto para alternar rápidamente de una respuesta a otra, respondiendo a las demandas cambiantes de una tarea o situación (Mateo y Villaplana, 2007). Implica un análisis de las consecuencias de la propia conducta y un aprendizaje de los errores, y requiere de la capacidad para inhibir un patrón de respuestas y poder cambiar de estrategia (Rosselli, Jurado y Matute, 2008).

Un análisis de la relación entre emoción y flexibilidad cognitiva lo podemos encontrar en el estudio realizado por la investigadora estadunidense Sacharin (2009). Esta autora divide la flexibilidad en tres categorías: asociativa, regulativa y atencional. La flexibilidad asociativa consiste en la capacidad de romper con las asociaciones y respuestas típicas para generar nuevas asociaciones. La regulativa se refiere a la capacidad de afrontar los cambios de reglas, de identificar y adaptarse a nuevas contingencias; y por último, la flexibilidad atencional es la capacidad de cambiar la atención ante los diferentes tipos de tareas o entre las diferentes características de los estímulos. Su estudio concluyó que existe una gran evidencia de investigaciones que detallan como las emociones y los estados emocionales positivos influyen directamente en la flexibilidad cognitiva, pero añade a través del metaanálisis que realiza, que también existen resultados que muestran como las emociones y estados negativos impulsan, pero de forma distinta, la flexibilidad. Además, intenta verificar 
cómo influyen las emociones positivas (ej. felicidad y alivio) en los diferentes tipos de flexibilidad, encontrando resultados significativos para la flexibilidad asociativa relacionada con la felicidad, pero no tan robustos ni tan fuertes para los otros dos tipos de flexibilidad, ni con la emoción de felicidad, ni con el alivio; argumentando que la relación entre los diferentes tipos de flexibilidad y estados emocionales positivos en laboratorio está bajo la influencia de variables moduladoras que afectan los posibles resultados como, el nivel de inteligencia de los sujetos experimentales, o las metas de desempeño exigidas en las tareas. Para esta autora, los estudios próximos que se deben de hacer en busca de la conexión entre emoción y flexibilidad deben tener en cuenta los distintos tipos de flexibilidad que, a su criterio, existen.

La flexibilidad cognitiva es importante para la creatividad, para reforzar el aprendizaje y para redirigir nuestra atención (Sacharin, 2009). En esta línea las investigaciones realizadas en las últimas décadas reflejan dos grandes tendencias de estudio de la creatividad y la emoción dependiendo de su valencia.

En relación a las emociones positivas y creatividad, la idea central de este grupo de investigaciones es que el estado positivo facilita la resolución creativa de problemas a través de un amplio espectro de tareas. Referente dentro de este campo de conocimiento es el grupo de investigación de Alice Isen. En uno de sus experimentos dividieron a los estudiantes en dos grupos clasificados según el estado a los que se les había inducido, emoción positiva o negativa. Una vez inducidos cada grupo a la emoción asignada con recreación de pensamientos, música, etc., debían de realizar tareas que ponían en juego su pensamiento creativo a través de la resolución de problemas y toma de decisiones. El grupo 
bajo el estado de emoción positiva obtuvo mejores resultados en las actividades demandadas (Estrada, Young e Isen, 1994; Isen, 1999; Isen, Daubman y Nowicki,

Las emociones positivas también promueven la utilización de categorías más inclusivas para ello ejercen un doble efecto sobre los procesos de categorización, por una parte, favorecen la ampliación del conjunto categorial y flexibilizan las asociaciones que se establecen (Isen y Daubman, 1984; Isen, Niedenthal y Cantor, 1992). Siguiendo a Aranguren (2013), el estado emocional positivo tiende a estar asociado a una mayor cantidad de interconexiones en la memoria y por ende, a mayor cantidad y calidad de información (Ashby, Isen, y Turken 1999;). Así mismo lo que sucede cuando las persona están con un estado de ánimo positivo es que se sienten con una mayor predisposición al realizar una tarea, lo que influye el subsiguiente procesamiento de información (Martin, Abend, Sedikides y Green, 1997; Newton, 2013). Por otro lado Lybomirsky, King y Diener (2005) relacionaron la afectividad positiva con el optimismo, la autoconfianza, la autoeficacia con el mejor funcionamiento de la flexibilidad y la creatividad, entre otras variables.

A nivel escolar también se ha podido demostrar que la introducción en el aula de estados afectivos positivos incide en un mejor desempeño escolar así como en el incremento de las habilidades emocionales (ej. percepción y comprensión emocional), la comprensión de problemas sociales, la capacidad de generar alternativas a los problemas e incrementa la flexibilidad cognitiva (Oros, Manucci, De Minzi, 2011; véase en Aranguren, 2013). De la misma manera, a nivel empresarial también se observó que las emociones positivas mejoraron el 
pensamiento flexible (Isen, 1987) y la productividad laboral (Vacharkulksemsuk, Sekerka y Fredrickson, 2011).

En cuanto a las emociones negativas y creatividad, se ha visto que pueden favorecer determinadas tareas creativas al promover un pensamiento más crítico, analítico y un procesamiento de la información más detallado (Ambady y Gray, 2002; De Dreu et al., 2007; Kaufman y Vosburg, 1997). Se ha intentado relacionar las emociones negativas con la producción de ideas al inicio y en el transcurso de la tarea, pero los resultados no son del todo concluyentes, ya que por un lado se encontraron investigaciones que describen que las emociones positivas tienen un fuerte efecto al inicio de la actividad, y por el contrario en otras investigaciones, en las negativas el efecto es más duradero en el transcurso de la realización de la tarea (Vosburg, 1998).

Con respecto al análisis del efecto de una emoción negativa como el enojo, se han hallado evidencias que cuando se percibe esta emoción, a pesar que genere mayores respuestas creativas que otras emociones como la tristeza o estados neutros (Bass, De Dreu, Nijstad, 2011), lo que provoca es un bloqueo del pensamiento completo y la resolución creativa de los participantes disminuía, y provocaba además estados de ansiedad y temor. Únicamente se apreciaba que el enojo sí se asociaba indirectamente con el sarcasmo producía respuestas creativas (Miron-Spektor, Efrat-Treister, Rafaeli y Schwarz-Cohen, 2011).

Independientemente del tipo de emoción que sintamos, sea positiva o negativa, existe una fuerte relación con la flexibilidad cognitiva y la capacidad de generar alternativas creativas cuando nos enfrentamos a un problema. La tendencia en los estudios realizados hasta la fecha ha sido la de centrarse en el impacto de las emociones positivas 
como constructoras de nuevas asociaciones de información que permiten movilizar al sujeto para procesar la información de forma flexible, abierta, ampliando nuestro campo de acción cognitivo. Las emociones positivas mejoran nuestra cognición permitiéndonos explorar nuevos caminos y posibilidades incrementando nuestra flexibilidad cognitiva. Un aspecto importante, tal y cómo señalaba Shacharin (2009), es que es necesario discriminar los diferentes tipos de flexibilidad y, de igual modo, los efectos que se encuentran en las emociones negativas sobre la creatividad revelan la idea que no hay que ver los dos tipos de emociones como enfrentadas como se suelen ofrecer. Estos resultados hallados plantean la idea de que ambos tipos de emociones se encuentran en un mismo continuo.

En conclusión, los resultados empíricos apuntan a la evidencia de una fuerte relación entre nuestras emociones y nuestra capacidad de flexibilidad y desarrollo del pensamiento creativo. 


\section{Capítulo II. Inteligencia Emocional y Liderazgo}

"Tu influencia no se mide por la cantidad de colaboradores que tengas, sino por la cantidad de personas que tu liderazgo inspire”

Neema Namadamu

"Si tus acciones inspiran a otros a soñar más, aprender más, hacer más y ser mejores, eres un lider" Jack Welch.

"Si crees que estás liderando y te volteas y no hay nadie siguiéndote, entonces sólo saliste a caminar" Benjamin Hooks, 


\subsection{Introducción}

Mucho se ha escrito, se ha hablado y se ha discutido sobre la inteligencia emocional hasta considerarla como un constructo psicológico independiente con validez teórica y predictiva. El lanzamiento del omnipresente y mundialmente conocido libro de Daniel Goleman "Inteligencia Emocional “(1995) supuso un antes y un después en la popularización de un término que, hasta ese momento, no era conocido por el público en general, y que inclusive, había pasado de soslayo para la ciencia ortodoxa. Este capítulo tiene como objetivo ofrecer una resumida descripción de la evolución del constructo de la inteligencia emocional y de los modelos que la han conceptualizado con sus distintos instrumentos de medición existentes. Además, se realizará una revisión de los hallazgos empíricos que describen el efecto de la inteligencia emocional en el contexto laboral. Por último, se recogerán las aportaciones más importantes a la conceptualización del liderazgo así como la relación existente con la inteligencia emocional.

\subsection{Antecedentes a la Inteligencia Emocional}

A principios del S. XX, cuando todavía se realizaba una separación entre emoción y cognición, los renombrados psicólogos Binet y Simon (1905) argumentaron que existían dos tipos de inteligencia: la ideativa, asociada al clasicismo de las teorías psicométricas, y otra instintiva, que operaba por medio de los sentimientos más relacionada con la intuición que con la aptitud mental, y que se manifestaba a través de las emociones (Mestre y Berrocal, 2007). Posteriormente, Thorndike (1920) propone el concepto de inteligencia social como "la habilidad para comprender y dirigir a los hombres y mujeres, muchachos y muchachas, y actuar sabiamente en las relaciones humanas” (Thorndike, 1920, p.128). 
Esta definición considera que el ser humano tiene una potencialidad para percibir el propio estado interno, el de los demás, de comprender sus motivaciones, y actuar de forma consecuente (Grewal y Salovey, 2006). Incluso Wechsler (1958) precursor de varios test de inteligencia, observaba que existían aspectos no intelectuales de una persona que contribuían a la inteligencia global.

Estas ideas iniciales quedaron relegadas por la aparición del conductismo que rechazaba dedicar esfuerzos investigativos en aquellos procesos que no fueran directamente observables. Dentro del dominio de este paradigma se abrió paso las iniciativas de Piaget y su modelo de desarrollo intelectual (1974) y sus colaboradores que lo ampliaron postulando una interacción entre intelecto y emoción (Mestre y Guil, 2012).

En la década de los ochenta, se extendió con fuerza el cognitivismo y su modelo de procesamiento de la información. Este modelo utilizaba como metáfora de explicación y comprensión de la mente humana la comparación con el funcionamiento de un ordenador. Inicialmente, esto provocó que se separase el estudio de la emoción y cognición hasta que, dentro de esta misma corriente psicológica, distintas investigaciones se interesasen en estudiar la interacción entre ambas.

Dos autores destacan como claros precursores de la inteligencia emocional, Robert Sternberg y Howard Gardner. Sternberg, alejado de las teorías clásicas psicométricas de la inteligencia, desarrolla su teoría triárquica de la inteligencia (Sternberg, 1985). Este autor sostiene que para entender la inteligencia es necesario explicar su relación con tres aspectos: el mundo exterior del individuo, el mundo interior del individuo y la experiencia que sirve de mediador entre el mundo exterior e interior del individuo. Para ello, detalla que existen tres tipos de inteligencia, a saber: analítica, práctica, y creativa. 
En ese contexto de contravenir lo establecido, emerge Howard Gardner con la publicación de su libro Frames of Mind. The Theory of Multiple Intelligences (1993). En esta obra se plantea una ruptura con la visión tradicional de la existencia de una única inteligencia evaluada con pruebas estandarizadas y que se centraba en aspectos que no eran predictivos de éxito profesional.

“En mi opinión, si hemos de abarcar adecuadamente el ámbito de la cognición humana, es menester incluir un repertorio de aptitudes más universal y más amplio del que solemos considerar. A su vez, es necesario permanecer abiertos a la posibilidad de que muchas de estas aptitudes — si no la mayoría - no se presten a la medición por métodos verbales que dependan en gran medida de una combinación de capacidades lógicas y lingüísticas" (Gardner, 1993, p.4).

Gardner revolucionó el contexto científico de la época con su Teoría de las Inteligencias Múltiples en la que en una primera versión clasifica siete tipos distintos de inteligencia para posteriormente añadir una octava (Gardner, 1983, 1995). Los tipos de inteligencia que inicialmente contempla son: la inteligencia lingüística y lógicomatemática; la inteligencia musical; la inteligencia espacial; la inteligencia cinestésicocorporal; y dos formas de inteligencia personal, una que se dirige hacia los demás (interpersonal) y otra que apunta hacia la propia persona (intrapersonal). Posteriormente, incorporará una octava inteligencia que denomina inteligencia naturalista (Gardner, 1995).

La inteligencia intrapersonal consiste en acceder a los propios sentimientos, al propio abanico de afectos o emociones; la capacidad de efectuar discriminaciones, clasificarlos y estructurarlos para poder guiar nuestra conducta. Por otro lado, entiende la 
inteligencia interpersonal como una capacidad de sentir y de apreciar los cambios y distinciones de los estados de ánimo, motivaciones, intenciones, y temperamentos de las personas con las que interactuamos (Gardner, 1995). A través de este conjunto multidimensional de inteligencias teoriza que el ser humano pueda dar mejor respuesta al contexto dónde se encuentre ya que la inteligencia es la capacidad de resolver problemas, o de crear productos que sean valiosos en uno, o más ambientes culturales (Gardner, 1995).

Su influencia como precursor de la inteligencia emocional se observa claramente al establecer dos tipos de inteligencia: la inteligencia intrapersonal y la inteligencia interpersonal, que esbozan niveles de funcionamiento que recogerá posteriormente la conceptualización formal de inteligencia emocional. Incluso, se plantea la cuestión de que la inteligencia emocional esté incluida en ellas y se una a una nueva forma de etiquetar inteligencias ya definidas. La respuesta de Salovey (2006) ante esta espinosa cuestión es que el constructo de inteligencia emocional, al menos dentro de su concepción, está más acotado al procesamiento de las emociones y en el conocimiento sobre la información relacionada con las emociones.

Con respecto a la aparición del término de inteligencia emocional hay que remontarse al año 1966 dónde surge por primera a través de Bárbara Leuner, aunque no explica muy bien a que se refiere. Veinte años después volvió a presentarse el término en una diserción no publicada de Wayne Leon Paine (1986). Por último, y ya dentro de la llamada era de las emociones, aparece el concepto en un artículo científico de Mayer y Salovey (1990) en el cual se identifica a la inteligencia emocional como un tipo de inteligencia esencial para el funcionamiento socio-cognitivo del ser humano. 


\subsection{Evolución del Constructo de Inteligencia Emocional}

Tal y cómo describe Mestre (2007), se puede dividir en tres fases históricas el estudio científico de la inteligencia emocional.

\section{1) 1990-199: Los comienzos}

En la literatura revisada (Extremera, y Fernández-Berrocal, 2003; Mestre, Guil, Brackett, y Salovey, 2008), se establece como el punto de origen del estudio y tratamiento científico de la inteligencia emocional la publicación del artículo Emotional Intelligence por los que se consideran los creadores del constructo, Peter Salovey y John Mayer. En este artículo se definió por primera vez la inteligencia emocional como "la habilidad para regular los sentimientos y las emociones propios de uno y de los otros, discriminar entre ellos y usar esta información para guiar el pensamiento y la acción de uno" (Salovey y Mayer, 1990, p. 189). En estos primeros años los esfuerzos estuvieron centrados en considerar la importancia de la percepción y expresión de las emociones en uno mismo y en los demás, en la comprensión, y en la regulación emocional. Salovey y Mayer fueron los investigadores que mayor producción científica realizaron al respecto. Aunque en esta primera versión del constructo todavía no aparecía la consideración de cómo las emociones facilitaban el pensamiento (Mestre, 2007). En este arranque, el objetivo de los dos investigadores fue dar un cuerpo teórico valido a la inteligencia emocional como un tipo de inteligencia distinta que rescataba la importancia de las emociones en el funcionamiento del ser humano. 


\section{2) 1996-2000: El despegue, ventajas e inconvenientes de su popularización}

Para Mestre (2007) el punto de despliegue del constructo a las grandes masas se establece con la publicación del célebre libro Inteligencia Emocional (Goleman, 1995). Aunque Goleman (1998) ha ido reformulando su propuesta en un primer momento se refirió a la inteligencia emocional como un conjunto de rasgos de personalidad, motivación, y habilidades sociales dividido en cinco dimensiones para posteriormente delimitarlo a cuatro.

Con esta fundamentación de Goleman, la idea original sobre lo que es la inteligencia emocional se perdió

"Lo que en un principio surgió como un interesante concepto científico y una nueva línea de investigación en el campo de la inteligencia y las diferencias individuales, pronto se convirtió en un concepto popular, más comercial que científico, que parecía ser la cura milagrosa para los males que acechaban a nuestra sociedad." (Fernández- Berrocal y Extremera, 2009, p. 90).

Esta popularización del nuevo constructo que, sobre todo, tuvo un gran impacto en el mundo de las organizaciones y desarrollo directivo ya que se le atribuía una alta predicción de éxito laboral, obligó a realizar mayores esfuerzos científicos para devolverle el estatus de constructo científico puesto en duda. La respuesta de Mayer y Salovey fue la de reformular su posición inicial y replantear la definición de inteligencia emocional en base a lo que se denomina modelo de las cuatro ramas (Caruso, y Salovey, 2005). Mayer y Salovey (1997), definieron la inteligencia emocional como "la habilidad para percibir y valorar con exactitud la emoción; la habilidad para acceder y/o generar sentimientos cuando éstos facilitan el pensamiento, la habilidad para comprender la emoción y el 
conocimiento emocional, y la habilidad para regular las emociones que promueven el crecimiento emocional e intelectual" (Salovey y Mayer, 1997, p. 10).

\section{3) 2001-2005. Consolidación y estudios de validez predictiva y aplicada}

En este periodo se consolida teóricamente y experimentalmente la existencia diferenciadora de la inteligencia emocional de los otros tipos de inteligencia (Extremera, 2003; Fernández-Berrocal y Salovey, 2006) e inclusive se inicia la construcción de herramientas de evaluación del constructo, teniendo como referencia la prueba Mayer, Salovey, Caruso Emotional Intelligence Test (MSCEIT) en sus diferentes versiones (Mayer, Salovey, y Caruso, 2003). La necesidad de evaluar la validez predictiva de la inteligencia emocional es comprobada en varios contextos, campos y áreas como la salud mental (Kleinberg, 2000; Extremera, Fernández-Berrocal y Durán, 2003), educación (Elias, Bruene-Butler, Blum y Schuyler, 2000; Petrides, Fredrickson y Furham, 2004) y el ámbito laboral (Goleman, Boyatzis y Mckee, 2002; Lopes, Côté y Salovey, 2006; Lopes, Grewal, Kadis, Gall y Salovey, 2006).

En la actualidad se observa, tanto en la literatura científica técnica revisada como en varias aplicaciones laborales analizadas en diferentes contextos organizacionales, que no existe una unificación conceptual del constructo. Convergen varias propuestas teóricas de las cuales se derivan los diversos modelos actuales que además utilizan herramientas de medición distintas. En este pluralismo teórico, para Cherniss (2010) existen una serie de premisas básicas compartidas y defendidas por las distintas conceptualizaciones, a saber:

1. Las emociones juegan un papel importante en la vida diaria. 
2. Las personas pueden variar en su capacidad de percibir, entender, usar y manejar las emociones.

3. Estas variaciones pueden afectar a la adaptación individual en una variedad de diferentes contextos, incluyendo el lugar de trabajo

Si bien es cierto, tal y como se va a explicar a continuación, la conceptualización con mayor aceptación académica y científica internacional es la de Mayer y Salovey que es la que se ha seguido en esta Tesis doctoral.

\subsection{Modelos de Inteligencia Emocional}

Aunque los autores originales del concepto últimamente ofrecen una clasificación de los modelos existentes en tres grupos (Mayer, Salovey y Barsade ,2008), para efecto de la presente investigación agruparemos los enfoque teóricos clasificados en: 1. Modelos de Habilidad; según se centran en habilidades específicas, y 2. Modelos Mixtos; que son aquellos que recogen un enfoque de variedad que incluyen rasgos de personalidad

El primer grupo resalta la capacidad cognitiva en conjunción con la emoción y se basa en los modelos de inteligencia y desempeño que explican cómo se procesan y regulan la información y adaptación emocional (Salovey y Mayer 1990, Mayer y Salovey, 2007). Los modelos de rasgos o mixtos plantean un acercamiento amplio de la inteligencia emocional, entendiéndola como un conjunto de rasgos estables de personalidad, competencias socio-emocionales, aspectos motivacionales y varias habilidades cognitivas (Bar-On, 2000; Boyatzis, Goleman y Rhee, 2000; Goleman, 1995; Petrides y Furnham, 2000, 2001). Seguidamente, se describen los modelos más representativos de cada grupo. 


\subsubsection{Modelos de habilidad}

\subsubsection{Modelo de las cuatro ramas de Mayer y Salovey (1997)}

Este modelo considera a la inteligencia emocional como la habilidad para percibir, valorar y expresar la emoción adecuada y adaptativamente; la habilidad para comprender la emoción y el conocimiento emocional; la habilidad para acceder y/o generar sentimientos que faciliten las actividades cognitivas y la acción adaptativa; y la habilidad para regular las emociones en uno mismo y en otros (Mayer y Salovey, 1997; Mayer, Salovey y Caruso, 2000). La inteligencia emocional, tal como es concebida por Mayer y Salovey (1997), está compuesta por un conjunto de habilidades emocionales que forman un continuo que abarca desde aquellas de nivel más básico, que ejecutan funciones fisiológicas fundamentales como la percepción y atención a nuestros estados fisiológicos o expresivos, a otras de mayor complejidad cognitiva que buscan el manejo personal e interpersonal (Mayer, Salovey y Caruso, 2008). Las cuatro habilidades emocionales de complejidad ascendente (ver Figura 2.1) planteadas por estos autores se conocen como el modelo de las cuatro ramas y se compone de: 1) Percepción Emocional, 2) Facilitación Emocional, 3) Comprensión Emocional, y 4) Manejo Emocional. 


\begin{tabular}{|c|c|c|c|c|c|}
\hline I & 4 & \multicolumn{4}{|c|}{ REGULACIÓN REFLEXNA DE LAS EMOCIONES PARA PROMOVER EL CRECIMIENTO EINOCIONAL E INTELECTUAL } \\
\hline $\begin{array}{l}\mathrm{N} \\
\mathrm{T} \\
\mathrm{E}\end{array}$ & & $\begin{array}{l}\text { HABILIDAD PARA ESTAR } \\
\text { ABIERTOS A LOS } \\
\text { SENTIMIENTOS TANTO } \\
\text { PARA AQUÉLLOS QUE SON } \\
\text { PLACENTEROS COMO } \\
\text { DISPLACENTEROS }\end{array}$ & $\begin{array}{l}\text { HABILIDAD PARA } \\
\text { REFLEXIVAMENTE ATRAER } \\
\text { O DISTANCIARSE DE UNA } \\
\text { EMOCIÓN DEPENDIENDO } \\
\text { DE SU INFORMACIÓN O } \\
\text { UTILIDAD JUZGADA }\end{array}$ & $\begin{array}{l}\text { HABILIDAD PARA } \\
\text { MONITORIZAR } \\
\text { REFLEXIVAMENTE LAŚ } \\
\text { EMOCIONES EN RELACIÓN A } \\
\text { UNO MISMO Y AOTROS, } \\
\text { TALES COMORECONOCER } \\
\text { CÓMO DECLLARO, TIPICOS, } \\
\text { INFLUYENTES O } \\
\text { RAZZONABLES SON }\end{array}$ & $\begin{array}{l}\text { HABILIDAD PARA REGULAR LAS } \\
\text { EMOCIONES EN UNO MISMO Y } \\
\text { EN OTROS, MITIGANDO LAS } \\
\text { EMOCIONES NEGATIVASE } \\
\text { INTENSIFICANDO LAS } \\
\text { PLACENTERAS, SIN REPRIMIR O } \\
\text { EXAGERAR LA INFORMACIÓN } \\
\text { QUE ELLAS TRANSMITEN }\end{array}$ \\
\hline G & 3 & \multicolumn{4}{|c|}{ COMPRENDER Y ANALIZAR LAS EMOCIONES; EMPLEANDQEL CONOCIMIENTO EMOCIONAL } \\
\hline $\begin{array}{l}\mathrm{N} \\
\mathrm{C}\end{array}$ & & $\begin{array}{l}\text { HABILIDAD PARA } \\
\text { ETIQUETAR EMOCIONES Y } \\
\text { RECONOCER LAS } \\
\text { RELACIONES ENTRE LAS } \\
\text { PALABRAS Y LAS } \\
\text { EMOCIONES MISMAS, } \\
\text { TALES COMO LA RELACIÓN } \\
\text { ENTRE GUSTAR YAMAR }\end{array}$ & $\begin{array}{l}\text { LA HABILIDAD PARA } \\
\text { INTERPRETAR LOS } \\
\text { SIGNIFICADOS QUE LAS } \\
\text { EMOCIONES CONLLEVAN } \\
\text { RESPECTO A LAS } \\
\text { RELACIONES, TALES COMO } \\
\text { QUE LA TRISTEZA A } \\
\text { MENUDO SE ACOMPANA DE } \\
\text { PERDIDA }\end{array}$ & $\begin{array}{l}\text { HABILIDAD PARA } \\
\text { COMPRENDER } \\
\text { SENTIMIENTOS COMPLEJOS: } \\
\text { SENTIMIENTOS } \\
\text { SIMULTÁNEOS DE AMOR Y } \\
\text { ODIO, O MEZCLADOS TALES } \\
\text { COMO EL TEMOR COMO UNA } \\
\text { COMBINACIÓN DE MIEDOY Y } \\
\text { SORPRESA }\end{array}$ & $\begin{array}{l}\text { HABILIDAD PARA RECONOCER } \\
\text { LAS EMOCIONES } \\
\text { APROXIMADAMENTE LAS } \\
\text { TRANSICIONES ENTRE } \\
\text { EMOCIONES, TALES COMO LA } \\
\text { TRANSICIÓN DE LA IRA A LA } \\
\text { SATISFACCIÓN, O DESDE LA IRA } \\
\text { ALA VERGÜENZA }\end{array}$ \\
\hline & 2 & \multicolumn{4}{|c|}{ FACILITACIÓN EMOCIONAL DEL PENSAMIENTO } \\
\hline $\begin{array}{c}\text { M } \\
0\end{array}$ & & $\begin{array}{l}\text { LAS EMOCIONES } \\
\text { PRIORIZANEL } \\
\text { PENSAMIENTO AL DIRIGIR } \\
\text { LA ATENCIÓNA LA } \\
\text { INFORMACIÓN } \\
\text { IMPORTANTE }\end{array}$ & $\begin{array}{l}\text { LAS EMOCIONES SON } \\
\text { SUFICIENTEMENTE } \\
\text { INTENSAS Y DISPONIBLES } \\
\text { QUE PUEDEN SER } \\
\text { GENERADAS COMO AYUDA } \\
\text { DEL JUICIO Y DE LA } \\
\text { MEMORIA SOBRE LOS } \\
\text { SENTIMIENTOS }\end{array}$ & $\begin{array}{l}\text { EL HUMOR CAMBIA LA } \\
\text { PERSPECTIVA DEL INDIVIDUO } \\
\text { DESDE EL OPTIMISMO AL } \\
\text { PESIMISMO, FAVORECIENDO } \\
\text { LA CONSIDERACIÓN DE } \\
\text { MUULTIPLES PUNTOS DE } \\
\text { VISTA }\end{array}$ & $\begin{array}{l}\text { LOS ESTADOS EMOCIONALES } \\
\text { ESTIMULAN ABORDAR } \\
\text { DIFERENCIALMENTE } \\
\text { PROBLEMAS ESPECIFICOS } \\
\text { TALES COMO CUANDO LA } \\
\text { FELICIDAD FACILITA EL } \\
\text { RAZONAMIENTO INDUCTIVOY } \\
\text { LA CREATIVIDAD }\end{array}$ \\
\hline & & \multicolumn{4}{|c|}{ PERCEPCIOON, VALORACION Y EXPRESION DE LA EMOCIÓN } \\
\hline A & & $\begin{array}{l}\text { LA HABILIDAD PARA } \\
\text { IDENTIPICAR LA EMOCIÓN } \\
\text { EN LOSS ESTADOS FISICOS, } \\
\text { SENTIMIENTOSY } \\
\text { PENSAMIENTOS DE UNO }\end{array}$ & $\begin{array}{l}\text { LA HABILIDAD PARA } \\
\text { IDENTIFICAR EMOCIONES } \\
\text { EN OTROS, EN BOCETOS, } \\
\text { EN OBRAS DE ARTE, A } \\
\text { TRAVES DEL LENGUAJE, } \\
\text { SONIDO, APARIENCIA Y } \\
\text { CONDUCTA }\end{array}$ & $\begin{array}{l}\text { HABILIDAD PARA EXPRESAR } \\
\text { EMOCIONES } \\
\text { ADECUADAMENTEY } \\
\text { EXPRESAR LAS } \\
\text { NECESIDADES } \\
\text { RELACIONADAS CON ESOS } \\
\text { SENTIMIENTOS }\end{array}$ & $\begin{array}{l}\text { HABILIDAD PARA DISCRIMINAR } \\
\text { ENTRE EXPRESIONES PRECISAS } \\
\text { O IMPRECISAS, U HONESTAS } \\
\text { VERSUS DESHONESTAS, DE LAS } \\
\text { EMOCIONES } \\
\end{array}$ \\
\hline
\end{tabular}

Figura 2.1: Modelo de Inteligencia Emocional de las cuatro ramas (Mayer y Salovey, 1997). Fuente: Mestre, Guil, Brackett, y Salovey (2008)

\section{Percepción Emocional}

Esta primera habilidad que se encuentra en la base del modelo, permite percibir e identificar las emociones de uno mismo y de los demás. Se relaciona con la conciencia emocional de uno mismo cuando se centra en el propio individuo. Cuando el objeto son las emociones de los demás esta dimensión engloba lo que se denomina sensibilidad afectiva, habilidad para recibir afecto, y sensibilidad no verbal. Gracias a esta sensibilidad se puede apreciar la honestidad de las expresiones emocionales de los demás (Fernández-Berrocal y

Extremera, 2009). 


\section{Facilitación Emocional del pensamiento}

Hace referencia a la habilidad para centrar la atención y pensar de forma más racional a través de la información emocional captada. Mediante la facilitación emocional, es posible influir en procesos cognitivos tales como el razonamiento, la toma de decisiones, la comunicación interpersonal e inclusive en la creatividad. Tal y cómo se recoge en el capítulo I, a través de las emociones se modela y se mejora el pensamiento debido a la relación tanto anatómica como funcional, que existe ente emoción y cognición. Gracias a la facilitación emocional se complementa el procesamiento de la información percibida y se facilita el cambio de perspectiva, la formación de los juicios y se puede adquirir nuevos puntos de vista (Mayer y Salovey, 1997). En consecuencia, la inteligencia emocional a través de esta habilidad supone asumir que nuestro estado emocional se vincula con nuestro pensamiento y que es necesario aprovechar la información emocional para ejecutar procesos cognitivos superiores de especial relevancia para el ser humano. A la largo del capítulo I de esta Tesis doctoral se ha analizado esta interacción entre emoción y pensamiento que se encuentra definida en el modelo de Mayer y Salovey (1997) como facilitación emocional.

\section{Comprensión Emocional}

Esta habilidad implica un alto dominio del vocabulario emocional para aplicar la etiqueta de la emoción correcta de lo que se está sintiendo o se está observando en los demás. Permite realizar un desglose minucioso de las diferentes señales emocionales que nos llegan para realizar un etiquetado emocional y reconocer en que categorías se pueden agrupar bajo un mismo nombre. Implica una actividad tanto anticipatoria como retrospectiva para conocer que causas son las generadoras del estado anímico y qué 
consecuencias puede acarrear (Fernández-Berrocal y Extremera, 2009). Permite reconocer el modo en que se combinan las emociones entre sí y progresan pudiendo, por ejemplo, detectar como una emoción de malestar puede ir subiendo en escala de impacto y convertirse en ira. Alberga la habilidad para reconocer las transiciones de unos estados emocionales a otros y la aparición de sentimientos simultáneos y contradictorios (por ejemplo pasar del miedo a la alegría y de ahí al amor). Gracias a esta habilidad, podemos incrementar no sólo nuestro autoconocimiento emocional sino comprender las emociones del otro, es decir, de sentir empatía (aunque es un constructo diferente como veremos en el capítulo III) que nos ayuda a entender el estado emocional de los demás y conocer la base emocional del porqué de sus comportamientos en las interacciones interpersonales. La comprensión emocional de las emociones del otro ayudará a gestionar y adaptar nuestros comportamientos a las expectativas y/o necesidades que comunica la otra persona con sus expresiones emocionales.

\section{Manejo de las emociones}

Es la habilidad más compleja de las cuatro. Consiste en estar abierto a los sentimientos, independientemente de su valencia, y reflexionar y modularlos en uno mismo o en los demás con el objetivo de incentivar la comprensión y el crecimiento personal. Posibilita que seamos capaces de regular nuestra emoción ante alguna situación que estemos viviendo, por ejemplo una enfermedad, y de igual modo permite que seamos capaces de regular cómo se están sintiendo los demás, por ejemplo ante un compañero/a que está enfermo/a y se siente triste, podemos lograr con nuestro comportamiento modular y regular la tristeza que le acompaña. 
Este modelo se plantea como una estructura jerárquica de avance, dónde el primer lugar lo ocupa la percepción emocional dotada de una complejidad menor y de un funcionamiento más básico, hasta la regulación emocional que se considera la rama más compleja. Claramente se aprecia una distinción entre las cuatro ramas, ya que las ramas de la percepción, comprensión, y regulación se pueden ver como un grupo de habilidades que incluyen el proceso de razonar acerca de las emociones, y por otro lado, la facilitación emocional incluye el uso de las emociones para mejorar el razonamiento. El modelo ha sido utilizado en diversos contextos como por ejemplo, el rendimiento académico, (Fernández Berrocal y Ruiz-Aranda, 2008), sobre las estrategias de afrontamiento de manejo emocional y depresión (Extremera, González-Herero, Rueda y Fernández-Berrocal, 2012), y liderazgo (Côté, Lopes, y Salovey y Miners, 2010).

\subsubsection{Propuesta Ampliación del Modelo de las Cuatro Ramas (Côté y Hideg, 2011)}

Los autores Côté y Hideg (2011) de la Universidad de Toronto ampliaron el modelo de las cuatro ramas de Mayer y Salovey (1997) e incluyeron una quinta habilidad, la influencia emocional, definida como la capacidad de influenciar en los demás a través de la expresión emocional. Esta propuesta que, a su vez se alinea con el modelo EASI planteado por Van Kleef (2009), encaja con uno de los objetivos centrales de esta Tesis que tratará de analizar el efecto interpersonal de la inteligencia emocional de los líderes en sus colaboradores/as.

Para Côté y Hideg (2011), la investigación de las emociones se ha venido centrando principalmente en su efecto intrapersonal, dejando de lado el análisis del efecto de las 
demostraciones de una persona en los pensamientos, sentimientos y acciones en otras personas; a este último efecto se le denomina efecto interpersonal. Esta disparidad de foco de atención se muestra en las escasas investigaciones realizadas para analizar el efecto interpersonal en contraposición con un número más alto que se han centrado en el estudio del efecto intrapersonal. Por ejemplo, estudiando el efecto interpersonal, se ha podido evidenciar que los/as colaboradores/as que ven a su líder mostrar ira infieren que este no está contento con el trabajo que realizan y eso les hace comportarse laboralmente con mayor esfuerzo (Sy, Côté, y Saavedra, 2005). Con respecto al factor de influencia, y recogiendo las ideas de Andrade y Ho (2009), y Grandey (2003), proponen que existen personas que conscientemente modifican sus emociones para influenciar en los demás. Es por esto que Côté y Hideg (2011) lanzan la idea de incluir en el modelo original de habilidades, la habilidad de influenciar en los demás, que consiste en: a) decidir qué despliegue de emoción tendrá el impacto deseado en los demás y b) usar eficazmente la emoción seleccionada en la interacción interpersonal. En primer lugar, los sujetos que son habilidosos en influenciar a los demás saben escoger que emoción es la conveniente mostrar y cómo hacerlo, por ejemplo, en el contexto laboral es importante la selección del canal a elegir para expresar una emoción (por e-mail, teléfono o reunión presencial), ya que se conoce que algunas emociones como la simpatía y la gratitud se comunican de forma fiable tocando entre el codo y la mano de la persona objetivo (Hertenstein et al., 2009). De igual modo, estas personas con esta habilidad saben cómo usar eficazmente la emoción, ya que conocen que efecto puede tener usar una expresión emocional u otra. Este uso eficaz de la expresión emocional depende en alto grado de la regulación emocional y de los mecanismos que se pueden utilizar para dicha regulación: la regulación profunda y/o la 
regulación superficial (Gross, 1998; Hochschild, 1983). Por ejemplo, con respecto a la regulación superficial los/as líderes pueden presentar tranquilidad en un proceso de cambio organizacional aunque interiormente la experiencia subjetiva sea otra. En cambio en la actuación de regulación profunda se une la experiencia subjetiva interna emotiva con la emoción que se exterioriza. Esta capacidad puede ser crucial en el rendimiento de unidades de trabajo dónde el rendimiento dependa de la coordinación esfuerzos y gestión de relaciones con los demás (Grant y Parker, 2009; Griffin, Neal, y Parker, 2007)

Côté y Hideg $(2011,2014)$ argumentaron para apuntalar su iniciativa que, incluso los creadores del modelo original, dejaron abierta la posibilidad de aumentar el modelo de habilidades de la inteligencia emocional. Para que una nueva habilidad emocional pasase a incorporase el modelo original, debería ser una habilidad que permitiese disponer de medidas de rendimiento vinculado al procesamiento emocional cumpliendo cinco criterios básicos, a saber:

1. Debe de mostrar el rendimiento máximo de las personas en tareas bajo condiciones favorables (Carroll, 1993)

2. Debe de haber variación entre los individuos (Carroll, 1993)

3. Debe de tener respuestas correctas /incorrectas (Mayer y Salovey, 1997)

4. Debe de implicar procesamiento emocional (Salovey y Mayer, 1990)

5. Debe de ayudar a los individuos en su vida cotidiana (Salovey y Mayer, 1990)

En este caso, Côté y Hideg, (2011) consideran que la habilidad de influencia cumple los cinco criterios para ser admitida como ampliación al modelo. En definitiva, esta capacidad de influenciar en los demás se basa en la toma de buenas decisiones, sobre qué emociones hay que expresar, y la elección y aplicación de estrategias eficaces para mostrar 
la emoción seleccionada. Debido a esta habilidad se modifican comportamientos, actitudes, emociones, pensamientos de otras personas (Côté y Hideg, 2011).

En su propuesta, estos autores, toman en cuenta el modelo de información y efecto social de las emociones (EASI) de Van Kleef $(2009,2011)$ y sugieren que existen dos mecanismos que moderan este proceso de influencia: reacciones afectivas e inferencias estratégicas. En primer lugar, los mecanismos de reacciones afectivas se refieren a las reacciones emocionales que se producen en el/la observador/a cuando observa las expresiones emocionales de otra persona. Una vez el emisor selecciona un canal y emite la expresión emocional adecuada, ésta es recibida por el observador/a provocándole una reacción afectiva que puede incluir contagio emocional (Hatfield, Cacioppo, y Rapson, 1994). Por ejemplo, las personas que expresan felicidad son juzgadas por quienes las observan como que son personas simpáticas y dignas de confianza (Clark, Pataki, y Carver, 1996). Una evidencia sobre el funcionamiento mediador de las reacciones afectivas en el ámbito laboral proviene de los hallazgos que apuntan que las emociones de los colaboradores/as median entre las emociones de los/as líderes y el grado de coordinación de los colaboradores/as (Sy, Côté y Saavedra, 2005).En segundo lugar, los mecanismos de inferencias estratégicas se refieren a los procesos de inferencia que se produce en los observadores en la interacción social y que dan forma a cómo se comporta (Van Kleef, 2009). Los observadores ajustan sus comportamientos infiriendo qué emociones son las que está expresando las personas con las que interactúa. Por ejemplo, la investigación explica como los/as colaboradores/as adaptan sus comportamientos en base a la emoción que expresa su líder (Van Kleef, Homan, Beersma, van Knippenberg, y van Knippenberg, 2010). 
Por último, estos mecanismos abren un camino a los modelos de competencia de la inteligencia emocional (Goleman, 2002), ya que consideran que las personas tienen la habilidad para influenciar en los demás y esto, sin duda, bien utilizado es una herramienta para incrementar sus competencias de liderazgo en el contexto laboral. Además, la habilidad de influenciar se relaciona con en el nivel de competencia laboral de los colaboradores/as dependiendo, entre otros factores, de su motivación y la habilidad de los mismos en procesar la información emocional, la cultura de los interlocutores, así como la adecuación cultural de la emoción expresada. En la Figura 2.2 se representa la asociación entre habilidad de influenciar y competencia de los colaboradores/as.

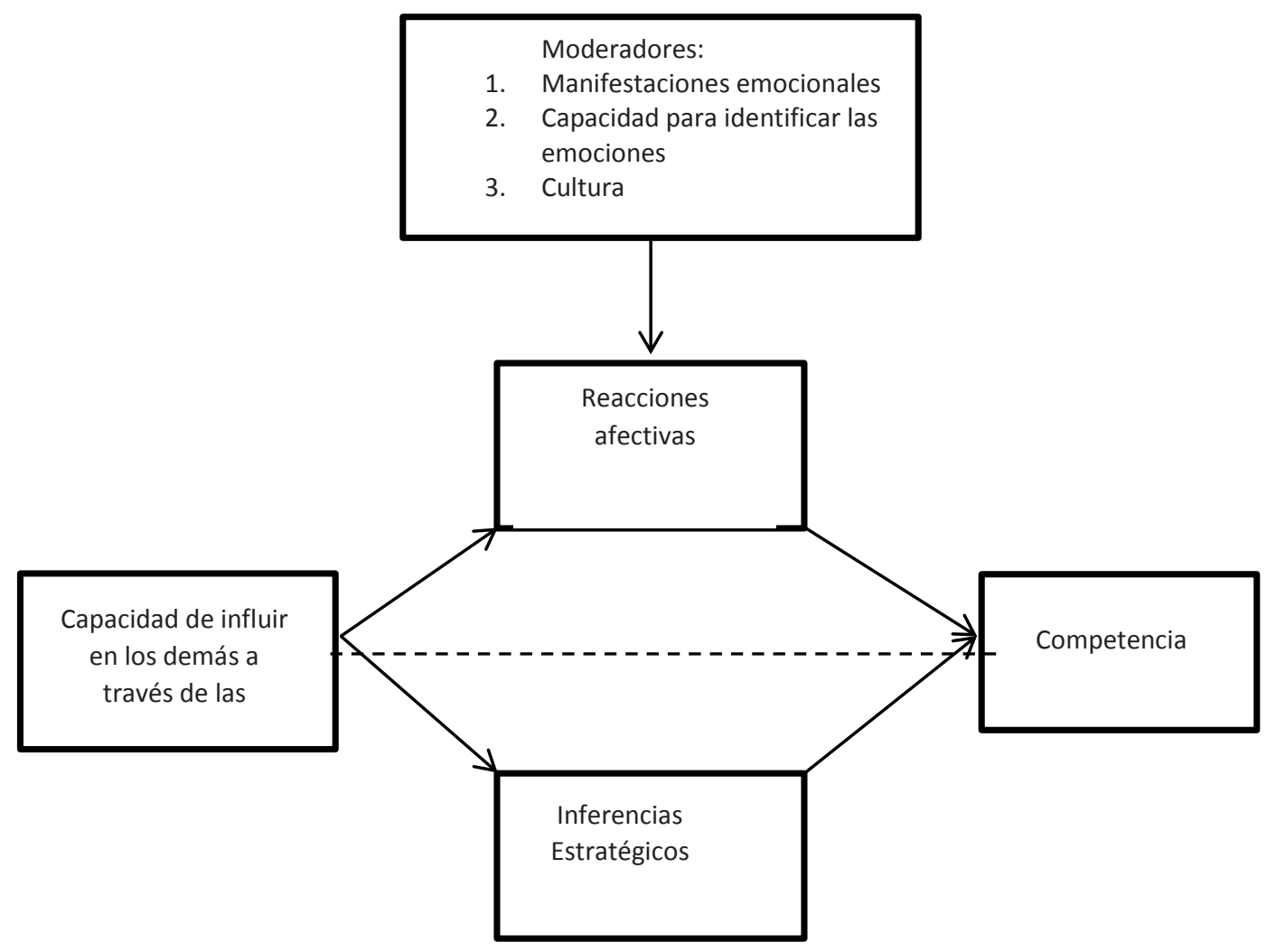

Figura 2.2.: Asociación habilidad de influenciar en otros vía expresión emocional y competencia (Adaptado de Côté y Hideg, 2011) 
En la presente Tesis doctoral, se recoge el desafío lanzado por Côté y Hideg (2011), cuando solicitan ampliar su propuesta y ofrecer predicciones más precisas en cuanto a los posibles efectos y modeladores que puedan existir con la aplicación de esta nueva habilidad de influencia interpersonal que amplía el modelo de las cuatro ramas. De ahí que en este estudio se analice el posible efecto interpersonal de la inteligencia emocional de los líderes en sus colaboradores/as, así como el papel de vigor como un nuevo modulador en la relación de influencia que se produce entre los líderes y sus colaboradores.

\subsubsection{Modelos mixtos.}

\subsubsection{Modelo de competencias (Goleman, Boyatzis y McKee, 2002).}

La publicación del best-seller de Goleman, Inteligencia Emocional (1995) tuvo un impacto sensacional sobre todo en el mundo empresarial a raíz de señalar como explicación fundamental del rendimiento laboral las competencias derivadas de los factores que componen el constructo de inteligencia emocional descrito por este autor. Goleman definió la inteligencia emocional como "la capacidad para reconocer nuestros propios sentimientos, motivarnos y monitorear nuestras relaciones" (Goleman, 1995, p.3).

A raíz de esta definición se generó el modelo teórico que establece que existen una serie de competencias que facilitan a las personas el manejo de las emociones hacia uno mismo y hacia los demás (Boyatzis, Goleman, y Rhee, 2000). La idea que subyace a este modelo es que, según los estudios iniciales de Gardner (1983), sólo se puede predecir a través del coeficiente intelectual el 20\% del éxito profesional, por lo que el resto depende de factores que Goleman, recuperando los trabajos de McClelland sobre estudios sobre los 
factores predictivos de éxito laboral, sitúa en un conjunto de competencias agrupadas en diferentes dominios. Para Goleman (1998), la competencia emocional es una capacidad aprendida basada en la inteligencia emocional que se traduce en un rendimiento excepcional en el trabajo

El modelo ha tenido algunas revisiones (Goleman, 1995, 1998; Goleman, Boyatzis, y McKee, 2002) para finalmente, describirlo como como un conjunto de competencias emocionales asociadas a un desempeño exitoso en el puesto de trabajo (ver Tabla 2.1).

Tabla 2.1: Modelo de Inteligencia Emocional (Goleman, Boyatzis, McKee, 2002)

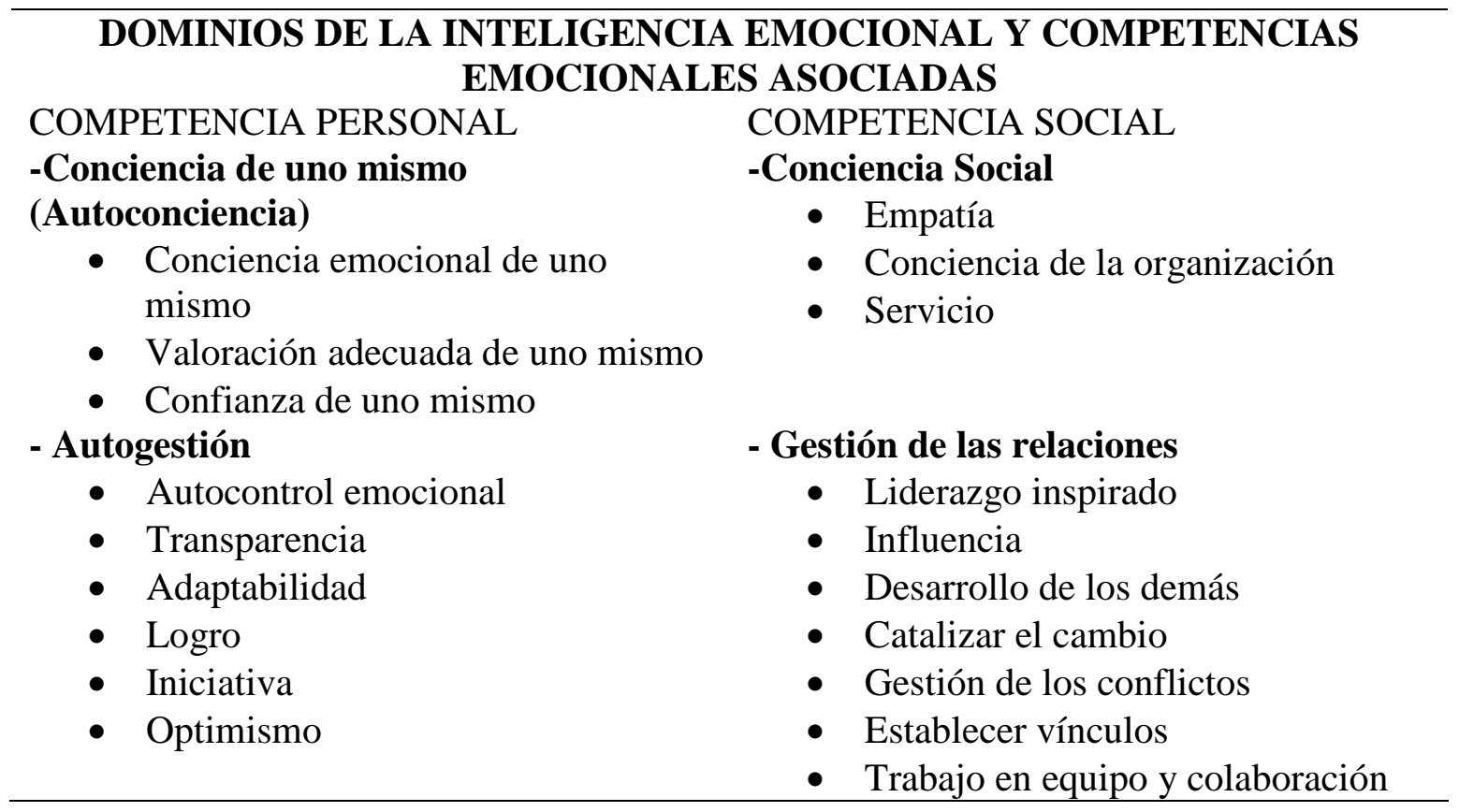

El dominio de la autoconciencia en este modelo constituye el fundamento del resto competencias de la inteligencia emocional, ya que según Goleman y sus colaboradores (2002), si no hay conciencia interna emocional, es complicado reconocer y gestionar las emociones de los demás. Los autores defienden que todas las competencias están 
relacionadas entre sí, al igual que los cuatro dominio dónde se agrupan. Por ejemplo, la autoconciencia posibilita la empatía y la gestión de uno/a mismo/a, y la adecuada combinación de éstas dos últimas permite la gestión eficaz de las relaciones. Bajo esta teoría se abre un espacio al desarrollo ya que se considera que estas competencias no tienen una base innata y se pueden ampliar. Richard Boyatzis, máximo exponente de este modelo junto a Goleman, reclama que su propuesta de inteligencia emocional, a diferencia de la de Mayer y Salovey, está orientada también a intentar predecir los patrones de comportamiento y sus consecuencias en la forma de vida y los resultados de trabajo (Boyatzis y Sala, 2004).

\subsubsection{Modelo de Barn-On (2000,2006)}

Al igual que el anterior, este modelo trata de dar respuesta a cuales son los factores que permiten diferenciar a las personas que consiguen el éxito de las que no. Recogiendo tradiciones anteriores de Darwin (1872), Weschler (19458), Gardner (1983) y Mayer y Salovey (1997), Bar-On, considera que la clave del éxito se establece en factores que no tienen que ver con la inteligencia cognitiva. De ahí que se dedica a estudiar y a investigar qué factores pueden ser los causantes de dicho éxito. Finalmente propone un modelo multifactorial con el objeto de aumentar las habilidades involucradas en la inteligencia no cognitiva.

Bar-On (1997) definió la inteligencia emocional como un conjunto de habilidades personales, emocionales y sociales y de destrezas que influyen en nuestra habilidad para adaptarnos y enfrentar las demandas y presiones del medio. A partir de esta idea 
fundamenta su modelo teórico dónde la inteligencia emocional se relaciona con el potencial para el rendimiento, pero considerándolo como un proceso mucho más importante que los logros a conseguir. Entiende que la inteligencia emocional se compone de cinco factores principales (ver Tabla 2.2) que son: componente intrapersonal, componente interpersonal, componente y manejo del estrés, adaptabilidad-ajuste, y estado de ánimo general. De cada uno de estos subcomponentes se desgranan quince subcomponentes

Tabla 2.2: Modelo de Bar-On (adaptado de Barn-On, 2000, 2006)

\begin{tabular}{|c|c|}
\hline Factores & Subcomponentes (Habilidades) \\
\hline Componente Intrapersonal & Autoconocimiento emocional \\
\hline Evalúa la auto identificación general del & Asertividad \\
\hline individuo haciendo referencia a la & Auto-concepto \\
\hline capacidad para expresar y comunicar los & Independencia \\
\hline sentimientos de uno mismo & Auto-evaluación \\
\hline Componente Interpersonal & Empatía \\
\hline Capacidad para escuchar, comprender y & Responsabilidad Social \\
\hline apreciar los sentimientos de los otros & Relaciones Interpersonales \\
\hline Componente Manejo del estrés & Tolerancia al estrés \\
\hline $\begin{array}{l}\text { Control que se tiene para mantener la } \\
\text { calma y afrontar las situaciones estresantes }\end{array}$ & Control impulsivo \\
\hline Adaptabilidad-Ajuste & Validación \\
\hline $\begin{array}{l}\text { Capacidad para tratar con los problemas } \\
\text { cotidianos. }\end{array}$ & Flexibilidad \\
\hline Estado de ánimo general & Solución de problemas \\
\hline $\begin{array}{l}\text { Optimismo y capacidad para mantener una } \\
\text { actitud positiva }\end{array}$ & Optimismo \\
\hline
\end{tabular}

Este modelo ha sido aplicado en diferentes ámbitos, como el laboral, educativo, y médico clínico (Mancini y Trobini, 2011). El modelo de Bar-On se complementa con la generación de un coeficiente emocional (EQ) que ofrece una medida general sobre la interacción factorial de los cinco componentes en un individuo. Para la medición de este coeficiente, Bar-On, diseñó un instrumento para su medida denominado EQ-i (Bar-On, 1997) que se describirá en el siguiente apartado. 
En contraposición, algunos expertos critican el modelo de Barn-On, alegando que es que no se puede agrupar características personales ligadas a las emociones (D’Amico, 2008).

\subsubsection{Modelo de Petrides y Furnham (2001)}

A estos autores se les reconoce el hecho que ya, a principio de la década pasada (2000, 2001), se dieran cuenta de la disparidad de instrumentos de medida que existían sobre la inteligencia emocional e intentaran clarificar y ordenar algunas de las ideas existentes. Para estos autores, el estado de confusión tenía como origen la forma con la que se evaluaban las variables, lo cual, afectaba directamente a cómo se operacionaba el constructo. Clarifican dos tendencias a la hora de medir el constructo. La primera era utilizar medidas de autoinforme que provocaba que el constructo sea visto como un rasgo de personalidad. Por el contrario, los instrumentos que miden las habilidades emocionales y el rendimiento obtenido del uso de las mismas, provocan que la inteligencia emocional se operacionalice como capacidad cognoscitiva. De ahí que Petrides y Furnham (2000), distinguieron entre inteligencia emocional rasgo (o autoeficacia emocional) e inteligencia emocional capacidad (capacidad cognitivo-emocional). Dichos autores encontraron evidencias de que la inteligencia emocional vista como rasgo se correlaciona con las cinco dimensiones que componen la teoría de personalidad de los Big Five (cinco grandes).

Esta aproximación interpreta la inteligencia emocional como un conjunto de rasgos de la personalidad que son dimensiones de las diferencias individuales en las tendencias para mostrar patrones consistentes de pensamientos, sentimientos y acciones. Se refieren a lo que se podría llamar "metaemoción”, un aspecto más de lo que los psicólogos cognitivos 
denominan "metacognición”, es decir, la capacidad para contemplar introspectivamente nuestros procesos mentales y reflexionar sobre ellos (Aguado, 2005). Petrides y Furham, entienden la inteligencia emocional como un conjunto de disposiciones emocionales y habilidades auto-perceptivas que representan el constructo de un compuesto bien definido en los niveles jerárquicos más bajos de la estructura de personalidad (Petrides, y Furnham, 2001). Con este concepto multifactorial de la inteligencia emocional introducen quince disposiciones y habilidades auto-percibidas que configuran su visión de la inteligencia emocional (Belmonte, 2013) (ver Tabla 2.3).

Tabla 2.3: Modelo de Inteligencia Emocional de Petrides y Furham. Adaptado de Belmonte (2013) a partir de Petrides y Furnham (2001)

\section{Factor Descripción}

Adaptabilidad

Asertividad

Percepción emocional (propia)

Expresión Emocional

Manejo Emocional

Regulación emocional

Impulsividad

Relaciones

Autoestima
Capacidad para ser flexibles y estar dispuestos a adaptarse a nuevas situaciones

Actitud para ser francos, sinceros, y dispuestos a dar la cara por los derechos propios

Ser claros sobre sus sentimientos y los de los demás

Capacidad de comunicar los sentimientos a los demás

Capacidad de influir en los sentimientos de los demás

Capacidad de manejar las emociones

Capacidad de reflexión y poco propensos a la impulsividad

Capacidad de tener relaciones personales plenas

Ser poco propenso a rechazar el afrontamiento con la adversidad 


\begin{tabular}{ll}
\hline Auto-motivación & $\begin{array}{l}\text { Habilidad para conexionar con la gente y tener } \\
\text { excelentes habilidades sociales }\end{array}$ \\
Conciencia social & $\begin{array}{l}\text { Capacidad de ponerse en el lugar del otro } \\
\text { Capacidad de resistir a la presión y de regular el estrés }\end{array}$ \\
Manejo del estrés & $\begin{array}{l}\text { Capacidad para ponerse en el lugar del otro } \\
\text { Rasgo de empatía }\end{array}$ \\
Rasgo de felicidad & Actitud alegre y satisfecha con la vida \\
Rasgo de optimismo & $\begin{array}{l}\text { Actitud segura y propensa a "mirar el lado bueno" de la } \\
\text { vida }\end{array}$ \\
\hline
\end{tabular}

A la vista de lo expuesto, todavía en la actualidad no está del todo clarificado un concepto uniforme de lo que es inteligencia emocional. Côté (2014), en una de las últimas revisiones realizadas sobre el constructo, apela a la necesidad de revisar los modelos mixtos y a los que incluyen, como en el caso del de Petrides y Furnham (2001), disposiciones como la asertividad, la felicidad y la autoestima que están fuera de ser considerados como un tipo de inteligencia (Pedhazur y Schmelkin, 1991). Côté (2014) añade que los modelos como el de competencias de Goleman y Boyatzis $(1998,2001)$ combinan, la autopercepción y disposiciones, con habilidades emocionales que nada tiene que ver con ser considerados como inteligencia. Para Côté, lo que está sucediendo es que se está dando lo que se denomina falacia del cascabel, o la creencia de pensar que diferentes cosas que se llaman por el mismo nombre son lo mismo, cuando en realidad, no lo son.

Comparto con este autor la recomendación de seguir como investigadores/as los modelos de habilidad de la inteligencia emocional. En la presente Tesis doctoral se adopta esta consideración ya que se basa en el modelo de habilidad de Mayer y Salovey (1997). Además, se tendrá muy en cuenta la propuesta de Côté y Hideg de incluir la habilidad de 
influenciar a los demás como parte del proceso de influencia de los líderes y que pueda ser considerada como la quinta rama del modelo inicial de habilidades de Mayer y Salovey (1997).

\subsection{Instrumentos de Evaluación de la Inteligencia Emocional}

Tal y como se ha podido observar, la disparidad de modelos conceptuales existentes sobre qué es la inteligencia emocional y sobre sus dimensiones, provoca irremediablemente que existan diversos instrumentos de medición. En esta revisión, se analizarán los instrumentos que se derivan de los modelos anteriormente expuestos y que han ofrecido un valor científico corroborado.

Se pueden agrupar en tres categorías, la primera categoría recoge las ideas iniciales de Mayer y Salovey (1997) y contiene medidas de autoinforme breves que recogen, en parte o en su totalidad, las habilidades emocionales básicas definidas por los creadores del constructo (Extremera y Fernández-Berrocal, 2007). Estos instrumentos se basan en recopilar la percepción del propio sujeto sobre sus capacidades emocionales intra e interpersonales a través de ítems tipo Likert con varias opciones de respuesta.

El segundo grupo se denomina de medidas de autoinforme extensivos (Extremera y Fernández-Berrocal, 2007) y también se basan en recoger la percepción del propio sujeto, pero a diferencia de los anteriores, se alejan de la concepción de Mayer y Salovey e incluyen en su evaluación factores tan distintos como competencias, aspectos de personalidad, cognitivos y sociales. Esta ampliación del objeto de medición se debe a que surgieron diversos modelos (Bar-On, 1997; Goleman, 1997, 2001; Petrides y Furnham, 2001) que empezaron a incluir aspectos de medición aplicados al desempeño laboral bajo el 
epígrafe de competencias laborales emocionales. De igual modo, otro aspecto que han incluido es la herramienta denominada de $360^{\circ}$, con la que personas que rodean e interactúan con el/la colaborador/a a evaluar emiten su evaluación sobre su desempeño. De esta manera, se dispone de la información del colaborador/a a través de dos fuentes, su auto-percepción individual, más las evaluaciones de quienes interactúan con él/ella. En la mayoría de las pruebas que se encuentran dentro de este grupo se conceptualiza a la inteligencia emocional como un conjunto de habilidades emocionales, cognitivas, afectivas y de personalidad que englobarían las bases de las personas emocionalmente inteligentes.

Dentro de este enfoque, los/as encuestados/as indican su acuerdo con las declaraciones de autodescripción sobre su habilidades tales como "Yo soy muy capaz de controlar mis emociones" (Law, Wong, y Song, 2004, p. 496).

El enfoque de autoinforme se basa en la suposición de que los individuos pueden estimar con precisión su máximo rendimiento en los problemas sobre las emociones y están dispuestos a manifestarlo en cuestionarios (Côté, 2014).

Hay evidencia, sin embargo, que el sesgo de autoinforme se manifiesta particularmente fuerte cuando la persona valora sus habilidades, esto es debido a que está motivada para desarrollar percepciones favorables de su inteligencia (Dunning. Health, y Suls, 2004). Tal y como recoge Côté (2014), casi el $80 \%$ de las personas informaron de que estaban entre el $50 \%$ de la gente más emocionalmente inteligentes, una cifra imposible que revela que las personas generalmente sobreestiman su inteligencia emocional (Brackett, Rivers, Shifman, Lerner, y Salovey ,2006). Además, los resultados sugieren que los individuos con baja inteligencia emocional sobreestiman su verdadero nivel porque carecen de los conocimientos necesarios para evaluar la precisión con que resuelven problemas 
acerca de las emociones, a este efecto se le denomina efecto Dunning-Kruger (Sheldon, Ames, y Dunning, 2013). Por otro lado, la evidencia sugiere que los individuos pueden falsear sus respuestas en los cuestionarios de autoinforme (Donovan et al., 2003). Por ejemplo, solicitantes de trabajo califican su propia inteligencia emocional como superior incluso a la de los titulares del puesto al que optan, lo que sugiere que los individuos falsean sus habilidades cunado tienen un incentivo para hacerlo (Lievens, Klehe, y Libbrecht, 2011).

Las limitaciones de este enfoque son confirmados en un metaanálisis realizado por Joseph y Newman (2010) en el cual evidencian que las medidas de autoinforme de la inteligencia emocional están más fuertemente correlacionados con medidas de rasgos de personalidad, que también capturan la auto-percepción, que con medidas basadas en el desempeño de la inteligencia emocional.

Finalmente, el último grupo recoge los instrumentos denominados de medidas de ejecución o de habilidad de la inteligencia emocional siguiendo la metodología clásica empleada para valorar las inteligencias cognitivas humanas (Brackett, et al., 2006). Estos instrumentos tienen su base en la redefinición del modelo original de Mayer y Salovey (1997) por el cual se determinan las cuatro ramas que actualmente componen la inteligencia emocional conceptualizada como conjunto de habilidades emocionales y capacidad para procesar la información emocional. La principal ventaja de este grupo de instrumentos es que permite recoger una medida sobre el rendimiento del individuo y no sobre su propia creencia o la de los demás, con lo que se reduce el efecto de la deseabilidad social o de la interacción subjetiva entre personas que comparten un mismo contexto. Al contrario de los instrumentos de autoinforme, los/as participantes no pueden aumentar sus puntuaciones en 
medidas basadas en el desempeño de la IE bajo ninguna instrucción ya que no puede saber cuál es la solución a problemas que tampoco conoce (Day y Carroll 2008).

A continuación se ofrece un resumen gráfico de cada una de las pruebas más

reconocidas según el modelo teórico por el cual se conceptualiza el constructo (ver Figura 2.3.). 


\begin{tabular}{|c|c|c|c|}
\hline $\begin{array}{l}\text { MODELO- } \\
\text { ENFOQUE }\end{array}$ & $\begin{array}{l}\text { PRUEBA- } \\
\text { AUTORES }\end{array}$ & DESCRIPCIÓN & $\begin{array}{l}\text { FIABILIDAD/ } \\
\text { CONSISTENCIA } \\
\text { INTERNA }\end{array}$ \\
\hline $\begin{array}{l}\text { Mayer y Salovey } \\
\text { (1997) IE como } \\
\text { conjunto de } \\
\text { habilidades de } \\
\text { procesamiento de } \\
\text { la información } \\
\text { emocional }\end{array}$ & $\begin{array}{l}\text { Extremera, N., } \\
\text { Fernández- } \\
\text { Berrocal, P. y } \\
\text { Salovey, P. } \\
\text { (2006). Spanish } \\
\text { Version of the } \\
\text { Mayer-Salovey- } \\
\text { Caruso Emotional } \\
\text { Intelligence Test } \\
\text { (MSCEIT) } \\
\text { Version 2.0: } \\
\text { Reliabilities, Age, } \\
\text { and Gender } \\
\text { Differences. } \\
\text { Psicothema, 18, } \\
\text { 42-48. }\end{array}$ & $\begin{array}{l}\text { Prueba de evaluación de ejecución. } \\
\text { Se divide en dos áreas: } \\
\text { Experiencial y Estratégica. Cada } \\
\text { área está compuesta por varias } \\
\text { pruebas que miden cada una de las } \\
\text { cuatro ramas del modelo: Área } \\
\text { Experiencial: Percepción: } 1 . \\
\text { Rostros 2. Paisajes y diseños } \\
\text { abstractos. Facilitación Emocional: } \\
\text { 3. Facilitación 4. Sensaciones; } \\
\text { Área Estratégica: Comprensión: } 5 . \\
\text { Transformaciones emocionales } 6 . \\
\text { Combinaciones de Emociones; } \\
\text { Manejo: } 7 . \text { Manejo de } \\
\text { Sentimientos Propios } 8 \text {. Manejo } \\
\text { Emocional de los demás } \\
N^{\circ} \text { de Ítems: } 141\end{array}$ & $\begin{array}{l}\text { La versión española del } \\
\text { MSCEIT versión } 2.0 \\
\text { tiene una fiabilidad total } \\
\text { de } 0,95 \text {, con una } \\
\text { fiabilidad por áreas de } \\
0,93 \text { para el área } \\
\text { experiencial y de } 0,90 \\
\text { para el área estratégica. } \\
\text { Además se han obtenido } \\
\text { elevadas correlaciones } \\
\text { entre las puntuaciones } \\
\text { obtenidas con los } \\
\text { sistemas de corrección } \\
\text { español y el original } \\
\text { consenso ( } \mathrm{r}=0,99 \text { ). Los } \\
\text { análisis factoriales } \\
\text { replican la estructura } \\
\text { original del instrumento, } \\
\text { compuesto por una } \\
\text { puntuación total, dos } \\
\text { áreas, cuatro habilidades } \\
\text { básicas y ocho subtareas. }\end{array}$ \\
\hline
\end{tabular}




\begin{tabular}{|c|c|c|c|}
\hline $\begin{array}{l}\text { Enfoque Mixto: } \\
\text { Bar-On }\end{array}$ & $\begin{array}{l}\text { EQ-i-Reuven Bar- } \\
\text { On (1997) }\end{array}$ & $\begin{array}{l}\text { Prueba Autoinforme compuesto } \\
\text { por cinco factores superiores: } \\
\text { Inteligencia Intrapersonal, } \\
\text { inteligencia interpersonal, } \\
\text { adaptación, gestión del estrés y } \\
\text { humor general. Al mismo tiempo } \\
\text { de divide en } 15 \text { subescalas; } 1 . \\
\text { Autoconciencia Emocional } 2 . \\
\text { Asertividad 3. Autoestima Personal } \\
\text { 4. Autoactualización 5. } \\
\text { Independencia 5. Independencia } 6 . \\
\text { Empatía 7. Relaciones } \\
\text { Interpersonales } 8 \text {. Responsabilidad } \\
\text { Social 9. Soluciones de Problemas } \\
\text { 10. Comprobación de la Realidad } \\
\text { 11. Flexibilidad 12. Tolerancia al } \\
\text { estrés 13. Control de Impulsos } 14 . \\
\text { Felicidad 15. Optimismo }\end{array}$ & $\begin{array}{l}\text { Coeficiente Emocional } \\
\text { Global: 0.95.(Zafra, } \\
\text { Pulido y Berrios, 2014) }\end{array}$ \\
\hline & & Número de Ítems: 133 & \\
\hline $\begin{array}{l}\text { Enfoque Mixto: } \\
\text { Goleman } \\
\text { Adaptado para } \\
\text { fines comerciales } \\
\text { por Hay Group }\end{array}$ & $\begin{array}{l}\text { ECI.2. (2004) } \\
\text { Boyatzis, } \\
\text { Goleman, Sala- } \\
\text { Hay Group, } \\
\text { McClelland } \\
\text { Center for } \\
\text { Research and } \\
\text { Innovation }\end{array}$ & $\begin{array}{l}\text { Medida de autoinforme que se } \\
\text { divide en dos versiones. La } \\
\text { primera corresponde a la } \\
\text { autoevaluación (autoreporte) y la } \\
\text { segunda es para es para el } \\
\text { evaluador externos obteniendo dos } \\
\text { puntuaciones, la de uno mismo, y } \\
\text { la de los demás. Esta prueba ha } \\
\text { evolucionado de los modelos de } \\
\text { competencia de Goleman y las } \\
\text { ideas de rendimiento laboral de } \\
\text { Boyatzis que dieron paso al ECI-1. } \\
\text { Se divide en la evaluación de } \\
\text { cuatro dimensiones y } 18 \text { subescalas } \\
\text { Autoconciencia: } 1 . \text { Conciencia } \\
\text { emocional 2. Valoración adecuada } \\
\text { de uno mismo 3. Confianza en uno } \\
\text { mismo, Autogestión: } 4 . \\
\text { Autocontrol 5. Transparencia } 6 . \\
\text { Adaptabilidad. } 7 . \text { Orientación al } \\
\text { logro } 8 \text {. Iniciativa 9. Optimismo, } \\
\text { Conciencia Social: 10. Empatía } \\
\text { 11.Conciencia Organizativa, } 12 \text {. }\end{array}$ & $\begin{array}{l}\text { No existe valoración } \\
\text { global: La consistencia } \\
\text { declarada por Hay-Group } \\
\text { se divide por la } \\
\text { autoreportada y por la de } \\
\text { los demás. En el caso de } \\
\text { la auto reportada se sitúa } \\
\text { en para las } 18 \text { subescalas } \\
\text { en un intervalo de } 0.47- \\
0.76 \text {. En el caso de la los } \\
\text { demás si sitúan en } \\
\text { intervalo de } 0.68-0.87\end{array}$ \\
\hline
\end{tabular}




\begin{tabular}{|c|c|c|c|}
\hline & & $\begin{array}{l}\text { Orientación al cliente, Gestión de } \\
\text { las Relaciones: 13. Desarrollo de } \\
\text { los demás, 14. Liderazgo } \\
\text { Inspirador } 15 . \text { Impulso al cambio } \\
\text { 16. Influencia } 17 . \text { Gestión de } \\
\text { Conflictos } 18 \text {. Trabajo en equipo y } \\
\text { colaboración }\end{array}$ & \\
\hline & & $\mathrm{N}^{\circ}$ de Ítems: 72 & \\
\hline $\begin{array}{l}\text { Enfoque IE como } \\
\text { Rasgo de } \\
\text { Personalidad: } \\
\text { Petrides y } \\
\text { Furnham }\end{array}$ & $\begin{array}{l}\text { TEI-QUE Versión } \\
\text { 1.5. Petrides } \\
2009 . \\
\text { Versión Española } \\
\text { Pérez (2003)- }\end{array}$ & $\begin{array}{l}\text { Prueba Autoinforme con } 15 \\
\text { subescalas agrupadas en cuatro } \\
\text { factores: Bienestar, habilidades de } \\
\text { autocontrol, habilidades } \\
\text { emocionales, y habilidades } \\
\text { sociales. } \\
\text { Subescalas: } 1 \text {. Adaptabilidad } 2 . \\
\text { Asertividad 3. Expresión } \\
\text { emocional 4. Manejo emocional } 5 . \\
\text { Percepción emocional } 6 . \\
\text { Regulación emocional } 7 \text {. Empatía } \\
\text { 8. Felicidad 9. Impulsividad } 10 . \\
\text { Optimismo 11. Habilidades } \\
\text { relacionales } 12 \text {. Autoestima } 13 . \\
\text { Automotivación } 14 \text {. Competencia } \\
\text { Social 15. Manejo del estrés } \\
\text { Ofrece una puntuación total de } \\
\text { inteligencia emocional entendida } \\
\text { como rasgo }\end{array}$ & $\begin{array}{l}\text { Esta prueba se ha } \\
\text { adaptado y validado a } \\
\text { diversas poblaciones UK, } \\
\text { Bélgica, Serbia, } \\
\text { Alemania y ha obtenido } \\
\text { una consistencia en su } \\
\text { escala global superior a } \\
0.80 \text { y de las subescalas } \\
\text { se situé en los diferentes } \\
\text { países dónde se ha } \\
\text { realizado la adaptación } \\
\text { por en un intervalo entre } \\
0.60-0.95\end{array}$ \\
\hline
\end{tabular}

Figura 2.3: Instrumentos de Evaluación de la Inteligencia Emocional (Elaborado a partir de Mestre y Fernández-Berrocal (2007)

Siendo rigurosos, aunque el MSCEIT es considerado como la prueba más adecuada de medición de las habilidades emocionales, ha recibido algunas críticas como la de su presunta debilidad en la consistencia interna (González, Petrides y Furnham, 2007). Sin 
embargo tanto el modelo de Salovey y Mayer (1997) y el MSCEIT como instrumento de medición de la inteligencia emocional son los que mayor validez y reconocimiento científico y académico tienen en la actualidad. De ahí que siguiendo también la recomendación de Mayer et al. (2008), Côté (2014), y Fernández-Berrocal, Berrios-Martos, Extremera, y Augusto (2012) en esta Tesis se ha utilizado la adaptación española del MSCEIT 2.0 realizada por Extremera, Fernández-Berrocal, y Salovey (2006) para medir el nivel de inteligencia emocional de los líderes.

\subsection{Liderazgo e Inteligencia Emocional}

Este análisis se divide en tres partes. En primer lugar, se describen los diversos enfoques teóricos que, históricamente se han ido desarrollando para explicar el liderazgo, así como las variables que intervienen en este proceso. Seguidamente, se realizará una explicación del factor común que recogen las diversas aproximaciones revisadas y que se centran en conceptualizar al liderazgo como un proceso de influencia. Si bien es cierto la tendencia actual es considerarlo como un proceso bidireccional, en esta investigación me centraré en la versión clásica unidireccional del efecto del/la líder sobre sus colaboradores $/ \mathrm{as}^{2}$. Y finalmente, se presentará una revisión actualizada de algunas de las propuestas e investigaciones bajo diversos modelos teóricos de inteligencia emocional, que a pesar de la consabida discusión conceptual, coinciden en mostrar el efecto de la inteligencia emocional del/la líder en sus colaboradores/as.

\footnotetext{
${ }^{2}$ En esta tesis se utilizará el termino colaborador/colaboradora para referirnos a aquellas personas que están bajo la influencia del líder recibiendo sus instrucciones y que pueden en otros textos se definen como seguidores/as, empleados/as o trabajadores/as a su cargo
} 


\subsubsection{Concepto de liderazgo.}

Realizando una simple búsqueda del término "Leadership " en Google se obtiene 490.000.000 resultados; y si se hace lo mismo con el concepto en castellano, "Liderazgo," la cifra se sitúa 39.900 .000 (búsqueda realizada el 09.03.2015). Estos datos evidencian que estamos ante un constructo muy amplio, dinámico, y de complicada síntesis en una única conceptualización. Stogdill ya advirtió en 1974 que "existen tantas definiciones de liderazgo como personas que han intentado definir el concepto". Stogdill (1974, p. 259). A lo largo de siglo pasado, y hasta la fecha actual, el concepto de liderazgo ha oscilado desde una búsqueda de cualidades y análisis de aspectos individuales, hasta tener en cuenta factores como los/as colaboradores/as, la cultura, el contexto, el lugar de trabajo que incluyen una gama amplia de individuos en representación de todo el espectro de la diversidad públicos, privados y sin fines de lucro (Avolio, Walumba, y Weber, 2009). Algunas de las definiciones más usuales recogidas en la literatura revisada son las siguientes:

- "Liderazgo es el proceso de influir en las actividades de una persona o un grupo para esforzarse hacia el logro de un objetivo en situaciones dadas" (Hersey y Blanchard, 1988 p. 86).

- "La única definición de líder es alguien que tiene colaboradores" (Drucker, 1992, p. 184)".

- "los gerentes son gente que hace las cosas correctamente y los líderes gente que hacen las cosas correctas" (Bennis y Nanus, 1985, p. 21)

\footnotetext{
${ }^{3}$ Búsqueda realizada 24 febrero 2015
} 
Desde el liderazgo transformador nos encontramos con la aportación de Bass que considera al líder la persona que transforma a sus colaboradores/as, aumenta su motivación y su compromiso, haciéndolos más conscientes de la importancia y el valor de los resultados de la tarea (Bass, 1990).

Por último, la definición que aglutina varios de los puntos en los que se apoya e identifica esta investigación es la que considera al liderazgo como "proceso de influir a otros/as, a entender y estar de acuerdo sobre lo que hay que hacer y cómo hacerlo, y el proceso de facilitar esfuerzos individuales y colectivos para lograr objetivos compartidos" (Yukl, 2010, p. 8).

A pesar de la heterogeneidad existente en las distintas conceptualizaciones y formas de definir el liderazgo se encuentran los siguientes puntos en común:

- El liderazgo es un proceso

- implica influir en los demás

- $\quad$ sucede dentro del contexto de un grupo

- implica el logro de metas, $y$

- Los objetivos son compartidos por los/as líderes y sus colaboradores/as.

El punto de acuerdo en concebir el liderazgo como un proceso significa que estamos ante una situación de transacción e interrelación social que sucede entre los líderes y sus colaboradores/as. Por tanto, el liderazgo se centra en dos funciones claves: 1) proveer dirección para cumplir objetivos compartidos y 2) ejercer influencia. Marcar una meta común e influir en otros/as para compartirla definen primariamente el liderazgo (Leithwood y Louis, 2011). La investigación clásica se ha centrado sobre todo en analizar las características del/la líder más que en el estudio de cómo se produce el proceso de 
influencia. En este proceso se incluyen variables como, la identificación de los factores que median en la relación entre el líder y sus colaboradores/as, el contexto, la naturaleza de la relación, y la posibilidad de que los/as colaboradores/as también ejerzan influencia sobre el/la líder.

El cómo se produce la influencia del/la líder sobre los/as colaboradores/as está siendo objeto de estudio por varios investigadores, destacando los trabajos iniciales de Yukl y Tracy que tuvieron su punto de partida formal en el artículo Consequences of influence tactics used with subordinates, peers, and the boss (Yukl y Tracey, 1992) (ver Figura 2.4).

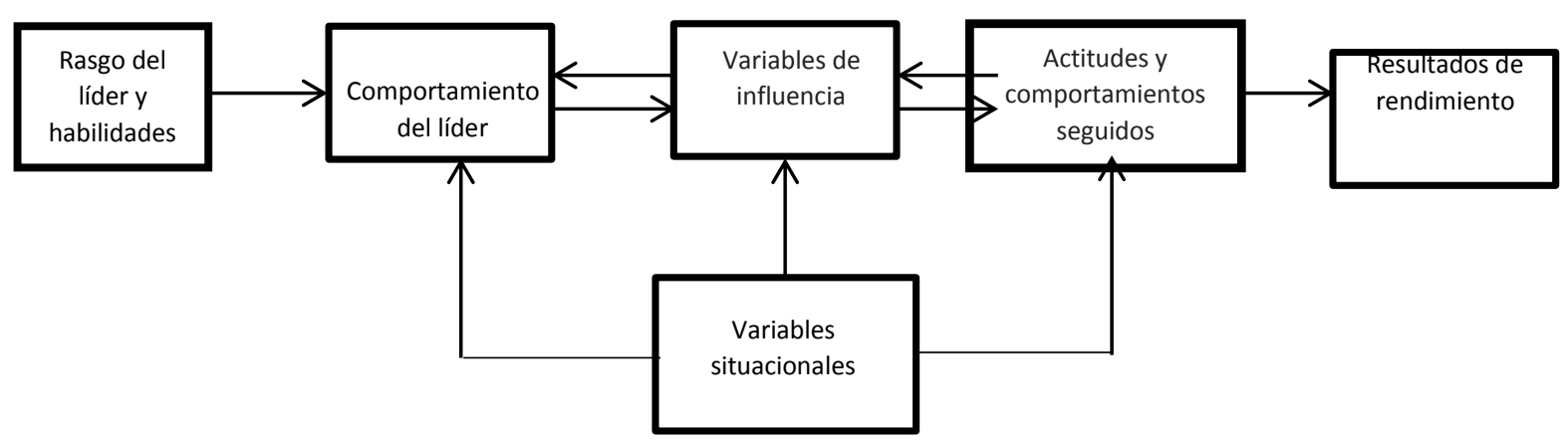

Figura 2.4. Relación causal entre los tipos primarios de procesos de liderazgo

En las investigaciones de Yukl (2010) se establece que el líder efectivo es capaz de influenciar realizando una eficiente selección de los diversos mecanismos existentes para influenciar y persuadir a sus colaboradores/as. Se destacan tres elementos claves en este proceso de liderazgo e influencia social: 1) Líder, 2) Colaboradores/as, y 3) Contexto.

En el contexto organizacional, la eficacia de los gestores depende de su influencia sobre los/as superiores y compañeros/as, así como sobre todo la influencia que puedan ejercer sobre sus colaboradores/as. Para desarrollar un liderazgo efectivo es necesario 
influenciar en los/as colaboradores/as para llevar a cabo las peticiones, propuestas de apoyo, y ejecutar decisiones.

La influencia es entendida como el efecto de la acción de una parte (el agente), sobre otra (el objeto) (Yukl, 2010). Cuando la influencia se enfoca en las personas, la influencia puede ser sobre actitudes, percepciones, comportamientos o combinaciones de ambos. El proceso de influenciar sobre los/as demás puede provocar tres efectos: compromiso, complacencia/conformidad y resistencia (Yurkl, 2010).

En primer lugar, el compromiso es el resultado idóneo, ya que el/la colaborador/a se muestra internamente de acuerdo con la decisión o petición del/la líder esforzándose en llevarlo a cabo de la forma más eficaz. En segundo lugar, la complacencia o conformidad, que describe un resultado en el que el/la colaborador/a realizará lo que le pide el/la líder pero de forma apática y no entusiasta aplicando el mínimo esfuerzo. Cuando se trata de tareas sencillas el impacto de este efecto no es importante ya que lo que interesa es que se realicen, sin embargo, cuando son tareas y solicitudes de actividades más complejas, la falta de compromiso real puede provocar dificultades a la hora de tener éxito. En tercer y último lugar, la resistencia, que se basa en que el/la colaborador/a se opone a la propuesta y activamente intenta evitarla con varias formas de resistencia como por ejemplo, negándose a realizar lo que se le requiere, poniendo excusas que no puede llevarse, tratando de convencer al líder que lo solicitado no se puede realizarse, pidiendo a las autoridades superiores que anulen la petición realizada por su líder, retrasando su ejecución esperando que su líder se olvide, o en grado extremo saboteando la tarea.

La influencia de una persona sobre otra involucra los motivos y percepciones de la meta en relación con las acciones del agente y el contexto en que se produce la interacción. 
Kelman (1958) propone tres tipos diferentes de procesos de influencia: cumplimiento instrumental, internalización y de identificación personal.

A nivel organizacional, Yukl (2010) sugiere que existen dos grandes factores por lo que el líder puede influenciar sobre los demás: el poder y las tácticas de influencia del/la líder.

a) Poder

El concepto de poder es entendido como la capacidad de una persona o grupo (agente) para influir en otro u otros (objeto) (Yukl, 2010) y se puede dividir en siete tipos distribuidos en dos categorías, 1) poder formal y 2) poder personal, según el origen venga del puesto y de la autoridad otorgada dentro de la organización, o su origen sea la propia persona (ver Tabla 2.4).

Tabla 2.4: Tipos de Poder (Yukl y Tracey, 1992, Yukl, 2010)

\section{Poder por Posición}

Legitimo

Recompensa

Coercitivo

Información

Ecológico

\section{Poder Personal}

Referente

Experto

\section{b) Tácticas de influencia}

Durante las últimas dos décadas, en lugar de centrarse exclusivamente en el poder como fuente de influencia potencial, los investigadores han comenzado a examinar el comportamiento específico utilizado para ejercer influencia. Este tipo de comportamiento 
utilizado intencionalmente para influir en las actitudes y el comportamiento de otra persona por lo general se denomina "mecanismos/estrategias de influencia" o "tácticas de influencia”. Las tácticas de influencia se definen como un concepto independiente pero a su vez, relacionado con el poder. Así pues, las tácticas de influencia es el poder en acción, mientras que el poder es la influencia potencial. El ejercicio de influencia hacia personas sobre las que no posee gran autoridad formal resulta especialmente relevante en muchas organizaciones actuales caracterizadas por estructuras que se alejan de las tradicionales formas jerárquicas y se orientan hacia estructuras más planas y cooperativas.

Dentro de la influencia en el contexto organizacional se pueden identificar tácticas reactivas y tácticas proactivas. Las tácticas reactivas son aquéllas que se utilizan una vez se ha producido la conducta del colaborador/a y, por tanto, tienen carácter correctivo, su objetivo es controlar y corregir. En contraposición, las tácticas proactivas son aquellas que se utilizan antes de que se produzca la conducta del colaborador/a con el objetivo de motivar una conducta o provocar una reacción. Las tácticas proactivas tienen carácter preventivo y se consideran las más efectivas.

A continuación, se recogen en la Tabla 2.5 las tácticas de influencia proactivas, sobre los que se ha habido un mayor consenso sobre su validez y son las más citadas en la literatura (Yukl, 2010).

Tabla 2.5: Tipos de Tácticas de Influencia (Yukl, 2010)

\begin{tabular}{ll}
\hline Táctica de Influencia & Conceptualización \\
Persuasión Racional & Implica el uso de explicaciones, argumentos lógicos y evidencia para \\
& demostrar que una solicitud o propuesta es factible y pertinente a la \\
& consecución de los objetivos establecidos para una tarea. Una forma \\
& débil de la persuasión racional puede incluir sólo una breve explicación \\
& de la razón de la solicitud, o una afirmación indocumentada que una \\
& propuesta de cambio deseable y factible. Formas más fuertes de la \\
& persuasión racional incluyen una explicación detallada de las razones \\
& por las cuales es importante una petición o propuesta de cambio. Esta \\
\hline
\end{tabular}


Apelación a los beneficios personales

Apelación a las emociones

Consulta

Tácticas de cambio-Negociación

Colaboración

Apelación a la confianza mutua

Impresión Positiva

Legitimidad

Presión táctica es más apropiado cuando la persona objetivo comparte los mismos objetivos de tareas como el gerente, pero no reconoce la propuesta es la mejor manera de alcanzar los objetivos.

Se explica que beneficios personales puede obtener la persona objetivo si cumple con las propuestas que se le plantean. Un beneficio puede ser mejorar la carrera del colaborador, hacer más interesante el trabajo de la persona, que va a aprender cosas nuevas e interesantes., mejorar su reputación, en definitiva se centra en los beneficios a alcanzar por parte del colaborador/a objetivo y no en los objetivos organizacionales.

En contraste con los argumentos lógicos utilizados en la persuasión racional en esta táctica el objetivo es despertar emociones fuertes en el colaborador/a para generar compromiso con el trabajo a realizar vinculándolo con los valores e ideales de la persona. Se trata de despertar en los demás el deseo de ser importante, sentirse útil, llevar a cabo un trabajo excepcional. Para que sea efectivo, el agente (en este el líder) debe de tener una idea previa de los valores, esperanzas y miedos de la persona o grupo. De igual modo la eficacia también depende de las habilidades de comunicación del/la líder para utilizar imágenes vivas y metáforas, manipular símbolos, y emplear la voz y los gestos para generar entusiasmo y emoción.

Se utiliza como táctica de influencia partiendo de la base que el líderagente-ya tiene claro o el plan que hay que desarrollar pero busca influenciar en el colaborador/a haciéndole partícipe para conocer si tiene alguna duda o inquietud al respecto.

Se utiliza sobre todo cuando el colaborador/a no quiere y se resiste a realizar una propuesta de trabajo ya que no le ofrece beneficios importantes e implica molestias En este caso el líder negocio una serie de incentivos que puede aplicar al colaborador/a si cumple con lo propuesto Si el colaborador/a no aprecia que en realidad el líder va a cumplir con lo propuesto no realizará la tarea.

Consiste en ayudar al colaborador/a a realizar la solicitud de propuesta de trabajo exigida proporcionándole todos los recursos necesarios que necesita para llevarla a cabo.

Consiste en pedirle al colaborador/a que realice un trabajo s fuera de las responsabilidades del colaborador/a y le pide como una muestra de hacer un favor personal al líder. "Hazlo por mi'”. No funciona si el colaborador/a no le disgusta el líder o les indiferente lo que ocurra con él.

Ofrecer adulación en positivo sobre el colaborador. Cuando se ofrece de forma positiva y sincera tiende a reforzar la relación entre ambos y genera la posibilidad del colaborador/a a realizar la solicitud del/la líder. Pero no es útil para la inmediatez de realizar una solicitud, es una estrategia que funciona a largo plazo pues mejora las relaciones positivas con los colaboradores/as.

Implica intentos de establecer la propia autoridad o el derecho al reclamo para realizar una petición. Puede ser necesaria cuando se solicita algo inusual o cuando el colaborador/a no sabe quién tiene o quien es la autoridad. En este caso hay que hacer referencia a que se trata de una petición coherente con la organización y las reglas internas, a los estatutos o con las condiciones de contratación.

Incluyen amenazas, advertencias y la conducta asertiva de repetir lo que hay que hacer o comprobar si se ha cumplido el trabajo. Dan éxito si el colaborador/a está apático o hay síntomas de vagancia al igual que es necesario cumplir con una norma o política organizacional Sin embargo, las medidas de presión fuertes como las amenazas y 
advertencias son susceptibles de causar resentimiento y socavar las relaciones de trabajo.

Coalición Implican obtener ayuda de otras personas para influir en el colaborador

Para Yukl, hasta los años 80 el proceso de influencia del/la líder sobre los/as colaboradores/as se centraba en el análisis de sus aspectos cognitivos, dejando de lado el factor emocional como variable moduladora en la influencia entre ambos. Esta tendencia en los últimos años se ha corregido y actualmente el factor emocional aparece como un elemento fundamental a considerar en la explicación del proceso de influencia (Yukl, 2010). Tal y cómo se ha podido observar en la Tabla 2.5, el aspecto emocional se sugiere como una de las tácticas proactivas de influencia del/la líder sobre sus colaboradores/as. Incluso se apunta a que puede llegar a ser la respuesta de cómo los/as líderes inspiran a sus colaboradores/as a ir más allá de la defensa de sus intereses personales y vitales, como puede ser el caso en ciertas profesiones en las que se arriesga la vida por una causa superior (Bomberos, militares). No obstante, la integración de los procesos racionales, emocionales y su interacción se sugiere que puede ser la respuesta combinada sobre la influencia ejercida así como de los efectos sobre los agentes que intervienen en el proceso (Yukl, 2010). Por ejemplo, un estudio realizado por investigadores españoles de la Universidad Pablo de Olavide, y de la Universidad de Sevilla (Martínez-Cots, Munduate-Jaca, y Medina-Diaz, 2008) ejemplifica la necesidad de integración de lo emocional y racional a la hora de ejercer influencia por parte de los/as líderes. Estos investigadores buscaban conocer qué nivel de efectividad tenían las diversas tácticas basadas en la propuesta de Falbe y Yukl (1992). Para ello agruparon las tácticas en tres grupos: a) Racionales, b) Duras (presión y legitimización por autoridad) y c) Blandas (incluyen aspectos personales y adulación y aspiraciones dónde entren en juego la influencia a través de las emociones). Midieron su nivel de efectividad para conseguir mayor compromiso, mayores niveles de 
bienestar y satisfacción entre sus colaboradores/as. Los resultados mostraron que los/as líderes más efectivos eran aquellos/as que tenían un patrón de comportamientos que aglutinaba variedad de tácticas de los tres grupos. Es decir, los/as líderes que eran más influyentes eran los/as que combinaban tácticas racionales, duras y blandas a diferencia de los/as que únicamente utilizaban únicamente un grupo de tácticas. Por tanto, los resultados apuntan a que la efectividad de influencia pasa por la integración y selección de diversas tácticas de influencia, tanto emocionales, como racionales.

\subsubsection{Enfoques teóricos en el estudio del liderazgo.}

En esta revisión sintética y breve de los diversos enfoques teóricos que han intentado explicar cómo funciona y que efectos provoca el liderazgo, siguiendo a Antonakis

y House (2002), se ha procedido a clasificarlos en dos grupos: teorías tradicionales y teorías modernas (New-Genere Leadership), distinción que es adoptada por otros autores a la hora de revisar las investigaciones sobre liderazgo (Avolio et al., 2009; Gil, Alcover, Rico y Sánchez-Manzanares, 2011).

El primero grupo reúne las teorías tradicionales desarrolladas desde principios del siglo pasado hasta finales de los años 70 . El segundo grupo engloba las teorías más recientes y actuales. Estas modernas teorías de liderazgo se refieren a aquellas teorías que han sido predominantes a partir de los años 80 (Antonakis y House, 2002).

\subsubsection{Teorías Tradicionales.}

a) Teoría de los Rasgos. 
La teoría de los rasgos sugiere que los/as líderes manifiestan ciertas características de personalidad, físicas o aspectos sociales, que influyen para que la persona actúe como un líder efectivo. Dominaba la idea de que el liderazgo es una cualidad de "grandes hombres" cuyos atributos personales les confiere la posición de líder. En esta época, la investigación no se ocupaba en estudiar o comprender los estilos de liderazgo, el foco de la investigación se centró en diferenciar a los/as líderes de los/as colaboradores/as y en diferenciar a los/as líderes eficaces de los/as ineficaces (Kaiser y DeVries, 2000). De las diversas investigaciones en busca de los rasgos que definían el/la verdadero/a líder destacan las de Stogdill $(1948,1974)$. Este autor llegó a la conclusión que un perfil con rasgos personales específicos no determinan un éxito asegurado en el ejercicio del liderazgo. Más bien lo que sugiere, a raíz de los resultados obtenidos en sus investigaciones, es que una persona con ciertos rasgos tiene más probabilidades de convertirse en un/a líder eficaz, sin embargo, en sí mismo, dichos rasgos no garantizan la eficacia (Moreira, 2010). Las dudas generadas abrieron el espacio al análisis de otras variables como los comportamientos y la situación en la que acontece el proceso de liderazgo.

Si bien es cierto que la teoría de rasgos fue abandonada durante años, recientemente ha resurgido debido a la aparición del estudio de nuevos tipos de liderazgo como el carismático y el auténtico (Palomo 2013; Wagner y Hollenbeck, 2004).

\section{b) Enfoque de la conducta}

Los estudios denominados "centrados en la conducta" engloban una serie de investigaciones realizadas en los años 50 y 60 del siglo pasado cuyo interés venía a ser los denominados "estilos de liderazgo", o "estilo de dirección". Estudiaban exclusivamente lo que los/as líderes hacen y cómo lo hacen (su conducta). Las investigaciones fueron llevadas 
principalmente desde el Ohio State Leadership Center (Stogdill y Coons, 1957), la Universidad de Michigan (Kahn y Katz, 1953; Mann, 1965), además de por Blake y Mouton (1964).

Según este enfoque, los/as líderes contribuyen al logro de las metas de la organización a través de dos dimensiones independientes: preocupación o interés por la tarea, y preocupación por las personas. Generalmente, ambas dimensiones se cruzan en un eje de coordenadas en el que se sitúan los diferentes estilos de liderazgo:

1. Interés por la tarea: Es el grado en el que un/a líder fomenta altos niveles de productividad, organiza y define las actividades del grupo en función de los objetivos de este. Mantiene la comunicación en un solo sentido, descendente, explicando lo que se debe de hacer a los/as empleados/as en su puesto de trabajo.

2. Interés por las personas (o centrado en la relación): Es el grado en el que el/la líder se preocupa por las necesidades, intereses, problemas, desarrollo, de los/as demás miembros del grupo. Mantiene comunicación de doble vía (ascendente y descendente) con sus colaboradores/as, aportando apoyo emocional.

\section{c) Enfoque situacional}

Con el objetivo de cubrir la falta de explicación de lo que sucede ante diversas situaciones y variables, surgió el enfoque situacional que se centraba en los aspectos contextuales/situacionales (características de los/as colaboradores/as, el contexto, la tarea a realizar) que afectan la relación del/la líder con sus colaboradores/as. Según esta aproximación, no existe un mejor y un único estilo de líderes, todo depende de la situación. Las teorías bajo este enfoque explican de qué modo los/as líderes deben de comportarse 
dependiendo de la situación para ser eficaces. Este enfoque engloba dos tipos de categorías dónde se agrupan las diferentes teorías.

La primera subcategoría considera el comportamiento del/la líder como una variable dependiente de la situación estando expuesto a la influencia de determinados aspectos como las políticas de la organización, la cultura organizativa, las relaciones con los clientes, las expectativas del capital humano conformado por colaboradores/as y autoridades, etc. Dentro de esta categoría se apoyan teóricamente en 1) Teoría del Rol (Kahn, Wolfe, Quinn Snoelk, y Rosenthal, 1964), por la cual se describe cómo la situación influye en la conducta de dirigir por medio de las expectativas de rol de superiores, pares, colaboradores/as y personas ajenas a la organización., 2) la Teoría Demandas-Constricciones-Elecciones (Stewart, 1976, 1982), la cual relaciona la cantidad y calidad de las relaciones de los/as líderes con subordinados/as, pares, superiores o personas fuera de la organización, con la naturaleza del trabajo si es auto-generado o reactivo, repetitivo o variable, incierto o predecible, con o sin urgencias 3) el Modelo de Influencia Múltiple (Hunt y Larson, 1982; Osborn y Hunt, 1975) que tiene en cuenta la influencia de determinantes situacionales a un nivel macro y micro sobre la conducta del/la líder.

La segunda subcategoría (teorías de contingencia) supone que los diferentes patrones de comportamientos son necesarios para un liderazgo eficaz en diferentes situaciones. En esta categoría se encuentran las teorías de contingencia que han tenido una gran influencia posterior en la investigación del liderazgo y su aplicación en el contexto organizacional. Se describen las teorías de mayor relevancia dentro de esta subcategoría.

\section{Modelo Contigencial de Fiedler (1967)}


La eficacia del/la líder depende de dos factores: sus atributos (orientación a la tarea o a la relación) y el control que tiene de la situación (grado de favorabilidad de la situación). Fiedler considera que el/la líder eficaz es aquel/aquella que puede modificar los elementos situacionales (incluyendo la estructuración de la tarea) con el fin de adaptarlos a su propio estilo de liderazgo. Según esta teoría los/as líderes más orientados/as hacia las tareas son más eficaces en situaciones de alto o bajo control (alta o baja favorabilidad) (Fiedler, 1967). En contraste, los/as líderes más orientados/as a las personas son más eficaces en situaciones de control moderado. Posteriormente, la Teoría de los Recursos Cognitivos (CRT) modificó el modelo original añadiendo algunos rasgos del/la líder y señalando la importancia de factores como el estrés para la efectividad del/la líder (Fiedler y García, 1987).

\section{Teoría Path-Goal (House, 1971).}

Esta teoría combina elementos de los estudios de la Universidad Estatal de Ohio y de la Teoría Motivacional de las Expectativas (Vroom, 1964). El término Path-Goal (camino-meta) proviene de la creencia de que los/as líderes efectivos/as deben de mostrar el camino a seguir a sus colaboradores/as hasta alcanzar la meta establecida reduciendo las barreras y dificultades que surjan. El rol del/la líder es apoyar a sus colaboradores/as para que alcancen sus metas, y facilitarles la dirección necesaria y/o el apoyo para asegurarse de que sus metas sean compatibles con los objetivos generales del equipo o de la organización. Los factores contingentes pueden deberse al ambiente (estructura de las tareas, sistema de autoridad formal, grupo de trabajo), o a los propios/as colaboradores/as (locus de control, experiencia y habilidad percibida). 


\section{Modelo Normativo de Vroom y Yetton (1973)}

Este modelo desarrollado por Vroom y Yetton (1973) y luego revisado por Vroom y Jago (1990) relaciona la conducta del/la líder y la participación, con la toma de decisiones en el contexto de la organización. Plantean siete alternativas de liderazgo como procesos de decisión para problemas tanto grupales como individuales (desde autocrático a delegador), las cuales estarían condicionadas por doce variables situacionales materializadas en preguntas que se relacionan con la percepción del "propio líder”, pero no de sus colaboradores/as, sobre sus actividades dentro de la organización y sobre el manejo de las decisiones y la participación (Mellado, 2005).

4. Modelo de Hersey y Blanchard (1969, 1988, Hersey, Blanchard, y Johnson 1999): Liderazgo Situacional

Sin duda es una de las teorías que ha tenido mayor aceptación tanto a nivel académico como en la aplicación en cuadros directivos "se ha incorporado a los programas de formación para el liderazgo de más de 400 de las 500 compañías de la revista Fortune y se piensa que sus elementos básicos se enseñan en más de un millón de gerentes al año” (Robbins y Judge, 2009, p. 395).

Esta teoría utiliza básicamente tres dimensiones (Gordon, 1997; Hellrieger y Slocum, 2009; Palomo, 2013; Robbins y Judge, 2009):

a) Comportamiento de dirección: Es el comportamiento relativo a la tarea, la cantidad de dirección que un/a líder proporciona sobre qué hacer, cuándo hacerlo y cómo hacerlo. 
b) Comportamiento de apoyo: Es el comportamiento relativo a las relaciones, la cantidad de apoyo emocional que el/la líder otorga al colaborador/a, escucha, motiva, implica a los/as colaboradores/as.

c) Madurez de los/as colaboradores/as: Integra dos tipos de madurez: en el cargo (conocimiento, experiencia, competencia para realizar la función) y psicológica (confianza en sí mismos/as, el compromiso y la motivación para realizar la función encomendada).

A la hora de aplicar un estilo de dirección el/la líder debe de realizar una lectura del nivel de madurez de sus colaboradores/as en una función en concreto y aplicar el tipo de comportamiento o de tarea que se precise. Por ello, dependiendo del grado de combinación de los dos tipos de madurez es posible identificar cuatro niveles:

Madurez 1: la persona no puede (no tiene los conocimientos o las habilidades) ni está preparada psicológicamente (seguridad en sí misma) para enfrentar la responsabilidad de la tarea: no sabe- ni quiere

Madurez 2: la persona tiene un grado mínimo de conocimiento o habilidades, se siente motivado a aprender, pero se percibe inseguro para asumir la responsabilidad completa por la tarea: no sabe-si quiere

Madurez 3: la persona cuenta con los conocimientos y habilidades necesarios para hacer la tarea, al punto que se siente preparado/a para hacer sus propios aportes en el qué y cómo hacer, por lo tanto no está dispuesto/a a seguir lo que el/la líder le pide: sabe-no quiere 
Madurez 4: la persona puede y quiere hacer la tarea; se siente preparado/a, seguro/a y experimenta una satisfacción intrínseca y un sentimiento de copropiedad frente a lo que se debe hacer: sabe-quiere

Una vez el/la líder ha identificado el nivel de madurez del colaborador/a aplicará un estilo de dirección para que se alcancen los resultados previstos en la tarea. A niveles más bajo de madurez el/la líder debe de utilizar estilos directivos enfocados a la orientación de tareas. A medida que el/la colaborador/a muestra una mayor madurez debe priorizar la utilización de la orientación a la persona cercana al empoderamiento.

Existen cuatro tipos de estilos directivos que se corresponden con el nivel de madurez del colaborador/a en la función específica a realizar (ver Tabla 2.6) 
Tabla 2.6: Niveles de Madurez y Estilo de Liderazgo

\begin{tabular}{ll}
\hline Nivel de Madurez & Tipo de Estilo Directivo \\
M1-NO SABE- NO QUIERE & Los/as colaboradores/as necesitan una \\
& clara orientación respecto de lo que se \\
& espera de ellos y una definición de los \\
& objetivos, procedimientos y estándares de \\
& calidad sobre los resultados. Es necesario \\
dar órdenes y dirigir & Debe de ir instruyendo y guiando al mismo \\
tiempo que se va generando conexiones & interpersonales \\
M4. SI SABE-SI QUIERE & Se va potenciando el apoyo socioemocional \\
M3-SI SABE-NO QUIERE & ya que los colaboradores tienen mejor \\
& desempeño y no se necesita marcar tanto \\
& las instrucciones. El líder debe de apoyar \\
& \\
&
\end{tabular}

La diagramación aplicada del modelo teórico de Hersey y Blanchard se aprecia en la siguiente Figura 2.5. 


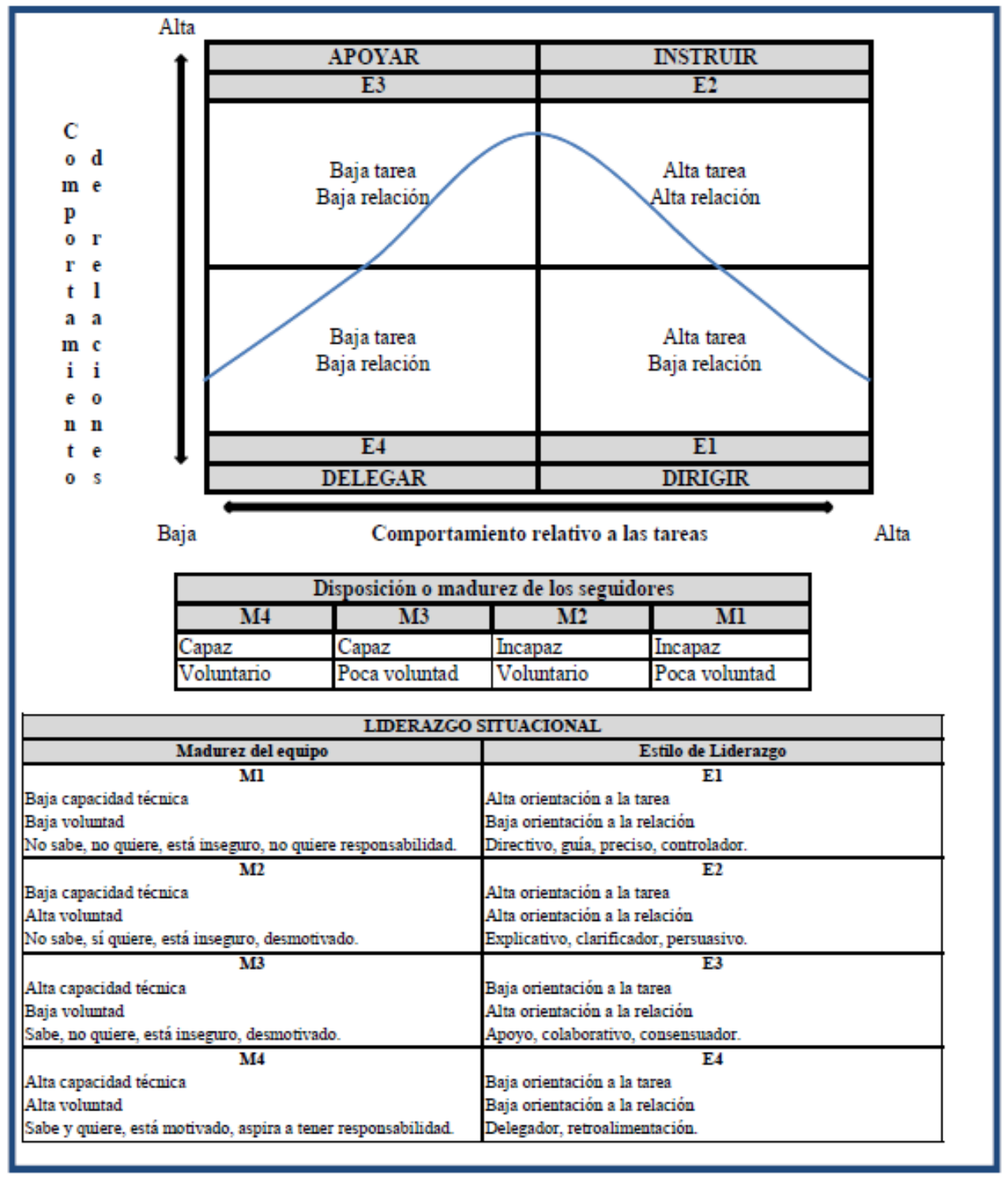

Figura 2.5: Liderazgo Situacional: Basado en Blanchard et al., 1993, Adaptado por Fernández-Iglesias (2013) 
Uno de los puntos a favor de esta teoría y que, se está recogiendo en el estudio actual del liderazgo, es que se debe de considerar al colaborador/a y sus diferencias individuales en el momento de aplicar un tipo de estilo de liderazgo determinado. Por tanto, la diversidad y flexibilidad a la hora de disponer y aplicar varios estilos de dirección es transcendental. En el liderazgo situacional el colaborador/a influenciaba en el líder ya que en función de su nivel de madurez el/la líder actuaba de una manera u otra dependiendo de su nivel de habilidad y/o actitud para realizar una función determinada. Esta idea de la importancia del colaborador/a y de cómo sus factores internos modulan el proceso de liderazgo la recogen en la actualidad autores como Gardner, Cogliser, Davis y Dickens (2011), abriendo un nuevo modo de tener en cuenta el liderazgo bajo un concepto de bidireccionalidad.

\section{d) Teoría de los Vínculos Múltiples (Yukl, 1981,1989)}

Como marco contextual considera que el desempeño de la unidad de trabajo depende principalmente de seis variables intervinientes: esfuerzo de los miembros, capacidad de los miembros, organización del trabajo, relaciones de equipo y cooperación, disponibilidad de recursos esenciales y (para los/as gerentes medios y bajos) coordinación externa con otras partes de la organización. Algunas variables situacionales influyen de manera directa en las variables intervinientes y otras variables situacionales determinan la importancia relativa de cada variable interviniente en una situación particular (Yukl, 1981).

Los/as líderes pueden influir en estas variables intervinientes de muchas formas, aunque los efectos de la conducta del/la líder dependen en parte de la situación. A corto plazo, la mayoría de las acciones del/la líder intentan corregir deficiencias en las variables 
intervinientes, mientras que, a largo plazo, los/as líderes buscan hacer la situación más favorable mediante acciones tales como implementar programas de mejoramiento, iniciar nuevas actitudes o productos, formar coaliciones para ganar más control sobre los recursos' modificar la estructura formal y cambiar la cultura de la unidad. (Yukl, 1989)

e) Teoría LMX-(Leader-Member Exchange)-Teoría del Intercambio del/la líder-miembros $(I L M)$

La premisa fundamental de este enfoque es que existen diferencias entre los tipos de intercambio establecidos entre líderes y colaboradores/as. Los líderes establecen relaciones cercanas sólo con algunos de sus colaboradores/as y estos intercambios pueden ser catalogados como de alta calidad con ellos (Graen y Uhl-Bien, 1995; Gerstner y Day, 1997)

En sus inicios fue denominada Modelo de Interacción Vertical (Danserau, Graen y Haga, 1975), pero luego evolucionó hacia la conceptualización como Teoría del Intercambio de Líder y Miembros (ILM). La teoría se centra en una díada, es decir, la relación entre el/la líder y cada colaborador/a considerada de forma independiente. Cada vinculación o relación, es probable que difieran en calidad. Por lo tanto, el/la mismo/a líder puede tener malas relaciones interpersonales con algunos/as colaboradores/as y, por el contrario, con otros/as puede tener una relación abierta y de confianza. El/la líder establece relaciones especiales con ciertos/as miembros del grupo, su "grupo de confianza", a los/as que presta mucha más atención y es más probable que reciban privilegios especiales, incluyéndolos/as en la toma de decisiones y en las consultas ante aspectos organizacionales fuera de su ámbito de trabajo, mientras que el resto del equipo recibe menos tiempo, menos información y las relaciones son más formales. 
Es la primera teoría que postula que el/la líder no se comporta de igual forma con todo el equipo que dirige. Esta teoría pronostica que los/as colaboradores/as con el estatus de "grupo de confianza" tienen calificaciones más altas de desempeño, menos rotación y mayor satisfacción con sus superiores/as. Los resultados de las investigaciones a lo largo de varios años confirman estas hipótesis avalando que los/as colaboradores/as que reciban esa influencia positiva del/la líder en atención, confianza, más allá de lo formal, obtienen mayores resultados de desempeño y satisfacción (Schriesheim, Castro y Cogliser, 1999). Recientemente se ha encontrado que los/as colaboradores/as dentro del grupo de confianza de su líder tienen una mayor productividad, satisfacción, mayor motivación, compromiso y participan en más conductas de colaboración (Chen, Lam, y Zhong, 2007; Ilies, Nahrgang, y Morgeson, 2007). El punto negativo que puede existir es que el/la líder genere un grupo que excluya a los/as demás miembros de su equipo dejándolos fuera de su círculo íntimo por lo que reciben menos atención, menos recompensas y son gestionados por las normas y políticas formales de la organización (Lunenburg, 2010). Al centrarse y dar más atención fuera de los aspectos formales a una serie de colaboradores/as se reafirma la profecía autocumplida, ya que los/as líderes se centran más en aquellos/as que piensan que son los/as más competentes siendo esta profecía la que facilita precisamente alcanzar los resultados previstos ya que invierten más sus recursos en aquellos/as (Eden, 1993).

\subsubsection{Teorías Modernas}

Tal y como recoge Valsania (2014) este grupo de teorías denominadas modernas se refieren a las teorías que han predominado a partir de los años 80 (Antonakis y House, 2002). En ese periodo, derivado del desencanto existente con las anteriores teorías basadas 
principalmente en una idea de liderazgo transaccional basado en intercambio, surgen nuevas teorías dónde el/la líder toma un rol de inspirador, transformador (Bass, 1985), que promete altos resultados En ese período, concretamente en 1985, y como respuesta a un malestar por la falta de modelos teóricos que diesen explicación y herramientas de aplicación, Bernard M. Bass publica el libro Leadership and Performance Beyond Expectations, donde argumenta de la superioridad de un nuevo estilo de liderazgo: el Liderazgo Transformacional, que frente al liderazgo tradicional basado en intercambios, que él denomina Liderazgo Transaccional, promete unos resultados que sobrepasan expectativas. A partir de la aparición de este nuevo tipo de liderazgo, comienzan a desarrollarse otros modelos teóricos derivados del transformacional como el liderazgo carismático e inspiracional (Barbuto y Burbach, 2006; Conger y Kanungo, 1987; House y Shamir, 1993), considerados modelos de liderazgo de gran impacto que ofrecían resultados superiores. Estos nuevos modelos teóricos fueron estudiados de forma empírica para validar su aplicabilidad, por lo que durante algo más de una década se vivió la "edad dorada" del liderazgo transformacional convirtiéndose en el nuevo paradigma que se enseñaba en las Universidades y Escuelas de Negocio más prestigiosas del planeta (Avolio et al., 2009). En la actualidad aparece el modelo de liderazgo resonante (Goleman, Boyatzis, McKee, 2002), derivado del modelo de inteligencia emocional de Goleman (1998), así como una serie de modelos nuevos amparados en la Psicología Positiva y el respeto a valores éticos que los denominados líderes pseudotransformacionales habían abandonado con la utilización de malas prácticas organizacionales y egoísmo recalcitrante. 


\section{1) Liderazgo transformacional.}

Entre las primeras proposiciones dentro de este nuevo paradigma emerge con fuerza el liderazgo transformador, el cual hace referencia a los procesos de influir cambios importantes en las actitudes y suposiciones de los/as miembros/as de la organización y el incremento del compromiso con la organización, sus objetivos, estrategias y su misión empresarial. El liderazgo transformacional implica la influencia del/la líder en sus colaboradores/as para hacerles participar en el proceso transformador de la organización. Así este tipo de liderazgo es visto normalmente como un proceso compartido que implica acciones de los/as líderes en diferentes niveles y en diferentes unidades organizacionales y/o las acciones del máximo ejecutivo junto a sus colaboradores/as (Burns, 1978).

Los/as líderes transformacionales inspiran a sus colaboradores/as a trascender sus intereses personales por el bien de la organización y son capaces de tener un efecto profundo y extraordinario sobre sus ellos/as (Casado, 2000). Están constantemente atentos/as a las tensiones y necesidades de desarrollo de sus colaboradores/as. En lo individual modifican la percepción de los problemas de sus colaboradores/as al ayudarlos/as a ver la nueva situación así como los problemas existentes. Desde una nueva perspectiva inspiradora son capaces de emocionar, despertar e inspirarlos para que hagan un esfuerzo adicional que permita alcanzar las metas del equipo. El liderazgo transformacional puede dar lugar a importantes cambios y resultados en la organización, ya que transforma al personal para que procure los objetivos de la organización en vez de sus propios intereses. Esta transformación de los/as colaboradores/as se logra induciendo cambios en sus objetivos, valores, necesidades, creencias y aspiraciones. Los/as líderes 
transformacionales prestan atención individualizada, estímulo intelectual, escucha activa y poseen carisma que moviliza al grupo.

Las teorías que estudian el/la líder transformacional resaltan cómo los/as líderes son estimulantes para los colaboradores/as, los/as motivan para alcanzar logros que van más allá de sus propias expectativas e intereses personales ampliando sus habilidades. Estas teorías realzan el papel del/la líder como un elemento inspirador ya que a través de sus comportamientos y palabras direccionan la visión organizacional incrementando así el rendimiento del equipo. Este tipo de líderes tienen un comportamiento ejemplar y logran convertir su visión en la visión del equipo, motivan, muestran confianza en sus colaboradores/as y en su punto de vista (Bass y Riggio, 2005; Gil et al., 2011; Molero, Recio y Cuadrado, 2010; Robbins y Judge, 2009).

El modelo de liderazgo transformacional de Bass y Avolio (1994) es el que más aceptación ha tenido organizando su enfoque bajo dos tipos de liderazgo complementarios: El transaccional, que se orienta al refuerzo eventual de los/as colaboradores/as para alcanzar los objetivos del/la líder; y el transformacional, que influye en los/as colaboradores/as para lograr que éstos/as asuman los objetivos del/la líder como propios. Ambos tipos de liderazgo se basan en el comportamiento del/la líder y su influencia sobre los/as colaboradores/as, pero difieren en el método: el transaccional se caracteriza en un intercambio y el transformacional se basa en creencias y valores. Con respecto al liderazgo transformacional, los autores lo descomponen en cuatro importantes características: a) estimulación intelectual, b) consideración individual, c) influencia de atributos e d) influencia de comportamientos (Avolio et al., 2004; Bass y Avolio, 1994; Ismail et al., 2010; Pillai et al., 1999). El modelo completo de Bass y Avolio (ver Figura 2.5) integra 
trece sub-escalas que corresponden a conductas que pueden presentar los/as líderes, seis corresponden al Liderazgo transformacional.

Por último, con el fin de evaluar el efecto de las sub-escalas transformacionales y transaccionales de los/as líderes en los/as colaboradores/as se pueden ofrecen tres variables de resultado que son: Satisfacción, Esfuerzo extra y Efectividad (ver Figura 2.6).

\section{Modelo de Liderazgo Transaccional y Transformacional de Bass y Avolio}

\begin{tabular}{|c|c|c|c|c|c|c|c|c|c|c|c|c|}
\hline \multicolumn{6}{|c|}{ Lider Transformacional } & \multicolumn{3}{|c|}{$\begin{array}{c}\text { Líder } \\
\text { Transaccional }\end{array}$} & \multirow{2}{*}{$\begin{array}{c}\text { No } \\
\text { Liderazgo }\end{array}$} & \multicolumn{3}{|c|}{$\begin{array}{c}\text { Variables de } \\
\text { Resultado }\end{array}$} \\
\hline \multicolumn{2}{|c|}{ Carisma } & \multirow[b]{2}{*}{ 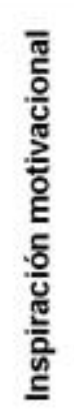 } & \multirow[b]{2}{*}{ 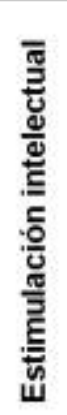 } & \multirow[b]{2}{*}{ 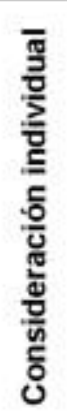 } & \multirow[b]{2}{*}{ 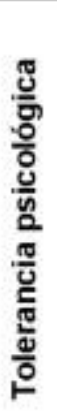 } & \multirow[b]{2}{*}{ 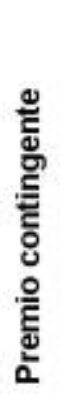 } & \multirow[b]{2}{*}{ 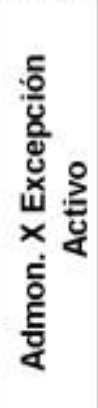 } & \multirow[b]{2}{*}{ 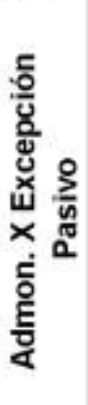 } & & \multirow[b]{2}{*}{ 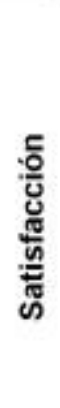 } & \multirow[b]{2}{*}{ 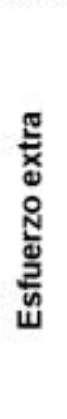 } & \multirow[b]{2}{*}{ 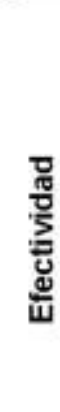 } \\
\hline 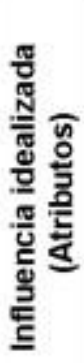 & 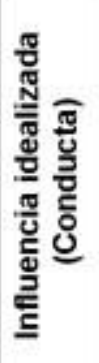 & & & & & & & & 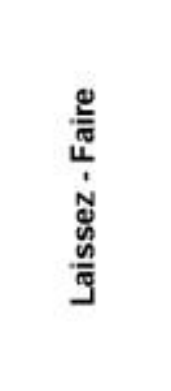 & & & \\
\hline 1 & 2 & 3 & 4 & 5 & 6 & 7 & 8 & 9 & 10 & 11 & 12 & 13 \\
\hline
\end{tabular}

Figura 2.6: Modelo de Liderazgo Transaccional y Transformacional Bass y Avolio (1997)

Tal y como recogen Avolio, Walumba y Weber (2009) durante la última década, un gran esfuerzo de investigación se ha invertido en la comprensión de los procesos mediante los cuales los/as líderes transformacionales influyen positivamente a sus colaboradores/as en el cambio de actitudes, comportamientos y rendimiento. Por ejemplo, existen estudios que han estudiado el efecto del/la líder transformacional en sus colaboradores/as en el compromiso, satisfacción, identificación percibida y equidad (Liao y Chuang, 2007, Walumbwa et al., 2008); las características del trabajo, tales como variedad, identidad, 
significado, autonomía y retroalimentación (por ejemplo, Piccolo y Colquitt, 2006);

confianza en el/la líder (por ejemplo, Wang et al., 2005); y cómo los colaboradores/as se llegan a sentir acerca de sí mismos/as y su grupo en términos de eficacia, potencia, y cohesión (por ejemplo, Bass et al., 2003; Bono y Juez de 2003, y Schaubroeck et al., 2007).

\section{2) Liderazgo resonante}

Este tipo de liderazgo es una derivación del modelo de inteligencia emocional de Goleman $(1995,1998)$. Este tipo de liderazgo aparece en el libro "El líder resonante crea más” en su versión española (2006) escrito por Daniel Goleman, Richard Boyatzis, y Annie Mckee. Para los autores la tarea principal del/la líder "es despertar los sentimientos positivos de sus subordinados, y esto ocurre cuando un líder produce resonancia, es decir, el clima emocional positivo indispensable para movilizar lo mejor del ser humano. La tarea fundamental del liderazgo es emocional" (Goleman, Boyatzis, y McKee, 2006, p. 17). Una de las ideas principales que subyace en este modelo es que las emociones se contagian y tienen su efecto en los/as colaboradores/as tanto en las relaciones, el clima laboral como el desempeño obtenido (Goleman, Boyatzis, y McKee, 2002). Además, estos autores distinguen dos tipos de liderazgo, el liderazgo resonante y el liderazgo disonante.

El liderazgo resonante es aquel que sintoniza con los sentimientos de las personas y los encauza en una dirección emocionalmente positiva. Cuando el/la líder expresa con sinceridad sus valores y sintoniza con los/as colaboradores/as puede llegar a transformar positivamente su estado de ánimo incrementando la motivación y la energía en el trabajo. A esta reacción de influencia la denominan resonancia, la cual provoca que, cuando el/la líder se sincroniza con las emociones de los/as colaboradores/as se produzca un efecto de 
vibración emocional sobre el/la colaborador/a resonando la emoción positiva en él. Los autores originalmente lo denominan "liderazgo primal" siendo la resonancia el mecanismo por el cual se prolonga el impacto emocional del/la líder sobre los/as colaboradores/as.

En otro sentido, el liderazgo disonante implica la falta de armonía entre el/la líder y sus colaboradores/as provocando un distanciamiento y efectos negativos en los/as colaboradores/as. En este tipo de liderazgo, el/la líder que muestra comportamientos de enfado, el miedo, la apatía y la hosquedad induce en el/la colaborador/a una respuesta básica de lucha o huida que incentiva los conflictos laborales (Baron, 1990).

Los autores consideran que el liderazgo emocionalmente inteligente oscila en una dimensión que va desde la resonancia a la disonancia, como dos polos opuestos que dependen de un par de variables, el tono emocional y la sincronía empática. El tono emocional del/la líder dependiendo si es positivo o negativo provocará un impacto positivo o negativo en el/la colaborador/a. La sincronía empática es conceptualizada como empatía, entendiéndola como el grado de sincronía emocional que existe entre el/la líder y sus colaboradores/as. A mayor sincronía emocional entre ambos más se acercan al polo de liderazgo resonante, y al contrario, cuanto más se aproximan a un tipo de liderazgo disonante (Goleman, Boyatzis, y McKee, 2002). Los/as líderes emocionalmente inteligentes bajo este modelo alientan a sus colaboradores/as cierto grado de bienestar que les lleva a compartir las ideas, aprender los unos/as de los/as otros/as, asumir responsabilidades y contrarrestar las posibles variables contextuales que pueden afectar al grupo, por el contrario los disonantes son dinamitadores de relaciones.

Desde de un punto de vista de efectividad los autores aclaran que existen seis tipos, o estilos de liderazgo y que el/la mejor líder es el/la que es capaz de utilizarlos y pasar de 
uno a otro dependiendo de la situación. La resonancia por tanto es vista como el resultado del modo en que utiliza los diferentes tipos de estilos de liderazgo. Cuatro de ellos (el visionario, el coaching, el afiliativo, y el democrático) promueven el liderazgo resonante, mientras que los otros dos (timonel y el autoritario) son útiles en situaciones muy concretas. A continuación se recogen los diferentes estilos de liderazgo y las situaciones recomendadas en su uso (ver Tabla 2.7). 
Tabla 2.7: Estilos de Dirección (adaptado de Goleman, Boyatzis, y McKee, 2002)

\begin{tabular}{|c|c|c|c|}
\hline Estilo de Liderazgo & Como Alienta la Resonancia & Impacto sobre el Clima & Cuando Utilizarlo \\
\hline Visionario & $\begin{array}{l}\text { Esboza un objetivo común que } \\
\text { resulta movilizador }\end{array}$ & Es el más positivo de todos & $\begin{array}{l}\text { Cuando la necesidad } \\
\text { de cambiar requiere de } \\
\text { una nueva visión o } \\
\text { dirección }\end{array}$ \\
\hline Coaching & $\begin{array}{l}\text { Establecimiento puentes de } \\
\text { conexión entre los objetivos }\end{array}$ & Muy positivo & $\begin{array}{l}\text { Contribuye a que un } \\
\text { trabajador mejore su } \\
\text { actividad o le ayude a } \\
\text { desarrollar su potencial } \\
\text { a largo plazo }\end{array}$ \\
\hline Afiliativo & $\begin{array}{l}\text { Estableciendo un clima de } \\
\text { relación armónica }\end{array}$ & Positivo & $\begin{array}{l}\text { Cuando se necesita } \\
\text { salvar diferencias } \\
\text { existentes entre los } \\
\text { miembros de un } \\
\text { equipo, motivarlos en } \\
\text { situaciones críticas o } \\
\text { fortalecer las } \\
\text { relaciones }\end{array}$ \\
\hline Democrático & $\begin{array}{l}\text { Tiene en cuenta los valores } \\
\text { personales y estimula el } \\
\text { compromiso }\end{array}$ & Positivo & $\begin{array}{l}\text { Cuando es necesario } \\
\text { llegar a un acuerdo }\end{array}$ \\
\hline Timonel & $\begin{array}{l}\text { Establece objetivos desafiantes y } \\
\text { estimulantes }\end{array}$ & $\begin{array}{l}\text { Inadecuadamente aplicado } \\
\text { suele ser muy negativo }\end{array}$ & $\begin{array}{l}\text { Para conseguir que un } \\
\text { equipo competente y } \\
\text { motivado alcance } \\
\text { resultados excelentes }\end{array}$ \\
\hline Autoritario & $\begin{array}{l}\text { Elimina el temor } \\
\text { proporcionando una dirección } \\
\text { clara en situaciones críticas }\end{array}$ & $\begin{array}{l}\text { Muy negativo, porque } \\
\text { suele aplicarse de un modo } \\
\text { inadecuado }\end{array}$ & $\begin{array}{l}\text { Cuando se requiere } \\
\text { realizar un cambio } \\
\text { muy rápido o con } \\
\text { trabajadores } \\
\text { conflictivos }\end{array}$ \\
\hline
\end{tabular}

Los autores toman como una referencia obligatoria para la comprobación de su postulado teórico las investigaciones realizadas en Johnson \& Johnson (Carvallo, 2002). En esta investigación, los/as líderes que habían sido altamente cualificados poseían casi todas las competencias descritas en su modelo por el cual la inteligencia emocional se dividía en cuatro dimensiones: conciencia de uno mismo, autogestión, conciencia social, y gestión de las relaciones. 


\section{3) Liderazgo de servicio (Sirviente)}

El concepto original de este tipo de liderazgo es Servant-Leadership y se debe a Robert Greenleaf. La idea que recoge este pensador estadounidense es que en el proceso del liderazgo los/as colaboradores/as son el objetivo, y la misión del/la líder es servirlos/as. Esa es parte de su grandeza como líder, ser siervo primero (Greenleaf, 1970). En su obra El Siervo como Líder (The Servant as Leader, 1970) es dónde se exponen las ideas básicas teóricas de este tipo de liderazgo que más tarde serían ampliadas por el continuador de su obra Larry Spears. Según Spears (1996), el liderazgo de servicio tiene como prioridad a los/as otros/as, y desde un punto de vista holista del trabajo, destaca la importancia de servir a los/as demás, promocionar un sentido de comunidad, así como facilitar el intercambio de poder en la toma de decisiones Esta idea de liderazgo contiene cuatro pilares básicos:

a) Servir al prójimo: La motivación y el propósito principales de un/a líder de servicio es animar a que los/as colaboradores/as se desarrollen.

b) Enfoque integral en el contexto laboral: El enfoque es que el puesto de trabajo debe de considerar a la persona en todos sus planos alentando a que se actué en el trabajo como se es en la vida personal.

c) Promover un sentido de comunidad: Sostiene que sólo la comunidad como grupos de individuos que son responsables solidarios el uno para el otro de forma individual y como una unidad pueden realizar una función de dotar de servicios "humanos".

d) Toma de decisiones participativa: En el liderazgo servidor el poder no se acapara ni acumula, sino que se comparte. 
Según Smith (2005) de la bibliografía revisada sobre este tipo de liderazgo se confirman diez características personales como esenciales en la determinación del/la líder de servicio: saber escuchar, empatía, curación, conciencia, persuasión, conceptualización, prospectiva, sirviente de la organización, compromiso con el crecimiento de las personas, y comunidad.

A pesar del impacto y la buena acogida de los escritos de Robert Greenleaf, su teoría ha recibido numerosas críticas por la falta de apoyo empírico a la misma (Stone, Russell y Patterson, 2003). Algunos autores como Lee y Zemke (1993) argumentan que la teoría es poco realista y que no tiene en cuenta, entre otras cuestiones, los niveles de competencia entre individuos. De igual modo se le achaca sus postulados religiosos más que empresariales a la hora de definir lo que es liderazgo (Sendjaya, 2002).

No obstante, el punto fuerte de la teoría de liderazgo de servicio es que en el momento de su aparición dio un giro en la forma de entender el liderazgo. Se pasó a considerar como variables fundamentales al/la líder y la situación, al centrarse en el/la colaborador/a y de ahí al líder. El liderazgo de servicio destacó sobre todo la necesidad de tener en cuenta el punto de vista del colaborador/a en el proceso de liderazgo. Y sobre todo, abrió el camino a la importancia de la autorrealización del colaborador/a como el eje más importante para las organizaciones. A diferencia del liderazgo transformador dónde el desarrollo personal y el empoderamiento de los/as colaboradores/as es visto como un medio para lograr el objetivo organizacional, en el liderazgo de servicio la meta son los/as colaboradores/as. 


\section{4) Liderazgo ético.}

Para la revisión de este tipo de liderazgo existe un trabajo realizado por Sofía Unda (2013) sobre el liderazgo ético en dirigentes universitarios que se utilizará como base de estudio. El liderazgo ético, que recoge muchas de las ideas anteriormente citadas, surge como respuesta a la necesidad de contar con líderes que tengan principios y valores éticos que den respuesta a las situaciones de corrupción, mal manejo de información contable y financiera que se iniciaron a principios de esta década. Solomon argumentó que:

"el ejemplo de los ejecutivos de los niveles más altos resulta de importancia crucial. Si es patente que ellos pasan por alto los principios y las disposiciones del código en su comportamiento, no hay probabilidades de que nadie más de los que trabajan en la compañía tome el código en serio” (Solomon, 2000, p. 53).

El liderazgo ético se entiende necesariamente desde un componente relacional que se explica a través de la calidad de las interacciones establecidas entre el/la líder y sus colaboradores/as, así como el/la líder consigo mismo/a (Unda, 2013). Aunque históricamente aparecen en los escritos de pensadores clásicos como Aristóteles, Sócrates, o Confucio, las bases éticas que deben de tener las grandes personalidades, la primera vez que aparece como un factor clave para el liderazgo fue con Chester Barnad (1938) que señaló que el liderazgo está compuesto esencialmente de dos dimensiones: ética o responsabilidad y técnica. Una de las definiciones más respetadas por la comunidad científica es la aportada por Brown, Treviño y Harrison (2005) que lo definen como la manifestación de la conducta adecuada a través de las acciones personales y las relaciones 
interpersonales, y la promoción de dicha conducta a los colaboradores/as a través de la comunicación de dos vías: el refuerzo y la toma de decisiones. Según Unda (2013), el liderazgo ético se relaciona con cuatro tipos de liderazgo: liderazgo transaccional, transformacional, resonante (ya que todos ellos se centran en la eficacia y desempeño organizacional), y por último, el liderazgo de servicio (al compartir con el ético la importancia de tener en cuenta y satisfacer las necesidades de los demás como objeto de actuación).

Dentro del reciente estudio del liderazgo, y su relación con la ética personal y organizativa, destaca la aportación de Treviño et al. (2003, 2005) y los estudios de Kanungo y Mendoca (1996). Treviño y su equipo, a raíz de una serie de estudios (2005) y con la finalidad de medir el constructo, determinaron diez características para definir lo que es el liderazgo ético y poder sintetizar el constructo y generar una escala de medición. La escala se denomina Ethical Leadership Scales y contempla los siguientes factores:

1. Escuchar lo que los/as empleados/as tienen que decirle.

2. Aplicar medidas disciplinarias a los/as empleados/as que violan los estándares éticos.

3. Conducir su vida personal de manera ética.

4. Tener en la cabeza las mejores intenciones con relación a sus empleados/as.

5. Hacer siempre justicia y tomar decisiones equilibradas.

6. Ser dignos/as de confianza.

7. Discutir con los/as empleados/as sobre temas éticos o valores.

8. Exponer claramente ejemplos sobre cómo ser éticos/as y hacer las cosas correctamente en la organización. 
9. Tener en mente los intereses de los/as empleados/as.

10. En el proceso de toma de decisiones, preguntar siempre a sus colaboradores/as sobre la mejor manera de hacer las cosas.

Un hallazgo importante de los estudios de Treviño es que el liderazgo ético está positivamente relacionado con la conducta ejemplar del/la líder, la justicia en las relaciones, la honestidad del/la líder, así como con la variable la influencia idealizada (idealized influenced) propia del liderazgo transformacional. También encontraron una relación positiva con el sentimiento de confianza en el/la líder y una relación negativa cuando los/as colaboradores/as perciben un abuso de autoridad (Treviño, 2005).

Uno de los modelos de referencia más utilizados para determinar la composición de los factores del liderazgo ético es el de Kanungo y Mendoca (1996), el cual señala que las dimensiones éticas de este tipo de liderazgo son:

a) Motivaciones del/la líder (por el cual la motivación que impulsa los comportamientos de los/as líderes debe ser altruista)

b) La formación ética del carácter del/la líder

c) Las estrategias de influencia empleadas por el/la líder se deben de centrar en el empoderamiento de las personas (empowerment)

Este modelo ha sido de referencia para alguno de los estudios empíricos más importantes que se han realizado sobre liderazgo ético (Khuntia y Suar, 2004).

El liderazgo ético se deriva de una dimensión personal y de los valores que cómo persona definen al líder. Tal y cómo se aprecia en esta teoría, y que recoge la obra de Sonnenfeld y Gómez, el liderazgo ético se explica desde una dimensión personal. En este sentido, “sin comportamiento ético personal no hay liderazgo ético” (Sonnenfeld, 2010, p. 
109). Con respecto a los valores los diversos autores de la literatura revisada coinciden en que en el/la líder ético/a, los valores y principios que más frecuentemente se encuentran son la integridad, la honestidad (Bennis, 2001; Covey 1993; Badaracco y Ellsworth, 1989), y la responsabilidad (Barnad, 1938).

Recientemente se ha publicado una importante metaanálisis que confirma la validez de criterio del liderazgo ético con las siguientes variables: actitud de los trabajadores/as, el desempeño laboral, y las evaluaciones de sus líderes (Thomas y Feldman, 2015). Una de las últimas tendencias del estudio del liderazgo ético es analizar si tiene impacto en aspectos como, clima laboral, equidad, justicia, resultados organizacionales, y la satisfacción laboral. Finalmente, es de destacar como uno de las tendencias actuales es el estudio de la relación del liderazgo ético con la eficiencia organizacional. En este sentido existen estudios que destacan como el liderazgo ético se relaciona positivamente con el desempeño laboral (Walumbwa, Mayer, Wang, Wang, Workman, y Christensen, 2011; Bouckenooghe, Zafar, y Raja, 2014 y Pucic, 2015)

\section{5) Liderazgo auténtico}

En estos últimos años surge con fuerza la teoría del liderazgo autentico dentro del desarrollo de la Psicología Positiva. El concepto de "autenticidad" tiene una larga tradición desde la época de la Grecia clásica y pasa por la Psicología Humanista (Avolio y Gardner, 2005). Tal y cómo describen Moriano, Molero y Lévy- Mangin (2011), la aplicación de este concepto al campo del liderazgo surge hace aproximadamente una década con un gran auge, en los últimos años, tanto a nivel académico como el contexto aplicado, debido a dos razones: la situación de crisis económica que se arrastra desde hace años, y el 
comportamiento decepcionante de los/as líderes políticos a la hora de respuestas efectivas ante la situación generada. Por ello, se recogen las ideas previas del liderazgo de servicio y del liderazgo ético para demandar un tipo de liderazgo basado en principios, valores éticos y morales. Al mismo tiempo, esta demanda de un nuevo tipo de liderazgo se asocia con el auge de la Psicología Positiva dónde se empieza a estudiar cómo el liderazgo se relaciona con los aspectos de la autorrealización de los/as colaboradores/as. La Psicología Positiva ha cambiado el enfoque de la psicología tradicional y se ha centrado en el desarrollo de las cualidades positivas y el desarrollo de las fortalezas de las personas (Seligman y Csikszentmihalyi, 2000). Dentro de la Psicología de las Organizaciones, este enfoque se ha aplicado al análisis del comportamiento organizacional positivo y al capital psicológico positivo (Luthans, 2002; Luthans, Avolio, Avey, y Norman, 2007). Y aplicado al liderazgo, esta nueva orientación ha dado como resultado el liderazgo autentico.

La primera publicación sobre el liderazgo auténtico se titula Authentic Leadership: A Positive Development Aproach (Luthans y Avolio, 2003) y aparece como un capítulo del libro Positive Organizational Schoolarship, con la finalidad de integrar el trabajo de Luthans (2002) sobre conducta organizacional positiva y el trabajo de Avolio (1999) sobre desarrollo de liderazgo y ciclo de vida. La conducta organizacional positiva (Luthans, 2002) es definida como el estudio y aplicación de las fortalezas y capacidades psicológicas de las personas, orientadas positivamente, que pueden ser medidas, desarrolladas y gestionadas para el beneficio de la organización (Luthans, 2002). El modelo de liderazgo auténtico integra estos planteamientos al plantear que los/as líderes auténticos son capaces de fomentar entre sus colaboradores/as este tipo de capacidades y comportamientos 
positivos, los cuales a su vez, predicen positivamente el rendimiento organizacional (Yammarino et al., 2008).

El liderazgo auténtico se puede definir como un patrón de conducta que promueve y se inspira tanto en las capacidades psicológicas positivas como en un clima ético positivo, para fomentar una mayor conciencia de uno/a mismo/a, una moral internalizada, un procesamiento de la información equilibrado y transparencia en las relaciones entre el/la líder y los/as colaboradores/as (Walumbwa et al., 2008).

La idea central del liderazgo autentico es que es que este tipo de líderes lo que hacen es acelerar el desarrollo de la autenticidad de los/as colaboradores/as. Este incremento de la autenticidad de los/as colaboradores/as contribuirá a su bienestar y al logro de un verdadero rendimiento que sobrepasa expectativas y que se mantiene a lo largo del tiempo favoreciendo que aparezcan efectos positivos en las organizaciones en las que trabajan (Valsania, 2014).

Bajo estas consideraciones, el liderazgo autentico es visto como un proceso social de influencia en el que el/la líder una vez realiza una identificación personal y social describe esperanza, confianza, y emociones positivas que provocan cambios actitudinales y comportamentales en los/as colaboradores/as (ver Figura 2.7). 


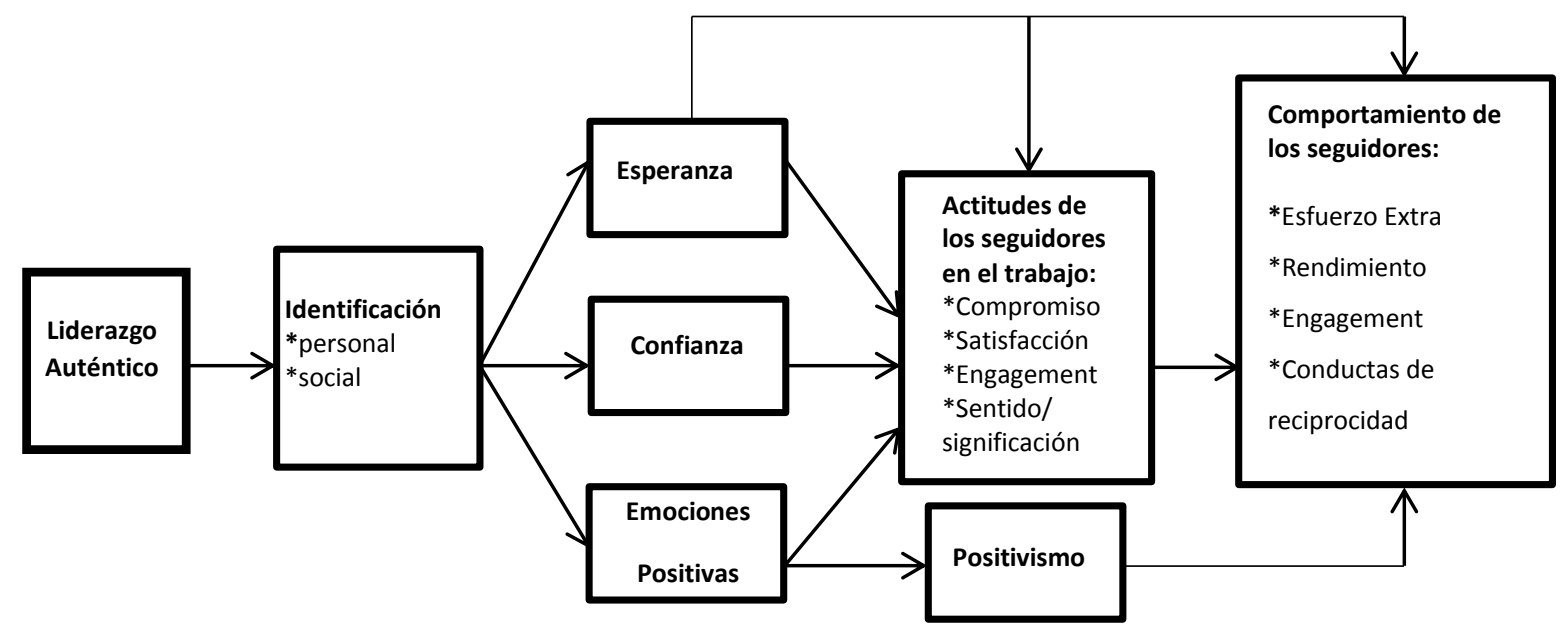

Figura 2.7: Proceso del Liderazgo Auténtico sobre los colaboradores. Adaptada por Valsania (2014) de Avolio et al. (2004, p. 803).

La investigación sobre el liderazgo autentico propone varios mecanismos por los cuales se produce el proceso de esta influencia: contagio emocional, apoyo a la autodeterminación, e intercambios sociales positivos.

Tal y como describe Moriano et al., (2011) se establecen diferencias con otros tipos de liderazgo que han aparecido en los últimos años. Con respecto al liderazgo ético se diferencia en que el liderazgo autentico no solamente utiliza una dirección moral para guiar e impulsar un comportamiento ético en los/as colaboradores/as. El liderazgo auténtico abarca más que el ser ético, ya que descansa en otros tres componentes: conciencia de uno/a mismo/a, un procesamiento de la información equilibrado, y transparencia en las relaciones entre el/la líder y los/as colaboradores/as (Walumbwa et al., 2008). La diferencia con el liderazgo transformacional es que el liderazgo auténtico se entiende como un proceso de intercambio por el cual el/la líder influye en los/as colaboradores/as, y no por el carisma o 
inspiración del/la líder como argumenta el liderazgo transformacional, sino por el carácter del/la líder, su dedicación y su conducta ejemplar y transparente.

Walumbwa et al., (2008) agruparon los diversos comportamientos que muestran los/as líderes auténticos en cuatro dimensiones que posteriormente fueron operacionalizadas en el instrumento que se está siendo utilizado en las diversas investigaciones que se están realizando actualmente denominado Authentic Leadership Questionnaire (ALQ, Walumba et al., 2008). Esta herramienta ha sido traducida y validada en distintos idiomas. En 2011, Moriano, Molero y Levy-Mangin publican la adaptación y validación de este instrumento al castellano. Las cuatro dimensiones que conforman el liderazgo autentico son:

\section{Conciencia de sí mismo/a}

Esta dimensión no solo consiste en la visión tradicional de conocer las fortalezas, áreas de mejora, valores y motivaciones propias. Incorpora también la conciencia sobre los aspectos contradictorios, sesgo y mecanismos de defensa, y sobre todo, en ser consciente de cómo los actos y comportamientos propios influyen de forma decisiva en los/as colaboradores/as y el contexto organizacional (Gardner et al., 2005; Illes et al., 2005; Luthans y Avolio, 2003). La conciencia de sí mismo/a se verá facilitada por el feedback que los/as propios/as colaboradores/as puedan facilitar así como el dominio de las diversas habilidades que integran la inteligencia emocional (Mayer y Salovey, 1997).

\section{Procesamiento equilibrado}

Los/as líderes auténticos/as analizan objetivamente datos y hechos, tanto externos como autorreferentes, a la hora de tomar una decisión, no sesgando sus percepciones y decisiones por motivos de autodefensa, autoensalzamiento y/o autoprotección (Gardner et 
al., 2005). Un/a líder autentico/a no busca únicamente información que asegure su punto de vista sino que se muestra abierto/a a otros puntos de vista y opiniones distintas que le hagan crecer. Al mismo tiempo, el procesamiento equilibrado se encuentra en la base de la integridad personal, influenciando significativamente en las decisiones y acciones estratégicas del/la líder (Ilies et al., 2005).

\section{Perspectiva moral internalizada}

Hace referencia a que los comportamientos de los/as líderes auténticos/as están sustentados por fuertes estándares morales y éticos frente a las posibles presiones grupales, sociales u organizacionales. Resultando en acciones dirigidas en todo momento para servir a los intereses colectivos, pudiendo suceder a veces, que entren en conflicto directo con los

propios intereses personales (Avolio, Sivasubramaniam, Murry Jung, y Garger, 2003). Para ello, los/as líderes auténticos/as tienen que tener un nivel de autoconocimiento de cuáles son los valores y principios éticos que gobiernan su forma de ser y comportarse. La existencia de una perspectiva moral internalizada fundamentada en valores y motivos basados en la sinceridad y el logro de un bien común facilitaría que los/as líderes auténticos/as puedan desarrollar relaciones transparentes, sinceras y honestas (Ilies et al., 2005).

\section{Transparencia relacional}

Se distinguen dos grupos de conductas dentro de esta dimensión. En primer lugar, las conductas que hacen referencia al hecho de compartir abiertamente información por parte de los/as líderes auténticos/as y estimular a que sus colaboradores/as hagan lo mismo (Avolio y Gardner, 2005; Luthans y Avolio, 2003; Gardner et al., 2005). El/la líder autentico/a ánima a que se comparta información por muy dura e incómoda que resulte 
escuchar con el objetivo de mejorar. Este tipo de comportamientos crean una cultura de apertura y crecimiento organizacional. En segundo lugar, las conductas que tiene que ver con la transparencia y apertura de los factores internos del/la líder auténtico/a. Cuando el/la líder auténtico/a conecta con su yo interno y actúa en consecuencia, se produce una conexión sincera sobre uno/a mismo/a que es el primer paso para tener relaciones con los/as colaboradores/as basadas en la sinceridad y honestidad; una vez conoce sus principios morales, valores y emociones los transmite de forma abierta a los/as demás. Este proceso de apertura interna favorece que se construyan con sus colaboradores/as relaciones de confianza e intimidad, lo que va a facilitar el trabajo en equipo y la cooperación (Gardner et al., 2005), por lo que este componente es clave para generar confianza en los/as colaboradores/as.

Diversas investigaciones, utilizando el ALQ, sugieren que este tipo de liderazgo permite mejorar la satisfacción, el compromiso y el rendimiento de los/as colaboradores/as (Caza, Bagozzi, Woolley, Levy y Caza, 2010; Clapp-Smith, Vogelgesang y Avey, 2009; Walumbwa, Avolio, Gardner, Wernsing y Peterson, 2008). De igual modo, estudios en diferentes culturas como China (Walumbwa et al., 2008), Estados Unidos (Clapp-Smith et al.,2009; Walumbwa et al., 2008; Walumbwa, Luthans, Avey y Oke,2009), Kenia (Walumbwa et al., 2008) y Nueva Zelanda (Caza et al., 2010), apuntan que el liderazgo autentico está positivamente relacionado con el capital psicológico colectivo, la satisfacción laboral y la satisfacción de los/as colaboradores/as con el/la líder, las conductas de ciudadanía organizacional, la confianza, el compromiso organizacional y el rendimiento laboral. 
Los/as líderes auténticos/as generan actitudes positivas de los/as empleados/as hacia su trabajo. Por ejemplo, varios estudios han mostrado que el liderazgo auténtico se relaciona de forma positiva con la implicación en el trabajo (work engagement) de los/as colaboradores/as (Giallonardo, Wong y Iwasiw, 2010; Walumbwa et al., 2010). De esta forma, cuanto más auténticos/as son los/as líderes, mayores son los niveles de vigor, dedicación y absorción de los/as empleados/as hacia su trabajo. En esta misma dirección, también se ha observado que los/as líderes auténticos/as fomentan la identificación de los/as empleados/as con ellos/as y que cuanto más se identifican los/as colaboradores/as con sus líderes, mayor será su implicación en el trabajo (Walumbwa et al., 2010).

\subsection{Influencia de la inteligencia emocional en el liderazgo}

Una vez revisada las diversas teorías de liderazgo existentes, se observa que el liderazgo es un proceso interacción social de influencia y de intercambio entre el/la líder y sus colaboradores/as. Siguiendo la revisión teórica, en este punto se intentará despejar dos incógnitas: ¿es importante la inteligencia emocional en los/as líderes? y ¿qué efectos produce la inteligencia emocional de los/as líderes en sus colaboradores/as?

\subsubsection{Primera cuestión: Importancia de la inteligencia emocional en los líderes}

Las funciones básicas que un/a líder debe desempeñar en una organización según

Caruso y Salovey (2005) son: 1) creación de equipos eficaces, 2) planificar y decidir eficazmente, 3) motivar a los demás, 4) comunicar los objetivos, 5) fomentar los cambios, y 6) crear relaciones interpersonales eficaces. 
En este marco de desempeño funcional del/la líder, las emociones son una herramienta importante para lograr las metas de la organización, para motivar personas y equipos, para fomentar la satisfacción y el compromiso, y para influir en el contexto laboral (Avolio y Gardner, 2005; Bass, 1997; George, 2000).

Actualmente la gestión del capital intelectual y de las personas, es la gestión más importante que favorece que, en un mercado tan competitivo y global post-industrial, unas empresas se distingan de la competencia gracias al valor del conocimiento y talento que aportan sus trabajadores/as del siglo XXI. Los elementos emocionales subyacen a la dinámica de muchos aspectos de las organizaciones modernas, y el papel de la inteligencia emocional en el liderazgo se debe considerar mientras se elaboran y ejecutan las políticas, los procesos y procedimientos de la organización. Welch (2003) argumentó que la inteligencia emocional permite a los equipos aumentar su rendimiento en una época donde el trabajo en equipo es esencial. Su investigación demostró que al igual que los individuos, los equipos más eficaces son los emocionalmente más inteligentes, y que cualquier equipo puede mejorar y alcanzar niveles más altos de la inteligencia emocional. La inteligencia emocional es considerada como un activo intangible que determina la diferencia entre el rendimiento individual y su actuación como integrante de un equipo (Ajay Goyal y Akhilesh 2007).

La importancia de la inteligencia emocional en el liderazgo se sustenta fundamentalmente en:

- Las teorías de liderazgo emergentes, que se construyen sobre la importancia de situar el elemento humano en primer plano. El liderazgo focalizado en los recursos humanos sustituye al liderazgo focalizado en el control. 
- Los estudios que demuestran que la Inteligencia Emocional favorece el desarrollo de las habilidades directivas esenciales como el trabajo en equipo, la comunicación y por tanto el clima laboral; mejora la adaptabilidad a los procesos de cambio; propicia una solución de conflictos con más facilidad y ayuda a prevenirlos; facilita los procesos de cambio de cultura; favorece la resolución de problemas favorece la integración de equipos; mejora la habilidad de negociar, la creatividad y la flexibilidad para innovar (Guerrero, Govea y Urdaneta, 2006).

Hay que tener en cuenta que en la clasificación tradicional de habilidades de los/as colaboradores/as se les colocaba el apelativo de "habilidades blandas" a aquellas vinculadas a lo intangible, a lo humano, a lo emocional. Y en contraposición se describen las "habilidades duras" aquellas vinculadas a la producción, al dominio financiero contable. En definitiva, se repetía la división entre emocional y racional dando supremacía a lo racional.

Ashkanasy y Daus (2005) identificaron la inteligencia emocional como un elemento esencial potenciador para la promoción efectiva de desarrollo organizacional. En este contexto, el/la líder necesita un alto desempeño en la percepción, comprensión, facilitación y manejo emocional de las emociones propias y de los/as colaboradores/as.

El proceso de liderazgo ha sido visto como un proceso emocional (George, 2000) representando una función critica del liderazgo (Humphrey, 2002, 2008). Bardzill y Slaski (2003) encontraron que los/as líderes organizacionales deben reconocer la importancia del comportamiento emocionalmente inteligente y recompensarlo activamente. Este refuerzo positivo de un ambiente emocionalmente inteligente garantiza el desarrollo de un clima de orientación al servicio. Por ejemplo, hallazgos empíricos demuestran que las emociones del/la líder influyen significativamente en los/as colaboradores/as, tanto en sus reacciones 
emocionales (Bono y Ilies, 2006; Sy, Côté, y Saavedra, 2005) como en el clima laboral (Carvallo, 2002). Con respecto a la salud psicosocial, se ha encontrado evidencia que los/as directivos/as y gerentes con alta inteligencia emocional son capaces de manejar el estrés que afecta al desgaste y calidad de las relaciones laborales (Lopes et al., 2003).

Por último, Sosik y Megerian (1999) describen una relación entre la inteligencia emocional y liderazgo, por la que sugieren que las personas con alta inteligencia emocional pueden tener mayor probabilidad de tener experiencias de liderazgo, y tal vez ser más propensos a ser líderes efectivos.

\subsubsection{Segunda cuestión: Impacto de la inteligencia emocional de los/as líderes en} los/as colaboradores/as.

El rol de la inteligencia emocional en el proceso de liderazgo es destacado por todos los/as autores revisados/as. El postulado general de estos autores/as es que los/as "líderes con alta inteligencia emocional son más capaces de manejar las emociones de los empleados para facilitar rendimiento de los empleados de manera efectiva" (Ashkanasy y Dasborough, 2003, p. 19).

Esta afirmación hay que concretarla y sistematizarla; por ello, en este punto de la investigación se intentará recoger de una forma más sistemática el estado del arte con respecto a qué relación hay entre la inteligencia emocional del/la líder y sus colaboradores/as. De la revisión teórica actualizada se desprenden varios resultados.

El primero de ellos es que la mayoría de estudios que relacionan inteligencia emocional y liderazgo se basan en el modelo teórico que conceptualiza la inteligencia emocional como un modelo de competencias (Goleman, 1995, 1998). De este modelo ha 
derivado el tipo de liderazgo descrito anteriormente como "Liderazgo Resonante" (Goleman, Boyatzis, y McKee, 2002). En segundo lugar, se aprecia que, a pesar que el modelo teórico de inteligencia emocional de Mayer y Salovey (1997) es el que más reconocimiento académico y claridad conceptual se le reconoce, las investigaciones sobre relación de la inteligencia emocional y el liderazgo no han sido muy prolijas, y mucho menos, el análisis de los posibles efectos interpersonales de inteligencia emocional de los/as líderes en sus colaboradores/as. De ahí que escaseen las publicaciones en ambos aspectos. Dentro de estas investigaciones aparecen resultados de como inteligencia emocional se asocia con el desempeño de tareas (Côté y Miners, 2006), el éxito de líderes designados formalmente (Rosete y Ciarrochi, 2005), y la efectividad de hablar en público (Rode et al., 2007) por encima de la inteligencia cognitiva y rasgos de personalidad.

Llama la atención que Caruso y Salovey (2005) realizaron un ligero intento de acercamiento al campo del liderazgo al ofrecer el concepto de lo que denominaron el “directivo emocionalmente inteligente”. En su obra “El Directivo Emocionalmente Inteligente" intentaron dar una tímida visión liderazgo que tuviese en cuenta las emociones en el trabajo así como, la propuesta de incluir las cuatro habilidades emocionales (percepción, facilitación, comprensión, y manejo emocional) en el perfil del/la líder emocionalmente inteligente (Caruso y Salovey, 2005).

Debido a que esta Tesis se centra en el modelo de habilidades de estos autores, se describe con mayor nivel de detalle dos de los estudios de referencia que muestran cómo se relaciona la inteligencia emocional y la aparición del liderazgo en pequeños grupos. Ambos estudios se recogen en el artículo Emotional intelligence and leadership emergence in small groups (Côté, Lopes, Salovey, y Miners, 2010). Este artículo es una de las últimas 
publicaciones encontradas que, siguiendo el modelo de habilidades de la inteligencia emocional (Mayer y Salovey, 1997), estudia la relación de la inteligencia emocional con el liderazgo y su validez predictiva en contraposición a la inteligencia cognitiva y los rasgos de personalidad. El objetivo de ambos estudios era intentar analizar si las habilidades que componen la inteligencia emocional favorecen a que una persona miembro de un equipo sea considerada por el resto como líder por su capacidad de influenciar sobre ellos/as (líder emergente), y de igual forma, intentar averiguar si la inteligencia emocional tiene validez discriminativa en la aparición del liderazgo en comparación con los rasgos de personalidad y la inteligencia cognitiva. La idea inicial de partida es que para que una persona pueda ser considerada como líder es necesario que influya en los demás. La distinción entre un/a líder formal y uno/a emergente es que en el formal la posición del puesto ya marca la definición de líder, mientras en el emergente, y sobre todo en los grupos pequeños que se autogestionan, el/la líder surge espontáneamente influyendo sobre el resto de miembros. Los roles en estos grupos pequeños son flexibles ya que no hay autoridad formal que los regule, de ahí que en estos grupos una persona pueda destacar y aparecer el liderazgo emergente. El diseño de la investigación se dividió en dos estudios. En el estudio 1 se centró en una muestra de 138 estudiantes de un programa de formación de comercio matriculados en un curso de comportamiento organizacional. En primer lugar a los participantes se les paso el MSCEIT V.2.0 así como una escala de autoinforme (Schutte et al., 1998) para evaluar su nivel de inteligencia emocional, y la medición de la variable personalidad fue medida a través de la escala International Personality Item Pool (Goldberg, 1999). Posteriormente se les dio las instrucciones del trabajo técnico que debían de realizar durante 10 semanas, que suponía el $40 \%$ de su nota en la materia, y que consistía, como consultores, en analizar la 
situación de una empresa centrándose en un problema en cuestión para ofrecer un informe de recomendaciones. La duración del trabajo permitiría ver cómo se desarrollaba la influencia a la hora de establecer los objetivos de grupo entre los/as miembros del equipo, cómo organizarse, y cómo se diseñaba las herramientas para el trabajo técnico de consultoría. A la finalización del trabajo técnico los/as participantes evaluaron el liderazgo emergente de cada compañero/a de grupo a través de la escala de liderazgo de CongerKanungo (1994). Los resultados obtenidos concluyeron que la inteligencia emocional y las habilidades para percibir y comprender las emociones estaban significativamente y positivas correlacionadas con el liderazgo emergente. De igual modo, la medida de inteligencia emocional global se relacionaba positivamente con el liderazgo emergente más allá del género y de los rasgos de personalidad (Big Five). Las habilidades para percibir y comprender las emociones también predijeron el liderazgo emergente por encima y más allá de los rasgos de personalidad y género. De las habilidades emocionales, la habilidad de comprender las emociones era la que más fuertemente se correlacionaba con el liderazgo emergente.

En el segundo estudio, se añadió como variables de control la inteligencia cognitiva y el automonitoreo para incrementar la rigurosidad en la prueba de validez incremental para asegurarse que las diferencias individuales no causaron las asociaciones espurias entre la inteligencia emocional y el liderazgo emergente. Los investigadores asignaron al azar a los participantes a los grupos de trabajo para evitar que la autoselección de los grupos explicase los resultados del primer estudio. En este caso, la muestra estuvo formada por 165 estudiantes del mismo programa de comercio matriculados en comportamiento organizacional. Se hizo el mismo procedimiento que en el anterior estudio añadiendo la 
medición de la inteligencia cognitiva, el auto-monitoreo y la mencionada asignación al azar de los/as participantes en cada grupo. Los resultados obtenidos, al igual que en el primer estudio, fueron que se obtuvo una correlación significativa y positiva entre la inteligencia emocional y el liderazgo emergente. Por otro lado, las habilidades para comprender, usar y manejar las emociones se correlacionaron con el liderazgo emergente. Y finalmente se encontró que la inteligencia emocional en general estaba relacionada en mayor medida con el liderazgo emergente que con la inteligencia cognitiva y el género. Al igual que en el primer estudio, la habilidad de comprender las emociones predijo el liderazgo emergente por encima del resto de variables estudiadas.

Esta investigación pone en relieve que la inteligencia emocional se relaciona positivamente con la aparición del liderazgo en pequeños grupos. En los dos estudios, los/as miembros del grupo con mayor inteligencia emocional general exhibieron más surgimiento de liderazgo que sus compañeros/as durante la realización del proyecto independientemente de los rasgos de personalidad y de la inteligencia cognitiva, lo que demuestra que es un constructo útil que puede mejorar la comprensión y la predicción de la conducta en general, y en específico, el liderazgo emergente. Estos resultados también apuntan que las habilidades emocionales son fundamentales para que un/a miembro de un equipo sin rol formal de líder pueda influenciar sobre los/as demás compañeros/as y sea visto/a como un/a líder. De estas habilidades emocionales destaca la comprensión emocional como el predictor más consistente de liderazgo. Incluso se ha podido comprobar que aquellas personas que saben distinguir perfectamente sus emociones pueden tomar mejores decisiones de inversión que aquellas que no. (Seo y Barret, 2007). Por tanto, desde el modelo que construye la inteligencia emocional como un conjunto de habilidades 
emocionales, esta reciente investigación de Côté et al. (2010), muestra como estas habilidades son fundamentales para que se dé la influencia entre el/la líder y los/as colaboradores/as.

Con respecto a la inteligencia emocional del/la líder y su relación con sus colaboradores/as bajo el Modelo de Competencias de la Inteligencia Emocional de Goleman (1995, 1998, 2002) se recoge la opinión de Caruso y Salovey:
"tampoco tratamos de echar por tierra los trabajos sobre la competencia directiva, muchos de ellos con un claro enfoque hacia las emociones. De hecho, las competencias de los directivos y los líderes eficaces descritas por el profesor de gestión Richard Boyatzis y ampliadas por Daniel Goleman están basadas hipotéticamente en la inteligencia emocional "(Caruso y Salovey, 2005, p. 21).

Es por esto que se ha querido recoger algunas de las conclusiones más significativas de algunos de los referentes de esta corriente. El interés de Goleman y Boyatzis tuvo su base en los estudios previos que intentaban explicar qué factores eran los que explicaban con mayor predicción el éxito empresarial. De ahí surgió la búsqueda de las competencias que el/la líder efectivo/a debía poseer para tener un desempeño por encima de la media (McClelland, 1973). La competencia emocional es definida como un comportamiento asociado con la intención de reconocer, la comprensión y el uso de la información emocional sobre uno mismo o los demás que lleva a un rendimiento superior (Boyatzis, 2009). Posteriormente, y a través de los estudios de Richard Boyatzis (1982) y David McClelland (1998) se determinó que la inteligencia emocional y las competencias 
emocionales derivadas de este constructo eran las responsable del $85 \%$ al $90 \%$ de la diferencia entre los líderes destacables y sus iguales más discretos (Goleman, Boyatzis y McKee, 2006). Los autores aclararon que no dejaron de lado el plano cognitivo, pues tal y como explicaron, la base cognitiva es fundamental para poder desempeñar adecuadamente un puesto, pero una vez obtenido este conocimiento previo, la diferencia entre un/a líder efectivo (líder estrella) que tiene resultados por encima de la media de otro/a que no alcance este nivel de desempeño, se encuentra en la utilización de su inteligencia emocional. Para McClelland, los/as líderes que poseen una masa crítica de seis competencias o más de la inteligencia emocional son más eficaces que aquellos/as que carecen de ellas (McClelland, 1998). Goleman y Boyatzis, siguiendo esta tradición de desempeño competencial se apoyan en varios estudios (Boyatzis, 2008; Boyatzis, 2011; Boyatzis, Goleman, y Rhee 2000; Boyatzis y Sala ,2004; Cavallo y Brienza, 2002; Nel 2001; Sergio 2001, Sevinc 2001; Stubss y Wolff, 2008; Wolf, 2008), para defender, la importancia de la inteligencia emocional en el liderazgo actual. Esta importancia se debe que a través de una correcta o incorrecta gestión emocional se puede provocar, la resonancia o disonancia en sus colaboradores/as.

La idea original que las competencias emocionales son aspectos claves para el desempeño laboral eficiente ha ido evolucionando hacia una triada de grupos de competencias que permite establecer un perfil competencial esencial en el mundo empresarial dinámico, globalizado y flexible actual (Boyatzis, 2008). Recientemente, Boyatzis (2011) establece la siguiente clasificación, que recoge la evolución y análisis de competencias laborales durante décadas de estudio y por la cual se estable un perfil competencial de liderazgo que contiene tres tipos de grupos competenciales, a saber: 
1) Competencias cognitivas, tales como el pensamiento sistémico y reconocimiento de patrones.

2) Competencias de la inteligencia emocional, que incluyen conciencia de uno mismo y autogestión.

3) Competencias de inteligencia social, que incluye conciencia social y gestión de las relaciones.

En esta segmentación de las competencias que debe de tener un/a líder para ser efectivo/a en el ámbito laboral, aparece el concepto de inteligencia social que recupera las idea iniciales de Thorndike (1920). La idea que subyace en esta reinterpretación del concepto de inteligencia social es que en la situación de interacción entre el/la líder y sus colaboradores/as, se genera un intercambio de comportamiento social como respuesta a las conexiones neuronales que se producen en ambos cerebros por los cuales acaban influyéndose mutuamente. Tanto Goleman (2006) como Boyatzis (2011), recogiendo los avances de la neuropsicología en el estudio de las sincronías emocionales a través de circuitos cerebrales, han evolucionado en el desarrollo del perfil competencial y en sus últimos artículos desde 2008 incluyen la inteligencia social en el liderazgo, la cual definen como un conjunto de competencias interpersonales incorporadas en los circuitos neuronales específicos y sistemas endocrino relacionados entre sí, que inspiran a otros/as para ser eficaces (Goleman y Boyatzis, 2008). De ahí de nuevo, y desde un punto de vista empresarial en alianza con la consultora HayGroup, se desarrolló el Emotional and Social Competency Inventory (ECSI, Boyatzis, 2007) que ya contempla la dimensión social. Es de destacar una de las últimas investigaciones realizadas por Richard Boyatzis (2012) que sigue defendiendo el peso de la inteligencia emocional como factor clave de éxito en 
contraposición de otras variables. En esta investigación, se comparó el peso de lo cognitivo, lo social y la inteligencia emocional en el éxito de líderes de ventas en el sector financiero. Con ello intentó responder a las críticas sobre la varianza predictiva de la inteligencia emocional y social en el liderazgo efectivo frente a la personalidad y a la inteligencia cognitiva (Davies, Stankov, y Roberts, 1998; MacCann, Roberts, Matthews, y Zeidner, 2003: Harms y Credé, 2010).

El estudio se desarrolló en el año 2012 en una empresa de servicios financieros y la muestra estuvo compuesta por 60 directores/as de división que tenían a su cargo la misión de incrementar las ventas de los productos comercializados por oficina. El objetivo del estudio era analizar y comparar la capacidad de predicción de rendimiento de los/as líderes de ventas (directores/as de división) entre la inteligencia emocional-social, la inteligencia cognitiva (medida como factor g) y la personalidad. La variable de análisis del rendimiento de estos/as directores/as de división fue el número de fuerza de ventas que reclutaron en las diferentes oficinas. El marco teórico del estudio desarrolló la idea de que el/la líder de ventas se caracteriza por influenciar emocionalmente sobre los/as analistas financieros para conseguir los resultados empresariales de ventas, de ahí que un/a líder que gestione efectivamente las emociones, juega un papel importante en la formación de una comunidad emocional en la división en la que trabaja. Los resultados obtenidos a los seis años de la realización del estudio fue que el nivel de inteligencia emocional -social de los/as líderes de venta predijeron mayor rendimiento que su inteligencia cognitiva y los factores de personalidad. Aunque la varianza explicada es pequeña, los resultados obtenidos apuntan a la importancia de la validez predictiva de la inteligencia emocional en el liderazgo emergente o informal. Dentro de las competencias emocionales analizadas se halló que la 
adaptabilidad y la influencia fueron predictores significativos del número de asesores financieros contratados. Estos resultados afianzan la importancia de la inteligencia emocional como factor de rendimiento en el liderazgo efectivo.

Para finalizar, se recoge en las siguientes tablas las investigaciones más importantes que, tanto desde los modelos mixtos (ver Tabla 2.8) como de habilidades (ver Tabla 2.9) relacionan a nivel interpersonal la inteligencia emocional de los/as líderes con diferentes variables laborales de desempeño. La recopilación expuesta tiene como base uno de los últimos metaanálisis publicados y de obligada referencia de estudio, ya que las evidencias encontradas destacan y refuerzan que la inteligencia emocional dispone de una alta validez discriminante por si misma independientemente de la inteligencia cognitiva y de la personalidad (Joseph, Jin, Newman, y O’Boyle, 2014). 
Tabla 2.8: Investigaciones IE (Modelo Mixtos), Liderazgo y Desempeño en el Trabajo.

(Joseph, Newman, Jin, y O’Boyle, 2014)

\begin{tabular}{|c|c|c|}
\hline Autores Estudio & $\begin{array}{l}\text { Instrumento de Medida } \\
\text { Inteligencia Emocional }\end{array}$ & Medida de Desempeño \\
\hline $\begin{array}{l}\text { Austin, Evans, Golwater y Potter } \\
(2005)\end{array}$ & $\begin{array}{l}\text { Austin, Saklofske, Huang, y } \\
\text { McKenney (2004) }\end{array}$ & Desempeño colaboradores \\
\hline $\begin{array}{l}\text { Bachman, Stein, Campell y } \\
\text { Sitarenios (2000) }\end{array}$ & EQ-i (Bar-On, 1997) & Éxito en cobros de deudas \\
\hline Brizz (2004) & ECI (2nd ed; Wolf,2006) & Apoyo financiero \\
\hline $\begin{array}{l}\text { F.W. Brown, Bryant, y Reilly } \\
\text { (2006) }\end{array}$ & EQ-i (Bar-On, 1997) & $\begin{array}{l}\text { Evaluación de los colaboradores } \\
\text { sobre la eficacia del/la líder }\end{array}$ \\
\hline Byrne (2003) & ECI (Sala, 2002) & $\begin{array}{l}\text { Rendimiento del supervisor según } \\
\text { cuestionario de habilidades } \\
\text { gerenciales }\end{array}$ \\
\hline $\begin{array}{l}\text { Byrne, Dominick, Smither, y } \\
\text { Reilly }\end{array}$ & ECI (2nd ed.; Wolff, 2006) & $\begin{array}{l}\text { Valoración de la gestión de los } \\
\text { líderes a través de compañeros de } \\
\text { trabajo }\end{array}$ \\
\hline Carmeli (2003) & Schutte et al. (1998) & $\begin{array}{l}\text { Autoevaluación del desempeño } \\
\text { laboral }\end{array}$ \\
\hline Carmeli y Josman (2006) & Schutte et al. (1998) & $\begin{array}{l}\text { Ejecución de la tarea evaluada } \\
\text { supervisor }\end{array}$ \\
\hline Cavins (2003) & EQ-i (Bar-On, 1997) & $\begin{array}{l}\text { Evaluación del Director sobre } \\
\text { líder estudiantil }\end{array}$ \\
\hline Chipain (2003) & $\begin{array}{l}\text { Success Tendencies Indicator } \\
\text { (STI; (Taccarino y Leonard, } \\
\text { 1999) }\end{array}$ & Objetivo de ventas \\
\hline Drew (2007) & EQ-i (Bar-On, 1997) & Evaluación de profesores \\
\hline Dulewicz, Higgs, y Slaski (2003) & $\begin{array}{l}\text { EIQ (Dulewicz y Higgs, } 1999, \\
2000)\end{array}$ & $\begin{array}{l}\text { Desempeño en la gestión del } \\
\text { supervisor }\end{array}$ \\
\hline Gabel, Dolan, y Cerdin (2005) & $\begin{array}{l}\text { EQ-i Spanish version (Ugarriza, } \\
\text { 2001) }\end{array}$ & $\begin{array}{l}\text { Evaluación del desempeño de los } \\
\text { supervisores }\end{array}$ \\
\hline Goldsmith (2008) & EQ-i (Bar-On, 1997) & $\begin{array}{l}\text { Rendimiento laboral medido por } \\
\text { supervisores }\end{array}$ \\
\hline Hader (2007) & EQI (Rahim et al., 2002) & $\begin{array}{l}\text { Desempeño laboral evaluado por } \\
\text { supervisores }\end{array}$ \\
\hline Hanna (2008) & ECI (Sala, 2002) & $\begin{array}{l}\text { Evaluación de la gestión de los } \\
\text { supervisores por las asistentes }\end{array}$ \\
\hline Higgs (2004) & $\begin{array}{l}\text { EIQ-G (Dulewicz y Higgs, } \\
\text { 2000) }\end{array}$ & $\begin{array}{l}\text { Evaluación del desempeño por } \\
\text { parte de los integrantes del } \\
\text { departamento }\end{array}$ \\
\hline Hopkins y Bilimoria (2008) & $\begin{array}{l}\text { ECI (Boyatzis y| Goleman, } \\
\text { 2001) }\end{array}$ & Rendimiento y potencial anual \\
\hline Jennings y Palmer (2007) & $\begin{array}{l}\text { 360-degree Genos Emotional } \\
\text { Intelligence Inventory (Gignac, } \\
2010 \text { ) }\end{array}$ & Objetivos alcanzados \\
\hline Kostman (2004) & $\begin{array}{l}\text { Bedwell Emotional Judgment } \\
\text { Inventory (Bedwell, 2002) }\end{array}$ & $\begin{array}{l}\text { Desempeño laboral de los } \\
\text { supervisores }\end{array}$ \\
\hline Lii y Wong (2008) & $\begin{array}{l}\text { Emotional Intelligence Quotient } \\
\text { Inventory (basado en Salovey y } \\
\text { Mayer, 1990) }\end{array}$ & Autopercepción \\
\hline
\end{tabular}




\begin{tabular}{|l|l|l|}
\hline Perlini y Halverson (2006) & EQ-i (Bar-On, 1997) & $\begin{array}{l}\text { Desempeño de jugadores de } \\
\text { hockey }\end{array}$ \\
\hline Prati (2004) & Schutte et al. (1998) & $\begin{array}{l}\text { Desempeño laboral de } \\
\text { supervisores }\end{array}$ \\
\hline Rozell, Pettijoh, y Parker (2004) & Schutte et al. (1998) & Rendimiento de ventas \\
\hline Schumacher (2005) & ECI-U (Boyatzis y Sala, 2004) & Desempeño laboral supervisores \\
\hline Semadar, Robins, y Ferris (2006) & SUEIT (Palmer y Stough, 2001) & Desempeño laboral supervisores \\
\hline Sergio (2001) & ECI (Sala, 2002) & Desempeño laboral supervisores \\
\hline Slaski y Cartwright (2002) & EQ-i (Bar-On, 1997) & $\begin{array}{l}\text { Desempeño de la gestión de los } \\
\text { supervisores }\end{array}$ \\
\hline Stone, Parker, y Wood (2005) & EQ-i (Bar-On, 1997) & $\begin{array}{l}\text { Desempeño habilidades liderazgo } \\
\text { orientado a la tarea }\end{array}$ \\
\hline Tombs (2005) & EQ-i (Bar-On, 1997) & Desempeño de Objetivos \\
\hline & $\begin{array}{l}\text { Leadership competency } \\
\text { inventory } \\
\text { designed to measure Goleman's } \\
(1995) \text { EI competencies }\end{array}$ & $\begin{array}{l}\text { Desempeño laboral supervisores } \\
\text { EQ-i (Bar-On, 1997 }\end{array}$ \\
\hline $\begin{array}{l}\text { Zizzi, Deaner, y Hirschhorn } \\
(2003)\end{array}$ & $\begin{array}{l}\text { Schutte et al. (1998) } \\
\text { Autopercepción del rendimiento }\end{array}$ \\
\hline
\end{tabular}


Tabla 2.9: Investigaciones IE (Modelo Habilidades), Liderazgo y Desempeño en el Trabajo. (Joseph, Newman, y O’Boyle, 2014)

\begin{tabular}{|c|c|c|}
\hline Autores Estudio & $\begin{array}{l}\text { Instrumento de Medida } \\
\text { Inteligencia Emocional }\end{array}$ & Medida de Desempeño \\
\hline Ashkanasy y Dasborough (2003) & MSCEIT (Mayer et al., 2002) & Evaluación Global del Curso \\
\hline Blickle et al. (2009) & $\begin{array}{l}\text { TEMINT (Schmidt-Atzert y } \\
\text { Bühner, } \\
\text { 2002) }\end{array}$ & Desempeño gerencial \\
\hline Bryant (2005) & $\begin{array}{l}\text { MSCEIT (Mayer y Salovey, } \\
\text { 1997) }\end{array}$ & Objetivo de ventas \\
\hline Byron (2007) & DANVA2 (Nowicki, 2000) & Desempeño laboral del supervisor \\
\hline $\begin{array}{l}\text { Christiansen, Janovics, y Siers } \\
\text { (2010) }\end{array}$ & MSCEIT (Mayer et al., 2000) & Desempeño laboral del supervisor \\
\hline Cobêro, Primi, y Muniz (2006) & MSCEIT (Mayer et al., 2002) & Desempeño laboral del supervisor \\
\hline Collins (2002) & MSCEIT (Mayer et al., 2000) & $\begin{array}{l}\text { Retroalimentación del éxito del } \\
\text { ejecutivo }\end{array}$ \\
\hline Côté y Miners (2006) & MSCEIT (Mayer et al., 2000) & Desempeño laboral del supervisor \\
\hline Farh, Seo, y Tesluk (2012) & MSCEIT (Mayer et al., 2002) & Desempeño laboral del supervisor \\
\hline Goldsmith (2008 & MSCEIT (Mayer et al., 2002) & Desempeño laboral del supervisor \\
\hline Graves (1999) & $\begin{array}{l}\text { EKT (short version of MEIS; } \\
\text { Mayer y Salovey, 1997) }\end{array}$ & $\begin{array}{l}\text { Desempeño en actividades } \\
\text { similares }\end{array}$ \\
\hline Hanna (2008) & MSCEIT (Mayer et al., 2002 & $\begin{array}{l}\text { Rendimiento del supervisor } \\
\text { basado en las asistentes }\end{array}$ \\
\hline Herbst, Maree, y Sibanda (2006) & MSCEIT (Mayer et al., 2002 & $\begin{array}{l}\text { Prácticas del liderazgo } \\
\text { transformacional }\end{array}$ \\
\hline $\begin{array}{l}\text { Kerr, Garvin, Heaton, y Boyle } \\
(2006)\end{array}$ & MSCEIT (Mayer et al., 2002 & $\begin{array}{l}\text { Desempeño del supervisor en el } \\
\text { trabajo }\end{array}$ \\
\hline Kluemper (2006) & MSCEIT (Mayer et al., 2002 & $\begin{array}{l}\text { Desempeño del supervisor en una } \\
\text { tarea }\end{array}$ \\
\hline $\begin{array}{l}\text { Kluemper, DeGroot, y Choi } \\
\text { (2013) }\end{array}$ & MSCEIT (Mayer et al., 2002 & $\begin{array}{l}\text { Desempeño del supervisor en una } \\
\text { tarea }\end{array}$ \\
\hline Law, Wong, Huang, y Li (2008) & MSCEIT (Mayer et al., 2002 & $\begin{array}{l}\text { Desempeño de objetivos } \\
\text { alcanzados }\end{array}$ \\
\hline Muniz y Primi (2007) & MSCEIT (Mayer et al., 2002 & $\begin{array}{l}\text { Desempeño del supervisor en el } \\
\text { trabajo }\end{array}$ \\
\hline Rosete y Ciarrochi (2005) & MSCEIT (Mayer et al., 2002 & $\begin{array}{l}\text { Desempeño del supervisor en el } \\
\text { trabajo }\end{array}$ \\
\hline
\end{tabular}




\section{Capítulo III. Comprensión Emocional}

"Cuando sonreímos a alguien, nueve de cada diez veces nos devuelve la sonrisa; o sea que en definitiva son dos las personas a las que comunicamos alegría y cuya existencia mejoramos"

Anónimo 


\subsection{Introducción}

En el capítulo 1 se ha descrito qué es emoción y qué relación existe fisiológica y funcionalmente entre la emoción y la cognición. Dicha relación obliga a tener en cuenta ambos factores para entender al ser humano desde una perspectiva integral. Por tanto, se ha rescatado y puesto en valor lo emocional en conjunción con lo cognitivo. En este sentido se argumenta como la facilitación emocional es una habilidad emocional que destaca la importancia de las emociones para la realización de funciones ejecutivas como la toma de decisiones, creatividad, etc. De la misma manera en el capítulo 2 se ha revisado qué significa el proceso de liderazgo, y cómo los/as líderes influyen a sus colaboradores/as utilizando indistintas estrategias de influencia destacando el papel de las estrategias emocionales y la importancia de la inteligencia emocional. En este punto, queda por explicar ¿cómo es posible que en este proceso de influencia social entre líderes y colaboradores/as éstos/as últimos/as sean capaces de influenciarse, de contagiarse y por tanto comprender, las emociones e intenciones de su líder y de actuar en consecuencia? Con el objetivo de dar respuesta a esta interrogante, el presente capítulo se adentra en la explicación de la comprensión emocional como una habilidad emocional que nos permite entender y comprender las emociones de los/as demás. Inicialmente se conceptualizará qué es comprensión emocional destacando su dimensión interpersonal comúnmente denominada empatía. Se describirán los diferentes marcos teóricos que intentan explicar desde varias aproximaciones cómo es posible entender a los/as demás a través de la empatía. Por último, se analizará cómo se produce el contagio emocional ya que es uno de los mecanismos básicos implicados en el efecto social que supone la inferencia del estado emocional del/la líder a sus colaboradores/as. Esta comprensión emocional de los/as líderes 
provocará cambios, emocionales, cognitivos, y comportamentales en los/as colaboradores/as.

\subsection{Definición de comprensión emocional}

Para definir en qué consiste la comprensión emocional se tomará como referencia el modelo de inteligencia emocional de Mayer y Salovey $(1997,2007)$.

La comprensión emocional hace referencia al conocimiento del sistema emocional propio y de las emociones de los/as otros/as, es decir, cómo la persona procesa a nivel cognitivo la emoción que percibe. Incluye el etiquetado correcto de las emociones, la comprensión del significado emocional no sólo en emociones sencillas sino también en otras más complejas, así como la evolución de unos estados emocionales a otros. Se compone de las siguientes sub-habilidades: (a) comprensión de cómo se relacionan diferentes emociones; (b) comprensión de las causas y las consecuencias de varias emociones; (c) interpretación de sentimientos complejos, tales como combinación de estados mezclados y estados contradictorios; y (d) comprensión de las transiciones entre emociones (Mestre, Guil, Brackett, y Salovey, 2008).

Gracias a la comprensión emocional, se adquiere conciencia tanto de las emociones propias, como las de los/as demás, siendo esta habilidad emocional la que nos permite comprender cuál es la emoción interna que provoca el comportamiento de las personas con las que interactuamos. Permite reconocer y tener conciencia de los sentimientos de las personas que nos rodean. Por tanto, existen dos niveles de conciencia emocional: el nivel intrapersonal, que corresponde al campo de la comprensión de las emociones que se producen en nuestro ser y que posteriormente denominamos sentimiento; y por otro lado, se 
encuentra el nivel de conciencia interpersonal que es la base de la empatía, ya que nos permite reconocer las emociones posteriores que están viviendo las personas que se encuentran a nuestro alrededor. Un nivel bajo de conciencia emocional intrapersonal puede afectar el nivel de calidad y cantidad de relaciones interpersonales que se pueden llegar a mantener. En la comprensión emocional es necesaria la puesta en marcha de procesos cognitivos como la percepción, la memoria, el lenguaje, el pensamiento, y el razonamiento. Por tanto, la cognición juega un papel trascendental para poder realizar una adecuada comprensión emocional.

Sin embargo, en el modelo de Mayer y Salovey no se explica cómo se produce la comprensión emocional, por lo que hay que buscar las explicaciones en otras áreas de la psicología y de la neuropsicología.

El enfoque de análisis que a continuación se describe, se centrará en la comprensión emocional a un nivel interpersonal debido a que uno de los objetivos centrales de esta Tesis es conocer si en el proceso de influencia del liderazgo la inteligencia emocional del/la líder se relaciona con las competencias mentales (cognición) del colaborador/a. Como ya se ha comentado anteriormente, en este nivel interpersonal, a la comprensión emocional se le denomina empatía. Y para analizar cómo se produce la empatía, a continuación se explicarán las teorías cognitivas actuales, las que vienen derivadas de las neurociencias y finalmente, bajo una aproximación social, se revisarán los modelos teóricos que intentan explicar los efectos sociales de la emoción.

\subsection{Empatía}

\subsubsection{Concepto de empatía.}


La empatía ha recibido múltiples definiciones, que se aglutinan en torno a dos tendencias. Por un lado, se encuentran aquellas que enfatizan el valor de las experiencias afectivas entre dos personas y por el cual una persona se "pone en los zapatos de otra"; y por otro lado, otro grupo de conceptualizaciones que destacan la habilidad cognitiva para procesar la realidad del otro/a. Con el fin de ofrecer una definición que integre esta dualidad existente, se recoge la conceptualización de Moya-Albiol, Herrero y Bernal (2010) que considera a la empatía como "la capacidad para experimentar de forma vicaria los estados emocionales de otros, siendo crucial en muchas formas de interacción social adaptativa. Tiene dos componentes: uno cognitivo, muy relacionado con la capacidad para abstraer los procesos mentales de otras personas, y otro emocional, que sería la reacción ante el estado emocional de otra persona (Moya-Albiol et al., 2010, p.91)

En el trabajo de Moya-Albiol et al. (2010) se ensalza la importancia de tener en cuenta la empatía como elemento fundamental en la disposición pro-social que permite al ser humano mejorar sus posibilidades de supervivencia, ya que de ésta depende la habilidad para interactuar los/as unos/as con los/as otros/as comprendiendo lo que sienten mutuamente (Mestre, Frías, y Samper, 2004). Teniendo en cuenta esta perspectiva social, se considera la cognición social como el conjunto de operaciones mentales que subyacen en las interacciones sociales, y que incluyen los procesos implicados en la percepción, interpretación y generación de respuestas ante las intenciones, disposiciones y conductas de otros/as. La empatía, por tanto, es una forma de cognición social. Sin una correcta cognición social sería muy complicado poder tener relaciones de calidad como les sucede a personas que sufren de autismo o de alguna patología neuronal que les afecta su capacidad empática. 
Gracias a la empatía se puede llegar a sentir las emociones y sentimientos de los/as demás, así como inferir cuáles son sus posibles intenciones y pensamientos. Se distinguen dos componentes en la empatía: el cognitivo y el afectivo.

El componente cognitivo hace que la persona que observa entienda los pensamientos y sentimientos de la otra, siendo capaz de adoptar su perspectiva. Permite atribuir a la otra persona un estado mental, una actitud, para inferir pensamientos y emociones, y predecir así su comportamiento. Por otro lado, el componente afectivo, es la respuesta emocional de la otra persona, en este caso el observador al percibir las emociones que expresa la persona con la que interactúa (García-García, González-Marqués, y Maestú, 2011).

Por tanto, a través de la empatía somos capaces de realizar un ejercicio de procesamiento de la intención y los comportamientos resultantes de los/as demás compartiendo, al mismo tiempo, su mismo marco emocional de referencia. Para poder explicar teóricamente como se puede producir la empatía, las investigaciones actuales sitúan el marco referencial en dos grandes teorías: la Teoría de la Mente (TdM), y de la Teoría de la Simulación (TS).

\subsubsection{Teoría de la Mente (TdM).}

A la mente entendida como un sistema de conocimientos e inferencias que permite interpretar y predecir la conducta de los demás se le denomina "teoría", ya que a pesar de no ser directamente observable sirve para predecir y modificar el comportamiento (GarcíaGarcía et al., 2011). La TdM hace referencia a la habilidad para comprender y predecir la conducta de otras personas, sus conocimientos, sus intenciones y sus creencias (Tirapu- 
Ustárroz, Pérez-Sayes, Erekatxo-Bilbao, y Peligrín-Valero, 2007). La TdM aparece con los estudios de Premack y Woodruf realizados a finales de los años setenta, y que tenían como objetivo demostrar como los chimpancés podían comprender la mente humana. A los chimpancés se les mostraban vídeos de algunos/as de sus cuidadores/as en jaulas con la intención en algunos casos de agarrar un plátano. En un momento del pase del vídeo en el cual el ser humano iniciaba acción operativa para coger el plátano, se paralizaba la imagen y se le mostraba al chimpancé dos fotografías, una de ellas con soluciones que podía acontecer a la acción iniciada. Una chimpancé llamada Sarah, acertó 21 veces de 24. Los investigadores concluyeron que la chimpancé era capaz de suponer y teorizar sobre la intención y el conocimiento del ser humano en la acción, es decir, al igual que el ser humano, realizan meta representaciones de lo que piensa y del estado emocional de los unos/as sobre los otros/as. Para estos autores:

“un individuo tiene una teoría de la mente si atribuye estados mentales a sí mismo y los atribuye a otros. Este sistema de inferencias se denomina teoría de la mente por que los estados no son observables directamente y el sistema se puede utilizar para hacer predicciones de la conducta de otros” (Premack y Woodruf, 1978, p 515).

El nivel de complejidad de la TdM se asocia a lo difuso de establecer el conjunto de habilidades meta-cognitivas que intervienen para conocer qué es lo que piensan y sienten los/as demás. Actualmente, aparecen diferentes posturas que intentan explicar los mecanismos que hacen posible la TdM. 
La primera postura considera que se trata de un mecanismo innato (Leslie, 1987). Para este autor, se produce una maduración evolutiva de la capacidad innata de comprender a los/as demás. Considera que en el primer año, a través de lo que denomina Teoría del Cuerpo, el/la niño/a reconoce que el movimiento de las personas tiene una fuente interna. Posteriormente, a los nueves meses y a los dieciocho meses se ponen en marcha dos mecanismos denominados teoría de la mente (TOMM1 y TOMM2, respectivamente) que permiten al/la niño/a realizar atribuciones de intencionalidad, basadas en las creencias, la imaginación y el deseo, entre otros estados mentales. Finalmente, sobre los tres o cuatro años, aparece un procesador de selección que le que permite al/la niño/a una comprensión nítida de las falsas creencias (Leslie, 2000; Scholl y Leslie, 2001).

La segunda postura centra su estudio en el mecanismo de la inferencia para poder comprender la mente de las otras personas ya que los estados mentales son invisibles e impenetrables (Astington, 1998). Sólo puede haber TdM cuando se ha conseguido inferir qué piensa la otra persona y por tanto predecir cómo se va a comportar.

En tercer y último lugar, aparece la postura denominada aproximación de la segunda persona (Ready, 2008) que considera que la mente es transparente desde las acciones derivadas de la interacción en las relaciones emocionales. Para esta autora, lo importante es la interacción mutua más que la introspección individual (yo-primera persona) y más que la representación mental (tercera persona). El diálogo entre las dos personas, de ahí la denominación de segunda persona, provoca que ambos se reconozcan e interactúen respondiéndose mutuamente reconociendo su existencia. 
Al igual que es complejo determinar los mecanismos por los que se da la TdM lo mismo sucede con su evaluación y composición. Tradicionalmente las pruebas de evaluación de la TdM han consistido en utilizar algunas de las siguientes pruebas:

\section{Reconocimiento facial de emociones.}

Esta prueba consiste en reconocer las emociones a través de las expresiones faciales de las mismas. El reconocimiento facial de las emociones, sobre todo del miedo y el asco está muy relacionado con la amígdala.

\section{Creencias de primer y segundo orden.}

Esta prueba ha sido la que más se ha utilizado para determinar la TdM (Tirapu-Ustárroz, et al., 2007). Inicialmente enfocada a niños de 4 a 6 años se les proponía realizar una tarea de comprensión de creencias falsas (Baron-Cohen, Leslie, y Frith, 1985). En este test aparecen dos muñecas Sally y Ana con sus cestas. El/la niño/a ve a Sally (una muñeca) que esconde una canica en su cesta y abandona la habitación. Seguidamente aparece Ana y pone la canica en su propia cesta. En ese momento se le pregunta al niño/a ¿dónde buscará Sally su canica? Los/a niños/as normales de 4 años responde correctamente la prueba que Sally miraría en su propia cesta al creer, erróneamente que la canica se encuentra allí. En cambio niños autistas se equivocan en la respuesta ya que no pueden ponerse en el lugar del personaje y pensar sobre los pensamientos de otro, por tanto responden que la canica está en la cesta de Ana.

\section{Comunicaciones metafóricas e historias extrañas:(ironía, mentira y mentira} piadosa). 
Happé (1994) desarrolló esta serie de historias inicialmente para evaluar la habilidad de los niños autistas a la hora de atribuir las intenciones a los/as demás. Ejemplo de las mismas son las de ironía, mentira y piadosa dónde el personaje dice algo que no debe de decirse de forma literal y se le pide al sujeto una explicación del por qué el personaje realiza esa afirmación. Por ejemplo, con respecto a la ironía una historia tipo utilizada sería de la siguiente:

Un niño está mirando a un grupo de niños que se cuentan cosas y se ríen. Se acerca y les pregunta ¿Puedo jugar con vosotros? Uno de los niños se gira y le dice.-Sí, claro, cuando las vacas vuelen, jugarás. (Tirapu-Ustárroz, et al., 2007, p. 482) A juicio de Happé (1994) esta prueba exige mayor complejidad en la comprensión de los/as demás ya que es necesario disponer de una capacidad para extraer un significado en función de un contexto social particular. Se debe de superar la literalidad de la contestación para darle una coherencia a lo que está sucediendo.

- 4. Meteduras de pata (faux pas)

El grupo de Baron-Cohen (1999) creó este test para medir la sensibilidad social. Los participantes leen 10 historias con situaciones de metedura de pata (faux pas) en distintas situaciones sociales y 10 historias asépticas. Un ejemplo de historia es la de Julia y Esther.

"Julia compró a su amiga Esther un jarrón de cristal como regalo de bodas. Esther hizo una gran boda y había tal cantidad de regalos que le fue imposible llevar la cuenta de qué le había regalado cada invitado. Un año después Julia estaba cenando en casa de Esther. A Julia se le cayó una botella de vino sin querer sobre el jarrón de cristal y éste se hizo añicos.-Lo siento mucho. He roto el jarrón-dijo 
Julia.-No te preocupes-dijo Esther-, nunca me gustó; alguien me lo regaló por mi boda.

Preguntas de comprensión: ¿Ha dicho alguien algo que no debería haber dicho o inoportuno? ¿Por qué no le debería haber dicho o por qué ha sido inoportuno? ¿Cómo crees que se sintió Julia? (Tirapu-Ustárroz et al., 2007, p. 482)

Este tipo de historia insiste en la capacidad del participante en comprender lo que está pasando y ponerse en lugar de la otra persona.

- 5. Empatía y juicio moral (cognición social)

Este tipo de prueba plantean dilemas morales denominados juicios éticos que debe de resolver el sujeto. Se reproduce el protocolo de evaluación de medición de la TdM de Tirapu-Ustárroz et al. (2007) denominado "Dilema del Tren" que mide el funcionamiento empático de los participantes.

Un vagón de tren se dirige sin control hacia un grupo de cinco operarios que realizan obras de mantenimiento en la vía. Todos ellos morirán aplastados por la máquina si no encontramos una solución. Usted tiene la posibilidad de apretar un botón que activará un cambio de agujas y desviará el tren hacia otra vía dónde se encuentra un trabajador realizando obras de reparación. El vagón mataría a este hombre pero los otros cinco se salvarían. ¿Pulsaría el botón?

Existe otra versión del dilema ampliada.

Usted se halla sobre un paso elevado que cruza sobre la vía y situado en un punto vertical entre la vía y las cinco personas. Un señor con aspecto desaliñado y con pintas de estar bebido se encuentra a su lado. Una manera de frenar el vagón asesino consiste en empujar al señor para que caiga sobre la vía y resulte 
atropelladamente, lo que provocará que el maquinista reacciones, frene el tren y salve las cinco vidas. ¿Le daría un empujón? (Tirapu-Ustárroz et al., 2007, p. 483) Lo que suele suceder es que al primer planteamiento se responde un "sín" por la acción sobre un botón, pero a la hora de dar un empujón la mayoría responde que "no", excepto cuando se le dice que las cinco personas son seres queridos para el sujeto, en esa situación se cambia la respuesta.

Por último, y desde un punto de vista neuropsicológico, en la siguiente neuroimagen (ver Figura 3.1) se muestra las diversas estructuras cerebrales que se activan en el momento de realizar las diversas pruebas de evaluación de la TdM. Tal y cómo se puede observar, las estructuras cerebrales que se activan en las pruebas van desde las relacionadas anatómicamente y funcionalmente con el procesamiento emocional (como la amígdala), con aquellas transcendentales para el procesamiento y razonamiento cognitivo (como el córtex frontal). Por tanto, se aprecia la relación fisiológica de lo emocional y lo cognitivo en el funcionamiento de la mente humana en su evaluación de la TdM. 


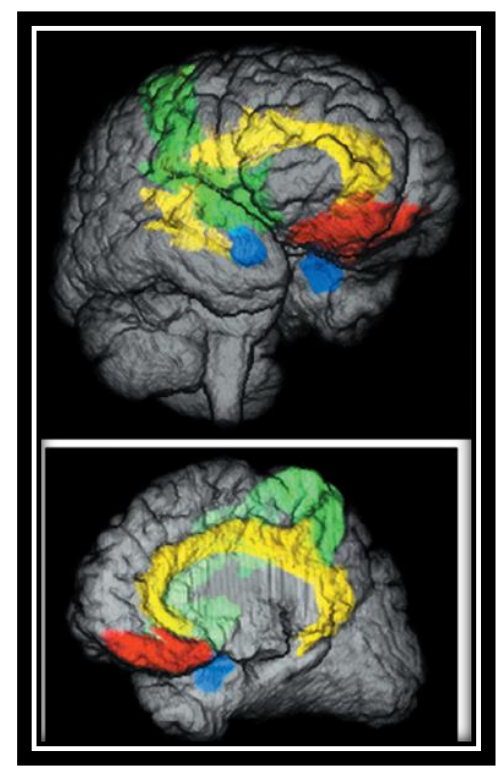

\begin{tabular}{|l|l|}
\hline $\begin{array}{l}\text { Reconocimiento facial de } \\
\text { emociones }\end{array}$ & Amígdala \\
\hline $\begin{array}{l}\text { Creencias de primer y segundo } \\
\text { orden }\end{array}$ & $\begin{array}{l}\text { Amígdala y corteza frontal } \\
\text { dorsolateral }\end{array}$ \\
\hline $\begin{array}{l}\text { Historia de ironía, mentira y } \\
\text { mentira piadosa }\end{array}$ & $\begin{array}{l}\text { Giro Frontal medial izquierdo y } \\
\text { cingulado posterior }\end{array}$ \\
\hline Metedura de Pata & $\begin{array}{l}\text { Frontal dorsolateral y } \\
\text { ventromedial }\end{array}$ \\
\hline Empatía y cognición social & $\begin{array}{l}\text { Giro frontal medial, cingulado } \\
\text { posterior surco temporal } \\
\text { superior, córtex frontal } \\
\text { orbifrontal ventromedial, polo } \\
\text { temporal, amígdala, córtex } \\
\text { frontal dorsolateral y lóbulo } \\
\text { parietal }\end{array}$ \\
\hline
\end{tabular}

Figura 3.1: Estructuras cerebrales relacionadas con la teoría de la mente-Adaptado de http://www.funlam.edu.co/uploads/facultadpsicologia/213_213_Teoria_de_la_mente_y_T DC.pps

\subsubsection{Teoría de la Simulación (TS).}

La Teoría de la Simulación (TS) apunta a que la habilidad de leer las mentes de los demás, mindreading, se debe a que el individuo utiliza sus recursos internos (motivación, emoción y razonamiento cognitivo) para atribuir estados mentales imaginando o simulando que se encuentra en la situación de la otra persona, con ello puede crear los estados mentales que se atribuirían a la otra persona. En primera persona, se realiza una representación en nosotros/as mismos/as de los estados de los/as demás simulando su estado mental y emocional. En la TS se simula el punto de vista de la primera persona ya que a través de uno/a mismo/a se puede entender a los demás. Para esta teoría la introspección es el mecanismo utilizado para comprender los estados mentales de las otras 
personas. Es a través de la propia proyección de las experiencias internas que se pueden comprender como las otras personas piensan, sienten o creen (Goldman, 1989; Gordon, 1986,1992; Harris, 1992; Heal; 1996,). Según las ideas teóricas iniciales de esta perspectiva, a través de la generación de modelos en nuestras mentes podemos simular la mente de los/as demás., En el contexto de esta teoría, la aparición de las neuronas espejo como mecanismos de explicación neurofisiológica de la intersubjetividad (Gallese y Golmand, 1998) ha revolucionado el panorama científico actual.

Existen dos posturas dentro de la TS. La primera, más conservadora, denominada simulación estándar, considera que la simulación es un proceso cognitivo deliberado y que requiere esfuerzo (Gallese, Migone, y Eagle, 2009). En este tipo de simulación el sujeto se pone de forma voluntaria en la condición del otro, intenta ver las cosas desde su perspectiva, recrea en sí mismo (también con la imaginación) los mismos estados mentales del otro/a. (Gordon, 1995, 1996; Gordon y Cruz, 2003).

La segunda postura, denominada simulación corporalizada, es en cambio más radical en su argumentación, ya que defiende que no hay ninguna inferencia o introspección, sino simplemente una reproducción, pre-reflexiva y no consciente, de los estados mentales del otro (Gallese, 2001, 2003, 2005). Dentro de esta última postura se sitúa uno de los descubrimientos que han revolucionado el panorama científico, que fue el hallazgo casual de las neuronas espejo (mirror neurons).

En los años 90, un grupo de neurocientíficos de la Universidad de Parma encabezados por Giacomo Rizzolatti descubrieron que una población de neuronas localizadas en el área premotora F5 del cerebro de mono se activaban no sólo cuando el mono realizaba la acción (coger un helado), sino también cuando observaba cómo lo hacía 
otro mono. Posteriormente, se buscó la evidencia de la activación de este tipo de neuronas en el cerebro humano, y gracias a las imágenes obtenidas por resonancia magnética funcional (fMRI) se ha señalado a la corteza pre-motora ventral (BA44/6), al lóbulo parietal inferior (IPL), así como áreas somato-sensoriales (en especial la B2), como áreas que se activan ante la visión o la escucha de acciones ejecutadas por otros y no solo ante la propia ejecución de actividades motrices (Bastiaansen, Thioux, y Keysers, 2009). Este descubrimiento provocó un sinfín de publicaciones y debates científicos, dónde los defensores de este proceso de simulación defienden que las neuronas espejo son las responsables de procesos muy importantes en la interacción humana como la empatía y del autismo (Rizzolatti, Fogassi y Gallese, 2001). Por ejemplo Jacob y Jeannerod, (2004) y Csibra (2004) evidenciaron la importancia de las neuronas espejo en la comprensión de los/as demás y por tanto en la inteligencia social.

Asimismo, la relación entre la predicción de la finalidad de una acción y la atribución de las intenciones ha sido descubierta por Fogassi, Ferrari, Gesierich, Rozzi, Chersi y Rizzolatti (2005). En su investigación determinó que sólo se activaban las neuronas espejo de los monos estudiados cuando existía una finalidad en la acción (en este caso la finalidad era agarrar un objeto y llevárselo a la boca). Las neuronas espejo situadas en la zona parietal del cerebro del mono se activaban en asociación con sus actos motores (agarrar un objeto con la mano) sólo cuando éstas forman parte de una acción específica cuyo objetivo es alcanzar un objeto distal diferente (llevárselo a la boca o tirarlo al contenedor). Es decir, hay una programación de un grupo de neuronas con la acción motora y una finalidad de la acción. Por ello, se sugirió que estás neuronas espejo parietales eran capaces de discriminar actos motores idénticos según la acción global que se va a realizar, 
por tanto predicen la intencionalidad en un contexto determinado (Gallese, Migone, Eagle, 2009).

De igual modo, un conjunto de investigadores enfatizaron que en la relación intersubjetiva entre las personas el rol del lenguaje es protagónico. Aparecen estudios que defienden la idea, bajo el marco teórico de la simulación corporalizada, que las mismas estructuras nerviosas que se encargan de la organización de la ejecución motora de las acciones, intervienen también en la comprensión semántica de las expresiones lingüísticas que las describen (Fodor, 1998; Pylyshyn, 1984). Uno de los aspectos sorprendentes que se ha descubierto en este sentido y, que se asocia a la idea de congruencia entre zonas cerebrales de gestión motora y la comprensión del significado lingüístico y la ejecución de la acción, es que cuando se realiza una lectura silenciosa, o se escuchan palabras o frases que describen acciones de partes del cuerpo como la mano, la boca, o del pie, se activan las distintas zonas de la corteza motora y premotora que controlan la realización de esas mismas acciones (Borghi, Glenberg y Kaschak, 2004).

Recientemente, uno de los defensores más entusiastas del rol de las neuronas espejo y su relación con la empatía, el investigador Marco Iacobini (2009), propuso la existencia de una conexión entre las regiones del cerebro humano dónde se localizan las neuronas espejo y el sistema límbico responsable del procesamiento de los estímulos emocionales. A través de esta interconexión, cuando se reciben las expresiones faciales de otras personas se produce un proceso de simulación automática, dónde reproducimos los mismos gestos sin darnos cuenta, y sin existir un reconocimiento explícito de la expresión imitada. Al mismo tiempo, las neuronas espejo, ya activadas, envían señales de alerta a los centros de procesamiento de la emoción situados en el sistema límbico. El sistema límbico, y más en 
concreto la corteza insular (o la ínsula), se dispara al recibir la señal de las neuronas espejo permitiendo sentir en nosotros mismos las emociones asociadas a las expresiones faciales que se están imitando. Por ejemplo, esto sucede cuando estamos en un aeropuerto, y durante la espera, nos fijamos como otro pasajero está viendo en su tablet un vídeo cómico que le provoca alegría y de ahí empieza a reírse sin parar; automáticamente imitamos su expresión facial de la risa provocándonos el contagio de su alegría. Iacobini (2009) recogió un investigación con imágenes de fMRI que mostraban que personas que observan e imitan rostros que expresan estados emocionales, como el miedo, la tristeza, furia, alegría, etc., presentaban patrones de activación neuronal en las áreas asociadas a las neuronas espejo, en la corteza insular y el sistema límbico. De igual modo, propuso que una mayor activación de las neuronas espejo (incitada por las situaciones en que se solicita imitar ciertas expresiones) provocaba una mayor activación neuronal en estas otras áreas, afirmando que ello muestra una vía, una conexión, que va de las neuronas espejo a la corteza insular y el sistema límbico, ambas áreas responsables de la sensación emocional. Según Iacobini (2009) estos resultados apoyan claramente la idea de que las áreas de las neuronas espejo ayudan a comprender las emociones de otras personas por medio de alguna forma de imitación interna. Por lo tanto, para este autor, la empatía es un proceso que se debe a la intervención de las neuronas espejo teniendo como punto de arranque la imitación involuntaria de las expresiones de las personas que nos rodean.

Desde la Psicología Cognitiva se realiza una serie de críticas a la teoría de la simulación que sobre todo se centran en señalar el sesgo interno de nuestra propia subjetividad a la hora de identificar con objetividad las atribuciones y deseos de las personas que observamos. Por tanto, si no hay un análisis previo de nuestra subjetividad y 
la extraemos de la persona que observamos, es muy complejo que se pueda dar la simulación.

De la misma manera, otra crítica que se le suele realizar a la teoría de la simulación es que es difícil simular lo que está sintiendo otra persona sin tener en cuenta las creencias discrepantes en las que basa su esquema y comportamientos de vida. Las personas nos comportamos según un sistema de creencias y valores personales propios que son el marco de las conductas que realizamos. En ocasiones, lo que sucede, es que se genera en cada persona alguna modalidad de creencia discrepante, que rompe con el esquema de creencias habitual por el que las personas se comportan. Como por ejemplo sucede cuando un director de recursos humanos, en un contexto laboral multinacional, tiene que despedir por decisión corporativa a varios trabajadores de la fábrica de Ecuador para no ser competencia de otra sucursal del holding empresarial en el Perú, a pesar que su creencia personal es la de facilitar trabajo a todos los/as colaboradores/as con buen desempeño. Por ello, la teoría de la simulación no puede dar explicación, según la crítica cognitiva, a conocer, ni predecir la creencia discrepante en la mente de otro sujeto.

El debate actual está abierto y las posturas muy encontradas. El siguiente paso es investigar y aclarar qué tipo de impacto produce las neuronas espejo en los procesos que intervienen en la inteligencia social y el funcionamiento del ser humano en aspectos como leguaje, empatía, intersubjetividad y autismo. Sin duda, éste será uno de los retos futuros que, desde mi punto de vista, pasa por integrar a la teoría de la simulación corporalizada (paradigma imperante por el poder de las neurociencias) con otras teorías que explican cómo entendemos a los/as demás teniendo en cuenta el tipo de interacción y el análisis 
interno del sistema de creencias que gobierna el modo de entender la vida de las personas con las que interactuamos.

\subsection{Efecto Social de la Emoción}

Abandonando el enfoque cognitivo y el neuropsicológico, en esta sección se revisará los modelos teóricos que explican la comprensión emocional como un efecto interpersonal fruto del resultado de la interacción social en al ámbito del trabajo.

\subsubsection{Modelo de Kelly-Barsade (2001).}

Barsade y Gibson (1998) señalaron que las emociones grupales son el resultado tanto de la combinación de los factores afectivos de nivel individual que los/as miembros del grupo poseen, como de los factores de nivel contextual o grupal que definen u originan la experiencia afectiva del grupo. Recogiendo esta aportación, Kelly y Barsade (2001) plantearon un modelo (ver Figura 3.2) basado en la conceptualización de la emoción grupal como el estado afectivo que surge de la combinación de los efectos de los componentes afectivos individuales “top-down" -enfoque abajo arriba- con los efectos afectivos contextuales del grupo "bottom-up” enfoque arriba abajo (Barsade y Gibson, 1998).

Según este modelo, la influencia afectiva en grupos arranca con una entrada inicial, a modo de antecedentes, asociados a los estados de ánimo y emociones que traen consigo cada individuo. Los/as miembros del grupo aportan sus experiencias emocionales, sentimientos, e inteligencia a la interacción grupal. A través de una serie de procesos afectivos implícitos y explícitos se produce la interacción grupal, configurando un estado emocional grupal que a la vez influye en cada individuo modificando su comportamiento. 
Dentro de los procesos afectivos implícitos se destaca el modelado-aprendizaje vicario, y el contagio emocional como factores por los cuales, aunque no necesariamente conscientes, se propagan el estado de ánimo y emociones de los/as diferentes miembros/as del grupo.

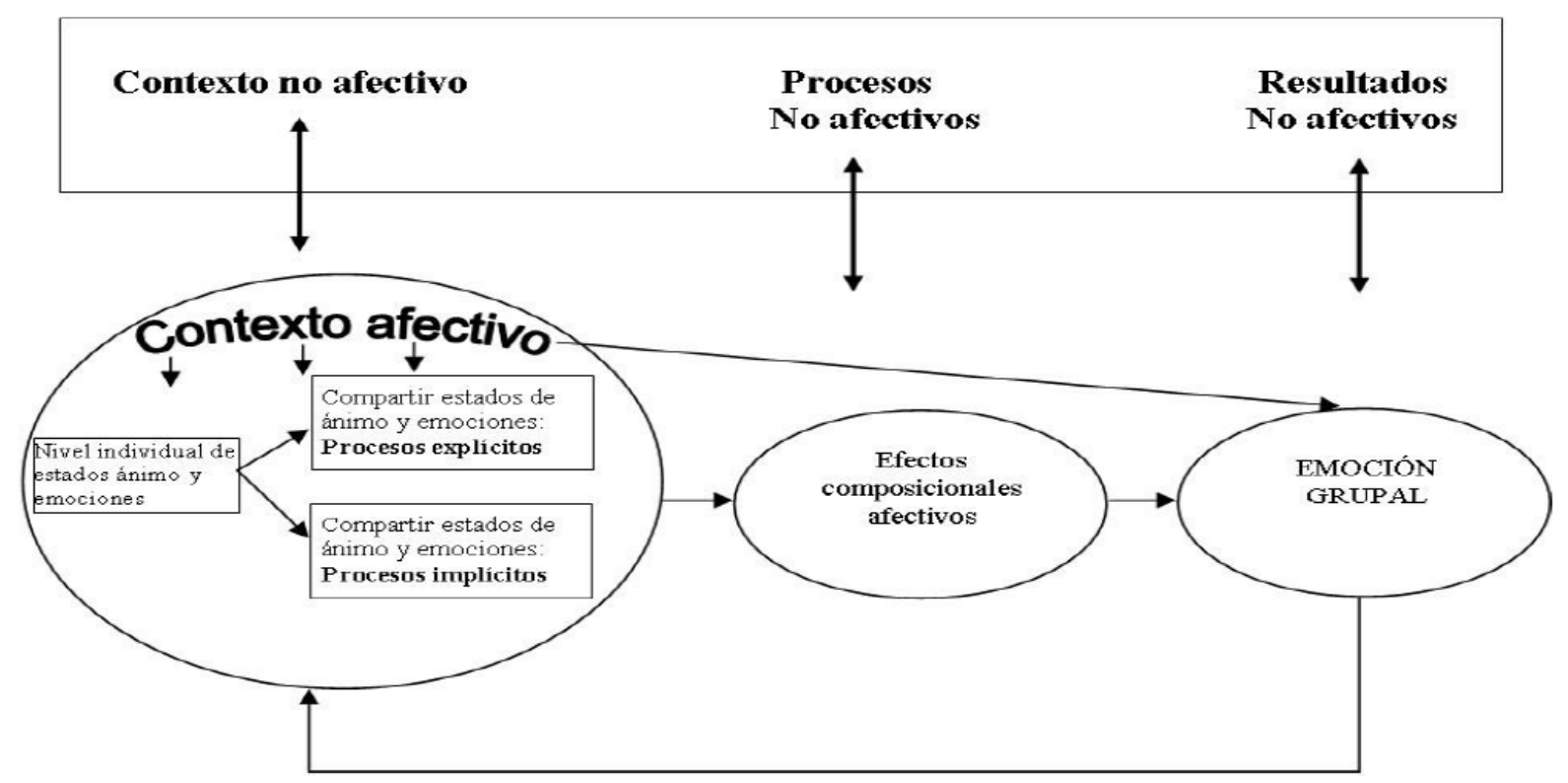

Figura 3.2: Estados de ánimo y emociones en grupos pequeños y en equipos de trabajo (Kelly, y Barsade, 2001)

\subsubsection{Modelo EASI: Universidad Ámsterdam (Van Kleef, 2009)}

En segundo lugar, y siguiendo con una perspectiva social en el estudio de la emoción, detallaremos el modelo teórico Emotion As Social Información (EASI) del departamento de Psicología de la Universidad de Ámsterdam que corresponde a uno de los ejes teóricos de esta investigación.

Este grupo de investigación holandés se enfocó en el análisis de la comprensión de la influencia emocional que se produce a nivel interpersonal; es decir, analiza como las expresiones emocionales del emisor en entornos grupales influye en las emociones, 
comportamientos, y cogniciones de la persona que observa. La vida social es ambigua y se necesita todo tipo de información para la toma de decisiones, por lo que para guiar las propias acciones se necesita interactuar con las emociones de los/as demás (Van Kleef, 2009, 2010; Van Kleef, De Dreu y Manstead, 2010; Van Kleef, Van Doorn, Heerdink y Koning, 2011). En la Figura 3.3 se recoge de forma gráfica los fundamentos y procesos básicos del Modelo EASI (Van Kleef, Homan, Cheshin, 2012). 


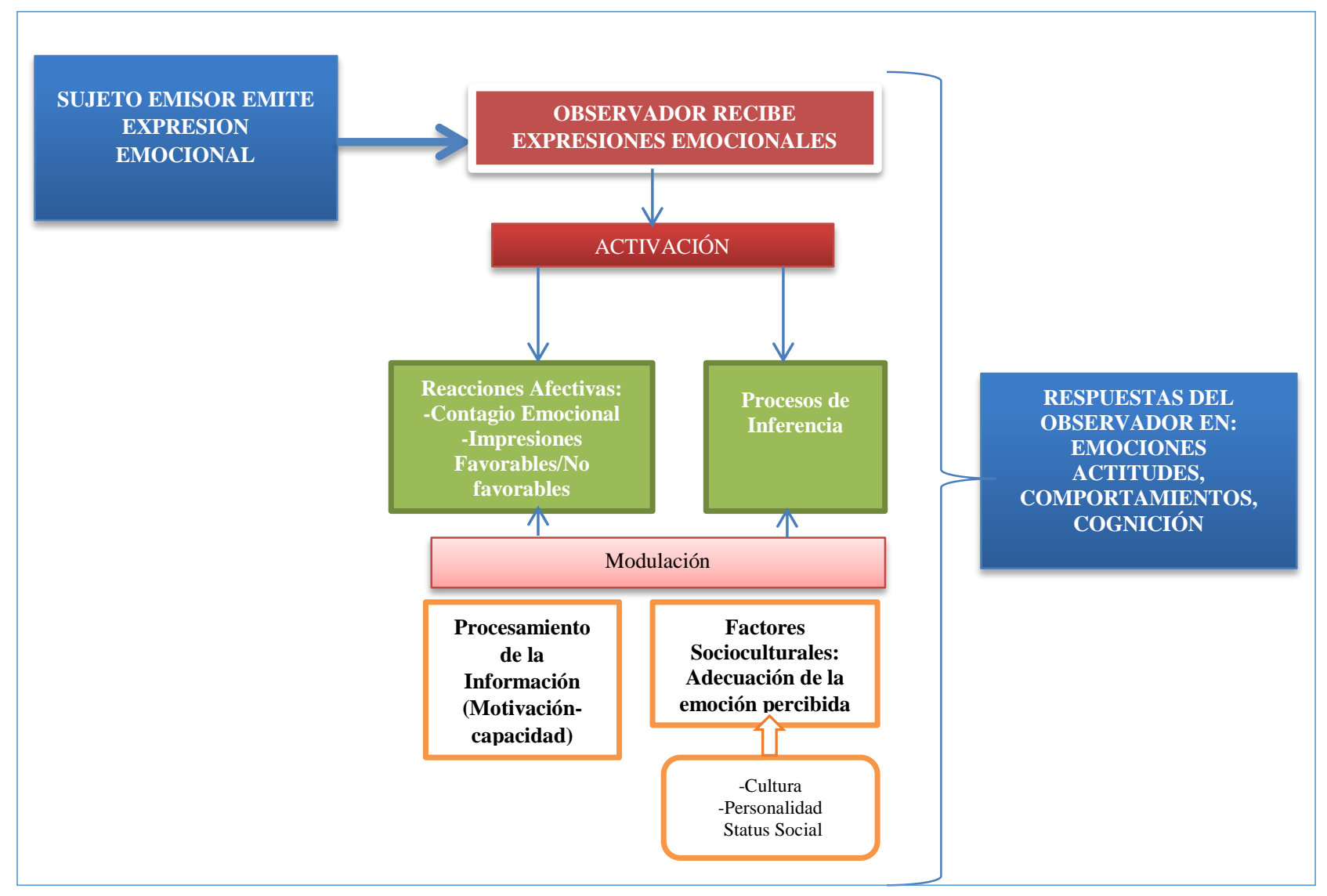

Figura 3.3: Modelo Teórico EASI-Universidad de Ámsterdam. Elaboración Propia Basado en Van Kleef, Homan, Cheshin, (2012)

Para estos investigadores el estudio de las emociones en el contexto organizacional ha adoptado exclusivamente un enfoque intrapersonal. La visión tradicional del estudio de la emoción se ha centrado en analizar cómo las emociones de un componente de una organización influyen en sus propias cogniciones, actitudes y comportamiento (Bass, De Dreu y Nijstad, 2011; Brief, Butcher y Roberson, 1995; Forgas, 1995; Staw y Barsade, 1993). Van Kleef y sus colaboradores $(2009,2012)$, defienden que esta visión tradicional hay que completarla con el fin de ofrecer un marco integral del efecto de las emociones en 
las organizaciones, por tanto proponen estudiar y analizar el efecto social interpersonal de las emociones entre los diferentes integrantes del entorno de trabajo.

Este enfoque social de la emoción humana y de la influencia de las emociones del emisor sobre el observador ha tenido como antecedentes algunos autores como Clark, Pataki y Carver (1996), y Keltner y Haidt (1999). En su desarrollo teórico, Van Kleef, et al. (2012) postulan que las expresiones emocionales que aparecen en las organizaciones, cuando son observadas por el resto de integrantes, provocan en quienes las observan consecuencias en sus propias acciones. Para los autores de esta teoría hay un evidente proceso de influencia entre emisor y observador. Esta influencia se inicia cuando el emisor (colaborador/a, compañero/a de trabajo, cliente/a, líder) emite una expresión emocional (ira, alegría, asco, etc.) y la persona que observa (cualquier miembro organizacional) la percibe. En ese momento se producen dos procesos: a) Reacciones afectivas y b) Procesos de Inferencia.

\section{a) Reacciones afectivas}

\section{a.1. Contagio emocional}

Aunque el contagio emocional se ampliará en el siguiente apartado, ya que es un eje central en esta investigación, dentro del marco teórico EASI se describe como un proceso por el cual las emociones del emisor son atrapadas por el observador, determinando y orientando su comportamiento. Por ejemplo, si un/a líder muestra ira ante un trabajo realizado por parte de un/a colaborador/a, lo que puede provocar en éste es la emoción de miedo (Dimberg y Öhman, 1996) y de ahí, paralizar la tarea que está desempeñando. La emoción expresada se riega como la pólvora en el grupo y puede provocar comportamientos tanto de evasión como de afiliación (Keltner y Haidt, 1999), y de 
complementariedad. En primer lugar si un/a compañero/a de trabajo expresa ante una situación de trabajo concreta la emoción de felicidad, el/la compañero/a con el/la que está interactuando juzga que la situación es favorable, induciendo a la cooperación. En segundo lugar, tenemos memoria emocional, y ante un estallido emocional de ira de unos/as de nuestros/as compañeros/as, o nuestro/a líder de equipo, lo que puede suceder es que quedemos atrapados/as por esa emoción y recordemos y hagamos explicitas las características negativas de nuestro compañero/a o líder, lo que podrá afectar a la motivación para trabajar juntos/as en una tarea o en el mismo departamento.

\section{a.2. Impresiones favorables vs desfavorables}

Cuando se expresan emociones positivas, éstas tienden a inspirar impresiones positivas; en la misma línea, cuando son expresiones de emociones negativas, las impresiones que tienden a causar en los demás son negativas. En el entorno de trabajo tendemos a buscar a las personas que nos expresan emociones positivas más que negativas. Los efectos de estas impresiones tienen una gran carga motivadora en nuestros comportamientos organizacionales.

Según Van Kleef et al. (2012) estos dos tipos de reacciones afectivas moldean nuestro comportamiento organizacional al mismo tiempo que entra en funcionamiento el segundo proceso básico que provoca cambios en quien observa; es decir, los procesos inferenciales.

\section{b) Procesos de inferencia.}

Una vez se percibe las expresiones de las emociones de la persona con quien se interactúa, lo que sucede en quienes observan, es un proceso interno de evaluación e interpretación de la situación específica que lleva a inferir cómo podrá comportarse 
aquél/aquella con quién se interrelaciona. En este punto, el grupo de la Universidad de Ámsterdam recoge las ideas de la perspectiva cognitiva de Lazarus (1991). La persona que observa las respuestas emocionales que acontecen en un puesto de trabajo puede evaluar como su jefe/a reacciona ante una situación de demandas laborales, o como un/a compañero/a está triste por no llegar a los resultados previstos e inferir por que se comportan de determinada manera en sus puestos de trabajo y con los/as demás.

Desde mi punto de vista, los procesos de inferencia que describen el grupo de EASI tienen gran similitud con el componente cognitivo de la empatía, tal y como se ha explicado anteriormente con profundidad. Ya que a través de los procesos de inferencia se produce, al igual que sucede con el elemento cognitivo de la empatía, un análisis y evaluación de la situación que está viviendo la persona con la que interactuamos con el fin de comprender por qué actúa como actúa. Mediante la evaluación cognitiva inferimos las variables situaciones que hace que las personas de nuestro alrededor se comporten de una manera $u$ otra pudiendo empatizar con ellas.

Para Van Kleef et al. (2012), estos dos procesos (reacciones afectivas y procesos inferenciales) que se producen en quien observa las expresiones emocionales de las personas con las que comparte espacio organizacional pueden provocar respuestas distintas dependiendo de cuál de los dos predomine en él/ella mismo/a. Por ejemplo, cuando se enfrenta el/la colaborador/a a otro/a compañero/a en una situación de competitividad interna y éste/a se encuentra enojado/a y en conflicto, la propia ira recibida podrá provocar la competencia y las represalias; pero también a través de la evaluación en el proceso de inferencia que realiza quien observa, puede llegar a pensar que el/la otra está molesto/a 
porque no han alcanzado sus propios límites, y por tanto puede fomentar la cooperación estratégica (Van Kleef, De Creu y Manstead, 2004; 2010).

Quien observa prioriza la utilización de un proceso u otro dependiendo de dos tipos de moduladores. Por un lado, se encuentran los moduladores que influyen en la profundidad del procesamiento de la información de quien observa, y por el otro están los que determinan la idoneidad de la expresión emocional percibida.

Con respecto al primer tipo de moduladores, la teoría EASI postula que el nivel de profundidad de la información que procesa quien observa depende de su motivación y de su capacidad de procesar la información. En relación a la motivación, un modulador esencial, es la motivación epistémica, que es considerada como la inclinación por lograr un conocimiento profundo de la experiencia que se está viviendo. Las personas con mayor nivel de motivación epistémica son más propensas a reflexionar sobre las emociones de las otras personas; es en estos casos, dónde los efectos de las expresiones emocionales de otros/as son más propensos a ser mediados por procesos inferenciales deliberados que por reacciones efectivas. La teoría EASI da mucha importancia a la motivación epistémica ya que defiende la idea de que, en la medida en que los/as miembros de una organización estén más motivados para buscar mayor información y realizar un procesamiento cognitivo más profundo, sus respuestas a las expresiones emocionales serán más propensas a ser dirigidas por procesos de inferencia más que por reacciones afectivas.

El segundo tipo de modulador que determina si la respuesta del observador está dirigida por procesos inferenciales o por reacciones afectivas comprenden los factores socio-contextuales que influyen en la adecuación percibida de la expresión emocional. La adecuación de la emoción percibida tiene que ver con que las personas que perciben la 
expresión emocional de otra persona son de alguna manera incompatibles con las expectativas y las normas culturales del grupo. En ocasiones, a nivel laboral se puede apreciar como la respuesta de ira que expresa un/a líder en una cultura individualista se puede ver adecuada, mientras que en una cultura colectivista se puede calificar como discordante. Expresiones inapropiadas de emoción pueden desencadenar estos sentimientos de injusticia interaccional ya que pueden ser vistos como una violación de las normas de conducta apropiada, el respeto, y sensibilidad interpersonal (Van Kleef y Côté, 2007). Los factores que influyen directamente en la percepción de la adecuación o no de una emoción son: la cultura, su nivel de intensidad y autenticidad, los factores de personalidad de quien observa, y finalmente el estatus del emisor de la expresión emocional (Van Kleef, et al., 2012).

La teoría EASI predice que si quien observa en un entorno organizacional recibe como inadecuadas las emociones del emisor, su respuesta es una reacción afectiva más que una respuesta derivada de los procesos de inferencia. Los dos procesos operan al mismo tiempo, tanto el de la reacción afectiva como el de inferencia, pero uno de ellos puede ser el más predictivo del comportamiento final de quien observa.

Para finalizar, un último postulado de la teoría EASI que destaca el efecto social de las emociones, es que se argumenta que los efectos interpersonales de las emociones son los mismos, independientemente del canal por donde viaja la expresión emocional, bien sea el rostro, la voz, el cuerpo, o las palabras. 


\subsection{Contagio Emocional}

Para las dos aproximaciones teóricas descritas anteriormente, teoría de contagio emocional de Kelly y Barsade (2001) y teoría EASI (Van Kleef et al., 2009,2012), el contagio emocional aparece como un efecto afectivo emocional trascendental en las relaciones interpersonales que acontecen en el contexto laboral, pero, ¿qué es exactamente el contagio emocional y qué teorías actuales intentan explicar cómo se produce?

\subsubsection{Concepto de contagio emocional.}

A diferencia de la empatía, en la que el sujeto que recibe la emoción tiene clara la separación entre la conciencia y experiencia emocional del otro y su "yo", en el contagio emocional no existe esta conciencia, tan sólo la vivencia de una emoción similar (Nilson, 2003). El componente cognitivo de la empatía que nos hace percibir, procesar los pensamientos de los/as demás, y por el cual tomamos conciencia de su estado emocional, no existe en el contagio emocional. Preston y Waal (2002) afirmaron que, en contraste con el contagio emocional, en la empatía la diferencia entre el yo y el otro es mantenida y el estado emocional permanece dirigido al objeto, no siendo autodirigido.

Existe un claro consenso en la utilización de la definición de contagio emocional aportada por Hatfield, Cacioppo y Rapson (1992, 1993), como la tendencia a imitar y sincronizar, de forma automática, expresiones faciales, voces, posturas y movimientos. Las experiencias emocionales se encuentran afectadas, a cada momento, por la retroalimentación de esa imitación involuntaria (Hatfield, Cacciopo y Rapson, 1994). Consiste, entonces, en "captar" la emoción del otro y experimentarla junto a él (Hatfield, Cacciopo y Rapson, 1994; Hatfield, Rapson y Yen-Chi, 2009; Singer y Lamm, 2009). De 
esta manera, algunos consideran el contagio emocional como una empatía primitiva (Singer y Lamm, 2009), ya que es una respuesta instintiva y no una acción voluntaria (Hatfield, Rapson y Yen-Chi, 2009).

Según Doherty (1997), las personas especialmente susceptibles al contagio emocional son aquellas que: (a) son capaces de leer las expresiones emocionales de los/as demás; (b) se perciben como interdependientes e interrelacionadas, mucho más que independientes y únicas; (c) tienden a imitar expresiones faciales, vocales y posturales; y (d) su experiencia emocional consciente está muy influida por feedbacks periféricos, es decir, comentarios u observaciones realizadas hacia ellos/as mismos/as por otros/as, aunque de forma indirecta.

Algunos autores consideran al contagio emocional como un fenómeno predominantemente social, resultado de la capacidad innata de las personas para sincronizar su estado afectivo con el otro y que se deriva la sincronía emocional que se produce de forma inconsciente (Doherty, 1997; Laird, 1974).

Hatfield, Cacioppo y Rapson $(1992,1994)$ consideraron que el grado en que se producía el contagio emocional era mediado por los procesos de atención; es decir, a mayor nivel de atención, mayor contagio emocional. Los procesos atencionales pueden ser influenciados por factores externos inherentes a la emoción, tales como el tipo y el nivel de energía con la cual la emoción se expresa, o por diferencias que influyen en la atención a las emociones de los/as demás, como el género dónde las mujeres apuntan a mayor nivel de contagio emocional que los hombres (Doherty, 1997; Lundqvist y Dimberg, 1995), las diferencias en tendencias hacia la imitación espontánea (Laird,1994), y en la propensión general a la captura emociones de los/as demás (Doherty, 1997). 
Para Barsade (2002), el contagio emocional y sus resultados pueden variar sobre todo por la valencia de la emoción y el grado de energía con la que es expresada. Por ejemplo, el impacto en los demás de emociones con valencia negativa como, la hostilidad, está mediatizado por el nivel de energía con el que se expresen, si se expresan con una alta energía se va a producir mayor nivel contagio que si se produce al contrario.

Se ha analizado la relación entre contagio emocional y el sentimiento de constreñimiento que es definido como un estado psicológico de naturaleza afectiva que ocurre en situaciones en las que se reconoce haber quebrantado una norma social (Keltner, 1999). Una de las consecuencias esenciales del constreñimiento en contextos de interacción social es la incapacidad de la persona para seguir adelante en el desempeño de un papel social (Goffman, 1956; Gross y Stone, 1964). Un grupo de investigación brasileño-español ha mostrado como el contagio emocional puede explicar, con un valor predictivo bajo pero significativo, la aparición del constreñimiento (Gondim, Gouveia Morais y Alberton, 2013)

Por último, existe un nuevo y polémico estudio sobre el contagio emocional a través de las redes sociales, en concreto de la red Facebook. Bajo un modelo matemático siguiendo el marco hipotético del contagio de las emociones, se ha demostrado que los usuarios de la red no sólo quedaban influenciados los días de lluvia, sino que la emoción negativa de tristeza que sentían era capaz de viajar en la red y contagiar esta emoción en una proporción de uno a dos amigos de diferentes ciudades dónde el clima era benigno haciendo que éstos escribiesen mensajes de estado negativo. Los resultados sugieren que las redes sociales pueden incrementar el potencial de sincronía emocional entre los/as usuarios/as (Kramer, Guillory y Hancock, 2014). 


\subsection{2. ¿Cómo se produce el contagio emocional?}

Para responder a esta cuestión se tomará en cuenta dos posturas complementarias.

Por un lado, se describe el punto de vista más social entendiendo el contagio emocional como un componente dentro del desarrollo de las interacciones sociales; y por otro, se explica qué posibles mecanismos neuronales inciden en la posible aparición del contagio emocional.

\subsubsection{Perspectiva social}

La primera postura describe el contagio emocional como un proceso de influencia social que se puede producir a través de una respuesta de contagio primitiva inconsciente o mediante una respuesta consciente de comparación emocional (Barsade, 2002) (ver Figura 3.4).

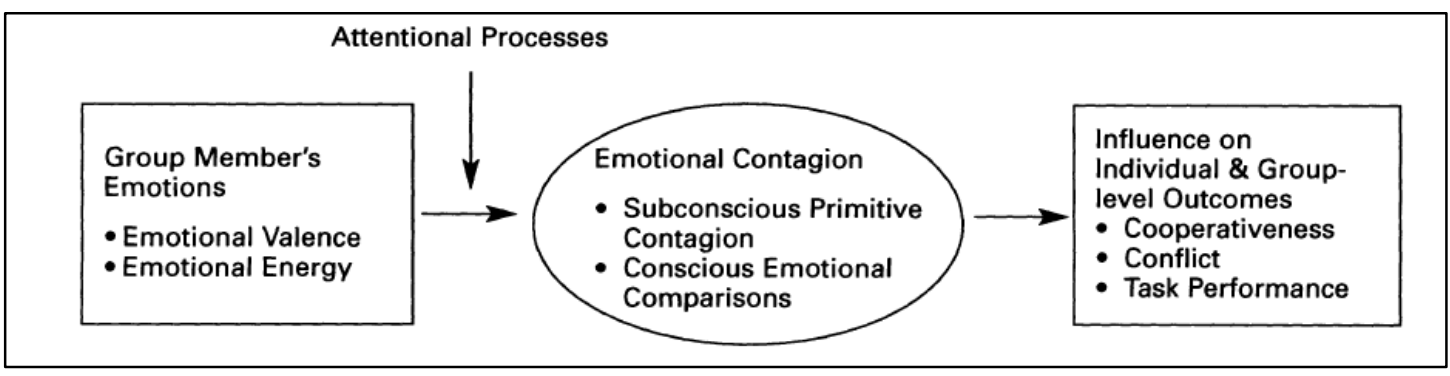

Figura 3.4: Modelo de Contagio Emocional Grupal (Barsade, 2002)

Barsade (2002) estableció un modelo de cómo se produce el contagio emocional, que actualmente es el más seguido desde una perspectiva social así como de los/as investigadores/as de los procesos de inteligencia emocional. Para esta autora, el proceso de 
contagio emocional puede acontecer de dos formas: (1) por contagio primitivo inconsciente, o (2) por contagio por comparación. El contagio primitivo se desarrolla en dos etapas: mímica emocional, y retroalimentación de imitación de gestos y comportamientos no verbales.

En la primera etapa las personas imitan inconscientemente las conductas emocionales de los/as demás, se produce lo que se denomina mímica emocional o sincronía (Barsade, 2002). Los investigadores han encontrado que este primer paso (más primitivo) implica el mimetismo no consciente, automático, en el cual las personas espontáneamente imitan expresiones faciales de los/as demás (Dimberg, 1982; Lundqvist y Dimberg, 1995), el lenguaje corporal (Chartrand y Bargh, 1999;), patrones del habla (Ekman, Friesen y Scherer, 1976), y tonos vocales (Hatfield, Hsse, 1995). Con respecto a las investigaciones que se han centrado en la expresión no verbal, Zajonc (1984) y su equipo hallaron que los/as participantes que intentaron recordar fotografías de su graduación cuando se les permitió observarlas lo que hacían era imitar las expresiones faciales que vieron en las fotografías de los/as graduados/as. Estos comportamientos de imitación se han encontrado en estudios con niños/as recién nacidos/as, que son capaces de imitar gestos de sus padres y madres con tan sólo unos días de vida (Field, Woodson, Greenberg, y Cohen, 1982; Haviland y Lelwica, 1987). Basándose en estos resultados, hay autores que postulan que esta imitación de comportamientos de otros/as es una tendencia innata en el ser humano (Davis, 1983; Levenson, 1996; Wild, Erb y Bartels, 2001). Para completar esta afirmación, esta conducta de imitar lo que se ve, aparece por la necesidad humana de buscar afiliaciones y de poder compenetrarnos entre nosotros/as incrementando los resultados de interacción interpersonal positivos (Lakin y Chartrand, 2003). 
La segunda etapa se refiere al proceso de retroalimentación de imitación de gestos y comportamientos no verbales, por el cual cuando nos involucramos en el comportamiento de imitación, generamos los mismos gestos que la otra persona, y por tanto somos capaces de sentir su estado emocional.

Para Barsade (2002) el contagio emocional también se puede producir como una forma de ajuste a la emoción que un grupo está viviendo. Es decir, se produce una comparación entre la emoción grupal y la de uno/a mismo/a, siendo el resultado de dicha comparación, una repuesta de ajuste emocional apropiada a la situación.

La valencia de la emoción y la energía emocional con la que se expresan las emociones influyen en el contagio emocional y, por ende, en la respuesta de los/as integrantes de un grupo o de la persona que está en situación de interacción. La energía emocional se refiere a la intensidad con que las emociones se expresan de una persona a otra (Barsade, 2002). Una alta expresión de desagrado puede inducir a efectos de contagios más acentuados que una baja expresividad de la misma emoción. Esto se debe a que las personas que observan emociones expresadas con mayor energía tienen mayor nivel de exposición, por tanto dichas emociones tienen mayor oportunidades de recibir atención (Robinson y McArthur, 1982), y de ahí a producir mayor efecto de contagio emocional (Barsade, 2002).

Las investigaciones de Barsade demostraron que el contagio emocional es una poderosa herramienta por la que se ejerce influencia emocional en los/as demás, afectando sus emociones y sus comportamientos, como más tarde incluiría Van Kleef $(2009,2012)$ en su modelo EASI. 


\subsubsection{Perspectiva neurofisiológica}

El impacto de la aparición de las neuronas espejo y el énfasis en buscar explicaciones del funcionamiento del ser humano desde las neurociencias ha alcanzado al contagio emocional.

El contagio emocional y la empatía, son dos procesos distintos que básicamente se diferencian en que a través de la empatía se es capaz de experimentar lo que otros sienten y atribuir esa experiencia a los demás y no asimismo (Gallese, Migone y Eagle, 2009). Por el contrario en el contagio emocional se produce un reflejo de la emoción del otro sin compartir su perspectiva, aunque puede provocar también cambios comportamentales en el/la observador/a. Se puede, de forma involuntaria, tomar las emociones de otros/as, aun sin conciencia de empatía o reconocimiento emocional (Ruggieri, 2013).

Tanto la empatía como el contagio emocional comparten una etapa inicial que es la de imitar las expresiones emocionales de la persona, o del grupo en el que estamos interactuando. La imitación es clave para el desarrollo de pautas sociales, ya que permite que imitemos gestos, expresiones faciales y acciones. Los seres humanos tendemos a imitarnos los/as unos/as a los/as otros/as cuando interactuamos entre nosotros/as. Con este mecanismo se da un ajuste social, un reconocimiento mutuo en lo que es denominado “fenómeno del camaleón” (Ruggieri, 2013).

El proceso de imitación se encuentra desde que somos bebés. Se ha podido demostrar que a las pocas horas de nacer somos capaces de imitar y reproducir los movimientos de la boca y de la cara de los adultos que nos miran (Meltzoff, 2002; Meltzoff y Moore, 1977). Por ejemplo, Harrison y sus colaboradores (Harrison, Singer, Rotshtein, Dolan, y Critchley, 2006) demostraron el contagio pupilar involuntario en resonancia 
magnética funcional (RMf). En otro tipo de investigación a un conjunto de participantes se les expuso una secuencia de fotos de caras tristes. Se comprobó que cuando veían caras tristes con pupilas pequeñas reducían sin darse cuenta sus pupilas ajustándose e imitando lo que observaban. Esto se producía por la activación inconsciente del núcleo EdingerWesphal que es el responsable del control pupilar (Harrison, et al., 2007)

En la actualidad, una de las teorías más defendidas es que, en este mecanismo de imitación, la activación de las neuronas espejo media en su ejecución (Rizzolatti y Craighero, 2004). También entran en juego otras estructuras cerebrales muy importantes para la recepción de expresiones emocionales como la amígdala y la ínsula. La tendencia de la investigación actual es la de situar a la activación de las neuronas espejo como responsables de las conductas de imitación a nivel cerebral. A partir de los resultados de algunas investigaciones (Gallese, 2001, 2003, 2005, Iacobini y Dapretto, 2004; Rizolatti, Fadiga, Gallese, y Fogassi, 1996) se teoriza que debido a la activación de las neuronas espejo se produce tanto la empatía como el contagio emocional.

\subsubsection{Liderazgo y contagio emocional.}

Sin duda, durante los últimos veinte años, las investigaciones sobre las emociones en el mundo organizacional se han desarrollado con gran fuerza (Côté y Hideg, 2011; Elfenbein, 2007; George, 2011). El contagio emocional es objeto de estudio, tanto desde un ámbito académico como empresarial, ya que influye en las relaciones interpersonales laborales. Los/as líderes y colaboradores/as, a través de la imitación y sincronía emocional de las emociones ajenas, establecen un vínculo afectivo que repercute en varios aspectos del entorno de trabajo. En esta interacción e influencia mutua es fundamental el baile 
emocional que se desarrolla entre ambos sin mediar el lenguaje verbal, dónde las señales no verbales adquieren una importancia capital en esta influencia (Hatfield et al., 1993; Gouveia et al., 2006). Las señales no verbales (expresiones faciales, lenguaje corporal y tono de voz) cumplen un papel fundamental en la influencia de emociones, mucho más que el comportamiento verbal (Gouveia et al., 2006; Hatfield et al., 1993). Para el/la colaborador/a es transcendental estar atento/a las emociones del/la líder, pues le permite mejorar su comprensión de la situación que se está viviendo, y adaptar sus actitudes y comportamientos para mejorar la interacción y el vínculo (Van Kleef et al., 2012).

La atención investigadora de la influencia de las emociones de los/as líderes sobre sus colaboradores/as tuvo el arranque con los experimentos de Sigal Barsade (2002). En uno de ellos (2002), reunió a un grupo de voluntarios/as que tenían que representar el papel de gerentes/líderes y debían discutir sobre que se hacía con las primas de final del año. Sus objetivos eran conseguir para sus colaboradores/as las mayores primas posibles, y al mismo tiempo, tratar de tomar las mejores decisiones para la organización en general. Lo que no sabían es que había contratado un actor que representaba varios estados emocionales diferentes: entusiasmo/a, efervescente, calidez, relajado/a, sereno/a, deprimido/a, e irritable, hostil y desagradable. Los/as participantes se contagiaron como un virus de la emoción representada por su líder llegando inclusive a cambiar su humor sin darse cuenta dependiendo de la emoción que expresaba el actor. De igual modo, los grupos contagiados con la emoción positiva presentaban menos conflictos y mayor cooperación que sus compañeros/as con un estado emocional negativo (Barsade, 2002).

A partir de este experimento se inició una serie de investigaciones en las que se pudo comprobar que las emociones del/la líder influían en aspectos como el 
comportamiento, clima de trabajo y desempeño de sus colaboradores/as a través del contagio emocional (Van Kleef, De Dreu y Manstead, 2010).

En la relación laboral diaria con su líder, los/as colaboradores/as le dan absoluta importancia a las expresiones que éste/a emite, siendo estímulos importantes para ellos/as y que son interpretados tomando en cuenta el tipo de valencia emocional con las que son emitidas. La evidencia científica de la existencia de tal efecto de influencia emocionalafectación es extensa y variada. Es importante destacar la investigación de Côté y Saavedra (2005) en la que se comprobó que el estado de ánimo del/la líder se transmite a sus colaboradores/as influenciando, tanto las emociones de los/as colaboradores/as, como su esfuerzo, como la efectividad en la coordinación del grupo para la realización de una tarea. Lo que hicieron los investigadores es dividir el grupo de participantes en equipos y de ellos se seleccionó a una persona que tenía que tenía que desempeñar las funciones de líder de equipo. A cada uno de estos/as líderes se les indujo un estado emocional negativo o positivo. Seguidamente, debían dar instrucciones a sus equipos de trabajo de cómo montar una tienda de campaña con los ojos vendados. Este estudio reveló que el estado emocional positivo del/la líder potenciaba una mejor coordinación del grupo. Por el contrario, cuando el/la líder estaba bajo un estado emocional negativo este se contagiaba a los/as colaboradores/as generando un mayor esfuerzo en la realización de la tarea que los colaboradores/as bajo un estado emocional positivo.

Ashkanasy y su equipo (2009) recogiendo la investigación anterior y, apoyándose en un modelo de análisis de la relación bidireccional entre el/la líder-colaborador/a dónde daban especial importancia al proceso de contagio emocional, también encontraron como 
las emociones negativas del/la líder se transmitían a sus colaboradores/as afectando al clima de trabajo y las relaciones entre los miembros del grupo de forma negativa.

La influencia de las expresiones emocionales del/la líder en el desempeño de las tareas de los/as colaboradores/as queda respaldada también con las investigaciones realizadas por Johnson (2009). Esta autora pudo comprobar, ya no sólo que se producía un contagio de emociones entre líderes y colaboradores/as, sino que el desempeño en una simulación de prueba de contratación quedaba mediado por el estado emocional que el/la líder mostraba a sus colaboradores/as. Previamente, la misma autora había mostrado la influencia del estado emocional del/la líder en los resultados organizacionales y en la valoración que hacían los/as colaboradores/as de su líder como carismático/a. En ambos estudios Johnson $(2008,2009)$ destacó el rol fundamental del contagio emocional y la necesidad de seguir explorando las causas del mismo, así como la influencia que también ejercen los/as colaboradores/as en su líder en una dirección de abajo a arriba. En esta misma dirección apuntaron Gaddis, Connely y Munford (2004) y George (1995) al demostrar como el/la líder con un estado emocional positivo incidió en el desempeño grupal. En la interacción entre líder y colaborador/a en ocasiones es más importante el cómo que el qué. Esta idea quedó evidenciada en los resultados obtenidos por Newcombe y Ashkanasy (2002) que demostraron que las emociones que desprendían los/as líderes podían tener un mayor impacto en los/as colaboradores/as, más que el contenido formal de las mismas. Estos autores mostraron a un grupo de participantes un vídeo sobre el feedback que una serie de líderes impartían a sus colaboradores/as sobre el desempeño positivo o negativo obtenido empleando expresiones faciales positivas o negativas. El resultado obtenido fue que los/as líderes que utilizaban expresiones negativas en desempeños 
positivos conllevó puntuaciones bajas por parte de los/as colaboradores/as. Los/as líderes que fueron mejor valorados fueron los que mostraban sinceridad, congruencia con el mensaje formal y las expresiones emocionales positivas. Côté, et al. (2010) encontraron que las personas que son capaces de: percibir con precisión las emociones, utilizar la comprensión, realizar una adecuada gestión se sus propias emociones y la de los demás, es más probable que alcancen un rol de líder en grupos pequeños. También se ha encontrado evidencias que el/la líder con sus expresiones emocionales influye en el clima emocional del grupo a través del efecto de sus emociones a los/as colaboradores/as de forma individual y de ahí a la percepción del grupo (Johnson, 2009, Vijayalakshmi y Bhattacharyya, 2012).

Con respecto al efecto interpersonal del contagio emocional del/la líder y los aspectos cognitivos y cumplimientos de metas del colaborador/a, se recogen dos de las pocas investigaciones existentes al respecto. La primera investigación ha sido desarrollada en Alemania (Volmer, 2012) y buscaba analizar el efecto de las emociones del/la líder en el tono afectivo del grupo, en el rendimiento del equipo, la potencia, y en el compromiso. Para ello, la investigadora siguió el siguiente modelo teórico (ver Figura 3.5).

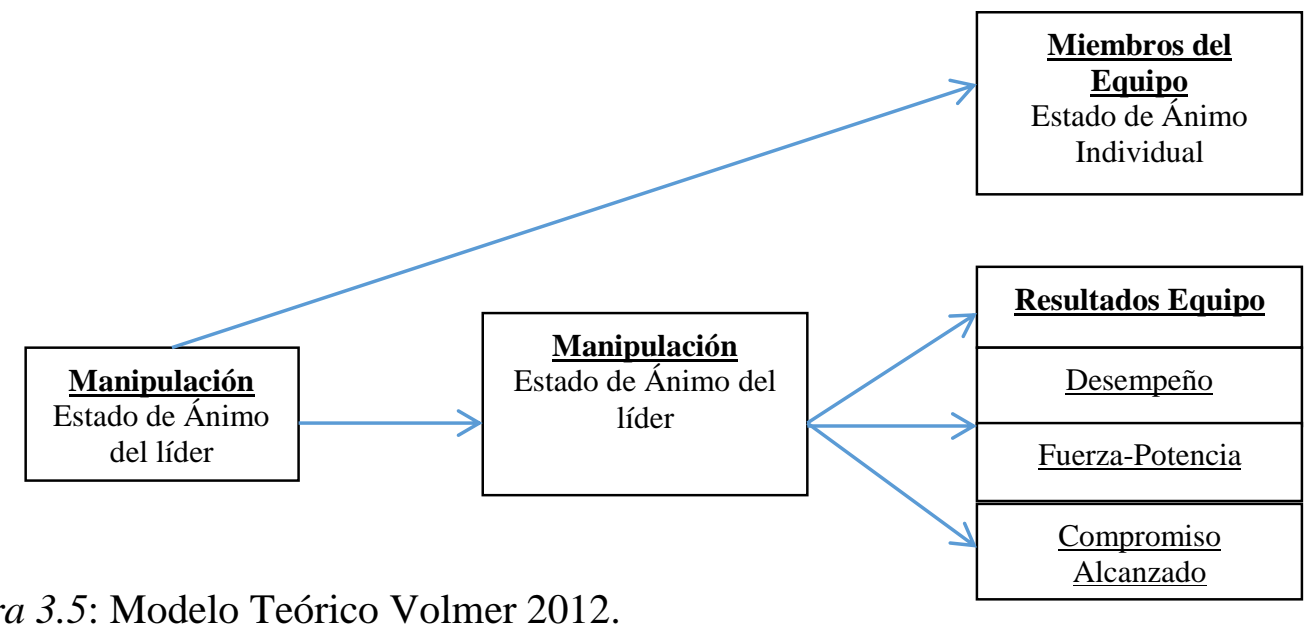

Figura 3.5: Modelo Teórico Volmer 2012. 
Volmer (2012) encontró que el estado emocional influenciaba en las emociones individuales de los/as miembros del equipo, así como en el desempeño, y en la potencia de los equipos. Por otra parte, los resultados obtenidos indicaron que el tono afectivo grupal mediaba la relación entre el estado de ánimo y la potencia de los/as colaboradores/as. Finalmente, demostró que los/as líderes influían en el estado de ánimo particular de los/as miembros/as del equipo, en el tono afectivo grupal, en el rendimiento del equipo, y en la potencia; éstas dos últimas variables enlazadas con el componente socio-cognitivo del colaborador/a.

La segunda investigación clave (Visser, Knippenberg, Van Kleef, y Wisse, 2013) trata la relación entre las emociones del/la líder y su influencia a través del contagio emocional en diferentes variables cognitivas de los/as colaboradores/as. Su hipótesis inicial era que tanto el tipo de expresión emocional del/la líder feliz o triste influenciaba en los resultados cognitivos de sus colaboradores/as dependiendo del tipo de tarea si era analítica o creativa. De igual modo, el/la líder que mostraba felicidad era visto por sus colaboradores/as, al contrario que los que expresaban tristeza, como más eficaces independientemente del tipo de tarea.

Para ello, diseñaron dos estudios que se complementaban mutuamente buscando corroborar las hipótesis iniciales planteadas.

En el primer estudio existían dos tipos de líderes: los/as líderes que expresaban felicidad y los/as que expresaban tristeza. La cognición de los/as colaboradores/as fue medida a través de los dos tipos de tareas que debían de realizar los/as colaboradores/as; por un lado la tarea creativa, que consistió en que debían de dar ejemplos de diferentes cosas que se podía realizar con un vaso de agua. Con ello se estimulaba el pensamiento 
divergente para la generación de ideas. Por otro lado, la tarea analítica se midió con un sudoku con veintisiete celdas ya completadas y se les pidió que completasen todas las que faltantes que pudiesen. En ambos tipos de tarea se les solicitó que se centrasen en respuestas de calidad; en el caso de la tarea que exigía creatividad las respuestas fueron evaluadas por evaluadores independientes, y para la tarea analítica fue medida por la proporción de respuestas correctas por el número de respuestas facilitadas. Para finalizar, en este primer estudio se les pidió que indicasen lo feliz o lo triste que les había parecido el líder asignado así como la evaluación del nivel de efectividad del liderazgo recibido.

En el segundo estudio se añadió como variable de control un tipo de líder que expresaba emociones neutrales además de las dos analizadas anteriormente de felicidad y tristeza. También se modificó las tareas a realizar y se amplió las exigencias de respuestas para cumplir la validación de las mismas, calidad, y cantidad. La tarea de creatividad diseñada para medir el pensamiento divergente consistía en que dibujasen todos los objetos posibles con forma de rectángulo, círculos, y/o triángulos poniéndoles nombre. La tarea analítica consistió en una actividad de concentración mental (Brickenkamp, 1981). La versión en ordenador consta de 42 símbolos que aparecen en la pantalla (Stam, van Knippenberg, y Wise, 2010). Había seis símbolos diferentes: $d s$ y ps con uno, dos, o ningún apostrofes por encima de ellos. Se pidió a los/as participantes a hacer clic sólo en $d s$ con dos apostrofes y no a los otros cinco símbolos. Este proceso de búsqueda de símbolos específicos requiere pensamiento convergente. Se muestran en la pantalla del ordenador combinaciones de símbolos durante 6 segundos pidiéndoles a los participantes que hagan clic en la combinación demandada y que no haga clic en cualquier otro tipo de símbolo. 
Al igual que en el primer estudio, se midió la emoción percibida del colaborador/a y el nivel de efectividad del tipo de líder visualizado.

Los resultados que obtuvieron en ambos estudios mostraron que un/a líder que expresa emoción de felicidad mejora el rendimiento del colaborador/a en la tarea creativa. Por otro lado, un/a líder que exprese tristeza consigue que el rendimiento de sus trabajadores/as mejore cuando realizan actividades que exigen procesamiento analítico de la tarea. De igual modo los/as colaboradores/as que estaban bajo la influencia del/la líder que expresaba felicidad consideraron que este/a líder era más eficaz, independientemente del tipo de tarea a desarrollar.

Desde mi punto de vista, esta investigación es clave porque, además de corroborar la influencia de las emociones del/la líder sobre sus colaboradores/as en factores cognitivos de rendimiento a través del contagio emocional, profundiza en cómo se produce esta relación teniendo en cuenta el tipo de naturaleza de la tarea a realizar por parte de los/as colaboradores/as. 


\section{Capítulo 4. Engagement, Vigor, y su influencia en el liderazgo}

"El conocimiento no es una pasión desde fuera de la mente, sino un ejercicio activo de la fuerza interior, el vigor y el poder de la mente, que muestra desde dentro"

Ralph Cudworth

"Estudié la vida de grandes y famosos hombres y mujeres, y descubrí que aquellos que llegaron a destacar fueron los que emprendían todo trabajo que les tocase hacer con el vigor, energía y entusiasmo del que eran capaces." Harry S. Truman 


\subsection{Marco contextual: Psicología Positiva aplicada al contexto organizacional}

A lo largo de la última década ha existido un creciente interés en utilizar un enfoque positivo en las investigaciones sobre el mundo organizacional (Bakker, Rodríguez-Muñoz y Derks, 2012). Sin embargo, a pesar de que han comenzado a aparecer numerosos libros (por ejemplo, Cooper y Nelson, 2006), y artículos especializados (por ejemplo, Bakker y Schaufeli, 2008), todavía en la investigación actual prima el análisis de los aspectos negativos, como la inseguridad en el trabajo, el estrés o el acoso (Bakker y RodríguezMuñoz, 2012).

La aparición de la Psicología Positiva ha provocado que se desarrolle un nuevo enfoque en el estudio de la Psicología Organizacional denominado Comportamiento Organizacional Positivo (COP) que incluye el Capital Positivo Organizacional, el estudio del Conocimiento Organizacional Positivo, la Psicología de la Salud Ocupacional Positiva (POSP), y el constructo de Organizaciones Saludables (OS).

De acuerdo con Luthans (2002), el COP se refiere al estudio y aplicación de las fortalezas y capacidades psicológicas del factor humano orientados positivamente, que pueden ser medidos, desarrollados y manejados de manera efectiva para mejorar el desempeño en el trabajo. Según este autor, el comportamiento organizacional positivo incorpora muchos conceptos existentes en el comportamiento organizacional tales como, las actitudes, la personalidad, la motivación y el liderazgo. Este campo de conocimiento, tal como lo señala Luthans (2002), requiere el desarrollo de nuevos constructos, teorías e investigaciones. Dentro de los comportamientos organizacionales positivos se pueden identificar aquellos estudiados por la psicología (asertividad, autoeficacia, motivación) y la Psicología Organizacional (bienestar en el trabajo, compromiso organizacional, 
engagement, satisfacción laboral, retención en el empleo, justicia organizacional) y los abordados por la Psicología Positiva (comportamiento pro-social, inteligencia emocional, optimismo, resiliencia). Mientras tanto, en el grupo de comportamientos organizacionales negativos encontramos muchos aspectos abordados tradicionalmente por la psicología (alienación, burnout, estrés laboral, evitación del trabajo, resistencia al cambio, absentismo, violencia y acoso en el trabajo, sobrecarga de trabajo), además de las desviaciones del comportamiento y conductas organizacionales (Kidwell y Martin, 2005; Robinson y Benett, 1995).

Según Luthans, Youssef, y Avolio (2007), el COP se diferencia de las Prácticas Organizacionales Positivas en que estas últimas tienden a concentrarse más en lo macro, en lo organizacional, mientras el COP, al menos en sus inicios, se centra en lo micro, en lo individual. Otra diferencia es que las Prácticas Organizacionales Positivas trabajan con constructos como la compasión y el virtuosismo (Cameron, Dutton y Quinn, 2003), los cuales, pueden, o no, ser un estado, mientras los constructos incluidos en el COP deben reunir el criterio de ser un estado, no sólo un rasgo, y por tanto abierto al desarrollo y mejora.

Tradicionalmente los estudios sobre el COP exploran las condiciones psicológicas positivas y fortalezas humanas que se relacionan con el bienestar de los/as trabajadores/as, o con la mejora del rendimiento (Bakker y Rodriguez-Muñoz, 2012). La investigación puede centrarse, por ejemplo, en las capacidades cognitivas de la creatividad y las capacidades afectivas del engagement y el humor en el lugar de trabajo (Van den Broeck, Vander Elst, Dikkers, De Lange y De Witte, 2012). Una de las teorías más seguidas por los/as investigadores/as en este nuevo enfoque de estudio del comportamiento humano 
organizacional es el del Capital Psicológico Positivo (CPP). A nivel general, se describe el CPP como un estado de desarrollo psicológico positivo del ser humano que va más allá del capital humano y social, comprende la inversión en tiempos y esfuerzos necesarios, y el desarrollo de las habilidades adquiridas para la mejora del rendimiento y la competitividad (Luthans, Avolio, Walumbwa y Li, 2005). El CPP es definido como un estado de desarrollo psicológico positivo individual que se caracteriza por: (1) perseverar hacia las metas y, cuando sea necesario, redireccionar los caminos hacia dichas metas (esperanza) para tener éxito; (2) tener confianza (autoeficacia) para asumir y realizar el esfuerzo necesario para tener éxito en tareas difíciles; (3) cuando uno/a se vea acosado/a por los problemas y adversidades, mantenerse y recuperarse (resiliencia) para alcanzar el éxito ; y (4) hacer atribuciones positivas (optimismo) sobre el éxito actual y futuro (Luthans, et al., 2007). Siguiendo las siglas en inglés, es lo que se conoce como HERO (Hope, Efficacy, Resilience, Optimism) (Luthans et al., 2007).

Tal y cómo argumentan Garazi, Domínguez, Moriano y Molero (2014), el CPP se presenta como un constructo que puede jugar un papel crucial en el desarrollo de los individuos, equipos y organizaciones (Luthans, 2002; Luthans y Avolio, 2003; Seligman, 2002; Seligman y Csikszentmihalyi, 2000;). Estudios recientes realizados en diversos países y utilizando diferentes grupos ocupacionales, apoyan la existencia de una relación positiva entre el CPP y otras variables psicosociales y organizacionales tales como el liderazgo, la confianza, la creatividad, y el rendimiento, entre otras (Clapp-Smith, Vogelgesang y Avey, 2009; Luthans, et al., 2007; Rego, Sousa, Marqués, Pina, y Cunha, 2012). Dentro de este interés por el estudio de variables positivas algunos/as investigadores/as se interesaron por analizar el Conocimiento Organizacional Positivo 
(Bakker y Rodriguez-Muñoz, 2012). Con ello se facilitó un marco teórico para organizar e integrar la investigación sobre las organizaciones positivas (Cameron, Dutton y Quinn, 2003). El Conocimiento Organizacional Positivo se ha definido como el estudio de los aspectos organizacionales positivos que facilitan el desarrollo (Cameron y Caza, 2004), cuyo énfasis radica principalmente en los factores positivos del contexto organizacional que influyen en la habilidad de los/as colaboradores/as para su crecimiento (Cameron, 2010). Finalmente, con respecto al área de Salud Organizacional, la influencia de la Psicología Positiva y del COP lleva a la aparición de la Psicología de la Salud Ocupacional Positiva (POSP).

“La PSOP se puede definir como estudio y la aplicación de las condiciones y proceso que contribuyen al funcionamiento óptimo en el lugar del trabajo. Promueve la salud en el trabajo y el desarrollo de los trabajadores, y examina cómo los fenómenos positivos (fortalezas, virtudes, recursos personales) pueden ser utilizados como protección frente a los riesgos laborales” (Bakker y Rodriguez-Muñoz, 2012, p. 63).

\subsection{Organizaciones Saludables}

El término organización saludable se compone de dos dimensiones; por un lado la visión organizacional que encierra los procesos organizaciones, la estrategia organizacional, las políticas de recursos humanos, el tipo de liderazgo y las acciones organizacionales para la adaptación de los/as colaboradores/as; y por el otro, el término saludable, que tal y como recoge Salanova (2008), deriva de la distinción de los procesos que provocan sistemas organizacionales sanos y enfermos. La organización saludable se 
define como aquella organización que establece procesos de trabajo que promueven y mantienen un estado de completo bienestar físico, mental y social de sus trabajadores/as y, a su vez, tiene una alta eficacia y rendimiento laboral. La estructura de la organización y como ésta funciona tiene una amplia repercusión en la salud y el bienestar de las personas trabajadoras, y, en última instancia, en la eficacia de la propia organización (Wilson, Dejoy, Vandenberg, Richardson y McGrath, 2004). Es por ello que en el ámbito organizacional pueden existir organizaciones saludables que se caracterizan por colaboradores/as con alto bienestar y rendimiento, así como una buena salud financiera (Arnet y Blomkvist, 2007), o bien organizaciones tóxicas que provocan estructuras enfermas en su funcionamiento provocando que los/as trabajadores/as sientan desmotivación, incidiendo en un alto absentismo, mala calidad de vida laboral y rotación, que se refleja en pérdidas económicas. Por ello, el postulado teórico es que las organizaciones saludables provocan el ganar-ganar entre la empresa y los/as colaboradores /as.

Actualmente uno de los modelos teóricos de mayor relevancia y acogida investigativa es el modelo Healthy and Resilient Organization (HERO). Esta propuesta teórica desarrollada por Salanova, Llorens, Cifre y Martínez (2012) aparece en un momento de turbulencia y crisis económica dónde las autoras destacan la necesidad de contar en las organizaciones con colaboradores/as resilientes que sean capaces de resistir y sobrevivir en esta coyuntura económica negativa. Las empresas HERO son aquellas organizaciones que hacen esfuerzos planeados, sistemáticos, y proactivos para la mejora de los colaboradores/as y de los procesos y resultados organizacionales (Salanova, 2008, 2009; Salanova, Cifre, Martínez, I.M., Llorens, S., y Lorente, 2011). 
El Modelo HERO es un modelo heurístico debido a que integra resultados basados en evidencia teórica y empírica que proviene de las investigaciones sobre estrés laboral, Dirección de Recursos Humanos (DRH), comportamiento organizacional, y desde la Psicología de la Salud Ocupacional Positiva (Llorens, Del Líbano y Salanova, 2009).

Dicho modelo (ver Figura 4.1) integra tres niveles de análisis (individual, grupal y organizacional) y recoge tres dimensiones: 1) recursos y prácticas saludables, 2) empleados saludables, y 3) resultados organizacionales saludables.

\section{Modelo HERO}

\begin{tabular}{|c|}
\hline $\begin{array}{c}\text { Recursos y Prácticas } \\
\text { organizacionales Saludables }\end{array}$ \\
\hline Demandas de tarea y sociales \\
Recursos de tarea y sociales \\
Prácticas Organizacionales \\
\hline
\end{tabular}

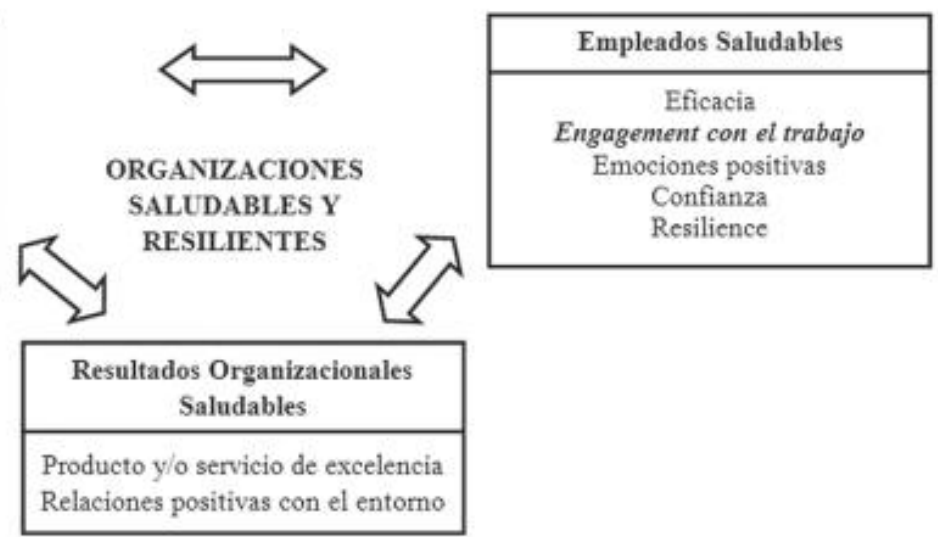

Figura 4.1: Modelo HERO (Healthy and Resilient Organizations Model). Adaptado de (Salanova, Llorens, Cifre y Martínez, 2012)

\subsubsection{Recursos y prácticas organizacionales saludables}

Los recursos y prácticas organizacionales saludables se refieren al despliegue constante de actividades efectivas destinadas a que la organización logre sus objetivos (Salanova, Martínez y Llorens, 2014). Las autoras basan su fundamentación teórica en varios modelos teóricos previos sobre salud psicosocial. En este sentido como claro 
antecesor aparece el modelo teórico de salud ocupacional de Demandas y Recursos Laborales (Demerouti, Bakker, Nacheriner y Schaufeli, 2001) que plantea que las condiciones de trabajo pueden dividirse en dos grandes categorías: demandas laborales y recursos laborales, y que se relacionan de modo distintos con resultados específicos de estrés y salud.

“Las demandas se definen como aquellos aspectos físicos y/o psicológicos, sociales y/u organizacionales que requieren del trabajador un esfuerzo físico y/o psicológico y que se asocian con costes físicos y/o psicológicos, mientras que los recursos laborales son aquellos aspectos físicos, psicológicos, sociales u organizacionales del trabajo que son funcionales en el logro de metas laborales, reducen las demandas laborales y estimulan el crecimiento y el desarrollo personal" (Rodríguez-Sánchez y Cifre, 2012, p.46)

A nivel general, las demandas laborales se refieren a aquellos factores del trabajo que requieren un esfuerzo y se relacionan con costes fisiológicos y psíquicos, como la fatiga, que llevan al agotamiento del colaborador/a a través de un proceso de erosión. Por el contrario, los recursos laborales tienen un efecto motivador y positivo en el colaborador/a. A mayor incremento de los recursos, se produce mayor bienestar del trabajador/a.

El modelo de Demandas y Recursos Laborales es ampliado por el grupo de investigación WONT (Work \& Organizacional NeTwork) de la Universidad Jaume I de Castellón (España), el cual propone una ampliación denominada Modelo RED (RecursosExperiencias-Demandas) o Modelo Espiral de la Salud Ocupacional (Salanova, Cifre, 
Martínez, Llorens,. 2007). Esta aproximación integra en el estudio de la salud tanto aspectos negativos (por ejemplo, burnout, adicción al trabajo) como positivos (por ejemplo, engagement y flow). Al contrario que el modelo de Demandas-Recursos, en éste se establece una categorización de las demandas laborales. Por un lado, están las demandas amenazantes (por ejemplo, mala dirección del superior) que presentan un riesgo para la salud y bienestar de la persona trabajadora, provocando emociones negativas; y por otro lado, existen demandas retadoras (por ejemplo un nueva tarea a realizar) que tiene una evaluación subjetiva positiva y son contempladas como un reto a superar, provocando emociones positivas y un estilo de afrontamiento de la situación desafiante. El modelo RED incorpora como principal novedad la importancia de los recursos personales (por ejemplo la autoeficacia) en la percepción y control de las condiciones de trabajo, así como la incorporación de dos procesos psicológicos de respuestas a las demandas y recursos que se desarrollan en forma de dos espirales. A saber, la espiral de deterioro de la salud, que conlleva una respuesta de erosión ante la falta de recursos existentes para afrontar las demandas existentes, lo que provocan daños en la salud, baja motivación, absentismo y bajo rendimiento. Y la espiral de motivación, que por el contrario, favorece un incremento de la motivación alimentando el compromiso del/a trabajador/a, incrementando su desempeño y bienestar psicológico (véase la teoría Broaden-and-Build de Bárbara Fredrickson, 2001).

Con respecto a los recursos organizacionales, el Modelo RED tiene en cuenta el modelo vitamínico de Warr (1987) que considera que las características ambientales tienen un efecto tanto positivo como negativo sobre el bienestar psicológico del/a trabajador/a de la misma manera en que las vitaminas ejercen una influencia particular en el cuerpo 
humano. Recogiendo esta idea inicial de Warr que, posteriormente es ampliada, se describen cuáles son los tipos de recursos que incluyen en la conceptualización de una organización saludable (Salanova, 2009).

\section{a) Recursos Organizacionales:}

Se relacionan con las prácticas organizacionales, directivas y de recursos humanos (por ejemplo, cultura, valores organizacionales, objetivos organizacionales, las estrategias de conciliación, programas de formación y desarrollo de carrera).

\section{b) Recursos Sociales:}

Tienen que ver con las relaciones que se forman con las personas con las que trabajamos y para las que trabajamos, como son los y las compañeros/as de trabajo, los/as jefes, y los/as clientes/usuarios/as. Fomentan la conexión del colaborador/a /a con las personas con las que se trabaja, y para las que se trabaja.

c) Recursos de tarea:

El Modelo HERO intenta facilitar y esclarecer las prácticas organizacionales que puedan ampliar los diferentes tipos de recursos y fortalezas existentes en una organización. En esta línea, una investigación cualitativa basándose en la identificación previa de cuáles son las prácticas organizacionales más óptimas (Proyecto ERCOVA, 2004), reveló que las prácticas de comunicación y desarrollo de habilidades, y fomento de la salud y seguridad laboral desde la percepción de gerentes y /o responsables de Recursos Humanos son las más utilizadas y útiles (Acosta, Salanova, y Llorens, 2011). 


\subsubsection{Colaboradores/as y grupos de trabajo saludables.}

La ejecución de prácticas saludables que potencian los recursos y fortalezas organizacionales inciden en los/as colaboradores/as provocando cambios positivos en la plantilla.

Para describir qué características describen a los colaboradores/as y grupos de trabajo saludables, el Modelo HERO se basa en los trabajos previos del concepto de capital psicológico positivo de Luthans y Yousself (2004) que incluía cuatro características básicas: autoeficacia, esperanza, el optimismo y la resiliencia. El modelo HERO actualizado recoge las siguientes dimensiones (Salanova, Martínez y Llorens, 2014):

- $\quad$ Autoeficacia: Se define como "las creencias en las propias capacidades para organizar y ejecutar los cursos de acción requeridos que producirán determinados logros o resultados" (Bandura, 1997, p. 3).

- Emociones Positivas: Una tendencia a sentir emociones positivas incrementa los recursos personales así como favorece a que se produzcan con vínculos sociales.

- Optimismo: Es una actitud que induce al/a trabajador/a a esperar que le sucedan cosas buenas (Carver y Scheier, 2002).

- Resiliencia: Se define como una capacidad psicológica positiva que rebota ante la adversidad y la incertidumbre.

Las autoras propusieron incluir una quinta, el engagement, que será descrita con mayor profundidad en el siguiente punto debido a su importancia asociada a los objetivos de esta Tesis.

Dentro de la investigación más importante que respalda empíricamente el Modelo HERO se observó que las relaciones más fuertes y significativas se produjeron entre las 
prácticas saludables estudiadas, la autoeficacia, la resiliencia y el engagement (Salanova et al., 2012).

\subsubsection{Resultados organizacionales saludables}

Los resultados organizacionales saludables se definen como una característica de una organización HERO que hace referencia a los resultados que se relacionan con el nivel de excelencia de productos/servicios y con las buenas relaciones con el entorno y la comunidad (Salanova, Llorens, Acosta y Torrente, 2013).

Entre los efectos hallados en la literatura revisada dentro del modelo HERO se ha encontrado que una mejora de las dimensiones del engagement, de la eficacia colectiva y de la resiliencia, incrementa los niveles de desempeño intra y extra rol de los colaboradores/as. También se ha evidenciado que las prácticas organizacionales (conciliación trabajo-familia, prevención del mobbing, salud psicosocial, comunicación organizacional) y confianza organizacional mejoran los niveles de engagement (Acosta et al., 2011). Por último, es importante mencionar como una de las investigaciones más solidadas hasta fecha realizada por Salanova, et al., (2012) en 137 organizaciones, ha mostrado que el Modelo HERO (y sus medidas) tiene validez teórica y predictiva para evaluar la salud y resiliencia de las organizaciones

En relación a los resultados obtenidos, dentro de las estrategias que recomienda el equipo WONT para promocionar los cambios positivos en las organizaciones y los equipos, se encuentra la necesidad de desarrollar un liderazgo positivo y transformacional que inspire, estimule la creatividad, y contagie optimismo, esperanza y resiliencia entre sus colaboradores/as. 


\subsection{Conceptualización del Engagement}

Tal y como describen Rodríguez-Muñoz y Bakker (2013), uno de los primeros autores en referirse y teorizar sobre el engagement concibiéndolo como la energía concentrada que se dirige hacia metas organizacionales fue Kahn en los años noventa (Kahn, 1990). La expresión en inglés del concepto es de complicada traducción al español, ya que existen conceptos similares pero con significado distinto como, compromiso organizacional (organizational commitment), dedicación al trabajo (work involvement), adicción al trabajo (workaholism) y enganche al trabajo (work attachment). La expresión más próxima en su traducción sería la de vinculación con el trabajo, pero no recoge todos los tipos de relación en el ámbito laboral, de ahí que es recomendable su uso en inglés (Rodríguez-Muñoz y Bakker, 2013; Salanova 2009).

El engagement surge en paralelo con el incipiente desarrollo de la Psicología Positiva y como constructo teórico opuesto al burnout o síndrome de estar quemado. El burnout convencionalmente se define como:

"Un síndrome psicológico de agotamiento emocional, despersonalización y reducida realización personal que puede ocurrir en individuos normales que trabajan con personas de alguna manera. El agotamiento emocional se refiere a los sentimientos de no poder dar más de sí a nivel emocional y a una disminución de los propios recursos emocionales. La despersonalización se refiere a una respuesta de distancia negativa, sentimientos y conductas cínicas respecto a otras personas, que son normalmente los usuarios del servicio o del cuidado. La reducida realización 
personal se refiere a la disminución en los propios sentimientos de competencia y logro en el trabajo" (Maslach, 1993, pp. 20-21).

Los y las trabajadores/as que se sienten quemados/as en sus puestos de trabajo consideran la actividad laboral como una carga, más que un reto desafiante. Presentan una baja motivación, con poca energía para conectar con sus actividades y con las personas que se vinculan a las mismas, así como un decreciente compromiso organizacional.

El engagement, por el contrario, se explica actualmente como un estado mental positivo de realización relacionado con el trabajo, que se caracteriza por vigor, dedicación, y absorción (Schaufeli y Bakker, 2010). El vigor se identifica con altos niveles de energía y resistencia mental mientras se trabaja, por el deseo de esforzarse en la tarea que se está realizando incluso cuando se presentan dificultades. La dedicación conlleva una alta implicación laboral al mismo tiempo que se exterioriza un sentimiento de entusiasmo, inspiración, orgullo y reto por el trabajo. La absorción, que guarda cierto paralelismo con una de las características del flow, ocurre cuando el/la trabajador/a está completamente concentrado/a en su actividad laboral y el tiempo le pasa fugazmente y presenta dificultades a la hora de desconectar con lo que está haciendo (Rodríguez-Muñoz y Bakker, 2013). Bajo esta conceptualización, al engagement se le considera como la antítesis del burnout, por lo que el vigor y dedicación son considerados los polos opuestos de agotamiento y cinismo. Por tanto, se estable un continuo entre el agotamiento y vigor que depende de la energía que siente el trabajador/a. Es decir, el trabajador/a con baja energía se situará en el polo negativo del agotamiento (burnout); por el contrario, conforme la energía del/a trabajador/a va en aumento nos encontramos con trabajadores/as con vigor (engagement). De igual 
modo, existe un continuo entre el cinismo (burnout) y dedicación (engagement). La persona trabajadora se desplaza a través de este continuo mediante el proceso de identificación. A menor identificación mayor cinismo, y conforme avanza su identificación se hace mayor la dedicación que siente con su trabajo (González-Romà, Schaufeli, Bakker y Lloret, 2006) (ver Figura 4.2).

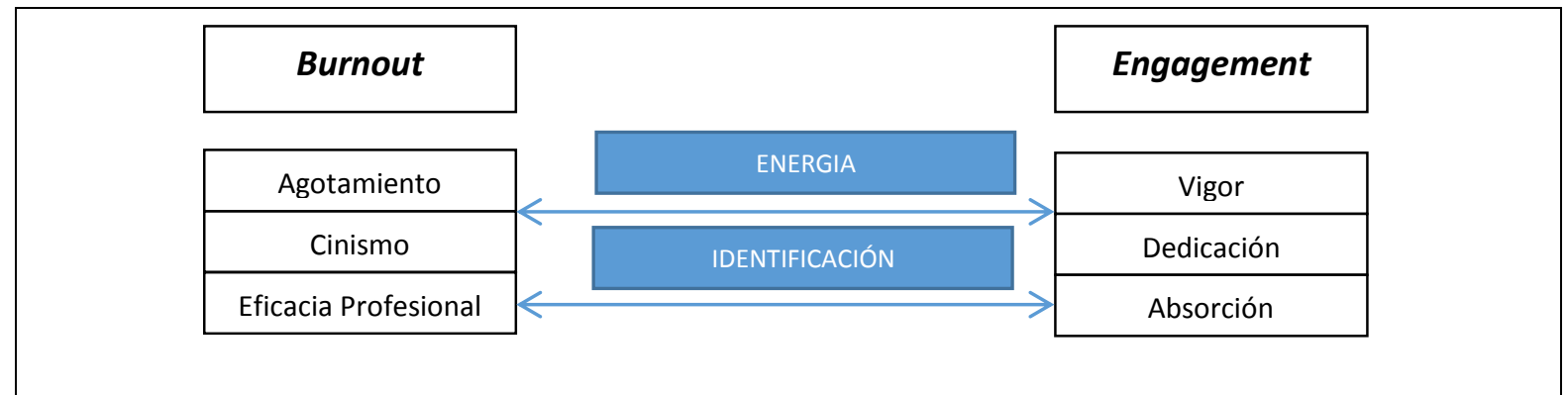

Figura 4.2: Relaciones entre Burnout y Engagement (Salanova, 2009)

En esencia, el engagement consiste en cómo los/as trabajadores/as viven su trabajo como una experiencia estimulante y enérgica, que los motiva a querer realmente destinar tiempo y esfuerzo (el componente vigor); como una actividad significativa y valiosa (dedicación); y como algo interesante y apasionante (absorción). Este tipo de trabajadores/as cuando se encuentran en este estado se les denomina trabajadores "engaged". Son trabajadores/as que se sienten muy comprometidos/as con lo que hacen pero al mismo tiempo pueden disfrutar de otras actividades fuera del trabajo. Para distinguir el engagement del resto de tipos de bienestar subjetivo (como satisfacción, adicción al trabajo) se ha sugerido (Bakker y Oerlemans, Demerouti, Bruins-Slot, y Karamat Ali, 2011) aplicar el modelo circumplejo del afecto de Rusell (1980, 2003). Según este modelo, los estados afectivos aparecen mediante dos sistemas neurofisiológicos: el primero se relaciona 
con el placer (desagrado-agrado) y el segundo de activación (alta activación- baja activación) (Bakker, Demerouti y Xanthopoulou, 2011).

Los estados emocionales se entienden como el resultado de una combinación lineal de estos dos sistemas con diferentes grados de placer y activación. Aplicando el modelo, se aprecia (ver Figura 4.3) que el engagement se sitúa en la parte superior derecha y se diferencia de otros estados como la adicción al trabajo y la satisfacción. Con el primero, a pesar que los dos destacan por su alta activación, el resultado de la adicción al trabajo es desagradable y viene acompañado de sentimientos negativos de displacer. La diferencia con la satisfacción del trabajo se da porque ésta es una respuesta pasiva a la ejecución de un trabajo, mientras que en el engagement combina dedicación, vigor y absorción (Bakker et al., 2011).

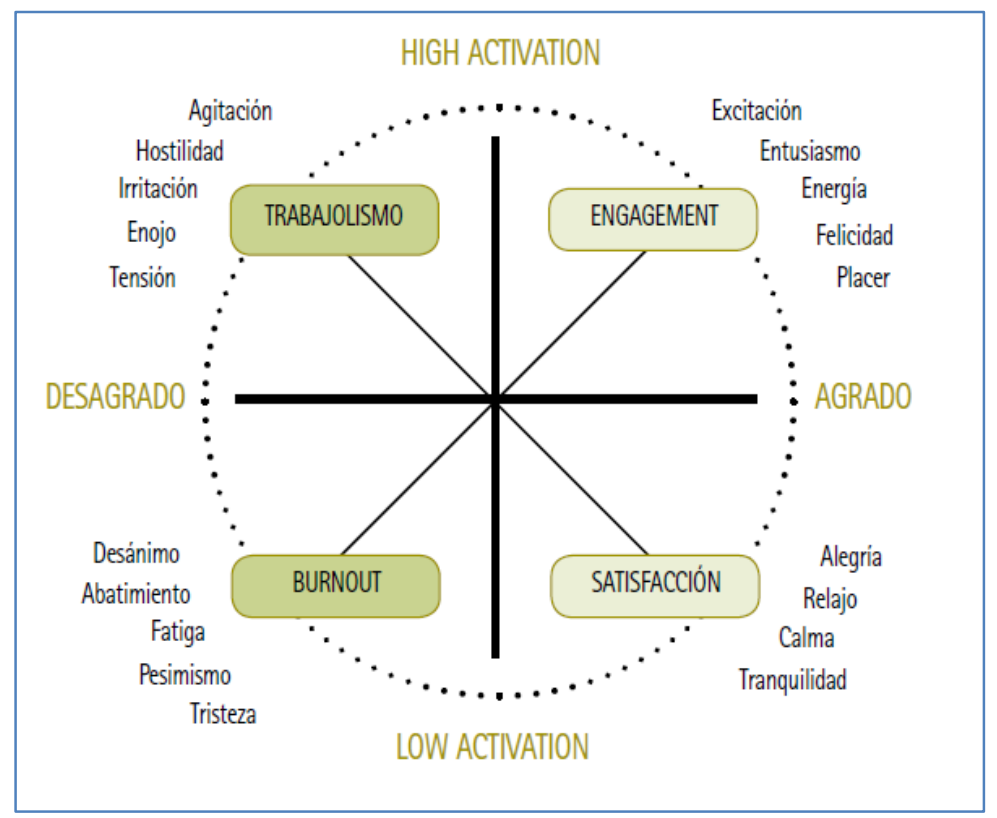

Figura 4.3: Visión bidimensional del bienestar subjetivo del trabajo y engagement. Adaptado de Bakker, Demerouti, y Xanthopoulou, 2011 (basado de Rusell, 1980, 2003) 
A nivel general, el estudio del engagement se ha considerado como un estado transitorio y no como un rasgo estable de personalidad. La mayoría de las investigaciones lo contemplan como un constructo que aparece en situaciones concretas y que pueden cambiar dependiendo de la persona, sucediendo en cortos periodos de tiempo. Esta perspectiva se investiga a través de estudios de diario y permite analizar las diferencias intrasujeto. Algunos investigadores/as (Bakker y Xanthopoulou, 2009; Tims, Bakker y Xanthopoulou, 2011) defienden la visión del engagement como un estado transitorio más que una experiencia estable (Sonnentang, Dormann y Demerouti, 2010). En este sentido, diversos estudios (véase Bakker, et al., 2011; Xanthopoulou, Bakker, Heuven, Demerouti y Schaufeli, 2008) confirman el hecho que al menos un tercio de la varianza total correspondiente al engagement diario puede atribuirse a las fluctuaciones en la persona. Se sugiere, pues, que las personas tienen diferentes niveles de engagement, por lo que muestran con diferente intensidad su compromiso laboral ya que éste tiene variaciones significativas en periodos breves.

\subsubsection{Medición del engagement}

Tomando como referencia la consideración del engagement como un constructo único, aunque relacionado al burnout, se construyó un cuestionario para medirlo denominado UWES (Utrecht Work Engagement Survey) (Schaufeli y Bakker, 2003). Es importante indicar la independencia de ambos constructos tanto para su conceptuación como para su medición (Demerouti, Mostert, y Bakker, 2010; González-Romá, et al. 2006); sin embargo, estudios recientes realizan fuertes críticas a la idea de diferenciación entre burnout y engagement argumentando que existe redundancia en ambos constructos (Cole, 
Walter, Bedeian, y O’Boyle, 2012). No obstante, la mayor parte de la evidencia empírica apoya la idea de que son constructos distintos y el UWES continúa siendo el cuestionario más utilizado para medirlo (Salanova y Schaufeli, 2009). Este cuestionario incluye tres subescalas: vigor, dedicación y absorción. Aunque la versión definitiva consta de 17 ítems Schaufeli, Bakker y Salanova (2006) desarrollan una versión reducida de 9 ítems. El UWES muestra altos índices de consistencia y fiabilidad test-retest (Schaufeli et al., 2006).

\subsubsection{Antecedentes y consecuencias del engagement}

\subsubsection{Antecedentes del engagement}

Para establecer los antecedentes y causas que pueden provocar el engagement hay que tener de referencia el Modelo de Recursos y Demandas Laborales (Bakker y Demerouti, 2007) (ver Figura 4.4). En este sentido las investigaciones se han centrado en averiguar qué recursos influyen en el engagement evidenciando, por ejemplo, que el apoyo social de los/as compañeros/as y supervisores/as, la retroalimentación sobre el rendimiento, la autonomía o las oportunidades de aprendizaje se asocian positivamente con el engagement. Los recursos laborales, por su parte, estimulan el desarrollo de entornos positivos de aprendizaje facilitando el incremento de la motivación intrínseca y extrínseca de los/as colaboradores/as. Los recursos laborales y no las demandas son los únicos predictores significativos del engagement (Salanova, Agut y Peiró, 2005; Schaufeli y Bakker, 2004). Los recursos personales también han sido vistos como impulsadores del engagement; por ejemplo, se ha sugerido que la autoeficacia y el optimismo (Bakker, Hakanen, Demerouti y Xanthopoulou, 2007), la personalidad resistente (Moreno-Jiménez, 
Garrosa, Corso, Boada y Rodríguez Carvajal, 2012), y la personalidad proactiva (Bakker, Tims y Derks, 2012) son predictores del engagement.

Las últimas investigaciones van más allá del análisis de los recursos laborales de tarea, personales y sociales, ya que incluso recogen que nuevas fuerzas de organización del trabajo (NFOT), internet, móvil, flexibilidad laboral, influyen en los niveles diarios de engagement de los/as colaborador/as (Ten Brummelhuis, Bakker, Hetland y Keulemans, 2012).

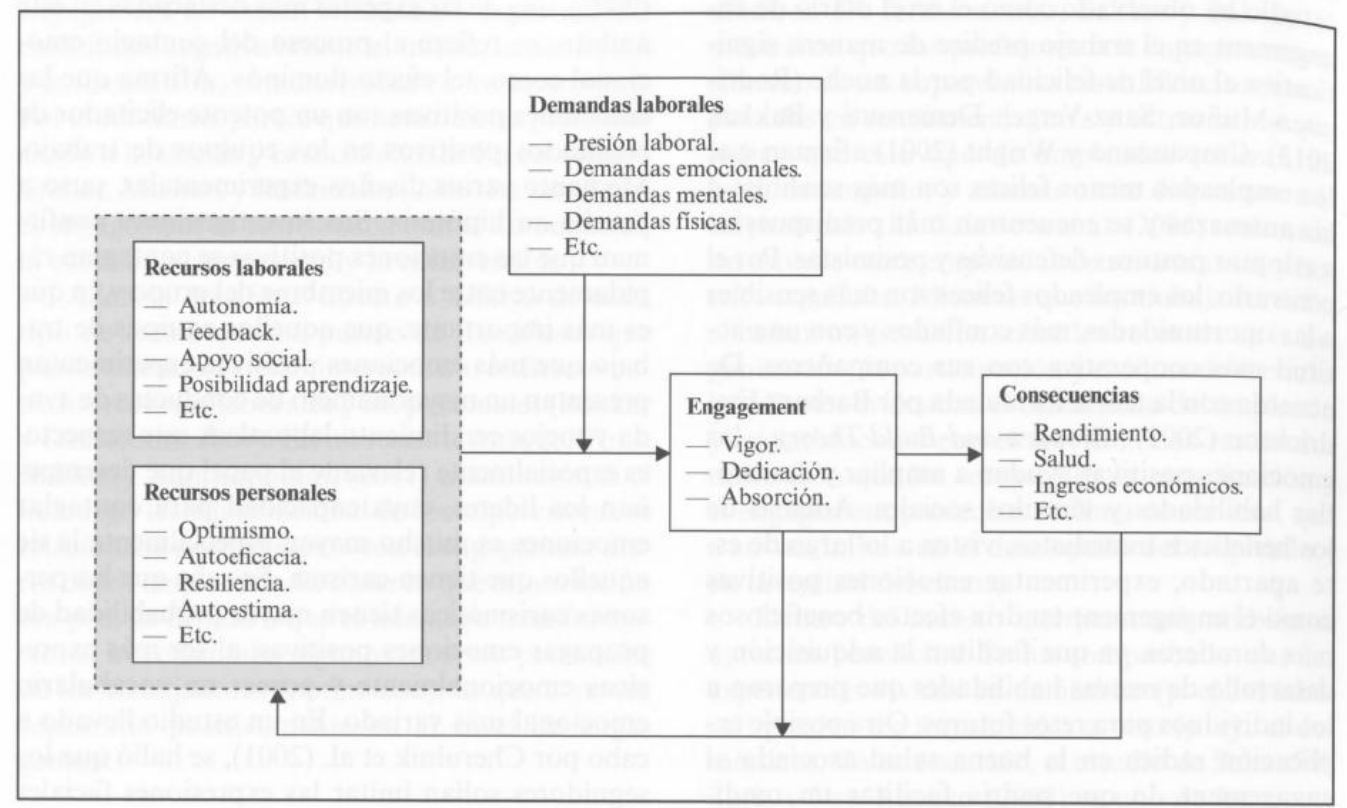

Figura 4.4: Modelo de demandas y recursos laborales del engagement (Bakker, 2009, Bakker y Demerouti, 2007)

\subsubsection{Consecuencias en el contexto laboral del engagement}

Actualmente se está viviendo un auge en el mundo empresarial sobre los resultados positivos que significa tener un/a colaborador/a engaged en las organizaciones. Autores de reconocido prestigio en el campo del engagement como Bakker (2010), Demerouti y 
Cronpanzano (2010), han mostrado que se relaciona significativamente con indicadores de alto desempeño laboral. Según Bakker $(2009,2013)$ parecen existir tres posibles explicaciones de cómo se produce el efecto del engagement en el rendimiento laboral: (1) En primer lugar el engagement viene acompañado de emociones positivas que impregnan al trabajador/a, de ahí que sienta más feliz, descansado/a, y proactivo/a, permitiéndole establecer vínculos sociales de calidad, desarrollando habilidades adicionales que le preparen para afrontar nuevos reto; (2) el engagement se asocia a la buena salud, lo que podría indicar que se tenga un rendimiento superior; (3) la última posible explicación se vincula con el contagio del engagement que se produce en el contexto de trabajo. El engagement se contagia entre los colaboradores/as través del contagio emocional (Bakker y Xanthopoulou, 2009).

Salanova et al. (2003) con trabajadores/as del área de hoteles y restaurantes obtuvieron que los niveles de engagement experimentados por los/as colaboradores/as tenían un impacto positivo en el clima de servicio, los cuales a su vez eran predictores de conductas superiores al rol y la satisfacción de los/as usuarios/as. De igual manera, se ha comprobado que el engagement tiene beneficios en la calidad de vida a través de las experiencias que vive en el entorno de trabajo, ayudando a mejorar el funcionamiento social y personal de los/as trabajadores/as que viven engaged (Schaufeli, Taris y van Rhenen, (2008).

\subsection{Liderazgo y Engagement}

Con respecto al liderazgo, la línea de investigación mayoritaria se sitúa en analizarlo como un antecedente que provoca el engagement de los/as colaboradores/as. Este hecho es 
consecuencia de concebir al líder como un recurso social motivador que influye en los/as colaboradores/as aportando feedback, apoyo, establecimiento de metas y dirección para cumplir con los objetivos organizacionales. Por ejemplo, Schaufeli y Bakker (2004) encontraron una fuerte relación entre el estilo de coaching de quien supervisa y el nivel de engagement de los/as colaboradores/as. De igual modo, se han encontrado evidencias de que los/as líderes producen un efecto en el engagement a través del incremento de los recursos personales de sus colaboradores/as. Este efecto indirecto se ha mostrado en recientes investigaciones dónde se analizó el liderazgo transformador de un grupo de supervisores/as y su relación positiva con el engagement diario de sus colaboradores/as. Las causas de este efecto se atribuyó a que el liderazgo transformador incrementaba algunos de los recursos personales (optimismo) de sus colaboradores/as, lo que conducía a un aumentar positivamente el nivel de engagement diario (Tims, Bakker y Xanthopoulou, 2011). Asimismo, en un estudio realizado con colaboradores/as griegos/as se pudo evidenciar que, entre otros recursos laborales, el acompañamiento del supervisor/a se relacionaba con la mejora de los niveles de optimismo, autoeficacia y autoestima de los/as colaborador/a s/as, los que al mismo tiempo explicaban su compromiso diario (Xanthopoulou, Bakker, Demerouti, y Schaufeli, 2011). Recientemente, y bajo el marco del Modelo de Demandas-Recursos Laborales, se comprobó en una investigación australiana con 540 bomberos/as voluntarios/as y sus 68 capitanes/as, como podía mediar en la motivación de los colaboradores/as el tipo de estilo de liderazgo basado en el empoderamiento. Se escogió este tipo de ambiente laboral ya que el trabajo de bombero/a se distingue por demandas cognitivas exigentes así como la necesidad de recursos cognitivos que puedan dar respuestas eficientes. La conclusión que se extrajo es que los/as 
líderes que utilizan un estilo de liderazgo de empoderamiento y de incentivar el trabajo que se realiza de forma independiente, pueden influir positivamente en el engagement de sus colaboradores/as a través del incremento de la motivación extrínseca e intrínseca. Al mismo tiempo, se halló pruebas que el liderazgo modula la percepción sobre las condiciones de trabajo individuales que mejoran la participación (Tuckey, Bakker, y Dollard, 2012).

Greco, Laschinger, y Wong (2006) propusieron que cuando existe un liderazgo de empoderamiento (significatividad de la tarea, oportunidad de participar en la toma de decisiones, libertad para organizar las actividades laborales, credibilidad en los/as colaborador/a s/as) hacia el personal de enfermería, aumentaban las expectativas con respecto al trabajo, reforzando el nivel de autoeficacia relacionada con el engagement.

En américa latina se ha encontrado evidencia de cómo diferentes tipos de liderazgo influyen en el engagement. En concreto, en Argentina con una muestra de 125 trabajadores de una empresa de servicios se pudo comprobar que el liderazgo transformacional y, en menor medida el liderazgo transaccional, afectó de manera positiva al engagement. En concreto, se apreció que el factor de inspiración del liderazgo transformacional fue el que mejor predijo la dedicación y el vigor, mientras que el factor de estimulación intelectual fue el más relevante en la predicción de la absorción (Trogolo, Pereyra y Sontón, 2013).

Las investigaciones mencionadas se asocian a la idea que expresan RodríguezMuñoz y Bakker (2013) sobre la importancia del/la líder para contagiar las emociones entre sus colaboradores/as, y en especial, las emociones positivas. Según estos investigadores, los líderes tienen un rol de suma relevancia en el contexto laboral y el engagement, ya que a través del contagio emocional consiguen trasmitir su estado afectivo. Cuando el líder muestra un estado afectivo positivo se incrementa el estado de engagement de sus 
colaboradores/as, ya que facilita la generación y ampliación de los recursos de los colaboradores.

\subsection{Inteligencia emocional y Engagement}

Con respecto a las investigaciones sobre inteligencia emocional y engagement destacan en territorio español las que se han realizado en contextos escolares que muestran una relación positiva entre los dos constructos en diferentes actores del sistema educativo. Esta relación se ha evidenciado en estudiantes (Durán, Extremera y Rey, 2005; Extremera y Fernández-Berrocal, 2003), en profesores de secundaria (Extremera, Fernández-Berrocal y Durán, 2003), docentes universitarios (Augusto-Landa, López-Zafra, Martínez y Pulido, 2006) y en profesorado de primaria (Pena y Extremera, 2012). Ampliando al sector de enfermería asistencial se han hallado relaciones significativas entre inteligencia emocional y las tres dimensiones del engagement que inciden en la calidad asistencial (Liébana, Fernández-Martínez, Bermejo, Carabias, Rodríguez y Villacieros, 2012). De igual modo, en una de las últimas investigaciones realizadas en España se concluyó que existe una relación entre la inteligencia emocional y las dimensiones vigor, absorción, y dedicación. Ante estos resultados los autores manifestaron la importancia de desarrollar la inteligencia emocional ya que conducía a un efecto personal de mejora del engagement (Esteban, 2014).

Brunetto, Teo, Shacklock y Farr-Wharton (2012) concluyeron que la inteligencia emocional predecía las percepciones de bienestar y satisfacción en el trabajo que a su vez influían en el engagement. De la misma manera, Ravichandran, Arasu y Kumar (2011) obtuvieron que niveles altos de inteligencia emocional predijeron mayores niveles de engagement. Finalmente, Akhtar, Boustani, Tsivrikos, y Chamorro-Premuzic (2015), de la 
Universidad de Londres, realizaron un estudio para averiguar si la inteligencia emocional y los rasgos de personalidad (Big Five) podían predecir el engagement. Los resultados corroboraron esta hipótesis e inclusive el estudio demostró como la inteligencia emocional (bajo el Modelo de Rasgos de Petrides y Furham, 2001) explicó una parte de la varianza del engagement organizacional, incluso controlando el efecto del resto de factores como edad, genero, y personalidad.

De la revisión realizada se desprende que la mayoría de las investigaciones encontradas sobre inteligencia emocional y engagement se centran en analizar un posible efecto entre ambas variables a un nivel intra. Los resultados encontrados apuntan una tendencia a que la inteligencia emocional de trabajadores/as de distintas nacionalidades y sectores es predictiva del engagement. No se han encontrado investigaciones que recojan un efecto inter como, por ejemplo, cómo afecta la inteligencia emocional de los/as líderes en las diferentes dimensiones que componen el engagement de sus colaboradores/as, ni que variables modulan esta relación. Este hecho precisamente será unos de los objetivos de la presente investigación.

\subsection{Conceptualización Multidimensional del Vigor}

\subsubsection{Modelo del Vigor y Trabajo (Shirom, 2004, 2011)}

Aunque tradicionalmente el engagement se ha venido estudiando como un constructo compuesto por tres dimensiones, hallazgos empíricos indican que el vigor y la dedicación configuran los que se ha venido a denominar el "corazón del engagement" (Schaufeli y Bakker, 2004). La absorción también forma parte de otros constructos psicológicos como el flow, y la adicción al trabajo, lo cual podría ser la razón que no se 
aprecie una robusta y fuerte relación con el engagement (Taris, Schaufeli, y Shimazu, 2010). En esta investigación se analizará el rol del vigor como una dimensión clave en la relación entre el/la líder y sus colaboradores/as. Por tanto, es necesario completar la aproximación del vigor como parte del engagement (Schaufeli y Bakker, 2010) analizando si es posible integrar la propuesta teórica de Shirom (2011) que considera al vigor como un constructo multidimensional. Esta visión del vigor como un constructo con personalidad propia tiene como base el marco teórico y los estudios realizados por el investigador de la Universidad de Tel-Aviv, Arie Shirom.

Shirom (2004) inició el estudio del vigor como un intento de ampliar la investigación sobre los estados afectivos positivos y su relación con el desempeño y salud laboral. Para este autor, el vigor es un tipo de afecto que responde a estímulos ambientales siguiendo un patrón de respuestas innatas. El vigor es definido, por tanto, como una respuesta afectiva a la interacción de la propia persona con los elementos significativos de su trabajo y el entorno laboral. Conceptualiza el vigor como un constructo compuesto por tres dimensiones: la fuerza física que se refiere a las capacidades físicas; energía emocional que se refiere a la propia capacidad de transmitir simpatía y la empatía con los demás; y la vivacidad cognitiva se asocia al flujo de los procesos del pensamiento y la agilidad mental.

Además, establece como punto de arranque de su modelo la teoría de Conservación de Recursos (“Conservation of Recourses”-COR) de Hobfoll (1989)). Su principal postulado es que las personas tienen como motivación básica obtener, retener y valorar aquello que se aprecia, a esto último se le denomina recursos, de los cuales hay varios tipos: materiales, sociales y energéticos. En general, los recursos son aquellas energías, características, personas, objetos y condiciones que son valorados por las personas o que 
sirven como medio para la consecución de otros objetivos, características personales, condiciones o energías (Shirom, 2004).

El vigor se refiere exclusivamente a los recursos energéticos, energía física, emocional y cognitiva. Representa un estado afectivo que atribuyen los individuos acerca de su trabajo en contraposición a la afectividad positiva como rasgo que se refiere a la tendencia a experimentar el afecto positivo a través del tiempo en diferentes situaciones. Para Shirom $(2004,2011)$ el vigor se corresponde únicamente con los recursos energéticos que cada persona posee, manifestándose en tres formas distintas de energía personal. Resultados encontrados de un meta-análisis, muestran que el vigor está relacionado con los recursos en el trabajo (por ejemplo, retroalimentación), en menor medida, a las demandas (por ejemplo, el conflicto trabajo-familia) y resultados importantes como el rendimiento (Halbesleben, 2010).

La propuesta de Shirom $(2004,2011)$ ha ido desarrollándose y evolucionando. La última conceptualización publicada antes de la desaparición de su autor (Arie Shirom falleció en 2012) fue en el año 2011 (ver Figura 4.5). 


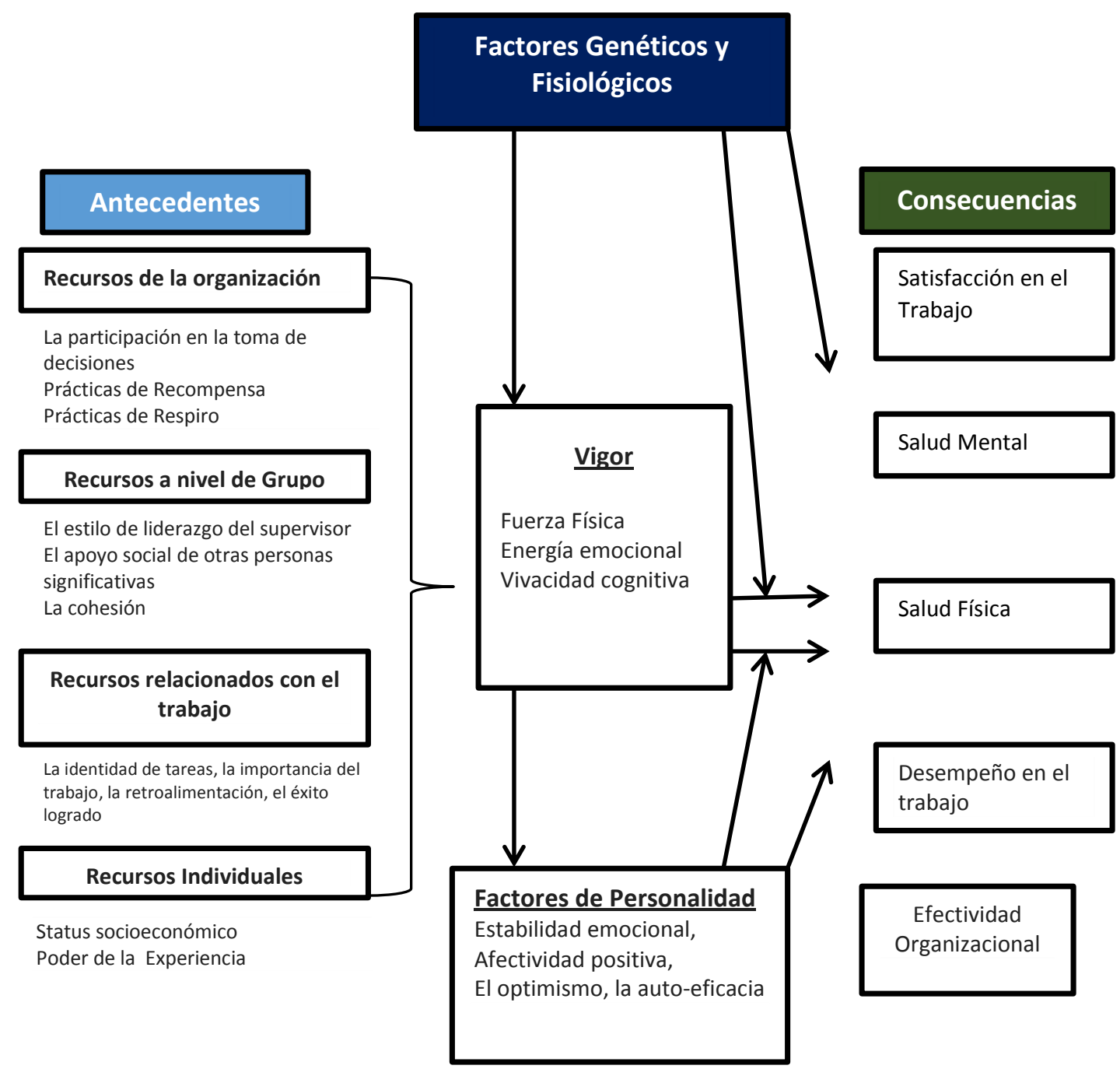

Figura 4.5: Modelo de Vigor y Trabajo: Antecedentes esperados, probables moderadores y posibles consecuencias. (Shirom, 2011)

A continuación, se describen los aspectos más relevantes del Modelo de Vigor y Trabajo (Shirom, 2011).

\subsubsection{Antecedentes}

Shirom (2011) estableció tres niveles de análisis, el organizacional, el grupal y el individual, a la hora de señalar los diferentes tipos de antecedentes que pueden impulsar el 
vigor en el trabajo. En su trabajo teórico póstumo enfatiza los siguientes posibles precursores vinculados específicamente a las características del trabajo:

\section{a. Características del trabajo.}

Siguiendo las argumentaciones de Grant y Sonnentag (2010), los trabajos con variedad de tareas, identificación con lo que se hace, y que reciben retroalimentación, permiten que aparezca el vigor. Shirom (2011) defiende que la característica del trabajo que posiblemente incida con mayor fuerza en la aparición del vigor sea la transcendencia de la tarea.

\section{b. Interacción con los demás.}

Se argumenta que en la interacción con los demás se produce un contagio de las emociones que más allá de las circunstancias y eventos laborales y que influye en las personas. Cuando la interacción emocional es debido a una relación de calidad, y ésta es positiva, se produce en forma de espiral un aumento de la energía personal. Esto produce un incremento del vigor, ya que el/a trabajador/a siente el apoyo social y emocional en su actividad laboral. El vigor que siente, le hace sentirse con más confianza, y de ahí que se refuerza sus comportamientos de búsqueda de relaciones con los demás. Esta espiral positiva en las interacciones interpersonales modifica y amplia los recursos personas como empatía, escucha y atención, así como de aprendizaje mutuo reforzando su eficacia y autoestima (Shirom, 2011).

\section{c. Estilos de Liderazgo}

Este punto será completado en la siguiente sección de este trabajo bajo la idea teórica de que los/as líderes influyen directamente sobre el vigor a través de la gestión 
emocional. En el modelo teórico se establece que la retroalimentación que ofrecen los/as líderes es un antecedente importante para la aparición del vigor (Shraga y Shirom, 2009). d. Recursos grupales

Dentro de los grupos se comparten expresiones con carga emocional, tanto comunicación no verbal (gestos, posturas, expresiones faciales) como comportamientos de socialización, por lo que, según recoge Shirom (2011), los/as colaboradores/as que interactúan regularmente con compañeros/as vigorosos/as recibirán esta emotividad positiva que les permitirá contagiarse (Bakker, y Xanthopoulou, 2009).

\section{e. Recursos organizativos}

En este grupo de recursos Shirom (2011) hipotetiza que la toma de decisiones compartidas, la retroalimentación sobre las tareas, y los programas que ayudan a que en el trabajo se tenga periodos de descanso y recuperación, son prácticas organizacionales que posibilitan un nivel más alto de vigor.

\subsubsection{Consecuencias}

Shirom (2011) se apoya en la teoría Broaden and Build sobre las emociones positivas y sus efectos (Fredrickson, y Losada, 2005) por la cual los estados afectivos positivos generan una tendencia a la acción y al desarrollo de recursos como el incremento de las relaciones sociales, la salud, y la resiliencia. Este efecto positivo facilita la flexibilidad conductual y el incremento del conocimiento del entorno y de la aplicación de estrategias cognitivas eficaces. Al mismo tiempo, se convierte en un contrapeso de los efectos negativos que se pueden producir. Además, recoge las ideas de esta teoría para 
hipotetizar que existen dos mecanismos por los cuales se explica el efecto del vigor sobre sus posibles consecuencias. El primer mecanismo tiene un carácter indirecto e informativo, ya que se produce como el resultado de la evaluación y juicios sobre los comportamientos de aproximación que se van a realizar derivados del segundo mecanismo. El segundo mecanismo se centra en la influencia directa del vigor sobre los intereses y preferencias de la persona. Teniendo en cuenta esta doble vía de funcionamiento, Shirom (2011) indica las posibles siguientes consecuencias del vigor.

\section{Motivación.}

Entiende la motivación laboral como una energía que dirige la forma, la dirección y la intensidad del comportamiento laboral. El vigor es considerado, por tanto, como un precursor motivacional ya que antes de la ejecución del comportamiento, permite la generación de una información positiva sobre la meta a alcanzar. De esta manera, el vigor como afecto positivo influye en la dirección y en el esfuerzo a desarrollar para ejecutar un comportamiento laboral. Esta idea se respalda por las investigaciones que revelan que cuando una persona realiza una representación mental de un objetivo conductual y se le asocia a un estado positivo, automáticamente considera la meta deseable, que vale la pena esforzarse por conseguirla, y por tanto se activa su motivación (Custers y Aarts, 2005).

\section{Desempeño en el Trabajo y eficacia organizacional.}

Enlazado con la idea anterior, se teoriza que el vigor es el resultado de una tendencia de acción positiva que provoca un incremento de la motivación laboral. El/a trabajador/a se siente vigoroso/a, con mejor salud física y psicológica, con alta dosis de energía, lo que posiblemente incide en un mayor desempeño laboral y eficacia organizacional (Shirom, 2011). Tan sólo existe un estudio del vigor considerado como 
constructo multidimensional que explique su efecto en el rendimiento y eficacia organizacional. En este estudio (Carmeli, Ben-Hador, Waldman, Rupp, 2009) se encontró una relación positiva significativa entre el vigor del supervisor/a y el rendimiento de trabajo de sus colaboradores/as.

\section{Salud física y mental.}

Se argumenta, basándose en estudios sobre el bienestar y calidad de vida, que cuando existe un incremento de vigor se produce una mejora de la salud física y mental (Shirom, 2011; Shirom, Toker, Jacobson, y Balicer, 2010) ya que favorece un estado afectivo positivo. Este afecto positivo se relaciona con los incrementos de niveles de dopamina del cerebro (Phelps, 2006) ampliando simultáneamente el funcionamiento cognitivo y regulando la actividad cardiovascular. Adicionalmente, se halló que el aumento del vigor en el trabajo del colaborador/a sano/a se relaciona con los efectos beneficiosos para reducir los riesgos de muerte por enfermedad cardiaca y la diabetes (Shirom, et al., 2010).

\section{Satisfacción laboral.}

La idea subyacente es que la emoción influye en la satisfacción laboral posiblemente a través de dos mecanismos. El primero, propone que la emoción incrementa la accesibilidad cognitiva y de la memoria (Phelps, 2006) y el segundo, que el estado afectivo sobre una meta provoca una actitud sobre lo que se quiere alcanzar (Slovic, Finucane, Peters y MacGregor, 2007). Por tanto, el vigor puede influir en la satisfacción, ya que genera emociones y estados afectivos positivos que probablemente influyan indirectamente en la satisfacción laboral al generar unas condiciones de trabajo estables y 
seguras que llevan a que una persona tenga actitudes específicas y previsibles y estados afectivos estables.

Por último, como variables moderadoras que influyen en el vigor y sus probables consecuencias, se determinan los factores de personalidad, genéticos y psicológicos (Shirom, 2011).

El modelo teórico de Shirom ha recibido poca atención por parte de la comunidad científica ya que, por ejemplo, tan sólo se han hallado cuatro investigaciones que tengan como objetivo analizar la validez del constructo e identificar cuáles son sus antecedentes, componentes y posibles consecuencias. Shraga y Shirom (2009) realizaron una investigación cualitativa utilizando como método la entrevista telefónica y se concluyó que en el $77 \%$ de los casos aparecían las tres dimensiones del vigor. Al mismo tiempo, se investigó cuáles eran los antecedentes del vigor relacionados con las características del trabajo; y se encontró que el trabajo significativo y la retroalimentación de los/as supervisores/as eran los más mencionados como antecedentes por los/as trabajadores/as entrevistado/as. De igual modo bajo este marco teórico se desarrolló una herramienta de medida del vigor denominada Shirom-Melamed Vigour Measure (SMVM) compuesta por tres subescalas: Resistencia Física (5 ítems); energía emocional (4 ítems) y vitalidad (vivacidad) cognitiva (5 ítems); (Shirom, 2004)

\subsubsection{Análisis de los modelos del vigor}

Wefald y Downey (2009) sugirieron, a través de un análisis comparado de los modelos de engagement de Schaufeli et al. (2002), Schaufeli y Bakker (2010), y el modelo de vigor y trabajo de Shirom (2004), que ambos constructos disponían de una correcta 
validez predictiva y factorial. Siguiendo la misma metodología, es de especial interés la investigación de Remo (2012), cuyo objetivo principal fue poner a prueba los dos modelos bajo los mismos antecedentes que teóricamente pueden provocar engagement y vigor, y analizar su posible efecto en el trabajo (presentismo y rotación). Aunque para Remo ambos modelos son diferentes pero válidos en su composición factorial, la fundamentación teórica de la propuesta de Schaufeli et al. (2002) está mejor fundamentada que la de Shirom (2003). Por tanto, Remo (2012) concluyó que el modelo de Schaufeli et al. (2002) es un modelo sólido y consistente para explicar teóricamente el engagement. Asimismo, Remo (2012) sugiere que probablemente, como argumenta Shirom, el vigor se explica mejor compuesto de tres dimensiones pero, no obstante, es necesaria un mayor número de investigaciones que confirmen estos resultados. En la investigación de Remo se tomaron en cuenta dentro de las características del trabajo otros antecedentes del vigor distintos a los que inicialmente había propuesto Shirom (2011) y que también influenciaban en el engagement. Con esta ampliación se concluyó que el modelo de engagement (Schaufeli et al., 2002) se relacionó positivamente con los antecedes del trabajo como autonomía, retroalimentación, y variedad de habilidades, mientras que la importancia, la identidad de las tarea, la autonomía y también la retroalimentación se relacionó positivamente con el modelo de vigor y trabajo de Shirom (2011). La validez empírica del modelo multidimensional de vigor sugerida por Remo ratificó los hallazgos similares que encontraron Wefald, Mills, Smith y Downey (2012) en un estudio que comparaban diferentes medidas del engagement.

Las evidencias empíricas encontradas apuntan a que, a pesar que son dos constructos distintos, es necesario tenerlos a ambos en cuenta de forma integrada para dar 
una explicación global del engagement en el trabajo y mejorar las intervenciones prácticas a implantar en las organizaciones. Se concluyó que en ambos modelos, la retroalimentación facilitada por los/as supervisores/as a sus colaboradores/as es un factor clave para incrementar su engagement y su vigor. Con el fin de corroborar la validez del modelo de Shirom se recomienda realizar nuevas investigaciones ya que debido a su reciente conceptualización los hallazgos y la evidente escasez de evidencias empíricas dificultan su confirmación.

\subsection{Liderazgo y vigor: Integración de modelos}

Las investigaciones tanto bajo el paradigma del modelo de Schaufeli (véase Breevaart, Bakker, Hetland, Demerouti, Olsen, y Espevik 2014); Tims, et al., 2010; Zhu, Avolio y Walumbwa, 2009) como las de Shirom, (tan sólo hemos podido encontrar una investigación al respecto; Carmerli, 2009), toman como referencia el liderazgo transformacional como antecedente del engagement y del vigor respectivamente. Es importante señalar que tanto autores/as defensores/as del modelo de vigor como parte del constructo del engagement (por ejemplo, Breevaart et al., 2014) coinciden con Shirom (2011) en afirmar que el/la líder transformacional influye en los/as colaboradores/as mediante la aplicación de estrategias de influencia que les inspiran a ir más allá de los resultados esperados.

Para Shirom (2011) el/la líder transformacional provoca que aparezca el vigor en sus colaboradores/as. Aunque en su teoría no se hace mucho hincapié en explicar cómo se produce este efecto, se deja entrever que el/la líder influye en el/la colaborador/a a través de las expresiones emocionales vigorosas que pueden ser contagiadas de unos/as a otros/as. 
Shirom considera que el líder transformacional inspira a los/as colaboradores/as a través de expresiones emocionales vigorizantes que se trasladan de arriba abajo. Esta idea recoge los estudios previos de Côté y Saavedra (2005) dónde se explicaba cómo el estado emocional del/la líder influye en el de sus colaboradores/as y en la coordinación grupal para ejecución de tareas. Probablemente Shirom esté haciendo referencia al contagio emocional sin hacerlo explícito en sus publicaciones e investigaciones. Carmeli (2009) es la única referencia empírica que, siguiendo el Modelo inicial de Vigor y Trabajo de Shirom (2004), intentó establecer como el/la líder transformacional impacta de alguna manera en el vigor de sus colaboradores/as. En su investigación Carmeli y sus colaboradores (2009) encontraron apoyo empírico sobre que los comportamientos de apoyo relacional del/la líder influyen en el vigor y en el rendimiento de sus colaboradores/as.

Tal y como se ha revisado, tanto el modelo de Schaufeli et al. (2002) como el de Shirom (2011), sitúan al liderazgo transformacional como un antecedente que influye directamente en el engagement y el vigor más concretamente. Las dos aproximaciones suponen que en la interacción entre el/a líder y el/a colaborador/a, el estado afectivo del/a líder así como la retroalimentación que ofrecen a sus colaboradores/as, tienen un rol básico para la transferencia del vigor de arriba abajo. De igual modo, ambas propuestas hacen referencia de alguna manera a las investigaciones iniciales existentes sobre el contagio emocional, por lo que consideran que posiblemente el contagio emocional sea un mecanismo por el cual se transfiere el estado energético del vigor del/la líder a sus colaboradores/as. La divergencia más importante entre ambas consiste en que Shirom establece tres dimensiones diferenciadas (energía física, energía emocional, y viveza cognitiva) como componentes multidimensionales del vigor. Es de destacar, que pueden 
observarse ciertas similitudes entre ambas aproximaciones, ya que cuando bajo el modelo de Schaufeli los investigadores se refieren al contagio emocional podría asociarse al factor emocional del modelo de Shirom. Lo mismo ocurre cuando los defensores del modelo de Schaufeli hablan de mejora de la salud a través del engagement podría ser que se hiciera referencia a la dimensión de resistencia física del modelo de Shirom. Lo que sí que está por ver es lo referente a la dimensión de viveza cognitiva del modelo de Shirom como se podría asociar a la conceptualización del vigor de Schaufeli y colaboradores/as.

\subsection{Inteligencia emocional del líder y Vigor}

No se han encontrado investigaciones que relacionen la inteligencia emocional del/a líder con el vigor, ni si el vigor influye de alguna manera en las habilidades emocionales del/la líder y su relación con los/as colaboradores/as. La presente Tesis doctoral intentará comprobar si el vigor muestra algún tipo de influencia sobre la relación de la inteligencia emocional del/la líder sobre sus colaboradores/as. Desde el punto de vista teórico, el vigor de los/as colaboradores/as, al ser un estado afectivo que contiene una importante carga emocional y que incentiva la agilidad cognitiva y la motivación, afectará de alguna manera la interacción entre ambos (Shirom, 2011). Esta interacción está muy mediada por el contagio emocional (Rodríguez-Muñoz y Bakker, 2011).

Estas hipótesis se basan en la integración de los modelos revisados sobre engagement (Schaufeli et al., 2002) y vigor (Shirom, 2011), tal y como sugiere Remo (2012). Esta integración permite tener en cuenta los diferentes puntos de vista existentes de conceptualización del vigor sin caer en exclusiones ya que los puntos en común son más que las diferencias encontradas. 


\section{METODOLOGÍA}




\section{Capítulo V: Metodología}

"Es de sentido común elegir un método y probarlo. Si falla, admitirlo francamente y probar con

otro. Pero, sobre todo, intentar algo"

Franklin D. Roosevelt 


\section{1. Objetivos e Hipótesis}

En este capítulo se describe la metodología utilizada en la presente Tesis doctoral. En un primer momento se señalan los objetivos e hipótesis de trabajo. Posteriormente, se describen las variables de estudio, los instrumentos utilizados en su evaluación, la muestra a recoger, así como el procedimiento utilizado en la recogida de información.

\subsubsection{Objetivo general.}

Analizar el nivel de inteligencia emocional del líder y su impacto en las competencias mentales de sus colaboradores/as teniendo en cuenta el papel modulador del vigor en este proceso.

\subsubsection{Objetivos específicos}

El objetivo general de la investigación se divide en los siguientes objetivos específicos:

(1) Analizar si el líder emocionalmente inteligente, es decir, aquel que tiene alta inteligencia emocional aplicada en la función de liderazgo (Salovey y Mayer, 1997; Caruso y Salovey, 2005) es capaz de influenciar, de manera transnivel, en las competencias mentales de sus colaboradores/as.

(2) Analizar el rol desempeñado por el vigor en la relación transnivel de la inteligencia emocional del/la líder y las competencias mentales y emocionales de los trabajadores a su cargo. 
(3) Estudiar, a un nivel intra, en los colaboradores la relación entre su componente emocional (competencias emocionales) y el componente cognitivo (competencia mentales).

\subsubsection{Hipótesis.}

Tomando como referencia los postulados teóricos que, ya han sido explicados durante los primeros capítulos de este trabajo, sobre inteligencia emocional de Salovey y Mayer (1997), las estrategias de influencia del/la líder de Yukl (2010), la propuesta de Côté y Hideg (2011) de considerar la influencia sobre los demás como una nueva habilidad emocional, las ideas sobre el vigor, visto tanto como un integrante del engagement (Schaufeli et al., 2002; Schaufeli y Bakker, 2010) como un constructo propio e independiente (Shirom, 2011), la teoría sobre el efecto social de las emociones entre las personas (Van Kleef, 2009), así como las investigaciones sobre cómo se produce el contagio emocional (Barsade, 2002; Iacobini, 2009) y facilitación emocional y su relación con la cognición (Damasio, 1996) se establecen las siguientes hipótesis:

$\mathrm{H}_{1}$ : El nivel de inteligencia emocional de los líderes se relaciona significativa y positivamente, en un efecto transnivel, con las competencias mentales (cognición) de sus colaboradores/as.

$\mathrm{H}_{2}$ : El vigor de los colaboradores modula la relación entre el nivel de inteligencia emocional del/la líder y las competencias mentales de los colaboradores/as a su cargo. 
$\mathrm{H}_{3}$ : Existe una relación positiva y significativa entre las competencias emocionales de los colaboradores/as y las competencias mentales de los mismos.

\subsection{Diseño de la Investigación}

Con el fin de alcanzar los objetivos previstos, se ha desarrollado un modelo de investigación multinivel que incorpora dos tipos de niveles de análisis: 1) nivel líder, y 2) nivel colaboradores/as a su cargo. La elección de un diseño multinivel genera una estructura explícita dentro de la cual aparece la similitud de los juicios destinados a combinar la información entre unidades (distintos niveles) para producir mejores estimaciones y predicciones a partir de las observaciones realizadas (Murillo, 2008). Los modelos multinivel son, en esencia, ampliaciones de los modelos de regresión lineal clásicos; ampliaciones mediante las cuales se elaboran varios modelos de regresión para cada nivel de análisis (Bickel, 2007; Reise y Duan, 2003). La principal característica de los modelos multinivel es que aportan un entorno natural dentro del cual se pueden comparar teorías sobre relaciones estructurales entre variables en cada uno de los niveles en los que se organizan los datos. El diseño multinivel desarrollado en esta investigación, también denominado modelo jerárquico, ha permitido agrupar los datos obtenidos de los líderes y colaboradores/as como dos grupos distintos y jerarquizados para evaluar su interacción. Los modelos multinivel ofrecen una estructura de análisis dentro de la cual se pueden reconocer los distintos niveles en los que se articulan los datos, al estar representados cada uno con su propio submodelo (Draper, 1995). Además, los modelos multinivel permiten formular y probar hipótesis sobre los efectos cruzados entre niveles (Murillo, 2008). En primer lugar se ha desarrollado un nivel-1 de análisis (líder) que pretende estudiar la interacción existente entre el líder y sus colaboradores/as en las diferentes variables de estudio. Cada 
líder está asociado a tres colaboradores/as bajo su responsabilidad en cada una de las tres empresas que componen la muestra. De esta manera, tres colaboradores/as reciben la influencia directa del mismo líder, lo que permitirá analizar desde diferentes perspectivas el efecto transnivel de su líder.

Con el fin de completar el diseño multinivel, se ha diseñado el nivel-2 de análisis que contempla la evaluación de un efecto intra (colaboradores/as a su cargo) en el mismo sujeto objeto de estudio, en este caso los colaboradores/as. El nivel-2 estudiará la relación directa entre las competencias emocionales y las competencias mentales que se produce en los colaboradores/as, así como el efecto modulador del vigor. Dentro de esta unidad de análisis se ha añadido el estudio de la variable del vigor y su relevancia en la relación entre la inteligencia emocional del/la líder y las competencias mentales del/a colaborador/a.

\subsection{Muestra}

La muestra está formada por 47 líderes y 141 colaboradores/as a su cargo (85\% de los líderes contactados, $100 \%$ de los colaboradores/as). Concretamente, cada líder o supervisor/a inmediato/a está al mando directamente de tres colaboradores/as. Todos ellos/as pertenecientes a tres empresas establecidas en Quito (Ecuador) en los siguientes sectores: educación, servicio de limpieza (aseo urbano) y sector turístico. Cada líder y sus

respectivos colaboradores/as participaron voluntariamente siendo convocados por la dirección de Recursos Humanos de cada empresa. Se ha tenido especial cuidado en que cada triada de colaboradores/as que se asocia a los diferentes líderes en una empresa no se repita. Es decir, los y las colaboradores/as que configuran el trio por cada líder son distintos con el objetivo de disponer de una mayor cantidad de evaluaciones de colaboradores/as 
enfocados/as a un mismo líder. Con ello se intentó evitar que un mismo colaborador/a se alinease con diferentes líderes en una misma empresa y que se produjese un efecto distorsionador del mismo colaborador/a asociados a diferentes líderes. Más de la mitad de los líderes (25 líderes, 53,2\%) corresponden a la empresa de aseo urbano ya que por tamaño organizacional tiene el doble de volumen de trabajadores que las otras dos empresas que son de similar tamaño entre sí. 12 líderes (25,5\%) pertenecen al sector de educación y 10 (21,3\%) al sector turístico. Cabe destacar, que la empresa de educación es privada, y la de aseo urbano y turismo son públicas. 35 líderes son hombres (74,5\% de la muestra) y 12 $(25,5 \%)$ son mujeres. Esta es, desgraciadamente, la realidad de la sociedad ecuatoriana, y en concreto quiteña, dónde el puesto con toma de decisiones directivas y líderes formales se asocia todavía de forma sesgada al hombre. De ahí que exista una gran diferencia porcentual en nuestra muestra entre el número de líderes-hombres y líderes-mujeres. Con respecto a la edad los 47 líderes se sitúan en un intervalo de edad entre los 31 años y los 68 siendo el promedio de 42 años $(D T=8.71)$. Datos esperados, ya que en la mayoría de organizaciones se necesita un cierto recorrido laboral hasta poder desempeñar un puesto de trabajo como líder organizacional (Ver Tabla 5.1).

Tabla 5.1: Descripción variables sociodemográficas edad y género de los líderes (N=47)

\begin{tabular}{lccc}
\hline Líderes & Género & Fr & $\%$ \\
\hline & $\mathrm{H}$ & 35 & 74.5 \\
& $\mathrm{M}$ & 12 & 24.5 \\
\multirow{4}{*}{ Edad } & & & \\
& MD & SD & \\
\hline
\end{tabular}


En la Tabla 5.2 se detalla la distribución de la muestra de los 141 colaboradores/as en las variables sociodemográficas de edad y género.

Tabla 5.2: Descripción variables sociodemográficas edad y género de lo colaboradores/as $(N=141)$

\begin{tabular}{lccc}
\hline Colaboradores/as & Genero & Fr & \% \\
\hline & H & 84 & 59,6 \\
Edad & M & 57 & 40,4 \\
& M & DT & \\
\hline
\end{tabular}

Tal y como se puede apreciar, la distribución entre hombres y mujeres es equilibrada ya que de los 141 colaboradores/es, $84(59,6 \%)$ son hombres y $57(40,4 \%)$ son mujeres. Con respecto a la edad el promedio se sitúa en 37,9 años $(D T=10,25)$, con una edad mínima de 20 años y máxima de 70 años. Esta edad de 70 años se explica en el entorno ecuatoriano dónde el sistema de cobertura de jubilaciones dentro de la seguridad social ecuatoriana todavía no ofrece un pago mensual suficiente que garantice una calidad vida óptima. Por este motivo, muchos/as trabajadores/as alargan su vida laboral con el fin contar con recursos económicos que aseguren su status de vida.

Seguidamente se recoge en la Tabla 5.3 el análisis descriptivo del resto de variables sociodemográficas de la muestra de colaboradores/as que se han dividido en dos subcategorías. En primer lugar se recogen las variables sociodemográficas laborales generales que corresponden a aspectos macro sobre sus expectativas de realizar la mima actividad y de permanecer en la misma empresa en un futuro cercano, así como aspectos de antigüedad en el puesto, en la empresa, y en el mercado de trabajo. En segundo lugar 
aparecen las variables sociodemográficas sociolaborales generales que se refieren al horario de trabajo en sus diferentes modalidades.

Tabla 5.3: Descripción variables sociolaborales de los colaboradores/as $(N=141)$

\begin{tabular}{|c|c|c|c|c|c|c|}
\hline & $\mathbf{M}$ & DT & Fr & $\%$ & Mínimo & Máximo \\
\hline \multicolumn{7}{|l|}{ 1. Variables } \\
\hline \multicolumn{7}{|l|}{ Sociolaborales } \\
\hline \multicolumn{7}{|l|}{ Generales } \\
\hline \multicolumn{7}{|l|}{ Seguridad realizar las } \\
\hline $\begin{array}{l}\text { mismas actividades } \\
\text { próximo año }(\%)\end{array}$ & 90.04 & 16.94 & & & & \\
\hline \multicolumn{7}{|l|}{ Seguridad de continuar en } \\
\hline $\begin{array}{l}\text { la misma empresa } \\
\text { próximo año }(\%)\end{array}$ & 90.28 & 16.93 & & & & \\
\hline $\begin{array}{l}\text { Antigüedad en el puesto } \\
\text { (meses) }\end{array}$ & 71.71 & 102.96 & & & 3 & 486 \\
\hline $\begin{array}{l}\text { Antigüedad en la empresa } \\
\text { (meses) }\end{array}$ & 80.49 & 104.15 & & & 3 & 486 \\
\hline \multicolumn{7}{|l|}{ Antigüedad laboral } \\
\hline 2. Variables & 196.8 & 126.296 & & & 8 & 586 \\
\hline \multicolumn{7}{|l|}{ Sociolaborales Horario } \\
\hline Jornada Continua & & & 93 & 66 & & \\
\hline Jornada Partida & & & 40 & 28.4 & & \\
\hline Horario nocturno & & & 4 & 2.8 & & \\
\hline Por turnos & & & 2 & 1.4 & & \\
\hline Horas irregulares & & & 1 & .7 & & \\
\hline Otros & & & 1 &, 7 & & \\
\hline
\end{tabular}

Para realizar el análisis estadístico de las variables sociolaborales de los colaboradores/as la muestra obtenida se dividió en varios grupos. Por un lado, tomando como referencia los porcentaje de respuesta para las variables sociolaborales de Seguridad en realizar la misma actividad, y Seguridad de permanecer en la misma empresa, se agruparon en las siguientes categorías: Bajo <25\%, Medio 26-50\%; y Medio-Alto: 76\% 
En el caso de las variables de antigüedad en el puesto y antigüedad en la empresa se agruparon de la siguiente forma: <de 1 año; entre 1 y 3 años, entre 3 y 5 años y > de 5 años. Y finalmente, con respecto al horario, se recogió las diferentes modalidades de jornada de trabajo en la que se desempeñan, a saber: Jornada Continua, Jornada Partida, Horario Nocturno, Por turnos, y Otros.

Tal y como describe la Tabla 5.3 los colaboradores/as analizados/as tienen una alta expectativa en que van a realizar las mismas actividades ( $\bar{X}=90,04 \%$-Alto), así como que van a continuar en la misma empresa ( $\overline{\mathrm{X}}=90,17 \%$-Alto). La antigüedad en el puesto $(\overline{\mathrm{X}}=71,71)$ así como en la empresa $(\overline{\mathrm{X}}=80,49)$ dan debida cuenta de la estabilidad laboral que caracteriza al mercado de trabajo ecuatoriano. Por último, las dos jornadas de trabajo que más de dan entre los colaboradores/as es en primer lugar la de jornada continua (66\%) y en segundo lugar la jornada partida $(28,4 \%)$.

A la hora de extraer la muestra de colaboradores/as lo más importante fue el acercamiento con las diferentes empresas y los departamentos que podían relacionarse con los objetivos de la investigación. Lo primero que se hizo fue obtener la muestra voluntaria de líderes organizacionales que quisieran participar en la investigación y de ahí, en coordinación con el representante responsable del proyecto de investigación, en el caso de las empresas de educación y aseo urbano el director de Recursos Humanos, y en la del sector turismo el Director de Planificación, se configuró la asignación de tres colaboradores/as en relación directa de dependencia y que tuviesen contacto regular presencial con su líder. La selección de la muestra de colaboradores/as se realizó de esta manera para intentar reducir la posible subjetividad ante el hecho de que fueran los líderes 
los que escogiesen a tres colaboradores/as directos que pudiesen defender sus intereses personales con la consiguiente pérdida de objetividad en sus respuestas.

\subsection{Procedimiento de Recogida de Datos}

A través de la Dirección de Investigación del Instituto Tecnológico Superior

Cordillera se contactó con diferentes empresas para buscar su participación en el proyecto de investigación. Los contactos con las empresas se establecieron directamente con las gerencias generales a las cuáles se les explicó con detalle tanto, los objetivos, fases, instrumentos a utilizar, como los beneficios por participar en esta investigación. En este último punto se le ofrecía a cada gerente un informe general del nivel de habilidades emocionales de sus líderes organizacionales a modo de diagnóstico interno y siempre sin una identificación individual de sus líderes para mantener el anonimato y confidencialidad de sus respuestas y resultados.

Una vez presentado el proyecto a la gerencia de cada empresa y, aceptada su participación por escrito, se solicitó la designación de un representante por empresa con el fin de establecer una comunicación fluida sobre las actividades a realizar. Los interlocutores internos por cada empresa fueron: en educación, la dirección de Recursos Humanos; en aseo urbano, la dirección de Talento Humano; en turismo, la dirección de Planificación. Con cada interlocutor interno se estableció un cronograma de trabajo así como las actividades a realizar con las responsabilidades asociadas. En cada una de las empresas participantes se siguió el mismo procedimiento: en primer lugar, se remitió por parte de cada interlocutor interno la convocatoria a los líderes organizacionales citándolos a una reunión grupal para explicarles por parte del investigador principal los por menores del 
estudio científico. En la reunión grupal con los líderes organizacionales se comentaron los siguientes aspectos:

1. Objetivos y fases de la investigación.

2. Participación voluntaria, confidencialidad y anonimato en las respuestas facilitadas.

3. Tiempo estimados en la participación.

4. Y sobre todo, se remarcó que los resultados obtenidos no iban a estar asociados a ninguna política de evaluación de desempeño organizacional. Esta cuestión era muy importante destacarla para evitar posibles rechazos y barreras a la posterior aplicación de los cuestionarios. Con el fin de garantizar este aspecto, en cada una de las hojas de respuesta no aparecían nombre sino códigos de letras y números con lo que el investigador no podría identificarlos; además, los informes que se ofrecían a la dirección de la empresa nunca eran informes individuales, sino colectivos.

Finalizada la reunión grupal, se coordinó con cada interlocutor interno el día y la hora señalados para el pase de la prueba con los líderes que se presentaron voluntariamente. Se destinó por empresa un espacio cómodo y aislado de las preocupaciones organizacionales diarias ya que se restringió el uso teléfono móvil y de dispositivos informáticos. El horario establecido fue dentro de la jornada de trabajo para evitar el uso del espacio personal. Una vez reunidos/as, se repartió por escrito los objetivos y fases de la investigación para aclarar cualquier duda. Se destacó que se trataba de una colaboración entre la empresa y el Instituto Tecnológico Superior Cordillera y la Universidad Jaume I de España para la realización de una investigación de carácter exclusivamente académico. Seguidamente, y siguiendo las instrucciones del manual de la prueba, se procedió a explicar las indicaciones de cómo contestar los ítems que la componen. Se resolvieron algunas 
dudas existentes y los/as participantes completaron la prueba dentro de un intervalo de 45 a 80 minutos. En la única empresa que hubo que realizar dos pases por el número de líderes existentes fue en la del sector de aseo urbano. En total realizaron la prueba 48 participantes, pero se invalidó las contestaciones de uno de ellos ya que no completó correctamente una de las partes del test. Por lo que la muestra final de líderes fue de 47.

En segundo lugar, una vez validadas las contestaciones de los líderes en las pruebas, se procedió a identificar a sus tres colaboradores/as directos. Esta identificación la realizó cada interlocutor de cada empresa y no el mismo líder para evitar posibles sesgos. Para la identificación de los colaboradores/as se estableció el criterio que estuviesen organizacionalmente en una clara relación jerárquica directa con su líder y que mantuviesen con él una regular interrelación presencial. El interlocutor de cada empresa coordinó los diferentes días de realización del pase de la prueba, que debido al número de colaboradores/as, hubo que establecer en varios días. En total se dedicaron 10 días de pase con la siguiente distribución de participantes según la empresa: 1 día de pase en educación, 3 días de pase en turismo y 6 días de pases en aseo urbano.

En todos los pases se actuó de la misma manera. Se citó a los colaboradores/as con un día mínimo de antelación para la realización de la prueba en una sala con las condiciones adecuadas de espacio e iluminación. La citación fue por escrito adjuntando una notificación con los objetivos de la reunión destacando los siguientes puntos:

1. Explicación de la búsqueda de su colaboración para la realización de una investigación científica en colaboración entre la empresa, el Instituto Tecnológico Superior Cordillera y la Universidad Jaume I de España

2. Objetivos y fases de la investigación 
3. Participación voluntaria, confidencialidad y anónima en las respuestas facilitadas

4. Tiempo estimados en la participación

5. Y sobre todo, se remarcó que los resultados obtenidos no iban a estar asociados a ninguna política de evaluación de desempeño organizacional. Esta cuestión era muy importante destacarla para evitar posibles rechazos y barreras a la posterior aplicación del cuestionario. En coordinación con el interlocutor de la empresa, se verificó la asistencia de los colaboradores/as citados/as. Acto seguido se procedió a explicar verbalmente el objeto de la convocatoria y el contenido de los cinco puntos recogidos en la citación que se les había hecho llegar de forma escrita. La totalidad de los/as convocados/as aceptaron voluntariamente participar en la investigación una vez se les confirmo, tanto por el investigador como por el representante de la empresa, que no era una iniciativa de evaluación de Recursos Humanos, sino una investigación académica internacional. Seguidamente, se leyó las instrucciones del instrumento en voz alta y se aclararon las dudas iniciales que surgieron. El tiempo de realización de la prueba osciló en un intervalo entre 60-90 minutos. Se configuró una muestra total de 141 colaboradores/as participantes.

\subsection{Instrumentos}

\subsubsection{Variables a nivel del líder organizacional}

Tal y cómo se ha explicado anteriormente nuestra investigación es de tipo multinivel compuesta por dos tipos de análisis. Por un lado, nos encontramos con un nivel 1 (Líder) dónde lo importante inicialmente es evaluar el nivel de inteligencia del/la líder para poder analizar posteriormente cómo impacta en sus colaboradores/as. En este nivel 1 nos centramos en evaluar la inteligencia emocional del/la líder y su impacto en las 
competencias mentales del colaborador/a así como si el efecto modulador del vigor en esta posible relación. Por ello, la variable a nivel del/la líder que nos interesa estudiar es su inteligencia emocional. Además, nos encontramos con el nivel 2 (trabajadores a su cargo) que se ciñe exclusivamente a la muestra de colaboradores/as y a la posible relación que pueda existir entre sus propias competencias emocionales y competencias mentales. A continuación, se describe la variable de nivel 1 que se mide en este estudio.

Inteligencia Emocional. Se evaluó la inteligencia emocional de los líderes mediante la adaptación española (Extremera y Fernández-Berrocal, 2009) del cuestionario MayerSalovey Caruso Intelligence Test (MSCIT, de Mayer et al., 2002). El cuestionario está formado por un total de 138 ítems, divididos en cuatro dimensiones. La primera es la percepción emocional, compuesta por 50 ítems ("Observe la cara de la imagen e indique en qué grado expresa los sentimientos que aparecen a continuación”) en esta dimensión se les pedía a los trabajadores que marcasen su respuesta en una escala Likert de cinco puntos de anclaje (1= Ausencia de emoción a 5= Extrema presencia $)$. La segunda dimensión es la facilitación emocional, compuesta por 30 ítems en dos formas distintas (“¿Qué estado de ánimo sería útil cuando preparamos unos adornos nuevos y emotivos para una fiesta de cumpleaños?”) en esta tipología de ítem, se les pedía a los trabajadores que marcasen su respuesta en con una escala Likert de cinco puntos $(1=$ Nada útil a $5=$ Muy útil $)$. En cuanto a la segunda tipología ("Imagínese que se está sintiendo frío, lento, y afilado. ¿En qué grado ese sentimiento se parece a cada uno de los siguientes términos?”) Se les pedía que marcasen su respuesta en con una escala Likert de cinco puntos de anclaje (1= Nada parecido a 5= Muy parecido). La tercera dimensión es la comprensión emocional, compuesta por 32 ítems ("Tamara estaba disgustada porque un compañero de trabajo se 
atribuyó el mérito de un proyecto y cuando volvió a hacerlo, se sintió”), en esta dimensión se les pedía a los trabajadores que seleccionaran en una escala de selección múltiple una de las cinco opciones que se les planteaba. La cuarta y última dimensión, manejo emocional, estaba compuesta por 26 ítems ("María se levantó sintiéndose bastante bien. Había dormido estupendamente, se encontraba muy descansada y no tenía ningún tipo de inquietud o preocupación. ¿Cómo ayudaría cada una de estas acciones a mantener su estado de ánimo?"). La escala utilizada para recoger las contestaciones fue de tipo Likert de cinco puntos de anclaje (1= Muy ineficaz a 5= Muy eficaz).

\subsubsection{Variables a nivel individual.}

Con respecto al nivel individual se han evaluado las siguientes variables de los colaboradores/as: competencias mentales, competencias emocionales, y vigor. Para ello se ha utilizado el cuestionario Recursos Experiencias y Demandas -RED diseñado por el equipo de investigación WONT de la Universidad Jaume I de España (Salanova, Llorens, Cifre, y Martínez, 2006). Es un cuestionario que se fundamenta en el Modelo de Demandas-Control de Karasek y Theorell (Karasek, 1979; Karasek y Theorell, 1990) y las extensiones posteriores (ej. Salanova, Peiró, y Schaufeli, 2002; Schaufeli y Bakker, 2004). En su forma reducida contiene 35 escalas y 135 ítems agrupados en cuatro bloques: Datos administrativos, Recursos, Emociones y Demandas laborales. En el primer bloque las respuestas son abiertas y en los otros tres bloques son de tipo Likert con siete puntos de anclajes de respuesta (0 a 6). De todas estas variables, a continuación se describen las variables utilizadas en este estudio. 
Competencias mentales: Con el fin de operativizar el constructo cognición de los colaboradores/as se estableció como variable operativa la medición del nivel de sus competencias mentales. Las competencias mentales se entienden como el grado en que el empleado/a se siente competente a nivel cognitivo para afrontar las demandas que el puesto de trabajo requiere (Salanova et a.l, 2002). Su evaluación se realizó mediante dos ítems reformulados en el cuestionario RED a partir de la escala de demandas mentales de Van Veldhoven y Meijman (1994). Un ejemplo de ítem es: "En mi trabajo soy capaz de estar pendientes y recordar muchas cosas a la vez". La escala utilizada para recoger las contestaciones fue de tipo Likert de siete puntos de anclaje $(0=$ Nunca a $6=$ Siempre/Todos los días).

Competencias emocionales: Respecto al constructo de la emoción, para poder operativizarlo de forma más concreta se midió las competencias emocionales de los colaboradores/as. Las competencias emocionales se conceptualizan como el grado en que el empleado/a se siente competente a nivel emocional, para afrontar las demandas que el puesto de trabajo requiere (Salanova et al, 2002). Su evaluación se realizó mediante cuatro ítems reformulados en el cuestionario RED a partir de la escala de demandas emocionales de Van Veldhoven y Meijman (1994). Un ejemplo de ítem es: "En mi trabajo soy capaz de afrontar problemas con la gente con la que trabajamos, de forma objetiva y directa". La escala utilizada para recoger las contestaciones fue de tipo Likert de siete puntos de anclaje $(0=$ Nunca a $6=$ Siempre/ Todos los días $)$.

Vigor: A efectos de esta investigación se ha utilizado la conceptualización del vigor como dimensión que forma parte del constructo del engagement. El vigor dentro de esta aproximación se caracteriza por altos niveles de energía y resistencia mental mientras se 
trabaja, el deseo de invertir esfuerzo en el trabajo que se está realizando, incluso cuando aparecen dificultades en el camino (Salanova y Schaufeli, 2004). Ha sido medido mediante los tres ítems que integran la escala del engagement del cuestionario RED adaptado del cuestionario original del Utrech Work Engagement Scale (UWES; Schaufeli y Bakker, 2003; Schaufeli, Bakker, y Salanova, 2006). Un ejemplo de ítems es "En el trabajo me siento lleno de energía". La escala utilizada para recoger las contestaciones fue de tipo Likert de siete puntos de anclaje $(0=$ Nunca a $6=$ Siempre $/$ Todos los días $)$. 


\subsection{Análisis de Datos}

\subsubsection{Análisis de datos descriptivos.}

En primer lugar, se llevaron a cabo análisis descriptivos, en los que se analizó las medias, desviaciones típicas, alfas de Cronbach y correlaciones de las cuatro variables de estudio. En segundo lugar se llevaron a cabo análisis ANOVA y pruebas $t$ para grupos independientes para ver si las variables sociodemográficas tenían un efecto en las cuatro variables de estudio, a saber: inteligencia emocional, competencias mentales y emocionales y vigor. Las variables sociodemográficas tanto de los líderes como de los colaboradores/as estudiadas y controladas han sido (ver Tabla 5.4):

Tabla 5.4: Variables Sociodemográficas

\section{Líderes}

\section{Colaboradores}

\section{Variables Sociodemográficas Personales}

\begin{tabular}{ll}
\hline 1. Género & \multicolumn{1}{c}{ 1. Género } \\
2. Edad & 2. Edad \\
\hline & Variables Sociodemográficas Laborales \\
\hline & 3. Seguridad de desempeñar las mismas \\
actividades en el próximo año & 4. Seguridad de trabajar en la misma empresa el \\
próximo año & 5. Antigüedad en el puesto \\
6. Antigüedad en la empresa \\
7. Horario \\
Jornada Continua \\
Jornada Partida \\
Horario nocturno \\
Por turnos \\
Horas irregulares \\
Otros \\
\hline
\end{tabular}


Tal y como aparece en la tabla anterior, se han agrupado las variables sociodemográficas en dos grandes categorías: variables personales y variables sociolaborales. La selección de estas variables se corresponde por las diversas investigaciones que apuntan una posible la relación de las mismas con diversas variables dependientes muy relacionadas con las de esta investigación. Por un lado, diversos autores/as apuntan a considerar relevantes las variables género, estado civil, edad, años de antigüedad laboral y categoría profesional (Boada, de Diego, y Agulló, 2004; Quaas, 2006; Sandoval, González, Sanhueza, Borjas, y Odgers, 2006). Con respecto a la inteligencia emocional y las competencias emocionales que la componen, diversas investigaciones han demostrado que existen diferencias significativas entre hombres y mujeres con una alta dominancia de las mujeres frente a los hombres (Brackett y Mayer 2003; FernándezBerrocal, Extremera y Ramos, 2004; Mayer, Salovey y Caruso, 2002). Aunque si bien es cierto, tal y cómo señalan Sánchez, Fernández-Berrocal, Montañez y Latorre (2008) si se utilizan medidas de autoinforme, las diferencias entre hombres y mujeres no son tan concluyentes.

En relación a las competencias mentales (cognición) nos encontramos con resultados contradictorios con respecto al género. Si bien es cierto que aparecen diferencias individuales con respecto a ciertas habilidades específicas como las espaciales, dónde los hombres puntúan más alto y las verbales dónde destacan las mujeres, especialmente la fluidez verbal (Stumpf y Eliot, 1995). El consenso tras años de discusión es que no hay diferencias significativas entre hombres y mujeres en el factor global de inteligencia general (Colom y García López 2002; Feingold, 1992). 
Con respecto al vigor existen numerosas investigaciones que sugieren que no existen diferencias significativas entre hombres y mujeres (Benevides-Pereira, Fraiz de Camargo y Porto-Martins, 2011; Chiang, Núñez, Gonzalez y Guerrero, 2013; Martín y Salazar, 2010), no obstante se incluyó en nuestra investigación el análisis de la relación del género con el vigor con el objeto de analizar su posible efecto.

\subsubsection{Análisis de datos multinivel para la comprobación de las hipótesis.}

Para poder llevar a cabo el contraste de las hipótesis, se consideró una situación de varios niveles (Snijders y Bosker, 1999), donde una variable dependiente medida en el nivel inferior (es decir, el colaborador) se explica por variables medidas en ese nivel más bajo o en un nivel superior (es decir, el líder). En este estudio, una variable dependiente Y (es decir, las competencias mentales), medida en el nivel más bajo (nivel-2), se supone que es explicada por la influencia de la variable X (es decir, competencias emocionales), también medido en el nivel más bajo, y por explicativa variable Z (es decir, la inteligencia emocional del/la líder), medida en el nivel superior (nivel-1). Por último la relación transnivel de Y y Z es además, modulada por la variable W (es decir, vigor) medida en el nivel más bajo (Nivel-2).

Los datos se estructuraron jerárquicamente de una manera tal que 141 casos a nivel individual (nivel-2) se anidan en 47 supervisores (nivel-1). Los datos fueron analizados a través de Hierarchical Linear Modeling (HLM; Hofmann y Gavin 1998; Hox 1995) utilizando el software LISREL. Este método es el adecuado para el análisis de datos en una estructura anidada mediante la construcción de un sub-modelo separado en cada uno de los niveles en la estructura de datos (Bryk y Raudenbush 2002). Permite hacer inferencias 
simultáneas sobre los efectos de las variaciones en las variables independientes a nivel individual (es decir, las competencias emocionales) y el nivel superior del supervisor (es decir, inteligencia emocional) sobre las variables dependientes (es decir, competencias mentales) y el efecto modulador de nivel transversal de la variables independiente sobre la variable dependiente a nivel individual (es decir, vigor). Además, las puntuaciones fueron centradas a la gran media, según lo sugerido por Hoffman y Gavin (1998). 


\section{RESULTADOS}




\section{Capítulo VI: Resultados}

"Si buscas resultados distintos no hagas siempre lo mismo"

Albert Einstein 
A continuación se describen los resultados obtenidos en los diferentes tipos de análisis realizados.

\subsection{Análisis descriptivos}

La Tabla 6.1 que aparece a continuación resume las medias, desviaciones típicas, las correlaciones y los alfas de Cronbach de las variables del estudio.

Tabla 6.1: Estadísticos Descriptivos y Fiabilidad $(N=141)$

\begin{tabular}{|c|c|c|c|c|c|c|}
\hline & $\mathrm{M}$ & DT & Fiabilidad & 1 & 2 & 3 \\
\hline $\begin{array}{l}\text { 1. Inteligencia } \\
\text { Emocional }\end{array}$ & 98.25 & 10.80 & ,95* & & & \\
\hline $\begin{array}{l}\text { 2. Competencia } \\
\text { Mental }\end{array}$ & 4.40 & 1.43 & $.34 * *$ & -.032 & & \\
\hline $\begin{array}{l}\text { 3. Competencia } \\
\text { Emocional }\end{array}$ & 4.05 & 1.43 &, 79 & .026 & $.521 * * *$ & \\
\hline 4. Vigor & 5.54 & .63 & ,82 & -.046 & -.030 & -.041 \\
\hline
\end{tabular}

En la Tabla 6.1 se muestra la relaciones entre las variables estudiadas estableciéndose como estadísticamente significativas aquellas con $(p<.01)$. Se observa que existe una relación significativa positiva $(r=.521)$ entre las competencia emocionales y las competencias mentales de los colaboradores. Este resultado va en línea con dos ideas: la primera es que tanto la emoción como la cognición son dos constructos que están en una constante interacción, por ello, cuando hay altas puntuaciones en competencias emocionales sucédelo mismo en las competencias mentales ya que hay una relación directa robusta. Y la segunda, se enlaza con la idea de facilitación emocional de la cual se desprende que la información emocional facilita el procesamiento cognitivo. 
Por otro lado, se esperaba obtener correlaciones significativas entre el resto de variables estudiadas. La carencia de esta correlación podría ser explicada por la muestra de bajo tamaño que se ha utilizado en la investigación (solo 47 líderes).

Con respecto a la fiabilidad se tiene resultados en un rango 0.70-0.95 para las variables inteligencia emocional $(\alpha=0.95)$, competencias emocionales $(\alpha=.79)$ y vigor $(\alpha=.82)$. Las puntuaciones obtenidas se sitúan en el rango que se considera recomendable por diversos autores para asegurar la consistencia interna de los instrumentos utilizados (Bland y Altman, 1997; Cervantes, 2005). Hay que señalar que se ha recogido la fiabilidad de la prueba que se describe en el manual de uso en su validación a muestra española. Según los autores (Extremera, y Fernández-Berrocal, 2009), el cálculo de la fiabilidad de la escala en general de inteligencia se realizó a través del coeficiente Spearman-Brown (dos mitades) y de las dos áreas que lo componen el alfa de Cronbach obteniéndose unos valores altos $($ Total $=0,95 ;$ Experiencial $=0,93 ;$ Estratégica $=0,90)$. En el caso de las competencias mentales al utilizar dos ítems de medición se obtuvo el coeficiente de correlación de Pearson. La puntuación obtenida fue de $\mathrm{r}_{\mathrm{xy}}=, 34$ valor que se considera aceptable (Robinson, Shaver, y Wrightsman, 1991).

\subsection{Análisis con variables sociodemográficas}

Para evitar que las variables dependientes e independientes de nuestro estudio, y por defecto las relaciones entre ellas, estén influenciadas por las variables sociodemográficas es necesario conocer si tienen algún efecto sobre éstas últimas. Es por ello que se han llevado a cabo dos tipos de pruebas, ANOVA y pruebas $t$ para muestras independientes (ver Tabla $6.2)$. 
Tabla 6.2: Análisis Variables Sociodemográficos ( $N$ líderes $=47 ;$ N colaboradores/as a su cargo=141)

\begin{tabular}{|c|c|c|c|c|c|c|c|c|c|c|c|c|c|c|}
\hline & \multicolumn{2}{|c|}{ Género } & \multicolumn{2}{|c|}{ Edad } & \multicolumn{2}{|c|}{$\begin{array}{l}\text { Seguridad } \\
\text { Realizar } \\
\text { Actividad }\end{array}$} & \multicolumn{2}{|c|}{$\begin{array}{l}\text { Seguridad } \\
\text { Continuar } \\
\text { Empresa }\end{array}$} & \multicolumn{2}{|c|}{$\begin{array}{l}\text { Antigüedad } \\
\text { Puesto }\end{array}$} & \multicolumn{2}{|c|}{$\begin{array}{l}\text { Antigüedad en } \\
\text { la empresa }\end{array}$} & \multicolumn{2}{|c|}{ Horario } \\
\hline & $\mathrm{t}$ & $p$ & $\mathrm{t}$ & $p$ & $\mathrm{~F}$ & $p$ & $\mathrm{~F}$ & $p$ & $\mathrm{~F}$ & $p$ & $\mathrm{~F}$ & $p$ & $\mathrm{~F}$ & $p$ \\
\hline Lideres & & & & & & & & & & & & & & \\
\hline $\begin{array}{l}\text { Inteligencia } \\
\text { Emocional }\end{array}$ &, 737 & ,465 & 2,45 &, $022 *$ & & & & & & & & & & \\
\hline Colaboradores & & & & & & & & & & & & & & \\
\hline $\begin{array}{l}\text { Competencias } \\
\text { Mentales }\end{array}$ & -.77 & ,079 & ,232 & ,633 & 1,226 & ,312 & 1,46 & ,931 & ,912 & ,451 & .478 & ,701 & 1,644 & ,208 \\
\hline $\begin{array}{l}\text { Competencias } \\
\text { Emocionales }\end{array}$ & $-2,58$ &, $011^{*}$ &, 000 & ,099 & 3,256 &, 057 & ,940 & ,438 &, 317 &, 813 & ,978 &, 420 & 2,081 & , 158 \\
\hline Vigor & 2,44 &, $017 *$ & ,003 & ,96 &, 115 & ,892 & ,668 &, 580 & ,904 & ,454 &, 773 &, 180 &, 745 & ,394 \\
\hline
\end{tabular}


Con respecto a los/as líderes se da un efecto significativo de la edad sobre su inteligencia emocional $(p=.022)$. Este resultado, analizando la tendencia gráfica de nuestros resultados que se representa en la Figura 6.1 podría ser debido a que a partir de una edad (en nuestro caso 42 años) se produce un efecto de descenso paulatino de las habilidades emocionales. Este hallazgo se enlaza con una investigación realizada con 1.996 personas mayores de 14 años en un contexto parecido al ecuatoriano como es Lima. Lo que se concluyó es que aunque la inteligencia emocional tiende a incrementarse con la edad, se produce un ligero decremento a partir de los 55 años (Ugariza, 2001). De igual manera Navarro, Latorre y Ros (2009) estudiaron las diferencias evolutivas en inteligencia emocional a través de la comparación entre jóvenes (edad media: 22 años) y mayores (edad media: 66 años) en la respuesta a la escala de Inteligencia Emocional Autoinformada a través del TMMS-24 (Extremera et al., 2006) y encontraron diferencias significativas a favor del grupo de mayores que en el grupo de jóvenes. En esta Tesis el decremento de la inteligencia emocional se produjo a partir de los 42 años hasta llegar a su nivel más bajo precisamente con las personas con mayor edad. Indudablemente, habría que ampliar la muestra obtenida de líderes para poder concluir que se produce una tendencia negativa a partir de una edad. No obstante, una de las habilidades emocionales como es la de percepción, depende en gran medida de nuestra capacidad de atención de estímulos visuales. Esta capacidad atencional con el paso de los años se ve mermada debido a la pérdida progresiva de capacidad fisiológica visual. 


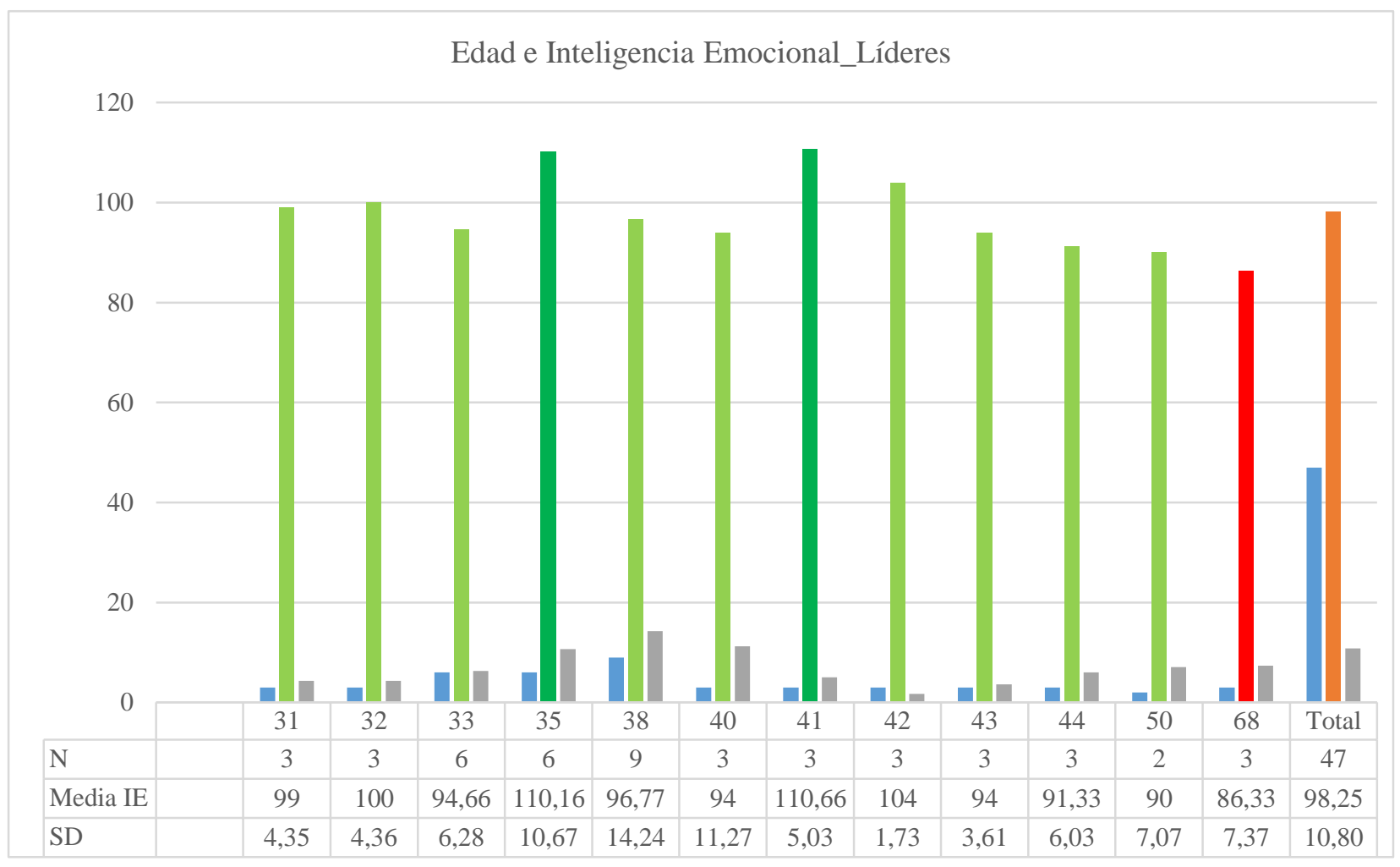

Inferior a la media (0-89)

En la media (90-109)

Superior a la media (110 o más)

Figura 6.1: Edad e Inteligencia Emocional Líderes

Se detalla en la Figura 6.1 como la edad de los líderes se distribuye en un intervalo de 31-68 años dónde la edad con mayor frecuencia de respuesta ha sido la edad de 38 $(\mathrm{N}=9)$. Las edades con mayores promedios alcanzados, superiores a la media, han sido la de 35, y 41 años con medias obtenidas de $(\overline{\mathrm{X}}=110,16)$ y $(\overline{\mathrm{X}}=110,66)$ respectivamente. Hay que resaltar que la escala de puntuaciones promedio del nivel de inteligencia emocional se clasifica en tres categorías: Inferior a la Media (0-89); En la media (90-109), y Superior a 
la Media (110 o más). Esta escala es la se establece como referencia en la adaptación española del MSCEIT (Extremera y Fernández Berrocal, 2009).

En relación a los colaboradores/as, existe un efecto significativo del género sobre las competencias emocionales $(p=, 011)$ y el vigor $(p=, 017)$. Con respecto a las competencias emocionales las mujeres han alcanzado un promedio de $(\overline{\mathrm{X}}=4,42)$, superior al de los hombres de $(\overline{\mathrm{X}}=3,80)$. Los resultados encontrados de diferencias significativas $(p=$ ,011) a favor de las mujeres van en la misma línea de investigaciones anteriores que, centrándose en la evaluación de la inteligencia emocional, describen puntuaciones más altas de las mujeres que de los hombres (Brackett y Mayer 2003; Fernández-Berrocal, Extremera y Ramos, 2004; Mayer, Salovey y Caruso, 2002).

Con respecto al vigor, existen numerosas investigaciones que apuntan que no existen diferencias significativas entre hombres y mujeres (Benevides-Pereira, Fraiz de Camargo y Porto-Martins, 2011; Chiang, Núñez, González y Guerrero, 2013). Nuestros resultados abren una posibilidad de discusión al respecto al haber encontrado diferencias significativas $(p=, 017)$ entre hombres y mujeres. Se observa como el promedio alcanzado de los hombres $(\overline{\mathrm{X}}=5,66)$ es ligeramente superior que el de la mujeres $(\overline{\mathrm{X}}=5,38)$. La falta de estudios al respecto hace complicado esgrimir una respuesta consolidada ya que habría que analizar los aspectos motivacionales y físicos de forma individual que componen el vigor, así como el contexto laboral de cada uno de los colaboradores/as. En este sentido, una posible explicación de la diferencia significativa a favor de los hombres podría ser que del total de 141 de colaboradores/as, 75 de ellos pertenecen a la empresa de aseo urbano. Estos colaboradores/as son en su mayoría hombres siendo escasas las mujeres participantes ya que el puesto de trabajo se asocia a tareas físicas, circunstancia que no sucede en las otras 
dos empresas que componen la muestra. Por tanto, su trabajo requiere y exige esfuerzo físico. Esta demanda laboral podría ser que lo contrarresten con un recurso como es la alta dosis de energía física y que, a su vez, que influye en el vigor analizado.

\subsection{Análisis Multinivel para la Comprobación de las Hipótesis}

En primer lugar, al tratarse de una investigación multinivel jerarquizada dónde tres colaboradores/as distintos/as (grupo) se anidan en un/a líder en concreto, es necesario obtener el cálculo del Índice de Correlación Intraclase (ICC) que es un indicador de la homogeneidad individual. El ICC es una medida de la similitud de las unidades del nivel individual (competencias mentales de los colaboradores/as) y las diferencias entre las unidades del nivel macro (inteligencia emocional líderes). Por tanto se define como la variabilidad total que se debe a la variabilidad de los sujetos (James, Demaree y Wolf, 1984, LeBreton y Senter, 2007). En nuestro estudio el ICC=26, es decir, que el 26\% de la varianza de la variable competencias mentales de los trabajadores depende de la inteligencia emocional de sus líderes respectivos.

La Tabla 6.3 resume los resultados HLM de los efectos de las competencias emocionales, y el vigor de los colaboradores/as, y la inteligencia emocional del/la líder en las competencias mentales de los trabajadores a su cargo. En esta tabla Modelo 1 se refiere al modelo nulo. 
Tabla 6.3: Resultados del Modelo Lineal Jerárquico (Nivel N=141; Nivel Líder N=47)

\begin{tabular}{|c|c|c|c|c|}
\hline Parámetros & Modelo 1 & Modelo 2 & Modelo 3 & Modelo 4 \\
\hline $\begin{array}{l}\text { Nivel Colaborador } \\
\text { Intercepto } \\
\text { Competencias } \\
\text { Emocionales } \\
\text { Vigor }\end{array}$ & $.52(0.23)^{*}$ & $\begin{array}{l}.11(0.14) \text { n.s. } \\
.50(0.07)^{* * *}\end{array}$ & $\begin{array}{l}.05(0.13) \text { n.s. } \\
0.48(0.07) * *\end{array}$ & $\begin{array}{l}.06(0.10) \text { n.s. } \\
0.47(0.08)^{* * *} \\
.05(0.16) \text { n.s. }\end{array}$ \\
\hline $\begin{array}{l}\text { Nivel Supervisor } \\
\text { Inteligencia } \\
\text { Emocional }\end{array}$ & & & $0.03(0.01)^{*}$ & $0.03(0.01)^{* *}$ \\
\hline $\begin{array}{l}\text { Inteligencia } \\
\text { Emocional X Vigor }\end{array}$ & & & & $0.03(0.01)^{*}$ \\
\hline$\sigma^{2}$ nivel trabajador & $1.54(0.22)^{* * *}$ & $1.39(0.21)^{* * *}$ & $1.36(0.21)^{* * *}$ & $0.62(0.10)^{* * *}$ \\
\hline $\begin{array}{l}\sigma^{2} \text { nivel supervisor } \\
-2 \times \log \\
\Delta-2 \times \log \\
g l\end{array}$ & $\begin{array}{l}0.53(0.23)^{*} \\
494.775 \\
3\end{array}$ & $\begin{array}{l}0.11(0.15) \text { n.s. } \\
461.285 \\
33.49 * * * \\
5\end{array}$ & $\begin{array}{l}0.045(0.13) \text { n.s. } \\
461.902 \\
0.635 \mathrm{~ns} \\
6\end{array}$ & $\begin{array}{l}0.03(0.03) \text { n.s. } \\
464.895 \\
2.993 \mathrm{~ns} \\
8\end{array}$ \\
\hline
\end{tabular}

Nota: $* * * p<0.000 ; * * p<0.01 ; * p<0.05 ;$ n.s. $=$ no significativo 
$\mathrm{La} \mathrm{H}_{1}$, a saber, el nivel de inteligencia emocional de los/as líderes se relaciona significativa y positivamente, en un efecto transnivel, con las competencias mentales (cognición) de sus colaboradores/as. Predice que la inteligencia emocional del/la líder está positivamente relacionada con las competencias mentales de los trabajadores/as a su cargo. Por tanto, esta hipótesis propone una relación transnivel. Y, en este caso y tal y como se muestra en la Tabla 6.3 (Modelo 3), la relación fue significativa y positiva ( $b=0,03$, $\mathrm{p}=0,01)$. Por tanto, la $\mathrm{H}_{1}$ queda confirmada.

En segundo lugar, para probar $\mathrm{H}_{2}$, a saber, el vigor de los colaboradores/as modula la relación entre el nivel de inteligencia emocional del/la líder y las competencias mentales de los/as colaboradores/as a su cargo, incluimos la interacción entre los diferentes niveles. El objetivo fue confirmar que la relación entre la inteligencia emocional del/la líder y las competencias mentales de los/as colaboradores/as a su cargo está modulada por el vigor de los colaboradores/as, por lo que la relación entre inteligencia emocional y competencias mentales es más fuerte cuando los es el vigor de los colaboradores/as. Para poner a prueba esta hipótesis se llevó a cabo el Modelo 4, que fue significativo y positivo ( $b=0,03$, $\mathrm{p}=0,05)$. Por tanto queda confirmada la $\mathrm{H}_{2}$.

En tercer lugar, la $\mathrm{H}_{3}$, a saber, existe una relación positiva y significativa entre las competencias emocionales de los colaboradores/as y las competencias mentales de los mismos, propone una relación a nivel individual. Esta hipótesis predice que las competencias mentales de los/as colaboradores/as se relacionan positivamente con las competencias emocionales de los/as colaboradores/as. Tal y como se puede observar en la Tabla 6.3 (Modelo 2), la relación fue significativa y positiva $(b=0,50, p \backslash 0,000)$, por lo tanto $\mathrm{H}_{3}$ queda confirmada. 
Los valores de la variable moderadora fueron escogidos al 1/2 SD por encima y por debajo de la media. La Figura 6.2 muestra gráficamente la moderación transnivel significativa, que implica que los líderes que reportan mayores niveles de inteligencia emocional en el trabajo, los/as colaboradores/as que posee a su cargo reportan mayores niveles de vigor y competencias mentales.

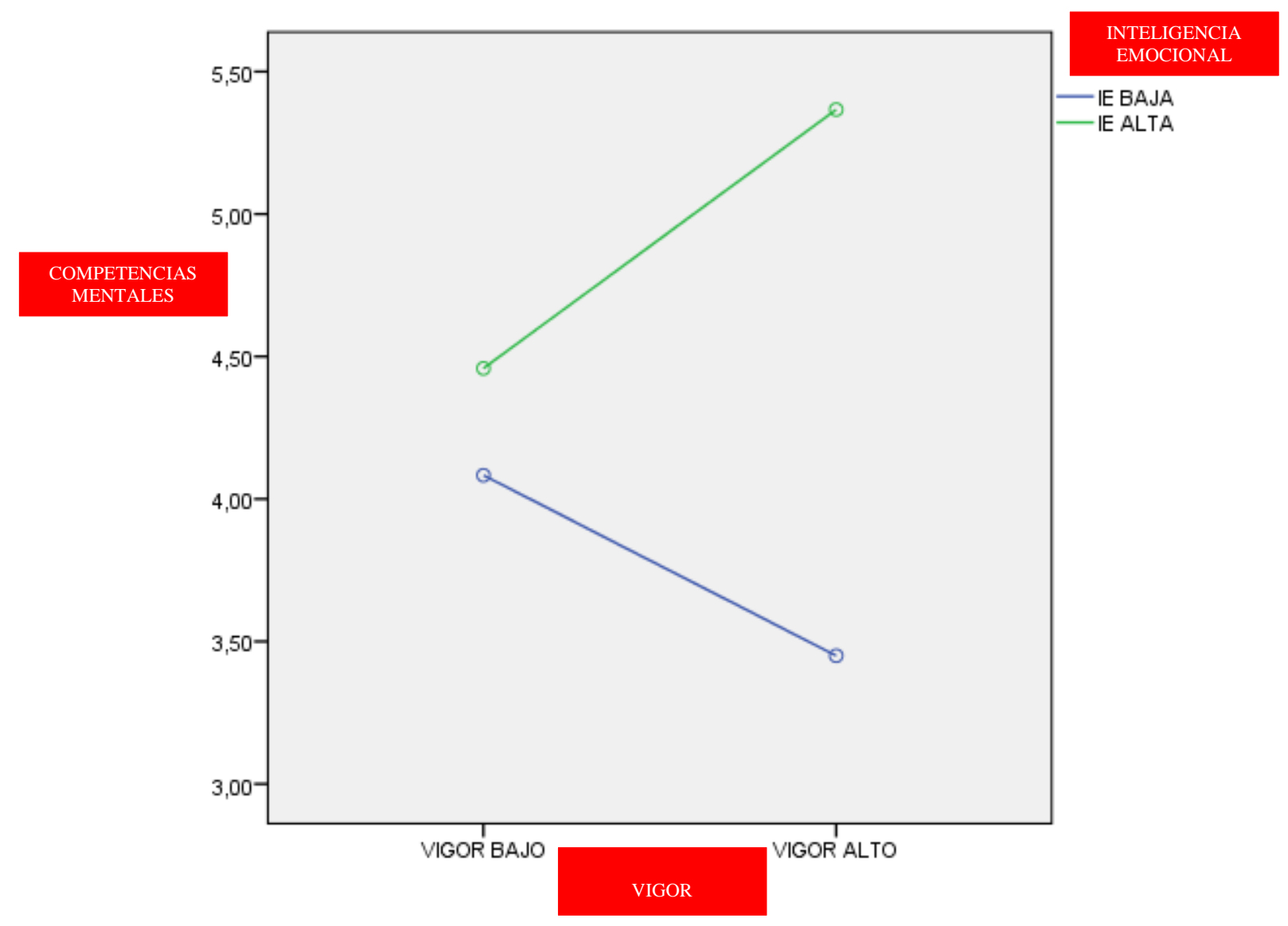

Figura 6.2: Efecto modulador del Vigor 


\section{DISCUSIÓN}




\section{Capítulo VII: Discusión}




\subsection{Discusión Inicial}

En este capítulo se describen y se discuten los principales resultados obtenidos en esta Tesis doctoral. Asimismo, se ofrecen algunas implicaciones teórico-prácticas que afectan, tanto a la esfera académica e investigativa, como a los profesionales del desarrollo organizacional y de la gestión del talento humano. Seguidamente, se exponen las limitaciones del estudio con el fin de que sean tenidas en cuenta en futuras investigaciones para mejorar el estudio realizado. Por último, se describen las conclusiones más importantes resultantes de la investigación.

Hay que indicar que esta Tesis tenía como uno de sus objetivos principales analizar el impacto de la inteligencia emocional del/la líder en la cognición (competencias mentales) de sus colaboradores/as, así como estudiar, si las competencias mentales de estos/as colaboradores/as, influían en sus propias competencias emocionales. De igual modo, se planteó si existía una acción moduladora del vigor de los/as colaboradores/as en esta relación con el/la líder. Hay que resaltar que es la primera investigación multinivel de este tipo existente en Ecuador, y en América Latina, siendo por otro lado, una las pocas investigaciones que analiza la interacción inteligencia emocional - cognición desde un punto de vista interpersonal. Para ello, se utilizó una metodología de estudio multinivel compuesta por un nivel inter (Macro) que analizó la relación entre la inteligencia emocional del/la líder y las competencias mentales de sus colaboradores/as. Posteriormente, y ya en un nivel intra (Micro) enfocado en los/as colaboradores/as, se analizó como la relación entre la inteligencia emocional del/la líder y las competencias mentales de los/as colaboradores/as, podría estar modulada por el nivel de vigor de éstos últimos, así como si sus propias competencias emocionales se relacionaban con sus competencias mentales. 
En la Figura 7.1 se recoge la representación del modelo teórico que se plantea en esta investigación.

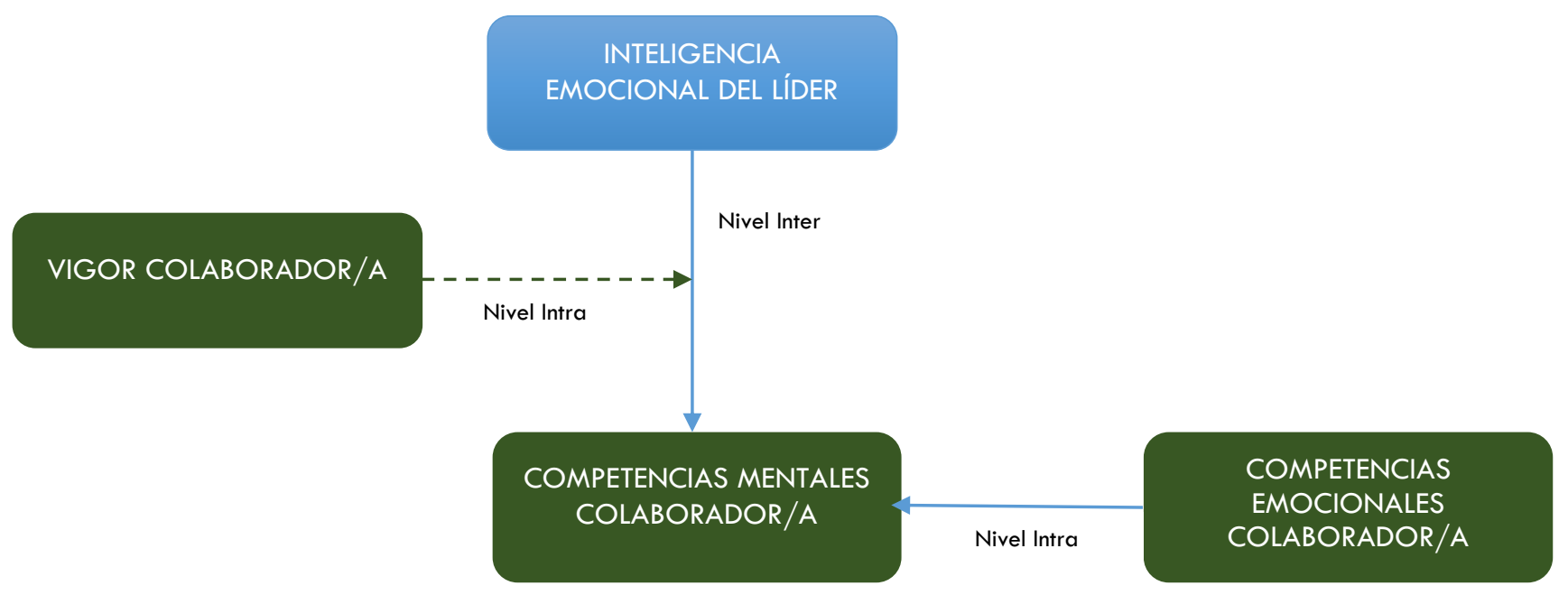

Figura 7.1: Efectos de la relación emoción-cognición y el vigor en el proceso de liderazgo

A continuación se discuten los resultados obtenidos según el tipo de análisis realizado.

\subsection{Resumen resultados obtenidos}

El primer análisis realizado fue el de nivel inter, mediante el cual se confirmó la hipótesis inicial, dícese, la inteligencia emocional, siguiendo el modelo de habilidades de (Mayer, y Salovey, 1997), impacta en la cognición (competencias emocionales) de sus colaboradores/as. Los resultados obtenidos muestran que existe una relación entre ambas variables. Lo que apunta a que aquellos/as líderes que obtienen altas puntuaciones en inteligencia emocional, es decir, son emocionalmente inteligentes ya que tienen alto dominio de la percepción, facilitación, comprensión y regulación emocional, influyen en 
sus colaboradores/as haciéndoles mejorar sus aptitudes cognitivas. Este resultado confirma la propuesta que las emociones tienen un efecto social (Van Kleef, 2008, 2009) sobre las otras personas que va más allá del mero contagio emocional. Es decir, no sólo se produce un contagio de emoción a emoción, lo cual supone un efecto ya recogido por la literatura de contagio de emociones (Barsade, 2002) situando el impacto en el continuo emociónemoción. El alto dominio de las habilidades emocionales del/la líder (alta inteligencia emocional) influye al colaborador/a haciendo que éste/a obtenga mejor desempeño en sus competencias mentales. Con lo que surge un nuevo nivel de impacto interpersonal entre líder y colaborador/a a través del continuo emoción-cognición que complementa el anterior de emoción-emoción. Específicamente, se observa que, a diferencia de los/as líderes con baja inteligencia emocional, los/as líderes que utilizan la inteligencia emocional en su proceso de liderazgo consiguen que sus colaboradores/as directos sean más eficientes en competencias mentales, aspecto básico para el desempeño de cualquier actividad laboral. Este resultado de influencia de la inteligencia emocional de los/as líderes sobre los/as colaboradores/as no sólo va en línea, sino que complementa, las investigaciones previas que han mostrado que la inteligencia emocional del/la líder influye en su equipo de trabajo (Goleman, Boyatzis y Mckee, 2002; Lopes, Côté y Salovey, 2006; Lopes, Grewal, Kadis, Gall y Salovey, 2006). Por otro lado, este efecto cognitivo hallado en los/as colaboradores/as viene a reforzar los postulados teóricos que contemplan el liderazgo como un proceso de influencia del/la líder sobre los/as colaboradores/as (Yukl, 2010) que puede provocar una serie de resultados afectivos y actitudinales en los/as colaboradores/as (Avolio et al., 2004). 
El segundo análisis realizado fue el del nivel intra y se divide en dos fases. La primera se vincula con el anterior tipo de análisis inter ya que, tomando como referencia la conceptualización del vigor propuestas por Schaufeli et al. (2002), y complementada por Shirom $(2004,2011)$, se ha comprobado que la relación existente entre la inteligencia emocional del/la líder y las competencias mentales de sus colaboradores/as está modulada por el nivel de vigor que tienen éstos últimos, es decir, la influencia de un/a líder emocionalmente inteligente sobre las competencias mentales de sus colaboradores/as se ve afectada por el nivel de vigor que muestran éstos últimos. A mayor nivel de vigor de los/as colaboradores/as más fuerte es la relación entre la inteligencia emocional del/la líder y la competencia mental de los/as colaboradores/as.

Por último, la segunda fase dentro de este análisis intrapersonal tenía como objetivo comprobar, tal y cómo se propuso, que las competencias emocionales de los colaboradores/as tenían un efecto sobre sus propias competencias mentales. Este efecto de facilitación emocional (Damasio, 1996) se pudo verificar en los/as colaboradores/as analizados/as ya que se consiguió comprobar una relación significativa positiva entre ambas variables. Por la cual, se predice que una alta ejecución en competencias emocionales de los/as colaboradores/as se relaciona con su nivel de competencias mentales. Este efecto apoya las ideas descritas en la literatura revisada de como las emociones se relacionan con la parte cognitiva del ser humano a través de su interrelación con las funciones ejecutivas facilitando el procesamiento cognitivo. 


\subsection{Implicaciones teóricas}

Los resultados obtenidos tienen implicaciones teóricas en las siguientes áreas de investigación: 1. Liderazgo e Inteligencia emocional, 2. Comprensión y Facilitación Emocional, 3. Efecto Social de las Emociones 4. Diferencias individuales y Vigor de los/as colaboradores/as.

\subsubsection{Liderazgo e inteligencia emocional}

En primer lugar esta investigación ratifica la idea más extendida en la literatura revisada que entiende el liderazgo como un proceso de interacción y de influencia entre el/la líder y sus colaboradores/as. En este sentido, las diversas teorías actuales que estudian el liderazgo, como el liderazgo transformador (Bass, 1985), o más recientemente el liderazgo auténtico (Luthans y Avolio, 2003), describen cómo los/as líderes se relacionan con sus colaboradores/as influyéndoles respectivamente hacia una visión y un propósito compartido positivamente.

Los resultados obtenidos en esta investigación aportan apoyo empírico a las últimas investigaciones de Yukl (2010) sobre las diversas estrategias que utilizan los líderes efectivos para influenciar y persuadir a sus colaboradores/a. Las investigaciones de Yukl desde hace más de 20 años se han centrado en conocer y explorar cuales son las estrategias más efectivas que un líder puede utilizar para movilizar a sus colaboradores/as para conseguir los objetivos organizacionales. Para este autor, existen diferentes tácticas que el/la líder puede utilizar para influenciar en los/as colaboradores/as. Se pueden clasificar en duras (cognitivas), mixtas, y blandas (emocionales). Éstas últimas, han aparecido 
recientemente con fuerza cuando diversas investigaciones han resaltado el poder de lo emocional en este proceso de interacción entre líder y colaborador/a. (Martínez, Munduate y Medina, 2008; Yukl, 2010).

Yukl (2010), destacó que la táctica de apelación a las emociones que, recoge los aspectos emocionales de la presente investigación, busca despertar emociones fuertes en el/la colaborador/a para generar compromiso con el trabajo a realizar, vinculándolo con los valores e ideales de la personas. Se trata de despertar en los equipos de trabajo el deseo de ser importante, sentirse útil, llevar a cabo un trabajo excepcional. Para que sea efectivo, el/la líder, debe de tener una idea previa de los valores, esperanzas y miedos sus colaboradores/as. De igual modo, el/la líder efectivo/a es el que utiliza sus habilidades de comunicación para describir imágenes vivas y emplear los gestos, la voz, el rostro, para generar entusiasmo y emoción. Estos aspectos emocionales agrupados en la estrategia de apelación a las emociones podrían condensarse en las habilidades emocionales que componen el modelo de inteligencia emocional seguido en esta Tesis de Mayer y Salovey (1997). Además, en esta investigación se ha sugerido que los/as líderes con alta inteligencia emocional van más allá del puro contagio emocional, ya que posiblemente al utilizar con sus colaboradores/as un liderazgo emocional que desarrolla tácticas de influencia emocionales, provocan un impacto en los/as colaboradores/as que incide en que obtengan mejores resultados en sus competencias mentales. Independientemente del porqué se produce esta mejora en las competencias mentales, que se explicará en el siguiente punto de implicaciones teóricas, esta Tesis apoya empíricamente las investigaciones previas que defienden que un/a líder con altos niveles habilidades emocionales repercute positivamente en sus colaboradores/as. La argumentación en este sentido se apoya en que, un/a líder con 
alta inteligencia emocional es aquel/lla que percibe con mayor claridad las expresiones emocionales de sus colaboradores/as ya que está atento/a a esta información emocional. Cuando las percibe, las procesa, las tiene en cuenta, lo que le ayuda a facilitar la toma de decisiones sobre las conductas que debe de llevar a cabo con sus colaboradores/as. Por otro lado comprende, entiende el porqué, (aunque no lo comparta), del estado emocional de sus colaboradores/as. Además, ese nivel de comprensión emocional del/a otro/a se combina con el manejo interno de sus propias emociones en la interacción que está viviendo. Por tanto, el alto desempeño en estas habilidades emocionales hace que el/la líder emocionalmente inteligente se relacione con el colaborador/a teniendo en cuenta los aspectos emocionales de ambos/as. El/ la líder ofrece al/la colaborador/a una respuesta en forma de estrategia emocional que hace influir que éste/a se sienta motivado/a a realizar las acciones de trabajo solicitadas alimentado la confianza y el compromiso entre los/as dos/as. Esta Tesis apoya la idea que un/a líder debe de tener en cuenta las emociones de sus colaboradores/as si quiere ser un/a líder eficiente ya que éstos, cuando perciben que su líder es emocionalmente inteligente, mejoran sus competencias mentales que son necesarias en cualquier actividad laboral.

Los resultados de esta investigación se alinean con los hallazgos empíricos previos que demuestran que las emociones del/la líder influyen significativamente en los/as colaboradores/as, tanto en sus reacciones emocionales (Bono y Ilies, 2006; Sy, Côté, y Saavedra, 2005), como en el rendimiento laboral (Ashkanasy y Dasborough, 2003).

Para finalizar, los hallazgos de este estudio, tal y como se ha comentado anteriormente, sugieren que los/as líderes con alta inteligencia emocional, es decir, los/as líderes emocionalmente inteligentes, impactan en los/as colaboradores/as, e influyen en 
ellos/as. Este efecto interpersonal se alinea con la reciente e interesante propuesta de ampliación del modelo de habilidades de inteligencia emocional de Mayer y Salovey (1997) defendida por Côté, Hideg (2011), y Côté (2014). Los resultados de la presente Tesis avalan la idea de estos dos autores que consideran que la habilidad de influenciar en los demás debe ser toma en cuenta como una quinta dimensión del modelo inicial. Para Côté y Hideg (2011) la habilidad de influenciar en los demás, consiste en a) decidir qué despliegue de emoción tendrá el impacto deseado en los/as demás y b) usar eficazmente la emoción seleccionada en la interacción interpersonal. La presente investigación con los/as líderes y su efecto de influencia e impacto en los/as colaboradores/as sugiere y apoya esta propuesta, ya que se considera que en el contexto laboral esta influencia emocional del/la líder es clave para obtener resultados, y es transcendental para que los/as colaboradores/as consideren a una persona como líder. Tal y como han demostrado recientemente Côté, Lopes, Salovey y Miners (2010) las personas para ser consideradas líderes deben de influenciar en los/as demás, y para ello, las habilidades emocionales (especialmente percepción y comprensión de las emociones de los/as demás) son esenciales. Estas habilidades emocionales, siguiendo a los investigadores mencionados, tiene incluso más importancia que los rasgos de personalidad y las habilidades cognitivas para que sean reconocidos como líderes. Por tanto, los resultados obtenidos en esta Tesis apoyan empíricamente la importancia de la habilidad emocional de los/as líderes para influenciar en sus colaboradores/as. De igual modo, esta Tesis defiende la propuesta de ampliación del modelo inicial de inteligencia emocional de Mayer y Salovey (1997) con la nueva habilidad de influencia emocional que plantean Côté y Hideg que, combina el resto de habilidades emocionales dotándole de un sentido práctico de efecto social que amplía la idea original 
del modelo. Posteriormente, esta idea se completará en la sección de investigaciones futuras, en la que se trata el tema ético que debe de estar siempre por encima de esta capacidad de influenciar en los/as demás.

\subsubsection{Efecto social de las emociones}

En línea con el anterior apartado, esta Tesis apoya empíricamente la importancia de los efectos sociales de las emociones que defiende la Teoría EASI (Van Kleef, 2009). Tal y como defiende esta teoría, al igual que lo hacen Côté y Hideg (2011), tradicionalmente el estudio de las emociones se ha centrado en el análisis del efecto intrapersonal, pero no en el interpersonal. Es por esto, que esta investigación sugiere que realmente existe dicho efecto y tiene gran relevancia su estudio. Siguiendo la propuesta EASI, posiblemente lo que sucede con los/as colaboradores/as, es que adaptan sus respuestas emocionales a las expresiones emocionales de su líder, por lo que de nuevo se aprecia el factor de influencia del/la líder sobre sus colaboradores/as. Gracias al efecto social de las emociones se regula la vida social en general, y en particular, la relación del/la líder con sus colaboradores/as. Posiblemente, los/as colaboradores/as ajustan su forma de actuar a las expresiones emocionales que emite su líder, con lo que se produce el efecto social que en esta investigación queda palpable al comprobarse la relación entre el nivel de inteligencia emocional de los/as líderes y las competencias mentales de sus colaboradores/as. 


\subsubsection{Inteligencia Emocional: Comprensión y Facilitación emocional}

En este tercer apartado se enlazarán los resultados obtenidos con las explicaciones teóricas de cómo funciona la compresión y facilitación emocional y que pueden ser las respuestas teóricas a las siguientes cuestiones:

1. ¿Cómo se produce el efecto de influencia emocional del/la líder hacia sus colaboradores/as?

2. ¿Cómo se produce el efecto en las mejora de la competencias mentales en los/as colaboradores/as una vez reciben la influencia emocional del/la líder?

Inicialmente, para que se produzca, ese primer salto, del/la líder al colaborador/a, es necesario que se desarrolle la comprensión emocional del colaborador/a sobre el estado emocional de su líder. Gracias a la comprensión emocional, se adquiere conciencia tanto de las emociones propias, como las de los/as demás, siendo esta habilidad emocional la que permite a los colaboradores/as comprender cuál es la emoción interna que provoca el comportamiento del/la líder con el que está interactuando. Permite reconocer y tener conciencia de sus emociones, propias y ajenas. Esta comprensión emocional, y poniendo el foco de atención en su dimensión interpersonal, enlaza con el efecto interpersonal hallado en los resultados de esta Tesis, y se le denomina empatía. De igual modo, los/as colaboradores/as quedan contagiados/as por las emociones de su líder. Por tanto, la confirmación de las hipótesis de la presente Tesis apunta a que se produce un efecto de contagio emocional y de empatía de los/as colaboradores/as hacia su líder. En este sentido en futuras investigaciones se podría analizar si este efecto de contagio emocional y empatía se produce de forma bidireccional. 
Es importante tener en cuenta las razones teóricas de cómo se produce ese contagio emocional, así como las que explican como el/la colaborador/a es capaz de empatizar con su líder para entender que es lo piensa. El contagio emocional y la empatía, son dos procesos distintos que básicamente se diferencian en que, a través de la empatía, se es capaz de experimentar lo que otros/as sienten y atribuir esa experiencia a los/as demás y no así mismo (Gallese, Migone y Eagle, 2009). Por el contrario, en el contagio emocional se produce en el/la observador/a un contagio de las emociones expresadas por el emisor sin mediar análisis de lo que estará sintiendo y viviendo éste/a. Ambos procesos parecen estar en la explicación de cómo reciben los/as colaboradores/as la influencia de sus líderes produciendo un efecto interpersonal.

El contagio de las emociones de los/as líderes hacia los/as colaboradores/as ha sido profundamente estudiado en diversas investigaciones (Askanasy et al., 2009; Johnson, 2009; Kelly y Barsade, 2001; Van Kleef, et al., 2010). Esta Tesis apoya los resultados previos de Côté y Saavedra (2005) que demostraron que el estado de ánimo del/la líder se transmite a sus colaboradores/as influenciándoles en distintos aspectos como, en lo emocional, en el esfuerzo, y en la efectividad en la coordinación del grupo para la realización de una tarea. Se sugiere a la vista de los resultados obtenidos, que el salto de las emociones e influencia emocional del/la líder al colaborador/a podría darse por un lado, principalmente a través del contagio emocional, y por otro, desde un punto de vista de cómo se produce la empatía, bien podría ser, cómo teorizó Iacobini (2009), que se activasen las neuronas espejo de los/as colaboradores/as en esta interacción emocional que se ocasiona con sus líderes. Esta estimulación de las neuronas espejo a través de la información emocional percibida activaría a la amígdala, al sistema límbico, y de ahí, al 
cortex prefrontal, por lo que se evidencia la interacción entre emoción y cognición al compartir estructuras cerebrales.

Por otro lado, y con respecto a la empatía entendida como el componente cognitivo por el cual existe conciencia del otro, sólo se puede realizar hipótesis y abrir nuevas posibilidades de investigación en el ámbito de la psicología cognitiva y del papel de las neuronas espejo en este proceso. Por ejemplo, sería interesante observar y analizar en laboratorio controlado, en qué términos y condiciones se produce una activación de estas neuronas espejo en la interacción entre los/as líderes y colaboradores/as que muestran diferentes puntuaciones en inteligencia emocional

El efecto interpersonal y social que aparece en la presente investigación respalda, como ya se ha comentado anteriormente, al modelo EASI sugerido por Van Kleef (2009). Este modelo teórico propone que las reacciones y expresiones emocionales del emisor en entornos grupales influyen en los comportamientos y cogniciones de la persona que observa, en nuestro caso, líderes y colaboradores/as. Siguiendo esta aproximación teórica de Van Kleef, se puede sugerir, que los/as colaboradores/as necesitan procesar todo la información posible que acontece a su alrededor para poder desempeñar su trabajo. Siendo la información de su líder inmediato/a una de las más importantes ya que, es él/ella quien marca los objetivos a alcanzar y puede evaluar su desempeño, es lógico pensar, que los/as colaboradores/as presten con especial interés las manifestaciones y expresiones emocionales de sus líderes inmediatos. En este sentido, la comprensión de las emociones del/la líder por parte del colaborador/a es fundamental. El/la colaborador/a, no sólo se contagia de las emociones del/la líder, sino que realizará procesos de inferencia de lo está pensando y de las expectativas e intenciones que su líder tiene sobré él/ella. Esta serie de 
expectativas e intenciones se acompañan con las expresiones emocionales que el/la líder ofrece a sus colaboradores/as. Estas reacciones afectivas y los procesos de inferencia que realiza el/la colaborador/a, están modulados por aspectos individuales diferenciales agrupados en a) cómo realiza el procesamiento de la información percibida determinado por la motivación y capacidad, y b) factores socioculturales como la cultura, personalidad, $\mathrm{y}$ estatus.

Se podría asegurar entonces, que los/as colaboradores/as realmente prestan mucha atención a su líder por lo que éste representa y supone en el contexto laboral. Esa atención provoca una mayor percepción de las emociones emitidas por el/la líder, por lo que a través del contagio emocional (Barsade, 2002), los/as colaboradores/as imitan y se contagian de las emociones del/la líder. Para el/la colaborador/a es transcendental estar atento/a las emociones del/la líder, pues le permite mejorar su comprensión de la situación que se está viviendo, y adaptar sus actitudes y comportamientos para mejorar la interacción y el vínculo entre ambos. (Van Kleef et al., 2012). Es decir, se pone en juego la habilidades de la empatía de los colaboradores/as en sus procesos de inferencia para analizar las razones del por qué el/la líder se expresa con ellos/as de una manera u otra.

Sobre la segunda cuestión de cómo funciona la compresión y facilitación emocional, y de cómo es posible que una vez dado el salto de influencia del/la líder al colaborador/a, se produzca en éste cambios en sus competencias mentales (componente cognitivo), nos lleva a recuperar el valor de lo emocional. Tal y como se ha recogido, en la literatura científica tradicionalmente el componente emocional, o en sí mismo lo emocional, se habría desprestigiado en comparación al componente cognitivo, es decir, a lo racional. Con ello, la eterna dualidad manifestada históricamente destacando lo negativo de 
lo emocional para defender que lo correcto, lo positivo, es lo racional, quedaría en entredicho. Los resultados obtenidos en esta investigación, tanto a nivel interpersonal como a nivel intrapersonal, defienden que en ambos casos los aspectos emocionales (competencias blandas) se relacionan con mayor resultado en las competencias mentales (competencias duras). Y esto, sin ninguna duda, da validez empírica a las teorías que defienden la habilidad de facilitación emocional como puente de interacción entre las emociones y lo cognitivo (Mayer y Salovey, 1997).

A nivel interpersonal, se podría sugerir que una vez los/as colaboradores/as se han contagiado y han empatizado con las emociones de su líder, la información emocional pasa a ser procesada por las estructuras cerebrales que van desde el sistema límbico hasta el neocortex. La información emocional que recibe de su líder le va a permitir realizar un mejor resultado en sus competencias cognitivas. Los resultados de esta Tesis se enlazan y complementan a otras dos investigaciones recientes que, también utilizando un diseño de investigación multinivel, encontraron que las emociones del/la líder influenciaban a sus colaboradores/as, entre otros aspectos, en su desempeño cognitivo. (Volmer, 2012, Visser, Knippenberg, Van Kleef y Wisse, 2013). De igual manera, los resultados de esta investigación a nivel intrapersonal apuntan a una relación positiva entre las competencias emocionales de los/as colaboradores/as y el nivel de sus competencias mentales. Todo parece indicar que, tanto el efecto interpersonal como el intrapersonal, y la relación que se da entre emoción y cognición van en la línea de respaldar los resultados de las investigaciones neurofisiológicas sobre la interacción cerebral integral entre ambos constructos (Le Doux, 1999, 2000). Además, en esta misma línea, el modelo de habilidades de Mayer y Salovey (1997) incluye la habilidad de facilitación emocional. Y gracias, a la 
facilitación emocional los/as colaboradores/as "impregnados/as de información emocional" pueden ser más efectivos/as en sus competencias mentales ya que esta información emocional complementa, e incluso impulsa, las funciones ejecutivas que configuran gran parte del procesamiento cognitivo que realizamos. Al igual que investigaciones anteriores que han incorporado y estudiando la relación que hay entre emoción y toma de decisiones (Damasio, 1994; Greene, Sommerville, Nystrom, Darley y Cohen, 2001; Lerner y Keltner, 2000), emoción y memoria (Erk et al, 2003), emoción y percepción/atención (Brosch, Sander, Pourtois y Scherer, 2008; Fenske y Raymond, 2006; Vuilleumier, 2005; Vuilleumier y Brosch, 2009), emoción y flexibilidad/creatividad (Sacharin, 2009; Oros, Manucci, De Minzi, 2011) esta Tesis se sitúa en la misma dirección aportando una relación significativa entre emoción y competencia mental, con lo que se refuerza la integración en un mismo continuo de la emoción-cognición.

\subsubsection{Diferencias individuales y Vigor de los colaboradores/as}

Es importante tener en cuenta las diferencias individuales de los/as colaboradores/as en el proceso de liderazgo tal y cómo argumenta la Teoría Leader Member Exchange (Gerstner y Day, 1997; Graen y Uhl-Bien, 1995). Tradicionalmente, y esta Tesis se podría encuadrar parcialmente dentro de este grupo, las investigaciones sobre la relación del/la líder con sus colaboradores/as se han centrado fundamentalmente en estudiar el impacto del/la líder en las actitudes y comportamientos de éstos/as últimos/as (Wilson, Sin y Conlon, 2010). Por tanto, ha sido poco estudiado cual es el rol del/la colaborador/a en esta relación. En la presente investigación, y a través de los resultados obtenidos, se confirma que el vigor de los/as colaboradores/as modula la relación existente entre la inteligencia 
emocional del/la líder y las competencias mentales de sus colaboradores/as. En este punto se abre una interesante interrogante ¿Por qué el vigor modula esta relación?

Para contestar a esta cuestión hay que integrar los postulados teóricos existentes sobre el vigor. Por un lado existe la conceptualización de Schaufeli et al., (2002) que defiende que el vigor se manifiesta como motivación para invertir esfuerzo en el trabajo y la capacidad de soportar las dificultades y persistir a pesar de los obstáculos. Y por otro lado, la postura de Shirom $(2004,2011)$ que define al vigor como un estado afectivo caracterizado por sentimientos de gran resistencia física, energía emocional y vitalidad cognitiva. Esta energía vital motivacional del colaborador/a influye en cómo se relaciona con su líder. El/la líder tiene un papel transcendental en la relación de trabajo que se establece con el/la colaborador/a, es una pieza clave para la evaluación del rendimiento y la asignación de recursos para su desarrollo (Bhal y Ansari, 2007). El/la líder les otorga a los/as colaboradores/as más cercanos/as mayor autonomía, apoyo y consideración que les llevará a percibir que se les trata de forma más justa y a tener una mayor confianza con él/ella. De igual modo los/as colaboradores/as que mantienen relaciones de buena calidad con sus líderes alcanzan mayores niveles de rendimiento, de satisfacción y de compromiso (Liden, Sparrow y Wayne, 1997) y tienen menor intención de dejar la organización (Ansari, Kee y Aafaqi, 2000). Lo que parece suceder (ver Figura 7.2) es que el/la líder, en su día a día con sus colaboradores/as, emite tanto comportamientos de lo qué hay que hacer, qué es lo que hay que conseguir, y cómo hacerlo (comportamientos de tarea), y de igual forma emite comportamientos de confianza, de apoyo (comportamientos de relación). Ambos comportamientos son emitidos con expresiones emocionales que pueden ser entendidas por 
sus colaboradores/as como extensiones de los pensamientos, intenciones, y expectativas que el/la líder tiene sobre ellos/as.

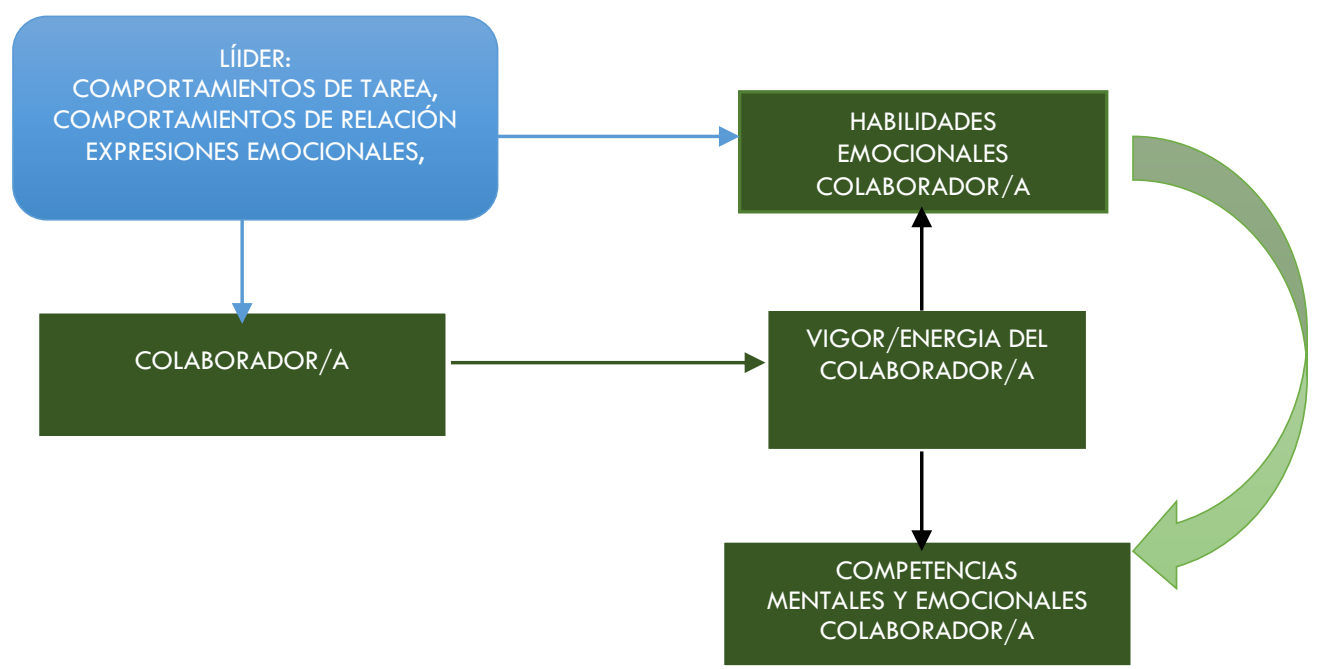

Figura 7.2: Función del vigor de los/as colaboradores/as en su relación con el/la líder

Esta emisión de comportamientos y expresiones emocionales del/la líder hace que el/la colaborador/a ponga en funcionamiento su energía vital, su vigor, para prestar atención con mayor interés a todos los estímulos que provienen de una fuente de estimulación tan importante como es el/la líder. De ahí que el/la colaborador/a ponga a en marcha, con un alto nivel de motivación, la habilidad de percepción emocional para captar la información emocional que desprende su líder a través del rostro, gestos, y el resto de canales emocionales. Con la información recibida, se ponen en marcha el resto de habilidades emocionales que a través de la facilitación emocional, también le ayudaran a la ejecución de tareas mentales y cognitivas.

Por tanto, la acción moduladora del vigor de los/as colaboradores/as entre la inteligencia emocional de su líder y las propias competencias mentales de los/as 
colaboradores/as se inicia, en primer lugar, como una energía motivacional de impulso para dar respuesta a las exigencias de su líder. De ahí, que se preste especial atención y entre en juego el resto de habilidades emocionales ante las exigencias representadas en las expresiones emocionales del/la líder. Por tanto, cuanto más vigoroso/a se encuentre el/la colaborador/a mayor motivación, resistencia física y sobre todo mayor contagio emocional. Es por esto que parece lógico pensar que cuanto mayor sea el vigor del/la colaborador/a mayores posibilidades de contagio se pueden dar de las expresiones emocionales de su líder. De igual modo, asociado a un estado vigoroso alto de los/as colaboradores/as, puede aparecer un incremento de su resistencia física y del aporte cognitivo que, junto al incremento del contagio emocional, provocan una ampliación de los efectos del nivel de inteligencia emocional de su líder Esta hipótesis sobre la importancia de la energía emocional de los/as colaboradores/as para contagiarse emocionalmente y posteriormente gestionar la información emocional que reciben de sus líderes, amplía la idea original de Barsade (2002) sobre el contagio emocional. La energía emocional se refiere a la intensidad con que las emociones se expresan de una persona a otra (Barsade, 2002). Para Barsade, el contagio emocional está condicionado por el nivel de energía a la hora de expresar las emociones que tienen los sujetos emisores. Si se expresan con una alta energía se va a producir mayor nivel de contagio que si se produce al contrario. En la presente investigación, y teniendo en cuenta los resultados obtenidos, se ve claramente como la parte emocional del vigor de los/as colaboradores/as incide también en el nivel de contagio y empatía emocional. En esta misma línea, Bakker et al., (2011) confirmaron que los/as colaboradores/as con altos niveles de engagement (que incluye índices altos de vigor) son 
capaces de estar más centrados en poner en marcha su habilidades de aprendizaje activo y desarrollar sus habilidades cognitivas como creatividad e innovación.

Finalmente, se confirmó que el/la mismo/a líder a través del dominio de sus habilidades emocionales (inteligencia emocional) influye en los niveles de energía de sus colaboradores/as. Para Bakker et al. (2011) en el funcionamiento del engagement se producen lo que denominan "ciclos del engagement". Como antecedentes del engagement están los recursos laborales (incluyendo al/la líder). Estos recursos laborales dan paso al engagement, y éste incita a la activación de recursos personales que provocan colaboradores/as engaged que tienen mayores posibilidades de ser eficaces. Por tanto, el/la mismo/a líder puede influenciar en incrementar el vigor de sus colaboradores/as ampliando su capacidad de respuesta laboral y personal. En una línea similar, Shirom (2011) confirmó que cuando la interacción emocional laboral es debida a una relación de calidad, y ésta es positiva, se produce en forma de espiral un aumento de la energía personal. Esto produce un incremento del vigor, ya que el/a trabajador/a siente el apoyo social y emocional en su actividad laboral. El vigor que siente, le hace sentirse con más confianza, y de ahí que se refuerza sus comportamientos de búsqueda de relaciones con los demás. Esta espiral positiva en las interacciones interpersonales modifica y amplia los recursos personales como la empatía, la escucha y atención, así como del aprendizaje mutuo, reforzando su eficacia y autoestima.

Sin duda, esta postura integradora del funcionamiento del vigor que recoge, por un lado, las ideas teóricas sobre el vigor de Shirom (2011), y por otro lado, el aporte de Schaufeli et al. (2003) y Bakker et al. (2011), sería interesante que fuera puesta a prueba en próximas investigaciones. 


\subsection{Implicaciones prácticas}

En este apartado, se conjugan los resultados y el aprendizaje académico obtenido en esta Tesis, con mi experiencia de cerca de 20 años en gestión y desarrollo de personas a nivel empresarial. Se distinguen tres grandes grupos de recomendaciones 1. Líder Emocionalmente Inteligente 2. Colaborador/a, 3. Valores y Liderazgo.

\subsubsection{Líder emocionalmente inteligente}

El/la líder, es la bisagra entre las políticas organizacionales y el conjunto del capital humano que hace posible que una organización funcione. Una organización moderna, dónde el resultado del trabajo que se produce y comercializa está basado en una red de personas, depende en gran parte de los/as líderes que alientan, motivan, y saben guiar a los/as colaboradores/as que la integran. El valor de contar con líderes que traspasen las funciones de dirección, planificación y control y se adentren en la zona del liderazgo para influenciar en los/as colaboradores/as, es un diferenciador en el mercado. Los/as líderes emocionalmente inteligentes son aquellos/as que poseyendo una alta inteligencia emocional la ponen funcionamiento leyendo las necesidades de cada colaborador/a para influenciarles con el objetivo de alcanzar las metas organizacionales. Los/as líderes emocionalmente inteligentes logran influir en sus colaboradores/as consiguiendo incrementar su desempeño para cualquier puesto. Por tanto se convierten en un recurso organizacional que puede producir mejoras organizacionales en diferentes niveles. Teniendo en cuenta los resultados obtenidos en esta investigación es necesario desarrollar diversos programas internos organizacionales para garantizar que en las organizaciones los equipos de trabajo cuenten con líderes emocionalmente inteligentes que desarrollen un tipo de liderazgo emocional integral. Cuando existe una buena relación entre el/la líder y el/la colaborador/a mejora el 
compromiso de éste/a con la organización, así como su percepción del clima de comunicación y el bienestar existentes en la misma, lo que a su vez vuelve a alimentar su compromiso (De la Rosa-Navarro y Carmona, 2010).

No obstante, y como más tarde se ampliará, todo este conjunto de habilidades emocionales y liderazgo emocional, quedan supeditados a que el/la líder, tal y cómo describe el liderazgo autentico y el ético, lo aplique bajo un estricta conducta ética y dimensión moral inquebrantable que debe ser dirigida por valores de coherencia e integridad. Se recomienda implementar las siguientes acciones:

\section{a) Perfil Competencial del Líder Emocionalmente Inteligente}

En primer lugar, es necesario que en el perfil de competencias del puesto de los/as líderes recojan aquellas competencias derivadas de las habilidades emocionales de percepción, facilitación, comprensión y manejo emocional. Existe una regla básica en la gestión del talento humano que es una contradicción con la filosofía de desarrollo de personas, y es que antes de aplicar programas de desarrollo de competencias, compromiso, formación, o equivalentes, es necesario construir la descripción de los puestos de trabajo. Es decir, primero el puesto y luego la persona. Por ello, y a la luz de los resultados obtenidos, es necesario integrar en los perfiles competenciales las habilidades emocionales vinculadas al constructo de inteligencia emocional, e incluso sería necesario integrar la capacidad de influenciar en los/as demás.

\section{b) Selección por competencias del Líder Emocionalmente Inteligente}

Una vez incorporado las habilidades emocionales en el perfil competencial, de nada sirven si no se utilizan herramientas de selección que puedan rastrearla en los candidatos/as a puestos de mandos intermedio, y/o de dirección. Por ello, recomendamos que se utilicen 
instrumentos técnicos validados y/o entrevistas de incidentes críticos, o dinámicas de grupo diseñados expresamente para medir el nivel de inteligencia emocional de los/as candidatos/as. De esta manera, las organizaciones se aseguran que la selección de nuevos/as líderes organizacionales tenga en cuenta, además de factores relacionados con el conocimiento sobre lo que hay que hacer y la experiencia, el valor de las habilidades emocionales. Con esto se cumpliría otra regla de oro en la gestión del talento humano, "se selecciona actitudes y se forma en conocimientos"

\section{c) Desarrollo de Habilidades Emocionales-Liderazgo Emocional}

En este grupo se describen las recomendaciones prácticas de desarrollo de la inteligencia emocional del/la líder que se pueden agrupar en:

\section{c.1) Formación}

Es necesario que para desarrollar estrategias de influencia apoyándose en un correcto "performance” de las habilidades emocionales, se generen programas de desarrollo de la inteligencia emocional. De igual modo, se recomienda tener en cuenta las diversas tácticas de influencia existentes para realizar una combinación en los diseños de las capacitaciones que combinen, las racionales-cognitivas (duras), con las emocionales (blandas). Este equilibrio entre lo cognitivo y lo emocional es lo más adecuado para poder alcanzar resultados en la gestión como líderes. Además, se vuelve transcendental que los programas de formación de sus directivos/as integren aspectos de desarrollo de habilidades emocionales, así como el conocimiento del funcionamiento integrado neurofisiológico del ser humano (neuromanagement) que se complementaría con el estudio de las neuronas espejo. Se recuerda que, para llegar tener líderes que apliquen un liderazgo emocional efectivo es necesario conocer cómo funciona la interacción emoción-cognición, el contagio 
de las emociones, y qué impacto existe en los/as colaboradores/as cuando hay un desborde por un mal manejo emocional como por ejemplo, no se cumple plazos de entrega o indicadores de calidad.

\section{c.2) Coaching Ejecutivo}

La siguiente recomendación para el desarrollo de la inteligencia emocional de los/as líderes es aplicar programas de coaching ejecutivo a aquellos/as líderes que impactan en la organización debido a la importancia estratégica en su toma de decisiones y en dirección de equipos de trabajo en el core del negocio. El coaching ejecutivo enfocado a la mejora de habilidades emocionales, es una herramienta eficaz de mejora competencial que implica un compromiso formal entre el/la líder, la empresa y el/la coach profesional. En línea con los resultados obtenidos, si el/la líder muestra un alto conocimiento de las emociones de los/as demás, sabe darle un significado a la información emocional interna, empatiza con su equipo, tiene en cuenta para la toma de decisiones su instinto emocional, y no se deja llevar ante situaciones complicadas por lo que suceda en su interacción con sus colaboradores/as, y por tanto, logrará influenciarles positivamente.

\section{c.3) Evaluación de Desempeño}

Se recomienda que en las organizaciones actuales se tenga en cuenta para evaluar el desempeño de los/as líderes no sólo, una pura dirección por objetivos dónde lo que vale es el resultado final, sino una integración con las habilidades emocionales mostradas, así como la evaluación de cómo se ha conseguido los resultados a través de la aplicación de un

liderazgo emocional supeditado a los valores organizacionales. Este es el punto de valores y ética organizacional que aparece en el liderazgo autentico. 


\section{d) Clima Laboral}

El/la líder que utiliza la inteligencia emocional en su día a día con sus colaboradores/as, puede inspirar, confianza, apoyo social, esperanza y diversas emociones positivas, que directamente generan una mejora en el clima laboral, proporcionando resultados positivos y una mejor salud laboral de los/as empleados/as. De ahí que se recomienda que desde la Dirección de las organizaciones y/o máxima autoridad en la empresa, se incentive a que los/as líderes departamentales apliquen comportamientos de escucha activa hacia sus colaboradores/as. Hay que hacerles ver que, en primer lugar, no es negativo que inviertan tiempo en escuchar y compartir las emociones de sus equipos, y en segundo lugar, que no es correcto que a pesar del estrés por conseguir resultados, se tengan desbordes de ira, de rabia descontrolada, y descalificaciones a la persona y no a la acción. Todo ello hará que se genere un contagio emocional que inspire al colaborador/a y se mejore el clima laboral. Se recomienda que desde el departamento de Talento Humano se realicen mediciones de clima laboral semestrales que incorpore la toma de opinión de los/as colaboradores/as sobre las habilidades emocionales de sus líderes. Se recomienda que los resultados de estas evaluaciones se incorporen a una variable en la política retributiva organizacional. Es de esperar que el/la líder emocionalmente inteligente genere relaciones de confianza y compromiso y se combata así uno de los males que acosan la rotación de personal que consiste en que los/as trabajadores/as describen que una de las causas de desvincularse del trabajo es por tener un/a mal/a líder.

\subsubsection{Colaboradores/as}

En esta apartado se agrupan las recomendaciones derivadas de los resultados que a nivel intrapersonal han sugerido una relación positiva entre las competencias emocionales y 
las competencias mentales de los/as colaboradores/as; así como el rol modulador del vigor en la relación entre la inteligencia emocional del/la líder y las competencias mentales de sus colaboradores/as.

\subsubsection{Competencias emocionales}

Se recomienda, al igual que en los/as líderes, que en las diferentes políticas de talento humano existentes, perfil competencial, selección, y formación se tengan en cuenta las competencias emocionales, ya que impulsan el desempeño eficiente de las competencias mentales. Todo colaborador/a de hoy en día necesita de una adecuada agilidad y correcta puesta en marcha de las funciones ejecutivas para realizar las actividades que se le demandan. No obstante, es importante realizar algunas observaciones. Con respecto al perfil competencial, se debe de identificar que habilidades emocionales son las importantes para un desempeño eficiente del puesto. Pueden existir puestos que no sea necesario recoger por igual todas las habilidades emocionales, o que tengan diferente exigencia de ponderación y nivelación. De igual modo sucederá en la política de selección. Sin embargo, un buen programa de formación en el desarrollo de competencias emocionales reforzando la habilidad emocional de percepción, comprensión y manejo emocional puede incidir en una mejora de las relaciones de equipos de trabajo y por ende, del clima laboral. Como se puede ver, la habilidad de facilitación emocional, y de cómo influir en los/as demás quedan enfocadas a los puestos de toma de decisiones y dirección de personas por el costebeneficio que supone un plan de formación con acciones no directamente asociadas al perfil competencial del puesto. Sí se recomienda que, antes de ejecutar proceso típicos de promoción, dónde al que es buen conductor de maquinaría se le nombre coordinador de 
equipo, por ejemplo, se tenga en cuenta las habilidades emocionales que exige el puesto a promocionar. Ya que suele pasar que el buen empleado/a no es el/la mejor líder y se promociona por los méritos alcanzados en su actual puesto, y no por que cumpla las exigencias del puesto superior vacante. Sin embargo, se recomienda implantar, poco a poco, y en sintonía con la madurez de la organización, unidades de trabajo con estructuras menos jerarquizadas, con personas responsables y líderes en su toma de decisiones para la realización de su trabajo. Con ello se ampliaría a un trabajo en red colaborativo de influencia entre personas más global, basado en un empoderamiento de los/as miembros/as de las empresas.

\subsubsection{Vigor de los/as colaboradores/as}

Cuando los/a colaboradores/as experimentan relaciones de alta calidad con sus colegas en el trabajo, registran un mayor estado de vigorosidad que incide en su motivación por querer ofrecer un alto rendimiento en el trabajo. Por tanto, estos colaboradores/as vigorosos probablemente se sientan más motivados/as y con mayor energía para estar atentos/as a las demandas, al apoyo, y a las expresiones emocionales de su líder. Esto puede

provocar que su nivel de atención sensorial sea muy alto, y con ello aumente el impacto de la inteligencia emocional de su líder sobre él/ella. Un/a colaborador/a con vigor, con energía para afrontar las demandas laborales es un/a colaborador/a que tiene mayores posibilidades de ser un trabajador engaged, mejorando la relación de intercambio con su líder. Lo que suele ocurrir ocasionalmente es que el vigor es un estado de los/as colaboradores/as que puede variar según los días y éste a su vez influye en el nivel de actividad laboral. Tal y cómo describió Sonnentag (2003) el engagement (en el que se 
incluye el vigor) era significativamente mayor en los días en los que los/as colaboradores/as se sentían más recuperados por la mañana, en comparación con los días en los que no se sentían de esa forma. Es por ello, que se recomienda a través de pruebas de evaluación físicas y psicosociales que, podrían realizarse desde el área de seguridad ocupacional (salud laboral), medir la fatiga física y mental de los/as trabajadores/as. Una vez evaluado el nivel de fatiga de los/as colaboradores/, si éste es alto, se sugiere aplicar prácticas de descanso, e incorporación de programas dentro de la empresa que facilite las emociones positivas, la comunicación positiva, jornadas de trabajo al aire libre, como mecanismos de recuperación físicos y psicosociales.

Un/a colaborador/a con vigor, con energía para afrontar las demandas laborales, es un colaborador/a que tiene mayores posibilidades de ser un/a trabajador/a engaged mejorando así la relación de intercambio con su líder. Una de las acciones que se podría desarrollar para conseguir trabajadores/as engaged sería incrementar sus recursos laborales y personales. Con respecto a los recursos laborales se ha revisado como las oportunidades de desarrollo profesional, las relaciones de apoyo entre compañeros de trabajo, la retroalimentación sobre el desempeño y el desarrollo de competencias de los empleados, facilitan el engagement (Bakker, et al., 2011). De igual manera un factor clave para el desarrollo de trabajadores engaged es que tengan la percepción de control sobre su puesto de trabajo, lo que conlleva a que influyan en sus puesto de trabajo ajustando las demandas a la aparición de más recursos, así como la generación de un entorno de trabajo desafiante y retador (Bakker et al., 2011). 


\subsubsection{Valores y Liderazgo Emocional}

Se ha dejado para el último apartado, lo que a mi consideración, es el eje que debe de guiar toda aplicación de cualquier tipo de liderazgo y/o tácticas de cómo influenciar en los/as demás. Hasta el momento se ha explicado que, si un trabajador/a de una empresa quiere ser reconocido como líder organizacional, debe de ser alguien con la habilidad de influenciar en los/as demás. El liderazgo emocional, recogiendo las ideas iniciales de Goleman et al. (2002), y de Caruso y Salovey (2005) propone influir en los/as demás a través del dominio de las habilidades emocionales, permitiéndole una eficiente toma de decisiones. Este tipo de líder es capaz de utilizar diversas estrategias de influencia, incluyendo sobre todo las emocionales. Del mismo modo, cómo tienen alta inteligencia emocional, pueden ejercer tal nivel de influencia en sus colaboradores/as que se relaciona con sus competencias mentales.

Pero, ¿qué sucedería si el líder emocional utilizase estas habilidades para fines poco éticos, partidistas y/o para beneficio personal? Esta cuestión es del todo relevante. Desde mi punto de vista, no puede, ni se debe dejar ocupar el puesto de líder organizacional a personas que no sigan un modelo de actuación ético intachable. Los/as verdaderos/as líderes deben guiar sus comportamientos con los valores de integridad, honestidad, y amor por el desarrollo de los/as demás. Se pueden alcanzar resultados empresariales con éstos valores. Es importante recordar que la capacidad de influenciar en los/as demás es una habilidad que dependiendo del uso que se haga de la misma puede tener consecuencias positivas o negativas, tanto para las organizaciones, cómo para los/as colaboradores/as que reciben esta influencia. Toda habilidad para movilizar a las personas debe tener un faro ético y moral que la guíe. Esta dimensión moral la recoge, por ejemplo, el modelo de 
liderazgo autentico (Avolio et al., 2004) y de una forma extendida como un modelo de liderazgo, y no sólo como un dimensión., el liderazgo ético. Esta aproximación teórica surge en la actualidad como un tipo de liderazgo por el cual los lideres organizacionales se convierten en modelos de actuación a seguir a través de las conductas éticas que esgrimen. Así mismo, y desde un punto de vista de eficiencia organizacional, ser un líder ético no está reñido con los resultados empresariales, como pudiese pensarse, ya que estudios actuales confirman la relación del liderazgo ético con el desempeño de sus colaboradores/as y la satisfacción laboral (Walumbwa et al., 2011; Bouckenooghe et al., 2014; y Pucic, 2015) así como como su mediación en el cansancio emocional y el engagement de los colaboradores/as (Chugtai, Byrne, Flodd, 2014).

Para ajustar un correcto y eficiente estilo de liderazgo que integre el dominio de habilidades emocionales se realizan las siguientes recomendaciones. En primer lugar, independientemente del tipo de organización de la cual se trate, se ha de tener una declaración de valores determinados por los/as integrantes de la misma, así como las conductas específicas asociadas a cada valor. En éstos valores organizacionales se deberían de incorporar valores con corte ético sobre resultados y formas de trabajar en eficacia y eficiencia. Si no hubiera conductas y comportamientos específicos y debidamente explicitados y socializados, simplemente se quedaría en un listado de términos que aparecen en las paredes de los despachos y en la web organizacional sin más. Al mismo tiempo, este conjunto de valores y conductas deben ser parte al mismo tiempo, del perfil competencial de los diferentes puestos organizacionales. Y en especial, de los/as líderes organizacionales. De igual modo, se debería tener un código de conducta que recoja todos los principios y valores incluyendo las formas éticas de mantener las diversas 
interrelaciones con los actores o stakeholders (proveedores/as, clientes/as, trabajadores/as, comunidad, etc.). Para finalizar, se recomienda, que las conductas asociadas a cada valor organizacional se integren en la medición de evaluación de desempeño para sellar la aplicación real de los comportamientos que hacen operativos cada valor organizacional. En definitiva, los modelos empresariales de gestión bajo los estándares de empresas con responsabilidad social, encajaría perfectamente con la de incorporar el control ético y moral a las habilidades del/la líder emocionalmente inteligente que práctica el liderazgo emocional en su interrelación diaria con sus colaboradores/as.

\subsection{Limitaciones}

La presente Tesis no está exenta de limitaciones. Metodológicamente hablando, existen principalmente cinco limitaciones. En primer lugar se trata de una Tesis transversal con un solo momento de recogida de información. Eso provoca que nuestras relaciones no puedan ser nunca causales, y que la dirección de las hipótesis tienen la dirección que se le ha dado gracias a la fundamentación teórica que las avala.

En segundo lugar, las variables correspondientes al nivel individual, es decir, la de los/as colaboradores/as (vigor, competencias emocionales y competencias mentales) han sido medidas con cuestionario de autoinforme, lo que podría conllevar a un sesgo por varianza común. El riesgo de sufrir este sesgo se ve reducido drásticamente por dos cuestiones. La primera de ellas es que la herramienta utilizada en el caso de los/as líderes es el MSCEIT, que se trata de una prueba de rendimiento y no de autoinforme. Y la segunda, es una investigación multinivel, y no sólo los/as colaboradores/as son preguntados/as por sus percepciones, sino también sus líderes. 
En tercer lugar, se trata de una muestra relativamente pequeña: 47 líderes y 141 colaboradores/as a su cargo. Aunque las empresas que se contactaron están absolutamente representadas, ya que contestaron el $85 \%$ de los/as líderes contactados/as y mejor aún, el $100 \%$ de los/as colaboradores/as. Pero sigue siendo una muestra relativamente pequeña, que aún se hace más pequeña cuando se utilizan los valores extremos de inteligencia emocional del/la líder para mostrar gráficamente la moderación.

En cuarto lugar, y en parte debido a la anterior limitación, las correlaciones de las variables no se comportan como había sido esperado, sólo existe una correlación significativa entre las competencias mentales y emocionales, pero no lo son con las otras variables de estudio. Sería interesante repetir estas correlaciones con un solo nivel de medida y con una mayor muestra, y estoy convencido de que se hallarían valores significativos.

En quinto lugar, para este estudio sólo se escogieron tres colaboradores/as por líder, y a posteriori se llegó a la conclusión de que, aunque el objetivo de esto fue que la muestra no estuviera sesgada, habría sido una buena idea no limitar el número de colaboradores a contestar el cuestionario, y que pudieran haberlo hecho todos los/as colaboradores/as.

En cuanto a las limitaciones teóricas, hay que destacar que las dudas que se plantean acerca del constructo del vigor, su conceptualización y su medición. Para esta Tesis se ha seguido el concepto de vigor entendido por altos niveles de energía y resistencia mental mientras se trabaja, por el deseo de esforzarse en la tarea que se está realizando incluso cuando se presentan dificultades (Schaufeli et al., 2002). Bajo esta conceptualización, el vigor forma parte del engagement y no tiene identidad propia, por lo cual, se mide como 
una dimensión del constructo engagement a través del UWES (Schaufeli y Bakker, 2003). Cabe destacar la conceptualización alternativa como un constructo multidimensional del vigor que defiende Shirom $(2004,2011)$. Bajo esta conceptualización el vigor tiene una validez teórica que permite explicar con mayor fuerza no sólo los resultados obtenidos, sino el mismo constructo del engagement. Para Schaufeli y sus colegas, el vigor se asocia con alta energía, motivación y resistencia pero no existe el componente emocional, como sí defiende Shirom. El problema estriba en que no existe actualmente una uniformidad entre las dos concepciones, y la herramienta de medición del vigor realmente válida y fiable en el panorama científico actual es el UWES, y sus variantes como el RED utilizado en esta Tesis. Este proceso riguroso en la generación, tanto del UWES, como el RED, no se aprecia en la construcción de la herramienta que Shirom propone para medir el vigor, es decir, el Shirom Melamed Vigor Measure (SMVM) (Shirom, 2004). La prueba SMVM fue desarrollada con una muestra de 87 empleados/as de Israel y que debido a su pequeño tamaño puede afectar a la validez y fiabilidad del instrumento. De igual forma no existen publicaciones sobre el análisis metodológico y estadístico detallado sobre su proceso de construcción y validación, ni en el mismo contexto de Israel, ni en otros países. Las adaptaciones de la prueba a otros contextos se han realizado simplemente con la traducción del hebreo, al inglés o al alemán del instrumento original.

\subsection{Líneas de Investigación futuras}

A continuación, se describen las diversas líneas de investigación derivadas, tanto de los resultados obtenidos que convergen con trabajo teóricos, como de los nuevos retos que han surgido en la elaboración de esta Tesis. 


\subsubsection{Influencia e Inteligencia Emocional}

En la revisión teórica se describió que existe una propuesta de Côté y Hideg (2011) de ampliar el modelo de inteligencia emocional basado en las habilidades de Salovey y Mayer (1997). Esta reciente ampliación teórica no ha encontrado por ahora una continuidad en trabajos empíricos que la avalen. Sin embargo, los resultados obtenidos en la presente investigación apoyan empíricamente la posibilidad de ver la influencia emocional no únicamente como un resultado de las habilidades emocionales, sino una dimensión independiente que se sumaría a las de percepción, comprensión, facilitación, y manejo emocional. Con ello se abre una nueva posibilidad de añadir una nueva habilidad emocional que posiblemente dé explicación a ciertos efectos sociales de la emociones a nivel interpersonal (Van Kleef, 2008, 2009) que no tenían explicación con el modelo actual. Este

efecto interpersonal de la inteligencia emocional, dónde se encaja la presente investigación, es necesario que se siga explorando y complementando con nuevos trabajos que expliquen cómo se desarrolla y qué efectos produce.

\subsubsection{Tácticas de influencia y liderazgo emocional}

El trabajo de Yukl (2010) sobre las tácticas de influencia más efectivas que utilizan los/as líderes, se destaca la importancia de combinar estrategias emocionales y racionales. En este sentido, habría que ver qué tipo habilidades emocionales son necesarias para llevar a cabo las estrategias emocionales que describe dicho autor ya que no se explican en sus publicaciones. Esta nueva línea de investigación abre la puerta a conocer cómo los/as líderes emocionalmente inteligentes utilizan sus habilidades emocionales para influenciar a sus colaboradores/as. Es posible que en la base de las tácticas emocionales pudieran estar las habilidades emocionales que construyen la base del modelo de inteligencia emocional 
de Mayer y Salovey (1997). Por ello, una línea de investigación apasionante es conocer que líderes son los/as que más influyen en los colaboradores/as a través de las diversas estrategias emocionales, y de ahí, analizar qué nivel de inteligencia emocional general disponen. De igual modo, siguiendo el modelo de Mayer y Salovey (1997), habría que identificar el peso de cada una de las habilidades emocionales que utiliza el líder (percepción, facilitación, comprensión, y manejo emocional) en el proceso de influencia emocional. 


\subsubsection{Emociones positivas y negativas en el contagio y facilitación emocional}

Actualmente, y dentro del marco de la Psicología Positiva se ha recuperado el papel de las emociones positivas y su impacto favorable en las personas (Fredrickson, 2003a, 2003b, 2005, 2008). Este impulso arrollador de la Psicología Positiva ha llegado también a los nuevos modelos de liderazgo, como el del liderazgo auténtico. Este liderazgo es visto como un proceso social de influencia en el que el/la líder una vez realiza una identificación personal y social describe esperanza, confianza, y emociones positivas que provocan cambios actitudinales y comportamentales en los/as colaboradores/as. Sería interesante estudiar sí existe un efecto positivo de las emociones negativas de los/as líderes sobre sus colaboradores/as. ¿Es posible como líder estimular a un colaborador/a expresando una emoción negativa cuando se obtiene un mal resultado? Está claro que se produce un contagio emocional de las emociones del/la líder al colaborador/a y que por ejemplo una forma de reforzar el engagement y la confianza es mostrar una actitud positiva hacia el/la colaborador/a. Pero también se ha visto que dependiendo del tipo de colaborador/a la expresión del/la líder de la ira es más favorable que una expresión neutra o de felicidad (Van Kleef, Homan, Beersma, y van Knippenberg, 2010). Y no es menos cierto que, a veces, en la acción de liderazgo y en la dirección de personas aparecen situaciones dónde el comportamiento y el desempeño ofrecido por el/la colaborador/a no es el adecuado. ¿Es correcto expresar en estos casos emociones positivas? ¿Podría la expresión emocional negativa equilibrada impactar en el/la colaborador/a ofreciendo desempeños organizacionales óptimos? Obviamente el desborde emocional (por ejemplo una ira desmedida) puede ocasionar impacto negativos graves en los/as colaboradores/as, ¿pero 
qué sucede si un/a colaborador/a realiza continuamente un mal desempeño que provoca pérdidas económica o sociales graves? Todo parece indicar que el equilibrio emocional entre lo positivo y negativo sería lo adecuado. Por lo que estando de acuerdo que el estilo de dirección de un/a líder debería basarse en una expresión y utilización de emociones positivas, se debería de disponer de investigaciones que apuntalaran en qué tipo de situaciones y en qué tipo de colaboradores/as las emociones negativas tienen un efecto positivo de influencia en éstos.

Lo mismo ocurre con la facilitación emocional. En la literatura se describe que si queremos tener buena salud, ser creativos y flexibles, es bueno tener un estado emocional positivo (Oros, Manucci y De Minzi, 2011). En la misma línea, Lybomirsky, King y Diener (2005) relacionaron, por un lado, la afectividad positiva con el optimismo y la autoconfianza, y por el otro, la autoeficacia con el mejor funcionamiento de la flexibilidad y la creatividad. En cambio, las personas bajo la influencia de las emociones negativas tienden a aumentar su capacidad de razonamiento deductivo, así como el razonamiento analítico concreto y focalizado, lo que complica que puedan tener en cuenta otras variables, por el contrario el uso de la memoria es más efectivo (Schwarz, 2000). Todo parece indicar que ambos tipos de emociones son necesarias en su interrelación con las funciones cognitivas más racionales del ser humano. Por tanto, en esta Tesis se aboga por una línea de investigación que contemple la integridad del factor emocional con dos tipos de valencia (positiva y negativa) para no sesgar los resultados en una dirección u otra. Con ello, aunque suponga alejarse del paradigma dominante actual, se podría ofrecer una visión de la interacción emoción-cognición desde un punto de vista integrador sin caer en lucha de polaridades. 


\subsubsection{Vigor}

Uno de los puntos clave de esta Tesis es la conceptualización del vigor. Y esta integración de la que se ha hablado en apartados anteriores, abre la puerta a nuevas investigaciones que lo definan como un constructo independiente formado por tres dimensiones: emocional, cognitiva, y física, tal y como argumentó Shirom (2004, 2011). La propuesta de Shirom, tal y cómo se ha descrito, posee fundamentación teórica válida, pero es necesaria complementarla con nuevas investigaciones y con instrumentos de medición de mayor rigor científico. A pesar de que la propuesta de Shirom posea una gran fortaleza teórica (Wefald, 2009; Remo, 2012), la escasez de investigaciones bajo esta aproximación se deba posiblemente a la falta de confianza en la fiabilidad y validez de la herramienta que Shirom diseñó. Esta debilidad, junto a la exigua difusión de las ideas teóricas de Shirom, posiblemente provoca en que se siga utilizando el UWES como herramienta de medición del vigor. Aunque, a diferencia de Shirom, en el UWES, el vigor sea visto como un factor unidimensional vinculado a la motivación y la resiliencia. Prueba de esta necesaria integración se ve claramente en una reciente publicación sobre el vigor y el agotamiento. Dicha publicación está firmada por uno de los creadores del engagament y UWES, Arnold Bakker (Mäkikangas et al., 2014). Esta investigación incorpora en sus bases teórica, tanto la propuesta de Schaufeli et al. (2002), como la conceptualización de Shirom (2004, 2011), aceptándolas e integrándolas. Aun así, la escala utilizada en dicha publicación sigue siendo el UWES.

Definitivamente creo que la propuesta de Shirom puede enriquecer el constructo del engagement. Considero que el vigor es parte del engagement como lo definen Schaufeli y sus colaboradores (2002, 2006), pero, como defiende Shirom $(2004,2011)$, también tiene a 
su vez identidad propia formado por tres dimensiones. Ambas ideas han sido ratificadas anteriormente (Wefald, 2012). Por ello, sería absolutamente necesario que en futuras investigaciones se realizase nuevos estudios y construcciones teóricas que busquen la integración de ambas posturas. De igual modo, con el objetivo de subsanar las limitaciones metodológicas de medición existentes, se podrían desarrollar nuevos estudios metodológicos centrados en comprobar de forma más exhaustiva la fiabilidad y validez de la herramienta de medición del vigor de Shirom (SMVM) o, en su defecto, una ampliación de la escala de medición del vigor en el UWES incorporando una reformulada revisión del constructo que se aleje de la visión de motivación y resistencia física inicial e incorpore la propuesta multidimensional de Shirom.

\subsection{Conclusiones Finales}

El objetivo principal de esta Tesis ha sido contribuir a ampliar el conocimiento existente en el proceso de influencia del liderazgo sobre cómo impacta el/la líder emocionalmente inteligente en el procesamiento cognitivo de sus colaboradores/as. Para ello se evaluó las respuestas de tres colaboradores/as a la influencia recibida por parte de cada uno/a de sus líderes, a los que cuales se les había medido previamente su nivel de inteligencia emocional. Los resultados obtenidos sugieren que los/as líderes con altas puntuaciones en inteligencia emocional son capaces de influenciar positivamente en sus colaboradores/as directos consiguiendo que éstos/as alcancen una influencia positiva en sus competencias mentales. Este efecto interpersonal refuerza la hipótesis de que existe un efecto social interpersonal de las emociones entre el/la líder y sus colaboradores/as más allá del simple contagio emocional. De igual modo, se desprende que es importante tener líderes que sean eficientes a la hora de percibir, comprender, facilitar, y manejar las 
emociones tanto propias como las de sus colaboradores/as. Esto resultados muestran la necesidad en el proceso de liderazgo de disponer de tácticas emocionales de influencia basadas en la inteligencia emocional. Con ello se podrá, posiblemente, ejercer un mayor impacto en los/as colaboradores/es que incluso se relaciona con el funcionamiento cognitivo de éstos/as últimos/as.

Esta relación entre líder y colaborador/a invita a seguir investigando qué variables pueden mediar y modular la misma. En esta misma línea, se encontró que el nivel de vigor que sienten los/as colaboradores/as hace que las habilidades emocionales del/la líder tenga mayor impacto en sus competencias mentales. Por tanto, todo parece indicar que es importante trabajar el vigor de los/as colaboradores/as para potenciar los efectos positivos de que los/as líderes posean alta inteligencia emocional. Se apunta con ello que el/la colaborador/a no es un agente pasivo en el proceso de liderazgo, y que al igual que su nivel de vigor modula este proceso, podría existir otras variables individuales y grupales que puedan estar afectando de algún modo. Por ello, el/la líder debe estar atento/a estas variaciones para ajustar su estilo de dirección para así, conseguir un mayor y mejor impacto en ellos/as.

En tercer lugar, se analizó, a nivel intrapersonal, el efecto de las competencias emocionales de lo/as s colaboradores/as en su sus competencias cognitivas. Efectivamente, los resultados apuntan que los/as colaboradores/as con altas competencias emocionales consiguen altos puntaciones en sus competencias mentales. Este resultado refuerza la idea de la interacción funcional, y neurofisiológica existente entre la emoción y cognición rompiendo el mito de dos constructos enfrentados. Del mismo modo, se abandona la visión 
negativa del mundo de las emociones, dónde la emoción siempre representaba el papel del patito feo en comparación con el papel del cisne blanco representado por la razón.

Por último, es importante recordar que la inteligencia emocional de los/as líderes tiene un impacto en los/as colaboradores/as. Dicho impacto será positivo o negativo dependiendo siempre de los valores éticos y morales del/la líder. Tener la habilidad de influir en los/as demás es tener un gran poder. En los últimos años, el pragmatismo amoral, y en ciertos casos, el mal uso de esta capacidad de influenciar en los/as demás, ha llevado a qué ciertos líderes en sectores empresariales, sociales, sindicales, y políticos condenen a la pobreza económica, cultural y espiritual a seres humanos simplemente por el mero hecho de actuar sin una dirección guiada por valores. 


\section{REFERENCIAS BIBLIOGRÁFICAS}


Acosta, H., Salanova, M., LLorens, S. (2011). ¿Qué prácticas organizacionales saludables son más frecuentes en las empresas? Un análisis cualitativo. Fòrum de recerca, 16, $811-826$.

Aguado, L. (2005). Emoción afecto y motivación. Madrid: Alianza Editorial

Ahern, G.L. y Schwartz, G. E. (1985). Differential lateralization for positive and negative emotion in the human brain: EEG spectral analysis. Neuropsychologia, 23, 745-755.

Ahern, G. L., Herring, A. M., Tackenberg, J. N., Schwartz, G.E., Seeger, J.F., Labiner, D. M., Weinand, M. E. y Oommen, K. J. (1994). Affective self-report during the intracarotid sodium amobarbital test. Journal of Clinical and Experimental Neuropsychology, 16, 372-376.

Algoe S., Haldt, J., y Gable, S. (2008). Beyond Reciprocity: Gratitude and Relationships in Everyday Life. Emotion, 8, 425-429.

Akhtar, R., Boustani, L., Tsivrikos, D., y Chamorro-Premuzic, T. (2015). The engageable personality: Personality and trait EI as predictors of work engagement. Personality and Individual Differences, 73, 44-49.

Ambady, N., y Gray, G. M. (2002). On being sad and mistaken: Mood effects on the accuracy of thin-slice judgments. Journal of Personality and Social Psychology, 83, 947-961.

Annemieke M. A, Schiller. D., LeDoux, J. y Phelps E. (2014). Extinction resistant changes in the human auditory association cortex following threat learning. Neurobiology of Learning and Memory, 113, 109-114. 
Ansari, M. A.; Kee, D. M. H. y Aafaqi, R. (2000). Fairness of human resource management practices, leader-member exchange, and intention to quit. Journal of International Business and Entrepreneurship, 8, 1-19.

Antonakis, J. y House, R. J. (2002). An analysis of the full-range leadership theory: The way forward. En B. J. Avolio y F. J. Yammarino (Eds.), Transformational and charismatic leadership: The road a head (pp. 3-33). Amsterdam: JAI Press.

Antonakis, J., Avolio, B. J., y Sivasubramaniam, N. (2003). Context and leadership: An examination of the nine factor full-range leadership theory using the multifactor leadership questionnaire. The Leadership Quarterly, 14, 261-295.

Aranguren, M. (2013). Emoción y creatividad: Una relación compleja. Suma Psicológica, 20, 217-230.

Ardila, A. (2008). On the evolutionary origins of executive functions. Brain and cognition, 68, 92-99.

Ardila, A., Ostrosky-Solis, F. (2008). Desarrollo Histórico de las Funciones Ejecutivas. Revista Neuropsicología, Neuropsiquiatría y Neurociencias, 8, 1-21.

Arnetz, B., y Blomkvist, V. (2007). Leadership, Mental Health, and Organizational Efficacy in Health Care Organizations. Psychotherapy Psychosomatics, 76, 242-248.

Arnold, M. B. (1960). Emotion and Personality: Psychological Aspects (Vol. 1). New York: Columbia University Press.

Ashby, F. G., Isen, A. M., y Turken, A. U. (1999). A neuropsychological theory of positive affect and its influence on cognition. Psychological Review, 106, 529-550. 
Ashkanasy, N. M. (2002). Studies of cognition and emotion in organizations: Attribution, affective events, emotional intelligence and perception of emotion. Australian Journal of Management, 27, 11-20.

Ashkanasy, N. M. y Daus, C.S. (2005). Rumors of the death of emotional intelligence in organizational behaviour are vastly exaggerated. Journal of Organizational Behavior, $26,441-452$.

Astington, J. (1998). Theory of mind, Humpty Dumpty, and the icebox.Human Development, 41, 30-39.

Augusto-Landa, J. M., López-Zafra, E., Martínez, R. y Pulido, M. (2006). Perceived emotional intelligence and life satisfaction among university teachers. Psicothema, $18,152-157$.

Avolio, B. J., y Bass, B. M. (1991). The full range leadership development programs: Basic and advanced manuals. Binghamton, NY: Bass.

Avolio, B. J. (1999). Full leadership development: Building the vital forces in organizations. Thousand Oaks, CA: Sage.

Avolio, B. J., Bass, B. M., y Jung, D. (1995). Multifactor leadership questionnaire technical report. Palo Alto, CA: Mind Garden.

Avolio, B., Sivasubramaniam, N., Murry, W., Jung, D., y Garger, J. (2003). Assessing shared leadership: Development and preliminary validation of a team multifactor leadership questionnaire. En C.L. Pearce y J.A.Conger (Eds.), Shared leadership: Reframing the how's and why's of leadership (pp. 143-172). Sage: Newbury Park, CA.

Avolio, B.J., Zhu, W., Koh, W., y Bhatia, P. (2004). Transformational leadership and 
organizational commitment: mediating role of psychological empowerment and moderating role of structural distance. Journal of Organizational Behavior, 25, 951-968.

Avolio, B. J., Gardner, W.L., Walumbwa, F.O., Luthans, F., y May, D.R. (2004). Unlocking the mask: A look at the process by which authentic leaders' impact follower attitudes and behaviors. The Leadership Quarterly, 15, 801-823.

Avolio, B.J., y Gardner, W.L. (2005). Authentic leadership development: Getting to the root of positive forms of leadership. Leadership Quarterly, 16, 315-338.

Avolio. B., Walumba, F. y Weber, T.J. (2009). Leadership: Current theories and research and future directions, Annual Review of Psychology, 60, 421-449.

Badaracco, J. L. y Ellsworth, R. (1989). Leadership and de quest for integrity. Boston: Harvard Business School Press.

Bakker, A. B., y Demerouti, E. (2007). The Job Demands-Resources model: State of the art. Journal of Managerial Psychology, 22, 309-328.

Bakker, A. B., Hakanen, J.J., Demerouti, E., y Xanthopoulou, D. (2007). Job resources boost work engagement, particularly when job demands are high. Journal of Educational Psychology, 99, 274-284.

Bakker, A.B., y Schaufeli, W.B. (2008). Positive organizational behavior: Engaged employees in flourishing organizations. Journal of Organizational Behavior, 29, $147-154$

Bakker, A.B., y Xanthopoulou, D. (2009). The crossover of daily work engagement: Test of an actor-partner interdependence model. Journal of Applied Psychology, 94, 15621571. 
Bakker, A. B., Demerouti, E., y Xanthopoulou, D. (2011). ¿Cómo los empleados mantienen su engagement en el trabajo? Ciencia y Trabajo, 13, 135-142.

Bakker, A. B., Oerlemans, W.G.M., Demerouti, E., Bruins-Slot, B., y Karamat Ali, D. (2011). Flow and performance: A study among talented Dutch soccer players. Psychology of Sport and Exercise, 12, 442-450.

Bakker, A. B., y Rodríguez-Muñoz, A. (2012). Introducción a la psicología de la salud ocupacional positiva. Psicothema, 24, 62-65.

Bakker, A. B., Tims, M., y Derks, D. (2012). Proactive personality and job performance: The role of job crafting and work engagement. Human Relations, 65, 1359-1378

Bakker, A. B., Rodríguez-Muñoz, A., y Derks, D. (2012). La emergencia de la Psicología de la Salud Ocupacional Positiva. Psicothema, 24, 66-72.

Bland, J. M., y Altman, D.G. (1997). Cronbach's alpha. British Medical Journal, 314, 572.

Bhal, K. T. y Ansari, M. A. (2007): Leader-member exchange-subordinate outcomes relationship: Role of voice and justice. Leadership \& Organization Development Journal, 28, 20-35.

Bandura, A. (1997). Self-Efficacy. The exercise of control. New Jersey: Freeman.

Barbuto, J.E., y Burbach, M.E. (2006).The emotional intelligence of transformational leaders: a field study of elected officials. Journal of Social Psychology, 146, 51-64.

Barnard, C.I. (1938). The Functions of the Executive. Cambridge, MA: Harvard University Press.

Bar-On, R. (1990). Countering the effects of Destructive Criticism. Journal of Applied Pyschology, 75, 235-246. 
Bar-On, R. (1997). The Bar-On Emotional Quotient Inventory (EQ-i): a test of emotional intelligence. Toronto: Multi-Health Systems.

Bar-On, R. (2000). Emotional and social intelligence: insights from the emotional quotient inventory. En R. Bar-On, y J.D.A. Parker (Eds). The Handbook of Emotional Intelligence (pp.363-388). San Francisco.

Bar-On, R., Tranel, D., Denburg, N. L., y Bechara, A. (2003). Exploring the neurological substrate of emotional and social intelligence. Brain, 126, 1790-1800.

Bar-On, R. M. (2006). The Bar-On model of emotional-social intelligence (ESI). Psicothema, 18, 13-25.

Baron-Cohen, S., Leslie, A. M., y Frith, U. (1985). Does the autistic child have a 'theory of mind'? Cognition, 21, 37-46.

Baron-Cohen, S., O'Riordan, M., Stone, V., Jones, R., y Plaisted, K. (1999). Recognition of faux pas by normally developing children and children with Asperger syndrome or high-functioning autism. Journal of autism and developmental disorders, 29, 407-418.

Barsade, S. G., y Gibson, D. E. (1998). Group emotion: A view from top and bottom. Research on managing groups and teams, 1, 81-102.

Barsade, S. G. (2002). The ripple effect: Emotional contagion and its influence on group behavior. Administrative Science Quarterly, 47, 644-675.

Bass, B. M. (1985). Comment: Transformational leadership. Looking at other possible antecedents and consequences. Journal of Management Inquiry, 4, 293-297

Bass, B.M. (1990). From transactional to transformational leadership: Learning to share the vision. Organizational dynamics, 18, 19-31. 
Bass, B. M., y Avolio, B. J. (1994). Improving organizational effectiveness through transformational Leadership. Sage, Thousand Oaks, CA.

Bass, M., De Dreu, C. K. W., y Nijstad, B. A. (2008). A meta-analysis of 25 years of mood creativity research: Hedonic tone, activation, or regulatory focus? Psychological Bulletin, 134, 779-806.

Bass, M., De Dreu, C. K. W., y Nijstad, B. A. (2011). Creative production by angry people peaks early on, decreases over time, and is relatively unstructured. Journal of Experimental Social Psychology, 47, 1107-1115.

Bastiaansen, J. A., Thioux, M., y Keysers, C. (2009). Evidence for mirror systems in emotions. Philosophical Transactions of the Royal Society B: Biological Sciences, $364,2391-2404$.

Bechara A, y Damasio, H. (1997). Deciding advantageously before knowing the advantageous strategy. Science, 275, 1293-1295.

Bechara, A., Damasio A. R, Damasio, H., Anderson, S.W. (1994). Insensitivity to future consequences following damage to human prefrontal cortex. Cognition, 50, 7-15.

Bechara, A., Damasio, H. y Damasio, A. R. (2003). The role of the amygdala in decision making. En P. Shinnick-Gallagher, A. Pitkanen, A. Shekhar y L. Cahill (Eds.), The Amygdala in Brain Function: Basic and Clinical Approaches. Annals of the New York Academy of Sciences, 985, 356-369.

Bechara, A., Damasio, H., Tranel, D., y Damasio, A. R. (2005). The Iowa Gambling Task and the somatic marker hypothesis: some questions and answers. Trends in cognitive sciences, 9, 159-162. 
Bedregal, P. (2010). Reflexiones en torno a las emociones en la toma de decisiones éticas en medicina. Revista Chilena de Neuropsicología, 5, 21-30.

Belmonte, C. (2007). Emociones y cerebro. Real Academia de Ciencias Exactas, Físicas y Naturales, 1, 59-68.

Belmonte, M.V. (2013). Inteligencia Emocional y Creatividad. Tesis Doctoral. Universidad de Murcia, España.

Benevides-Pereira, A., Fraiz de Camargo, D. y Porto-Martins, P. (2011). UWES: Utrech Work Engagement Scale. Escala Utrecht de Engagement en el Trabajo.Occupational Health Psychology Unit. Holanda: Utrecht University. Bennis, W. y Nanus, B. (1985). Leaders: The strategies for taking charge.

New York: Harper \& Row.

Bennis, W. (2001) (3ª edic). Dirigir personas es como adiestrar gatos. Madrid: Centro de estudios Ramón Areces.

Bernieri, F. J. (1988). Coordinated movement and rapport in teacher-student interactions. Journal of Nonverbal behavior, 12, 120-138.

Berubé, L. (1991). Terminologie de neuropsychologieet de neurologie du comportement. Les Ëditions de la Cheneleliére Inc., Montréal.

Bickel, R. (2007). Multilevel Analysis for Applied Research. New York: The Guilford Press;

Binet, A., Simon, Th. (1905). Méthodes nouvelles pour le diagnostic du niveau intellectuel des anormaux, L'Année Psychologique, 11, 191-244.

Bland, J. M., y Altman, D.G. (1997). Cronbach's alpha. British Medical Journal, 314, 572. 
Bless, H., y Schwarz, N. (1999). Sufficient and necessary conditions in dual process models: The case of mood and information processing. En S. Chaiken \& Y. Trope (Eds.), Dual process theories in social psychology (pp. 423-440). New York: Guilford Press.

Boada, J., De Diego, R. y Agulló, E. (2004). El burnout y las manifestaciones psicosomáticas como consecuentes del clima organizacional y de la motivación laboral. Psicothema, 16, 125-131.

Bonilla, A. (2004). El enfoque diferencial en el estudio del sistema sexo/género. En E. Barbera y I. Martínez-Benlloch (coords.). Psicología y género. Madrid: Pearson Prentice Hall.

Borod, J. C., Cicero, B. A., Obler, L. K., Welkowitz, J., Erhan, H. M., Santschi, C.,y Whalen, J. R. (1998). Right hemisphere emotional perception: evidence across multiple channels. Neuropsychology, 12, 446.

Borghi, A. M., Glenberg, A. M., y Kaschak, M. P. (2004). Putting words in perspective. Memory \& Cognition, 32, 863-873.

Bosse, T., Jonker, C.M., Meij, Van Der, L., y Treur, J. (2007). A Language and Environment for Analysis of Dynamics by Simulation. International Journal of Artificial Intelligence Tools, 16, 435-464.

Bosse, T., Jonker, C.M., y Treur, J., (2008). Formalisation of Damasio's Theory of Emotion, Feeling and Core Consciousness. Consciousness and Cognition Journal, 17, 94-113.

Bouckenooghe, D., Zafar, A., y Raja, U. (2015). How Ethical Leadership Shapes 
Employees' Job Performance: The Mediating Roles of Goal Congruence and Psychological Capital. Journal of Business Ethics, 129, 251-264.

Bourne, V. J. (2005). Lateralized processing of positive facial emotion: Sex differences in strength of hemispheric dominance. Neuropsychologia, 43, 953-956.

Bourne, V. J. (2008). Examining the relationship between degree of handedness and degree of cerebral lateralization for processing facial emotion. Neuropsychology, 22, 350356.

Bourne, V. J., y Gray, D. L. (2009). Hormone exposure and functional lateralization: Examining the contributions of prenatal and later life hormonal exposure. Psychoneuroendocrinology, 34, 1214-1221.

Bourne, V. J. (2010). How are emotions lateralized in the brain? Contrasting existing hypotheses using the Chimeric Faces Test. Cognition \& Emotion, 24, 903-911.

Bourne, V. J. y Maxwell, A. M. (2010). Examining the sex difference in lateralization for processing facial emotion: Does biological sex or psychological gender identity matter? Neuropsychologia, 48, 1289-1294.

Bourne, V. J. y Vladeanu, M. (2011). Lateralization for processing facial emotion and anxiety: contrasting state, trait and social anxiety. Neuropsychologia, 49, 1343-1349.

Bourne, V. J., y Watling, D. (2015). Individual differences in emotion lateralization and the processing of emotional information arising from social interactions. Laterality: Asymmetries of Body, Brain and Cognition, 20, 95-111. 
Bowers, D., Bauer, R., Coslett, H.B. y Heilman, K. M. (1985). Processing of faces by patients with unilateral hemisphere lesions: I. Dissociation between judgments of facial affect and facial identity. Brain and Cognition, 4, 258-272.

Boyatzis, R. (1982). The competent manager A Model for Effective Performance. New York: John Willey \& Sons.

Boyatzis, R. E., Goleman, D., y Rhee, K. (2000). Clustering competence in emotional intelligence: Insights from the Emotional Competence Inventory (ECI). In R. BarOn and J.D.A. Parker (eds.), Handbook of emotional intelligence (pp. 343-362). San Francisco: Jossey-Bass,

Boyatzis, R. E., Stubbs, E.C., y Taylor, S. N. (2002). Learning cognitive and emotional intelligence competencies through graduate management education. Academy of Management Journal on Learning and Education, 1,150-162.

Boyatzis, R. E., y Sala, F. (2004). Assessing Emotional Intelligence Competencies. En Geher, G. (Eds.), The Measurement of Emotional Intelligence (pp.147-180). Hauppauge, NY, Novas Science Publishers.

Boyatzis, R .E. (2007). The creation of the Emotional and Social Competency Inventory (ESCI). Recuperado el 8 de abril de 2015 de http://www.eiconsortium.org/research/ESCI_Technical_Paper.pdf.

Boyatzis, R. E. (2008). Competencies in the 21 st century. Journal of management development, 27, 5-12.

Boyatzis, R. E. (2011). Managerial and Leadership Competencies A Behavioral Approach to Emotional, Social and Cognitive Intelligence. Vision: The Journal of Business Perspective, 15, 91-100. 
Boyatzis, R. E., Good, D., y Massa, R. (2012). Emotional, social, and cognitive intelligence and personality as predictors of sales leadership performance. Journal of Leadership \& Organizational Studies, 19, 191-201.

Bourne, V. J., y Watling, D. (2015). Individual differences in emotion lateralization and the processing of emotional information arising from social interactions. Laterality: Asymmetries of Body, Brain and Cognition, 20, 95-111.

Brackett, M. A. y Mayer, J.D. (2003). Convergent, discriminant and incremental validity of competing measures of emotional intelligence, Personality and Social Psychology Bulletin, 29, 1147-1158.

Brackett, M. A., Rivers, S. E., Shiffman, S., Lerner, N., y Salovey, P. (2006). Relating emotional abilities to social functioning: a comparison of self-report and performance measures of emotional intelligence, Journal of personality and social psychology, 9, 780-795.

Bradburn, N. M. (1969). The Structure of Psychological Wellbeing. Chicago, IL Aldine.

Bradley, M., y Lang, P. (2000). Affective reactions to acoustic stimuli, Psychophysiology, 37, 204-215.

Breevaart, K., Bakker, A., Hetland, J., Demerouti, E., Olsen, O. K., y Espevik, R. (2014). Daily transactional and transformational leadership and daily employee engagement. Journal of occupational and organizational psychology, 87(1), 138157.

Brickenkamp, R. (1981). Test d2 (7th edn). Göttingen, Germany: Hogrefe.

Brief A. P., Butcher, A. H., y Roberson, L. (1995). Cookies, disposition, and job attitudes: 
The effects of positive mood-inducing events and negative affectivity on job satisfaction in a field experiment. Organizational Behavior and Human Decision Processes, 62, 55-62.

Broca, P. (1878). Anatomie comparee des circonvolutions cerebrales: Le grand lobe limbique et la scissure limbique dans la serie des mammiferes.

Brosch, T., Sander, D., Pourtois, G., y Scherer, K. R. (2008). Beyond fear rapid spatial orienting toward positive emotional stimuli. Psychological science, 19, 362-370.

Brosch, T., Pourtois, G., Sander, D., y Vuilleumier, P. (2011). Additive effects of emotional, endogenous, and exogenous attention: Behavioral and electrophysiological evidence. Neuropsychologia, 49, 1779-1787.

Brown, M. E., Treviño, L. K., y Harrison, D. A. (2005). Ethical leadership: A social learning perspective for construct development and testing. Organizational Behavior and Human Decision Processes, 97, 117-134.

Bowers, D., Bauer, R. M., Coslett, H. B., y Heilman, K. M. (1985). Processing of faces by patients with unilateral hemisphere lesions: I. Dissociation between judgments of facial affect and facial identity. Brain and cognition, 4, 258-272.

Brunetto, Y., Teo, S., Shacklock, K., y Farr-Wharton, R. (2012). Emotional intelligence, job satisfaction, well-being and engagement: Explaining organizational commitment and turnover intentions in policing. Human Resource Management Journal, 22, $428-441$.

Bryk, A. S., y Raudenbush, S. W. (2002). Hierarchical linear models: Applications and data analysis methods. Newbury Park, CA: Sage.

Buchanan, T. W., y Adolphs, R. (2002). The role of the human amygdala in emotional 
modulation of long-term declarative memory. Advances in Consciousness Research, 44, 9-34.

Cacioppo, J. T., y Gardner, W. L. (1999). Emotion. Annual Review of Psychology, 50, 191-214.

Cameron, K.; Dutton, J. y Quinn, R. (2003). Foundations of Positive Organizational Scholarship. En: Cameron, K., Dutton, J. y Quinn, R. (Eds.).Positive Organizational Scholarship: Foundations of a new discipline (pp. 3-13). San Francisco: Berrett Koehler.

Cameron, K., y Caza, A. (2004). Introduction: Contributions to the Discipline of Positive Organizational Scholarship. American Behavioral Scientist, 47, 731-739.

Cameron, K. (2010). Organizational effectiveness. Northampton, MA: Edward Elgar

Cahill, L., y McGaugh, J. L. (1995). A novel demonstration of enhanced memory associated with emotional arousal. Consciousness and cognition, 4, 410-421.

Carmeli, A. (2003). The relationship between emotional intelligence and work attitudes, behavior and outcomes: An examination among senior managers. Journal of Managerial Psychology, 18, 788-813.

Carmeli, A., Ben-Hador, B., Waldman, D. A., y Rupp, D. E. (2009). How leaders cultivate social capital and nurture employee vigor: Implications for job performance. Journal of Applied Psychology, 94, 1553-1561.

Caruso, D. R., y Salovey, P. (2005). El directivo emocionalmente inteligente: La Inteligencia Emocional en la Empresa. Málaga: Algaba.

Carretié, L., López-Martín, S., y Albert, J. (2010). Papel de la corteza prefrontal 
ventromedial en la respuesta a eventos emocionalmente negativos. Revista de neurología, 50, 245-252.

Carretié, L. (2012). Ciclo de Conferencias sobre Neurociencia Cognitiva 2012 organizado por Instituto Tomás Pascual Sanz y la Sección de Neurociencia Cognitiva del Centro Mixto UCM-ISCIII para la Evolución y el Comportamiento Humano.

Carver, S. y Scheier, M. F. (2002). Optimism. En C.R Snyder y S. Lopez. (Eds.) The handbook of positive psychology (pp. 231-243). Oxford: Oxford University Press.

Casado, J. (2000). El Directivo del Siglo XXI. España: Ediciones Gestión 2000

Castro, A. (Comp.). (2010). Fundamentos de Psicología Positiva. Buenos Aires: Paidós.

Castro, F., Gomes, J., y de Sousa, F. C. (2012). Do intelligent leaders make a difference? The effect of a leader's emotional intelligence on followers' creativity. Creativity and Innovation Management, 21, 171-182.

Cavallo, K. y Brienza, D. (2002). Emotional competence and leadership excellence at Johnson \& Johnson: The emotional intelligence and leadership study. Recuperado el 2 de febrero de 2015 de http://www.eiconsortium.org/.

Caza, A., Bagozzi, R.P., Woolley, L., Levy, L., y Caza, B.B. (2010). Psychological capital and authentic leadership: Measurement, gender and cultural extension. Asia-Pacific. Journal of Business Administration, 2, 53-70.

Cervantes, V. H. (2005). Interpretaciones del coeficiente de alpha de Cronbach. Avances en Medición, 3, 9-25. 
Chamorro-Premuzic, T., Benett, E., y Furnham, A. (2007). The happy personality: Mediational role of trait emotional intelligence. Personality and Individual Differences, 42, 1633-1639.

Chartrand, T. L., y Bargh, J. A. (1999). The chameleon effect: The perception-behavior link and social interaction. Journal of Personality and Social Psychology, 76, 893910.

Chen, Z., Lam, W., y Zhong, (2007). Leader-member exchange and member performance: A new look at individual-level negative feedback-seeking behavior and team-level empowerment culture. Journal of Applied Psychology, 92, 202212.

Cherniss, C. (2010). Emotional intelligence: toward clarification of a concept. Industrial and Organizational Psychology, 3, 110-126

Chiang, M., Núñez, A., Martín, M. y Salazar, M. (2010). Compromiso del trabajador hacia su organización y la relación con el clima organizacional: un análisis de género y edad. Panorama Socioeconómico, 28, 90-100.

Choriz, M. (1995). La expresión de las emociones en la obra de Darwin. Prácticas de Historia de la Psicología. Valencia: Promolibro.

Choriz, M. (2005). Psicología de la emoción: el proceso emocional. Recuperado el 10 de febrero de 2015 de www.uv.es/=choliz.

Chughtai, A., Byrne, M., y Flood, B. (2014). Linking ethical leadership to employee wellbeing: The role of trust in supervisor. Journal of Business Ethics, 128, 653-663

Csibra, G. (2004). Mirror neurons and action observation. Is simulation involved? 
Interdisciplines. Recuperado el 30 de mayo de 2015 de http://www.interdisciplines.org/mirror/papers/4.

Ciulla, J. B. (1998). Leadership Ethics: mapping the territory. En Ciulla, J. (Ed.): Ethics in the heart of leadership. New York: Praeger.

Clapp-Smith, R., Vogelgesang, G.R., y Avey, J.B. (2009). Authentic leadership and positive psychological capital: The mediating role of trust at the group level of analysis. Journal of Leadership and Organizational Studies, 15, 227-240.

Clark, M. S., Pataki, S. P., y Carver, V. H. (1996). Some thoughts and findings on self presentation of emotions in relationships. In G. J. O. Fletcher y J. Fitness (Eds.), Knowledge structures in close relationships: A social psychological approach (pp. 247-274). Mahwah, NJ: Erlbaum.

Cole, M. S., Walter, F., Bedeian, A. G., y O’Boyle, E. H. (2012). Job burnout and employee engagement: A meta-analytic examination of construct proliferation. Journal of Management, 38, 1550-1581.

Colom, R, y Garcia-López, O. (2002). Sex Differences in Fluid Intelligence among High School Graduates. Personality and Individual Differences, 32, 445- 451

Compton, R. J. (2003). The interface between emotion and attention: A review of evidence from psychology and neuroscience. Behavioral and Cognitive Neuroscience Reviews, 2, 115-129.

Conger, J. A., y Kanungo, R. N. (1994). Charismatic leadership in organizations: Perceived behavioral attributes and their measurement. Journal of organizational behavior, $15,439-452$. 
Cooper, C. L., y Nelson, D. L. (Eds.) (2006). Positive Organizational Behavior: Accentuating the positive at work. Thousand Oaks, CA: Sage.

Côté, S., y Miners, C. T. H. (2006). Emotional intelligence, cognitive intelligence, and job performance. Administrative Science Quarterly, 51, 1-28.

Côté, S., Lopes, P. N., Salovey, P., y Miners, C. T. H. (2010). Emotional intelligence and leadership emergence in small groups. The Leadership Quarterly, 21, 496-508.

Côté, S., y Hideg, I. (2011). The ability to influence others via emotion displays: A new dimension of emotional intelligence. Organizational Psychology Review, 1, 53-71.

Côté, S. (2014). Emotional intelligence in organizations. Annual Review of Organizational Psychology and Organizational Behavior, 1, 459-488.

Cranford, J., Shrout, P., Lida, M., Rafaeli, E., Yip, T., y Bolger, N. (2006). A procedure for evaluating sensitivity to within-person change: Can mood measures in diary studies detect change reliably? Personality and Social Psychology Bulletin, 32, 917.

Csikszentmihalyi, M. (1996). Fluir (Flow).Una psicología de la felicidad. Barcelona: Kairós.

Csikszentmihalyi, M. (1996).Creativity: Flow and the Psychology of Discovery and Invention. New York: Harper Perennial.

Custers, R., y Aarts, H. (2005). Positive affect as implicit motivator: On the noconscious operation of behavioral goals. Journal of Personality and Social Psychology, 89, $129-142$.

Damasio, A. (1996). El error de Descartes. Santiago de Chile: Andrés Bello Damasio, A. (1999). The feeling of what happens: Body and emotion in the making of consciousness. New York: Harcourt Brace. 
D’Amico, A. (2012). Test IE ACCME- Intelligenza emotiva: Abilita, Credenze e Concetto di Sé Meta-Emotivo.Test pre Adolescenti. Firenze: Giunti Organizzazioni Speciali

Dansereau, F., Graen, G., y Haga, W. J. (1975). A vertical dyad linkage approach to leadership within formal organizations: A longitudinal investigation of the role making process. Organizational behavior and human performance, 13, 46-78.

Darwin, C.A. (1872). The expression of the emotions in man and animals. London: John Murray.

Daus, C. S., y Ashkanasy, N. M. (2005). The case for an ability-based model of emotional intelligence in organizational behavior. Journal of Organizational Behavior, 26, 453-466.

Davies, M.; Stankov, L. y Roberts, R. D. (1998). Emotional intelligence: In search of an elusive construct. Journal of Personality and Social Psychology, 75, 989-1015.

Davis, M. H. (1983). Measuring individual differences in empathy: Evidence for a multidimensional approach. Journal of Personality and Social Psychology, 44, 113-126.

Davidson, R. J., (2002). Anxiety and affective style: role of prefrontal cortex and amygdala. Biological Psychiatry, 51, 68-80.

Davidson, R. J. (2004). What does the prefrontal cortex "do" in affect: perspectives on frontal EEG asymmetry research. Biological Psychology, 67, 219-233.

Day, A. L., y Carroll, S. A. (2008). Faking emotional intelligence (EI): comparing response distortion on ability and trait-based EI measures. Journal of Organizational Behavior, 29, 761-784. 
Demerouti, E., Bakker, A.B., Nachreiner, F., y Schaufeli, W.B. (2001). The job demandsresources model of burnout. Journal of Applied Psychology, 86, 499-512.

Demerouti, E., y Cropanzano, R. (2010). From thought to action: Employee work engagement and job performance. In A.B. Bakker \& M.P. Leiter (Eds.), Work engagement: A handbook of essential theory and research (pp. 147-163). New York: Psychology Press.

Demerouti, E., Mostert, K., y Bakker, A.B. (2010). Burnout and work engagement: A thorough investigation of the independency of both constructs. Journal of Occupational Health Psychology, 15, 209-222.

De Dreu, C. K. W., Beersma, B., Steinel, W., y Van Kleef, G. A. (2007). The psychology of negotiation: Principles and basic processes. En A. W. Kruglanski, \& E. T. Higgins (Eds.), Social psychology: Handbook of basic principles (2nd ed.). New York: Guilford

De Dreu, C. K. W., Nijstad, B. A., y van Knippen-berg, D. (2008). Motivated information processing in group judgment and decision making. Personality and Social Psychology Review, 12, 22-49.

De Gelder, B. (2006). Towards the neurobiology of emotional body language. Nature Reviews Neuroscience, 7, 242-249.

De la Rosa Navarro, M. D., y Carmona, A. L. (2010). Cómo afecta la relación del empleado con el líder a su compromiso con la organización. Universia Business Review, 26, $112-133$.

Dimberg, U., y Öhman, A. (1996). Behold the wrath: Psychophysiological responses to facial stimuli. Motivation and Emotion, 20, 149-182. 
Dimberg, U. (1982). Facial reactions to facial expressions. Psychophysiology, 26, 643647.

Dionne S. D., Yammarino F. J., Atwater L. E., y Spangler, W. D. (2003).Transformational leadership and team performance. Journal of Organizational Change Management, 17, 177-193.

Doherty, R. W. (1997). The emotional contagion scale: A measure of individual differences. Journal of nonverbal Behavior, 21, 131-154.

Draper, D. (1995). Inference and hierarchical modeling in the Social Sciences. School Effectiveness and School Improvement, 20, 115-147.

Drath, W., y Palus, C. J. (1994). Making common sense: Leadership as meaning making in a community of practice. Greensboro, NC: Center for Creative Leadership.

Drevets, W. C., y Raichle, M. E. (1998). Reciprocal suppression of regional cerebral blood flow during emotional versus higher cognitive processes: Implications for interactions between emotion and cognition. Cognition and emotion, 12, 353385.

Drucker, P. (1992). Managing for the future, New York: Truman Talley Books Dutton

Dunning, D., Heath, C., y Suls, J. M. (2004). Flawed self-assessment implications for health, education, and the workplace. Psychological science in the public interest, 5, 69-106.

Duffy, E. (1934). Emotion: An example of the need for reorientation in psychology. Psychological Review, 41, 184-198.

Durán, M. A.; Extremera, N. y Rey, L. (2005). Burnout y Engagement en el marco de la Experiencia Piloto para la Adaptación a los Créditos Europeos. En J. Romay 
Martínez y R. García Mira (Eds), Psicología Social y Problemas Sociales (pp741749). Madrid: Biblioteca Nueva Eden.

Eden, D. (1993). Leadership and expectations: Pygmalion effects and other self-fulfilling prophecies in organizations. The Leadership Quarterly, 3, 271-305.

Ekman, P. (1972). Universals and cultural differences in facial expressions of emotions. En J. Cole (Eds) Nebraska Symposium on Motivation, 1971, Vol.19 (p.207282).Lincoln, Neb.: University of Nebraska Press.

Ekman, P., W. V. Friesen, y K. Scherer (1976). Body movement and voice pitch in deceptive interaction. Semiótica, 16: 23-27.

Ekman, P. (1981). Expresiones faciales de la emoción. Estudios de Psicología, 7, 116-144.

Ekman, P., Friesen, W. V., y Ellsworth, P. (1982). Research foundations. Emotion in the human face, 2, 1-143

Ekman, P. (1984). Expression and the nature of emotion. En K.R. Scherer y P. Ekman (Eds). Approaches to emotion (p.319-344). Hillsdate, N.J: Lawrence Eribaum Associates, Inc.

Ekman, P. (1992). An argument for basic emotions. Cognition and Emotion, 6,169-200.

Ekman, P. (1999). Basic emotions. En T. Dalglesih y T. Powers (Eds), Handbook of cognition and emotion (p.45.60). New York: Wiley

Ekman, P., Friesen, W. V., y Scherer, K. R. (1976). Body movement and voice pitch in deceptive interaction. Semiótica, 16, 23-28.

Elfenbein, H. A. (2007). 7 Emotion in Organizations: A Review and Theoretical Integration. The academy of management annals, 1, 315-386. 
Elias, M.J., Bruene-Butler, L., Blum, L., y Schuyler, T. (2000). Voices from the field: Identifying and overcoming road blocks to carrying out programs in social and emotional learning/emotional intelligence. Journal of educational and Psychological Consultation, 11, 253.

ERCOVA- European Project (2004). Recuperado el 20 de marzo de 2015 de http://ec.europa.eu/employment_social/equal/index_en.cfm.

Erk, S., Kiefer, M., Grothe, J., Wunderlich, A. P., Spitzer, M., y Walter, H. (2003). Emotional context modulates subsequent memory effect. NeuroImage, 18, 439-447

Erk, S., Von Kalckreuth, A., y Walter, H. (2010). Neural long-term effects of emotion regulation on episodic memory processes. Neuropsychologia, 48, 989-996.

Esteban, B. (2014). Una aproximación a la influencia de la Inteligencia Emocional Percibida en su relación con los niveles de Burnout y Engagement en el desempeño del Trabajo Social. Revista Internacional de Trabajo Social y Bienestar. 3, 123-131.

Estrada C.A, Isen A.M y Young M. J. (1994). Positive affect improves creative problem solving and influences reported source of practice satisfaction in physician. Motivation and Emotions, 18, 285-299.

Extremera, N. y Fernández-Berrocal, P. (2003). La inteligencia emocional en el contexto educativo: hallazgos científicos de sus efectos en el aula. Revista de Educación, 332, 97-116.

Extremera, N., Fernández-Berrocal, P. y Durán, A. (2003). Inteligencia emocional y burnout en profesores. Encuentros en Psicología Social, 1, 260-265 
Extremera, N. (2003). El modelo de inteligencia emocional de Mayer y Salovey y su validez predictiva en muestras españolas. Tesis Doctoral. Universidad de Málaga, España.

Extremera, N., Fernández-Berrocal, P. y Durán A. (2003). Inteligencia emocional y burnout en profesores. Encuentros en Psicología Social, 1, 260-265.

Extremera, N., Durán, M. A., y Rey, L. (2005). La inteligencia emocional percibida y su influencia sobre la satisfacción vital, la felicidad subjetiva y el "engagement" en trabajadores de centros para personas con discapacidad intelectual. Ansiedad y Estrés, 11, 63-73.

Extremera, N., Fernández-Berrocal, P. y Salovey, P. (2006). Spanish version of the Mayer Salovey-Caruso Emotional Intelligence Test (MSCEIT) Version 2.0: Reliabilities, Age, and Gender Differences. Psicothema, 18, 42-48.

Extremera, N. y Fernández-Berrocal, P. (2009). Test de Inteligencia Emocional de Mayer Salovey Caruso. Madrid: TEA Ediciones.

Eysenberg, N. (2000) Emotion, regulation and moral development. Annual Review in Psychology, 51, 665-697.

Falbe, C. M. y Yukl, G. (1992). Consequences for managers of using single influence tactics and combinations of tactics. Academy of Management Journal, 35, 638-652.

Feingold, A. (1992). Sex Differences in Variability in Intellectual Abilities: A New Look at an Old Controversy. Review of Educational Research, 62, 61- 84.

Fenske, M. J., y Raymond, J. E. (2006). Affective influences of selective attention. Current Directions in Psychological Science, 15, 312-316. 
Fernández, C.M. (2012). Tesis Doctoral. Inducción de emociones en condiciones experimentales: Un banco de estímulos audiovisuales. Universidad Autónoma de Barcelona. España.

Fernández-Abascal, E. G., y Jiménez, P. (2000). Cien años de estudio para la emoción. Revista de Historia de la Psicología, 21, 707-717.

Fernández-Berrocal, P., Extremera, N., y Ramos, N. (2004). Validity and reliability of the Spanish modified version of the Trait Meta-mood Scale. Psychological Reports, 94, $751-755$

Fernández-Berrocal, P., y Extremera, N. (2009). La inteligencia emocional y el estudio de la felicidad. Revista Interuniversitaria de Formación del Profesorado, 66, 85-108.

Fernández-Berrocal, P., Extremera, N., Ramos, N. (2004). Validity and reliability of the Spanish modified version of the Trait Meta-Mood Scale. Psychological Reports, 94, $751-755$.

Fernández-Berrocal, P., y Aranda, D. R. (2008). La inteligencia emocional en la educación. Electronic journal of research in educational psychology, 6, 421-436.

Fernández-Berrocal, P., Berrios-Martos, M. P., Extremera, N., y Augusto, J. M. (2012) Inteligencia emocional: 22 años de avances empíricos. Psicología Conductual, 20, $5-13$.

Field, T. M., Woodson, R., Greenberg, R., y Cohen, D. (1982). Discrimination and imitation of facial expressions by neonates. Science, 218, 179-181.

Fiedler, F. E. (1967). The contingency model and the dynamics of the leadership process. En BERKOWITZ, L. (Ed.). Advances in experimental social psychology. New York. Academic Press 
Fiedler, F. E. y Garcia, J. E. (1987). New approaches to leadership: Cognitive resources and organizational performance. New York. Wiley

Fitness, J. (2000). Anger in the workplace: An emotion script approach to anger episodes between workers and their superiors, co-workers and subordinates. Journal of Organizational Behavior, 21, 147-162.

Fodor, J. (1992). A theory of the child's theory of mind. Cognition, 44, 283-296.

Fogassi, L., Ferrari, P. F., Gesierich, B., Rozzi, S., Chersi, F., y Rizzolatti, G. (2005). Parietal lobe: from action organization to intention understanding. Science, 308, 662-667.

Forgas, J. P. (1995). Mood and judgment: The affect infusion model (AIM). Psychological Bulletin, 117, 39-66.

Fredrickson, B. L. (2001). The role of positive emotions in positive psychology: The broaden-and-build theory of positive emotions. American Psychologist, 56, 218226.

Fredrickson, B. L. (2003a). The value of positive emotions. American Scientist, 91, 330335.

Fredrickson, B. L. (2003b). Positive emotions and upward spirals in organizational settings. In K. S. Cameron, J. E. Dutton \& R. E. Quinn (Eds.), Positive Organizational Scholarship (pp. 163-175). San Francisco, CA: Berrett-Koehler Publishers.

Fredrickson, B. L. (2005). The broaden-and-build theory of positive emotions. In F. A. Huppert, N. Baylis, \& B. Keverne (Eds.), The Science of Well-Being (pp. 217-238). New York: Oxford University Press.

Fredrickson, B. L., y Losada, M. F. (2005). Positive affect and the complex dynamics of 
human flourishing. American Psychologist, 60, 678.

Fredrickson, B. L., y Cohn, M. A. (2008). Positive emotions. In M. Lewis, J. Haviland, \& L. F. Barrett (Eds.), Handbook of emotions (3rd Ed.). New York: Guilford Press

Fredrickson, B. L., Cohn, M. A., Coffey, K. A., Pek, J., y Finkel, S. M. (2008). Open hearts build lives: Positive emotions, induced through loving-kindness meditation, build consequential personal resources. Journal of Personality and Social Psychology, 95, 1045-1062.

Fredrickson, B. L. (2008). Promoting Positive Affect. En M. Eid \& R.J. Larsen (Eds), The Science of Subjective Well-Being (pp. 449-468). New York, NY: Guilford Press.

Fredrickson, B. L. (2013). Positive emotions broaden and build. En E. Ashby Plant \& P.G. Devine (Eds.), Advances on Experimental Social Psychology, (pp. 1-53.) Burlington: Academic Press.

Frijda N.H (1986). The Emotions. Cambridge, UK: Cambridge University Press.

Frijda, N.H. (1993). Moods, emotion episodes, and emotions. En M. Lewis and LM. Haviland (Eds.). Handbook of Emotions (pp. 381-403). New York: Guilford.

Gaddis, B., Connely, S., y Mumford, M. D. (2004). Failure feedback as an affective event: Influences of leader affect on subordinate attitudes and performance. The Leadership Quarterly, 15, 663-686.

Gancedo, M. (2009). Psicología Positiva: posible futuro y derivaciones clínicas. Psicodebate, 9, 15-26.

Gallese, P., Goldman, A. (1988). Mirror neurons and the simulation theory of mindreading. Trends in cognitive Science. 2, 493-501.

Gallese, V. (2001). The'shared manifold'hypothesis. From mirror neurons to 
empathy. Journal of consciousness studies, 8, 33-50.

Gallese, V. (2003). The roots of empathy: the shared manifold hypothesis and the neural basis of intersubjectivity. Psychopathology, 36, 171-180.

Gallese, V. (2005). Embodied simulation: From neurons to phenomenal experience. Phenomenology and the cognitive sciences, 4, 23-48.

Gallese, V., Migone, P., y Eagle, M. N. (2009). La simulación corporalizada: las neuronas espejo, las bases neurofisiológicas de la intersubjetividad y algunas implicaciones para el psicoanálisis1. Clínica e investigación relacional, 3, 525.

García-García E., González Marqués J., y Maestú, F.U. (2011). Neuronas espejo y teoría de la mente en la explicación de la mente. Ansiedad y Estrés, 17, 265-279.

Garazi, A., Domínguez; A., Moriano, J., y Molero, J. (2014). Capital psicológico positivo. Validación del cuestionario PCQ en España. Anales de Psicología, 30, 294-301.

Gardner, H. (1983). Frames of mind: The theory of multiple intelligences. New York: Basic Gardner, H. (1995). Inteligencias Múltiples. La teoría en la práctica. Barcelona: Paidós

Gardner, W. L., Avolio, B. J., Luthans, F., May, D. R., y Walumbwa, F. (2005). Can you see the real me? A self-based model of authentic leader and follower development. The Leadership Quarterly, 16, 343-372.

Gardner, W. L., Cogliser, C. C., Davis, K. M., y Dickens, M. P. (2011). Authentic leadership: A review of the literature and research agenda. The Leadership Quarterly, 22, 1120-1145.

Gaudine, A. y Thorne L. (2001) Emotion and ethical decision making in organizations. Journal of Business Ethics, 31, 175-187. 
George, J. M. (1995). Leader positive mood and group performance: The case of customer service. Journal of Applied Social Psychology, 25, 778-794.

George, J. M. (2000). Emotions and leadership: The role of emotional intelligence. Human relations, 53, 1027-1055.

George, J. M. (2011). Dual tuning A minimum condition for understanding affect in organizations? Organizational Psychology Review, 1, 147-164.

Gerstner, C. R. y Day, D. V. (1997). Meta-analytic review of leader-member exchange theory: Correlates and construct issues. Journal of Applied Psychology, 82, 827844.

Giallonardo, L. M., Wong, C. A., y Iwasiw, C. L. (2010). Authentic leadership of preceptors: predictor of new graduate nurses' work engagement and job satisfaction. Journal of nursing management, 18, 993-1003.

Gil, F., Alcover, C. M., Rico, R., y Sánchez-Manzanares, M. (2011). Nuevas formas de liderazgo en equipos de trabajo. Papeles del Psicólogo, 32, 38-47.

Gilbert, S. J., y Burgess, P. W. (2008). Executive function. Current Biology, 18, 110-114.

Glover, S. (2004). Separate visual representations in the planning and control of action. Behavioral and Brain Sciences. 27, 3-24.

Goffman, E. (1956). Embarrassment and social organization. American Journal of Sociology, 62, 264-271.

Goldberg, E. (2001). The executive brain, frontal lobes and the civilized mind. NuevaYork: Oxford University Press.

Goleman, D. (1995). Inteligencia emocional. Barcelona: Editorial Kairós.

Goleman D. 1998. What Makes a Leader? Harvard Business Review. 76, 93-102. 
Goleman, D. (1999). La práctica de la inteligencia emocional. Barcelona: Editorial Kairós.

Goleman, D. (2000). Leadership that gets results. Harvard business review, 78(2), 78-93.

Goleman, D., Boyatzis, R., y McKee, A. (2001). Primal leadership. Harvard Business Review, 79, 42-51.

Goleman, D., y Boyatzis, R. y McKee, A. (2002): El líder resonante crea más. El poder de la inteligencia emocional. Barcelona: Plaza y Janés.

Goleman, D. (2006). Inteligencia Social: La nueva ciencia de las relaciones humanas. Barcelona: Editorial Kairos

Goleman, D. y Boyatzis, R. (2008). Social intelligence and the biology of leadership. Harvard Business Review, 86, 74-81.

Goldberg, L. R. (1999). A broad-bandwidth, public domain, personality inventory measuring the lower-level facets of several five-factor models. En I. Mervielde, I. Deary, F. De Fruyt, \& F. Ostendorf (Eds.), Personality Psychology in Europe, Vol. 7 (pp. 7-28). Tilburg, Netherlands: Tilburg University Press.

Gómez, E. (2006). El liderazgo ético. Buenos Aires: Gestión 2000.

Gondim, S. M. G., Gouveia, V. V., Morais, F. A., y Alberton, G. D. (2013). Contagio Emocional y Constreñimiento en Gestores Emotional Contagion and Embarrassment in Managers. CEP, 41940, 220.

Petrides, K. V., Pérez-González, J. C., y Furnham, A. (2007). On the criterion and incremental validity of trait emotional intelligence. Cognition and Emotion, 21, 2655. 
González-Romà, V., Schaufeli, W. B., Bakker, A. B. y Lloret, S. (2006). Burnout and work engagement: Independent factors or opposite poles? Journal of Vocational Behavior, 68, 165-174.

Gordon, R. M. (1995). Simulation without introspection or inference from me to you. In M Davies and T. Stone (Eds), Mental Simulation. pp. 53-67. Oxford: Blackwell,

Gordon, R. M. 1996: 'Radical' simulationism. In P. Carruthers and P. K. Smith (Eds), Theories of Theories of Mind, (pp. 11-21), Cambridge University Press.

Gordon, R. M, y Cruz, J. (2003). Simulation theory. Encyclopedia of cognitive science. London: The Nature Publishing Group McMillian.

Gordon, J. R. (1997). Comportamiento organizacional. México: Prentice Hall.

Graen, G. y Uhl-Bien, M. (1995). Relationship-based approach to leadership: Development of leader-member exchange theory of leadership over 25 years: Applying a multi-level multi-domain perspective, The Leadership Quarterly, 6, 219-247.

Grant, A. M., y Sonnentag, S. (2010). Doing good buffers against feeling bad: Prosocial impact compensates for negative task and self-evaluations. Organizational Behavior and Human Decision Processes, 111, 13-22.

Gray, J. R (2001). Emotional modulation of cognitive control: Approach-withdrawal states double-dissociate spatial from verbal two-back task performance. Journal of Experimental Psychology. General, 130, 436-452.

Gray, J. R. (2004). Integration of emotion and cognitive control. Current Directions in Psychological Science, 13, 46-48.

Greco, P., Laschinger, H. K. S., y Wong, C. (2006). Leader empowering behaviours, staff 
nurse empowerment and work engagement/burnout. Nursing Leadership, 19, 41-56.

Greenleaf, R. K. (1991). The servant as leader. Indianapolis: The Robert K. Greenleaf Center.

Greene, J., Sommerville, R., Nystrom L., Darley, J., y Cohen, J (2001). An fMRI investigation of emotional engagement in moral judgement. Science, 293, 21052108.

Greene, J. y Haidt, J (2002). How (and where) does moral judgment work? Trends in Cognitive Science, 6, 517-523.

Grewal, D. y Salovey, P. (2005). Feeling Smart: The Science of Emotional Intelligence”. American Scientist, 93, 330-339.

Gross, E., y Stone, G. P. (1964). Embarrassment and the analysis of role requirements. American Journal of Sociology, 70, 1-15.

Gross, J. J., y Levenson, R. W. (1995). Emotion elicitation using films. Cognition \& emotion, 9, 87-108.

Gross, J. J., y Barrett, L. F. (2011). Emotion generation and emotion regulation: One or two depends on your point of view. Emotion Review, 3, 8-16.

Gully, S., Incalcaterra, K. A., Joshi, A., y Beaubien, J. M. (2002). A meta-analysis of team. Efficacy, Potency and Performance: Interdependence and level as moderators of observed relationship. Journal of Applied Psychology, 5, 819-832.

Guzzo, R. A., Yost, P. R., Campbell, R. J. y Shea, G. P. (1993). Potency in groups: Articulating a construct. British Journal of Social Psychology, 3, 87-106. Harrison, Halbesleben, J. R. (2010). A meta-analysis of work engagement: Relationships with 
burnout, demands, resources, and consequences. Work engagement: A handbook of essential theory and research, 8, 102-117.

Happé, F. G. (1994). An advanced test of theory of mind: Understanding of story characters' thoughts and feelings by able autistic, mentally handicapped, and normal children and adults. Journal of autism and Developmental disorders, 24, $129-154$.

Harms, P. D. y Crede, M. (2010). Emotional intelligence and transformational and transactional leadership: A meta-analysis. Journal of Leadership and Organizational Studies, 17, 5 -17

Harris, P. L. (1992). From simulation to folle psychology: The case for development. Mind and language, 7, 120-144.

Harrison, N. A., Singer, T., Rotshtein, P., Dolan, R. J., y Critchley, H. D. (2006). Pupillary contagion: central mechanisms engaged in sadness processing. Social cognitive and affective neuroscience, 1, 5-17.

Hatfield, E., J. Cacioppo, y R. L. Rapson (1992). Primitive emotional contagion. En M. S. Clark (Ed.), Review of Personality and Social Psychology: Emotion and Social Behavior, (pp. 151-177). Newbury Park, CA: Sage.

Hatfield, E., J. Cacioppo, y R. L. Rapson (1993). Emotional contagion. Current. Directions in Psychological Science, 2, 96-99.

Hatfield, E., J. Cacioppo, y R. L. Rapson (1994). Emotional Contagion. New York: Cambridge University Press.

Hatfield, E., y Hsee, C. K. (1995). The impact of vocal feedback on emotional experience and expression. Journal of Social Behavior and Personality, 10, 293-313. 
Hatfield, E., Rapson, R. L., Yen-Chi, L. (2009). Ethnic and gender differences in emotional ideology, experience, and expression. Interpersonal, 3, 30-57.

Haviland, J. M., y Lelwica, M. (1987). The induced affect response: 10-week-old infants' responses to three emotion expressions. Developmental Psychology, 23, $97-$ 104.

Haviland-Jones J. M y Kahlbaugh P (2000). Handbook of emotions. London: The Guildford Press.

Hay Group, McClelland Center for Research and Innovation, y Wolff, S. B. (2005).The emotional competence inventory (ECI) technical manual. Recuperado el 18 de enero de 2015 de http://www.eiconsortium.org/pdf/ECI_2_0_Technical_Manual_v2.pdf.

Hayati, D., Charkhabi, M., y Naami, A. (2014). The relationship between transformational leadership and work engagement in governmental hospitals nurses: a survey study. Springer Plus, 3, 25.

Heal, J. 1996: Simulation, theory and content. En P. Carruthers and P. Smith (Eds), Theories of Theories of Mind. Cambridge, (pp.75-89). Cambridge University Press,

Hebb, D. O. (1955). Drives and the C.N.S. (Conceptual Nervous ystem).Psychological. Review, 62, 243-254.

Hellriegel, D., y Slocum, J. W. (2009). Comportamiento Organizacional. México. Cengage Learning Editores

Hersey, P. y Blanchard, K. H. (1969). Life cycle theory of leadership .Training and Development Journal, 23, 26-40. 
Hersey, P., Blanchard, K. H., y Johnson, D. E. (1998). Administración del comportamiento organizacional: liderazgo situacional. México: Prentice Hall.

Hersey, P. y Blanchard, K. H. (1988). Management of organizational behavior: Utilizing human resources. (5th Ed.). Englewood Cliffs, NJ: Prentice-Hall.

Hobfoll, S. E. (1989). Conservation of resources: A new attempt at conceptualizing stress. American psychologist, 44, 513.

Hofmann, D. A., y Gavin, M. B. (1998). Centering decisions in hierarchical linear models: Implications for research in organizations. Journal of Management, 24, 623-641.

House, R. J. (1996). Path-Goal theory of leadership: Lessons, legacy, and a reformulated theory. Leadership Quarterly, 7, 323-352.

Hox, J. (1995). Applied multilevel analysis. Amsterdam, The Netherlands: TT-Publikaties.

Hunt, J.G. y Larson, L. L. (1982). Leadership: The Cutting Edge. Carbondale, Southern Illinois: University Press.

Iacobini, M., y Dapretto, M. (2006). The mirror neuron system and the consequences of its dysfunction. Nature Reviews Neuroscience, 7, 942-951.

Iacobini, M. (2009). Las neuronas espejo. Buenos Aires: Katz.

Ilies, R., Morgeson, F. P., y Nahrgang, J. D. (2005). Authentic leadership and eudaemonic wellbeing: Understanding leader-follower outcomes. The Leadership Quarterly, 16, 373-394.

Ilies, R., Nahrgang, J. D., y Morgeson, F. P. (2007). Leader-member exchange and citizenship behaviors: A meta-analysis. Journal of Applied Psychology, 92, 269-277. 
Isen, A. M., y Daubman, K. A. (1984). The influence of affect on categorization. Journal of personality and social psychology, 47, 1206.

Isen, A. M., Johnson, M. M., Mertz, E., y Robinson, G. F. (1985). The influence of positive affect on the unusualness of word associations. Journal of personality and social psychology, 48, 1413.

Isen, A. M. (1987). Positive affect, cognitive processes, and social behavior. Advances in Experimental Social Psychology, 20, 203-253.

Isen, A. M., Daubman, K. A., y Nowicki, G. P. (1987). Positive affect facilitates creative problem solving. Journal of Personality and Social Psychology, 52, 1122-1131.

Isen, A. M., Rosenzweig, A. S., y Young, M. J. (1991). The influence of positive affect on clinical problem solving. Medical Decision Making, 11, 221-227.

Isen, A. M., Niedenthal, P. M., y Cantor, N. (1992). An influence of positive affect on social categorization. Motivation and Emotion, 16, 65-78.

Isen, A. M. (1999). Positive affect. Handbook of cognition and emotion, 20, 522-539.

Ismail, A., Mohamad, M. H., Mohamed, H. A. B., Saludin, M. N., Abdullah, M., y Yusuf, M. H. (2010). An empirical study of the relationship between transformational leadership, empowerment and organizational commitment. Proceeding del $2^{\circ}$ Knowledge Management. International Conference (KMICe), May 25-27, 2010, Primula Beach Hotel, Northern University of Malaysia (UUM), Malaysia.

Izard, C.E. (1977). Human emotions. New York: Plenum Press.

Izard, C. E. (1991). The Psychology of Emotions. Nueva York.: Plenum Press

Jacob, P., y Jeannerod, M. (2004). The motor theory of social cognition: a critique. 
Interdisciplines. Recuperado el 2 de febrero de 2015 de

http://www.interdisciplines.org/mirror/papers/2

James, W. (1884). What is an emotion? Mind, 9, 188-205.

James, L. R., Demaree, R. G., y Wolf, G. (1984). Estimating within-group interrater reliability with and without response bias. Journal of Applied Psychology, 69, 8598.

Jansari, A., Tranel, D., y Adolphs, R. (2000). A valence-specific lateral bias for discriminating emotional facial expressions in free field. Cognition \& Emotion, 14, 341-353.

Johnson, S. K. (2008). I second that emotion: Effects of emotional contagion and affect at work on leader and follower outcomes. The Leadership Quarterly, 19, 1 -19.

Johnson, S. K. (2009). Do you feel what I feel? Mood contagion and leadership outcomes. The leadership Quarterly, 20, $814-827$.

Johnson, M. K., Foley, M. A., Suengas, A. G. y Raye, C. L. (1988). Phenomenal Characteristics of Memories for Perceived and Imagined Autobiographical Events. Journal of Experimental Psychology General, 117, 371-376.

Johnson, S. L., Murray, G., Fredrickson, B., Youngstrom, E. A., Hinshaw, S., Malbrancq Bass, J.; Salloum, I. (2012).Creativity and bipolar disorder: Touched by fire or burning with questions? Clinical Psychology Review, 32, 1-12.

Jones, B., y Mishkin, M. (1972). Limbic lesions and the problem of stimulusreinforcement associations. Experimental neurology, 36, 362-377.

Joseph, D. L., y Newman, D. A. (2010). Emotional intelligence: an integrative metaanalysis and cascading model. Journal of Applied Psychology, 95, 54-78. 
Joseph, D. L., Jin, J., Newman, D. A., y O’Boyle, E. H. (2014). Why Does Self-Reported Emotional Intelligence Predict Job Performance? A Meta-Analytic Investigation of Mixed EI.

Kanungo, R. N. y Mendoca, M. (1996). Ethical Dimensions of Leadership. California: Sage, Thousand Oaks.

Kahn, R. L., y Katz, D. (1953). Leadership practices in relation to productivity and morale. En D. Cartwright, \& A. Zander (Eds.), Group dynamics (pp. 612-628). New York: Harper \& Row

Kahn, R. L., Wolfe, D. M., Quinn, R. P., Snoek, J. D. y Rosenthal, R. A. (1964). Occupational stress: Studies in role conflict and ambiguity. New York: John Wiley

Kahn, W. A. (1990). Psychological conditions of personal engagement and disengagement at work. Academy of management journal, 33, 692-724.

Kahn, B.E. e Isen, A.M. (1993). The influence of positive affect on variety of seeking among safe, enjoyable products. Journal of Consumer Research, 150, 18-36.

Kaiser, R. B., y DeVries, D. L. (2000). Leadership training. The Corsini encyclopedia of psychology and behavioral science, 3rd Ed. New York: Wiley \& Sons.

Kanungo, R. N. y Mendoca, M. (1996). Ethical Dimensions of Leadership. California: Sage, Thousand Oaks.

Karasek, R. A. (1979). Job demands, job decision latitude and mental strain: Implications for job redesign. Administrative Science Quarterly, 24, 285-308.

Karasek, R., y Theorell, T. (1990). Healthy Work, Stress, Productivity and the Reconstruction of Working Life. New York: Basic Books.

Katz, D., y Kahn, R. L. (1978). The social psychology of organizations. New York: Wiley 
Kaufmann, G., y Vosburg, S. K. (1997). Paradoxical mood effects on creative problemsolving. Cognition and Emotion, 11, 151-170.

Kelman, H. C. (1958). Compliance. identification and internalization, three processes of attitude change. Journal of Conflict Resolution, 2, 51-60.

Keltner, D., Ellsworth, P. C., y Edwards, K. (1993). Beyond simple pessimism: effects of sadness and anger on social perception. Journal of personality and social psychology, 64, 740 .

Keltner, D., y Haidt, J. (1999). Social functions of emotions at four levels of analysis. Cognition and Emotion, 13, 505-521.

Keltner, D., y Haidt, J. (2001). Social functions of emotions. En T. Mayne y G. A. Bonanno (Eds.), Emotions: Current issues and future directions .(pp. 192213). New York: Guilford Press

Kelly, J. R., y Barsade, S. G. (2001). Mood and emotions in small groups and work teams. Organizational behavior and human decision processes, 86, 99-130.

Kensinger, E. A., y Corkin, S. (2003). Memory enhancement for emotional words: Are emotional words more vividly remembered than neutral words? Memory and Cognition, 31, 1169-1180.

Kensinger, E. A., y Schacter, D. L. (2006). Amygdala activity is associated with the successful encoding of item, but not source, information for positive and negative stimuli. Journal of Neuroscience, 26, 2564-2570.

Kensinger, E. A., y Schacter, D. L. (2008). Memory and emotion. En M. Lewis, J. M. Haviland-Jones, y L. F. Barrett (Eds.).The handbook of emotions (pp. 601-617). New York: Guilford Press. 
Khuntia, R. y Suar, D. (2004). A scale to assess ethical leadership of indian private and public sectors managers. Journal of business ethics, 49, 13-26.

Kidwell, R. E., y Martin, Ch. L. (2005). Managing organizational deviance. Estados Unidos: Sage Publications.

Kimura, D. y Clarke, P. G. (2002). Women's advantage on verbal memory is not restricted to concrete words. Psychological Reports, 91, 1137-1142.

Kleinberg, J. L. (2000). Beyond emotional intelligence at work. Adding insight to injury through group psychotherapy. Group, 24, 261-278.

Klinnert, M., Campos, J., Sorce, J., Emde, R., y Svejda, M. (1983). Emotions as behavior regulators: Social referencing in infants. In R. Plutchik, \& H. Kellerman (Ed.), Emotion theory, research, and experience (pp. 57-68). New York: Academic Press.

Kolb, B., y Whishaw, I. Q. (2006). Neuropsicología humana. Ed. Médica Panamericana.

Kramer, A. D., Guillory, J. E., y Hancock, J. T. (2014). Experimental evidence of massivescale emotional contagion through social networks. Proceedings of the National Academy of Sciences, 111, 8788-8790.

Lambert, N. M., Clark, M., Durtschi, J., Fincham, F. D., y Graham, S. (2010). Benefits of expressing gratitude: Expressing gratitude to a partner changes the expresser's view of the relationship. Psychological Science, 21, 574-580.

Lane, R. D., Reiman, E.M.; Ahern, G .L; Schwartz, G, E., y Davidson, R.J. (1997). Neuroanatomical Correlates of Happiness, Sadness, and Disgust. Journal Psychiatry, 154, 926-933.

Laird, J. D. (1974). Self-attribution of emotion: the effects of expressive behavior on the 
quality of emotional experience. Journal of personality and social psychology, 29, 475.

Lakin, J.L. y Chartrand, T.L. (2003). Using noconscious behavioral mimicy to create affiliation and rapport. Psychological Science, 14, 334-339.

Law K. S, Wong C.S, Song L.J. 2004. The construct and criterion validity of emotional intelligence and its potential utility for management studies. Journal of applied Psychology, 89, 483-496.

Law, K. S., Wong, C., Huang, G., y Li, X. (2008). The effects of emotional intelligence on job performance and life satisfaction for the research and development scientist in China. Asia Pacific Journal of Management, 25, 51-69.

Lazarus, R. (1984). On the primacy of cognition. American Psychologist, 39, 124-129.

Lazarus, R. (1991). Emotion and adaptation. New York: Oxford University Press.

Lazarus, R. (2001). Relational meaning and discrete emotions. En K.R. Scherer, A. Schorry T. Johnstone (Ed), Appraisal processes in emotion: Theory, methods, research (pp 37-67). New York: Oxford University Press.

Lazarus, R. S., y Folkman, S. (1984). Stress, Appraisal and coping. New York: Springer Publishing Company.

LeBreton, J. M., y Senter, J. L. (2007). Answers to 20 questions about interrater reliability and interrater agreement. Organizational Research Methods, 11, 815-852.

LeDoux, J. E. (1993). Emotional Memory: In Search of Systems and Synapsesa. Annals of the New York Academy of Sciences, 702, 149-157.

LeDoux, J. El cerebro emocional. Barcelona: Ariel-Planeta, 1999.

LeDoux, J.E. (2007). Emotional memory. Scholarpedia, 2, 1806. 
Leithwood, K. y Louis, K. S. (2011). Linking Leadership to Student Learning: Empirical Insights. San Francisco: Jossey Bass.

León, F. G., Martínez, J. M. A., Cruz, J. S., y Hernández, L. M. (2011). Emoción y toma de decisiones: teoría y aplicación de la Iowa gambling task. Revista Electrónica de Psicología Iztacala, 14, 333.

León, I. (2000). Evaluación Cognitiva y Emoción. Emociones THÉMATA, 25, 255-259.

Lerner, J. S., Goldberg, J. H., y Tetlock, P. E. (1998). Sober second thought: The effects of accountability, anger, and authoritarianism on attributions of responsibility. Personality and Social Psychology Bulletin, 24, 563-574.

Lerner, J. S., y Keltner, D. (2000). Beyond valence: Toward a model of emotion-specific influences on judgement and choice. Cognition \& Emotion, 14, 473-493.

Leslie, A. M. (1987). Pretense and representation: The origins of" theory of mind. Psychological review, 94, 412.

Leslie, A. M. (2000). How to acquire a "representational theory of mind." En D.Sperber (Ed.), Metarepresentations: A multidisciplinary perspective (pp. 197-223). Oxford, UK: Oxford University Press.

Lester, S.W., Meglino, B.M., y Korsgaard, M.A. (2002). The antecedents and consequences of group potency: A longitudinal investigation of newly formed groups. Academy of Management Journal, 45, 352-368.

Levenson, R. W. (1996). Biological substrates of empathy and facial modulation of emotion: Two facets of the scientific legacy of John Lanzetta. Motivation and Emotion, 20, 185-204.

Liden, R. C.; Sparrow, R. T. y Wayne, S. J. (1997). Leader-member exchange theory: the 
past and potential for the future. Research in Personnel and Human Resources Management, 15, 47-119.

Liébana, P. C., Fernández -Martínez, M., Bermejo, J. C., Carabias Maza, M., Rodríguez, M., y Villacieros, M. (2012). Inteligencia emocional y vínculo laboral en trabajadores del Centro San Camilo. Gerokomos, 23, 63-68.

Lievens, F., Klehe U.C, Libbrecht N. (2011). Applicant versus employee scores on selfreport emotional intelligence measures. Journal of applied Psychology, 10, 89-95.

LLorens, S., Del Líbano, M., y Salanova, M. (2009). Modelos teóricos de salud ocupacional. En M. Salanova (Ed.), Psicología de la Salud Ocupacional (pp. 6393). Madrid: Síntesis.

Lindell, A. K. (2013). Continuities in emotion lateralization in human and non-human primates. Frontiers in human neuroscience, 7.

Lindsey, D. (1951). Emotion. Handbook of Experimental Psychology Nueva York: S.S. Stevens.

Lopes, P. N., Côté, S. y Salovey, P. (2006). An ability model of emocional intelligence: Implications for assessment and training. En V. Druskat, F. Sala, y G. Mount (Eds.). Linking emotional intelligence and performance at work: Current research evidence (pp. 53-80). Mahwah, NJ: Lawrence Erlbaum.

Lopes, P. N., Grewal, D., Kadis, J., Gall, M., y Salovey, P. (2006). Evidence that emotional intelligence is related to job performance and affect and attitudes at work. Psicothema, 18, 132-138.

Losada, M.; Heaphy, E. (2004). The Role of Positivity and Connectivity in the 
performance of Business Teams: A Nonlinear Dynamics Model American Behavioral Scientist, 47, 740-765.

Lowe, K. B., y Gardner, W. L. (2000). Ten years of The Leadership Quarterly: Contributions and challenges for the future. The Leadership Quarterly, 11, 459514.

Luce, M. F., Bettman, J. R., y Payne, J. W. (1997). Choice processing in emotionally difficult decisions. Journal of Experimental Psychology: Learning, Memory, and Cognition, 23, 384 .

Lundqvist, L. O, Dimberg, U. (1995). Facial expressions are contagious. Journal of Psychophysiology, 9, 203-211.

Lundqvist, D. y Öhman, A. (2005). Caught by the evil eye: nonconscious information processing, emotion, and attention to facial stimuli. En L. F. Barrett, P. M. Niedenthal y P. Winkielman (Eds.), Emotion and consciousness (pp. 97-122). Nueva York: The Guilford Press

Lunenburg, F. C. (2010). Leader-member exchange theory: Another perspective on the leadership process. International Journal of Management, Business and Administration, 13, 1-5.

Luthans, F. (2002). The need for and meaning of positive organizational behavior. Journal of Organizational Behavior, 23, 695-706.

Luthans, F., y Avolio, B. J. (2003). Authentic leadership: A positive development approach. En K.S. Cameron, J.E. Dutton y R.E. Quinn (Ed.). Positive organizational scholarship: Foundations of a new discipline (pp. 241-261). San Francisco. Berrett-Koehler. 
Luthans, F., y Youssef, C. M. (2004). Human, social, and now positive psychological capital management: Investing in people for competitive advantage. Organizational Dynamics, 33, 143-160.

Luthans, F., Avolio, B. J., Walumbwa, F.O., y Li, W. (2005). The psychological capital of Chinese workers: Exploring the relationship with performance. Management and Organization Review, 1, 247-269.

Luthans, F.; Youssef, C. y Avolio, J. B. (2007). Psychological Capital: developing the human competitive edge. New York: Oxford University Press.

Luthans, F., Avolio, B.J., Avey, J.B., y Norman, S.M. (2007). Positive psychological capital: Measurement and relationship with performance and satisfaction. Personnel Psychology, 60, 541-572.

Lyubomirsky, S., King, L., y Diener, E. (2005). The benefits of frequent positive affect: does happiness lead to success? Psychological bulletin, 131, 803.

McCann, C., Roberts, R. D., Matthews, G and Zeidner, M. (2004). Effects of empirical option weighting on the reliability and validity of performance-based emotional intelligence (El) tests. Personality and Individual Differences, 36, 645-662.

Maccoby, E .E. y Jacklin, C. N. (1974). The Psychology of sex differences. Stanford: Stanford University Press.

MacLean, P. D. (1970). The triune brain, emotion and scientific bias. En:Schmitt, FO., (Eds), The Neurosciences: Second Study Program, (p.336-349.). New York: Rockefeller University Press.

Malmo, R.B. (1958).Measurement of drive: An unsolved problem in Psychology. En M.R 
Jones (ed.): Nebraska Symposium on Motivation 1958 (pp. 229-265). Lincoln: University of Nebraska Press.

Malmo, R. B. (1959). Activation: a neuropsychological dimension. Psychological Review, 66, 367-386.

Mann, F. C. (1965). Toward an understanding of the leadership role in formal organization En R. Dublin (Ed.), Leadership and productivity (pp. 68-103). San Francisco: Chandler

Mancini, G., y Trombini, E. (2011). Dalle emozioni all'intelligenza emotive "comprendere per educare”.Torino: Esspres edizioni.

Manes, F. (2008). Tratado de neuropsicología y neuropsiquiatría clínica. Buenos Aires: Akadia.

Mandler, G. (1975). Mind and Emotion. Nueva York: Wiley.

Mandler, G. (1984). Mind and Body: Psychology of Emotion and Stress. Nueva York: Norton.

Mäkikangas, A., Kinnunen, S., Rantanen, J., Mauno, S., Tolvanen, A., y Bakker, A.B. (2014). Association between vigor and exhaustion during the workweek: A personcentered approach to daily assessments. Anxiety, Stress, and Coping, 27, 555-575

Márquez, M., Salguero, P., Paíno, S., Alameda, J.R. (2013). La hipótesis del Marcador Somático y su nivel de incidencia en el proceso de toma de decisiones. Revista Electrónica de Metodología Aplicada, 18, 17-36.

Marshall, G. D., y Zimbardo, P. G. (1979). Affective consequences of inadequately explained physiological arousal. Journal of Personality and Social Psychology, 37, 970-988. 
Martin, L. L., Abend, T., Sedikides, C., y Green, J. D. (1997). How would I feel if...? Mood as input to a role fulfillment evaluation process. Journal of Personality and Social Psychology, 73, 242.

Martínez, I., Munduate Jaca, L., y Medina Díaz, F. J. (2008). Efectividad de los patrones de influencia. Psicothema, 20, 369-375.

Martínez-Selva, J. M., Sánchez-Navarro, J.P., Bechara, A. y Román, F. (2006). Mecanismos cerebrales de la toma de decisiones. Revista Neurología.42, 411-418.

Maslach, C. (1979). Negative emotional biasing of unexplained arousal. Journal of Personality and Social, 37, 953-969.

Mayer, J. D., y Salovey, P. (1993). The intelligence of emotional intelligence. Intelligence, $17,433-442$.

Mayer, J. D., y Salovey, P. (1997). What is emotional intelligence? En P. Salovey \& D. Sluyter (Eds.), Emotional development and emotional intelligence: Implications for educators (pp. 3-31). New York: Basic Books

Mayer, J. D., Caruso, D., y Salovey, P. (1999). Emotional intelligence meets traditional standards for an intelligence. Intelligence, 27, 267-298.

Mayer, J. D., Caruso, D. y Salovey, P. (2000). Selecting a measure of emotional intelligence: The case for ability scales. En R. Bar-On \& J.D.A. Parker (Eds.), The handbook of emotional intelligence (pp. 320-342). San Francisco: Jossey-Bass.

Mayer J. D, Salovey, P. y Caruso D. R., (2002). Mayer-Salovey-Caruso Emotional Intelligence Test (MSCEIT), Toronto, Ontario: Multi-Health Systems, Inc

Mayer, J. D., Salovey, P., Caruso, D.R., y Sitarenios, G. (2003). Measuring emotional intelligence with the MSCEIT V2.0. Emotion, 3, 97-105 
Mayer, J. D. y Salovey, P. (2007). ¿Qué es Inteligencia Emocional? En J. M.

Mestre Navas P. Fernández Berrocal (coords.), Manual de inteligencia emocional (pp. 25-45). Madrid: Pirámide.

Mayer, J.D., Roberts, R.D., y Barsade, S.G. (2008). Human abilities: Emotional intelligence. Annual Review of Psychology, 59, 507-536.

Mayor, M. L. (1998). Motivación. En A. Puente Ferreras (Ed.) Cognición y Aprendizaje. Madrid: Pirámide.

Mateo, V., y Vilaplana, A. (2007). Estrategias de identificación del alumno inatento e impulsivo desde el contexto escolar. Quaderns Digitals, 5, 13-28.

McClelland, C. D. (1973). Testing for competence rather than for intelligence. American psychologist .28, 1.

McClelland, D. C. (1998). Identifying competencies with behavioral-event interviews. Psychological Science, 9, 331-339.

Medin, D., Ross B., Markman, A. (2005). En Cognitive Psychology 4Th edition. (Ed), Judgment and Decision Making, (Capitulo14), USA: John Wiley and Sons, Inc.

Mestre, V., Samper, P., y Frías, D. (2004). Personalidad y contexto familiar como factores predictores de la disposición prosocial y antisocial de adolescentes. Revista. Latinoamericana de Psicología, 36, 445-457.

Mestre, J. M. y Fernández Berrocal, P. (2007) Manual de Inteligencia Emocional, Madrid: Pirámide.

Mestre, J. M., Guil, M. R., Brackett, M., y Salovey, P. (2008). Inteligencia emocional: Definición, evaluación y aplicaciones desde el modelo de habilidades de Mayer y Salovey. En Motivación y emoción (pp. 407-438) McGraw-Hill 
Mellado, C. (2005). Gestión de la Comunicación Interna en la Pequeña Empresa Industrial: un Análisis de los Procesos Organizacionales: Clima y Liderazgo. Razón y Palabra, $10,43$.

Meltzoff, A. N., y Moore, M. K. (1977). Imitation of facial and manual gestures by human neonates. Science, 198, 75-78.

Meltzoff, A.N. (2002). Elements of a developmental theory of imitation. En A. N. Meltzoff, y W. Prinz (Eds.), The imitative mind: Development, evolution, and brain bases (pp. 19-41). Cambridge: Cambridge University Press

Mestre, J. M., y Guil R. (2012). La Regulación de las emociones. Una vía de adaptación personal y social. Madrid: Pirámide

Miron-Spektor, E., Efrat-Treister, D., Rafaeli, A., y Schwarz-Cohen, O. (2011). Others anger makes people work harder not smarter: The effect of observing anger and sarcasm on creative and analytic thinking. Journal of Applied Psychology, 96, 1065-1075.

Mojardín-Heráldez, H. A. (2008). Origen y manifestaciones de las falsas memorias. Acta Colombiana de Psicología, 11,37-43.

Mojardín-Heráldez, A., Elizalde-Monjardín, M., Rodelo-Morales, N.I., N., GonzálezOceguera, M.M, y Urquidez, M.E. (2012). ¿Cómo interactúan la memoria y las emociones? En UAS-UANL-COECYT (Eds), Nuevas Rutas de Investigación e Intervención Psicológicas (Capítulo 4).

Moreno-Jiménez, B., Garrosa, E., Corso, S., Boada, M., y Rodríguez Carvajal, R. (2012). Personalidad resistente y capital psicológico: las variables personales positivas y los procesos de agotamiento y vigor. Psicothema, 24, 79-86. 
Moriano, J.A., Molero, F., y Lévy-Mangin, J.P. (2011). Liderazgo auténtico. Concepto y validación del cuestionario ALQ en España. Psicothema, 23, 336-341.

Moruzzi, G., y Magoun, H. (1949). Brain stem reticular formation and activation of EEG. Electroencephalography and Neurophysiology, 455-473.

Moya-Albiol, L., Herrero, N., y Bernal, M. C. (2010). Bases neuronales de la empatía. Revista de Neurología, 50, 89-100.

Murillo Torrecilla, F. J. (2008). Los modelos multinivel como herramienta para la investigación educativa. Revista Internacional de Investigación en Educación, 1, 45-62.

Newcombe, M., J., Ashkanasy N.M. (2002). The role of affect and affective congruence in perceptions of leaders: An experimental study. Leadership Quarterly, 13, 601-14.

Nel, M. (2001). An Industrial Psychological investigation into the Relationship between Emotional Intelligence and Performance in the Call Centre Environment. Tesis fin de Master. Universidad de Stellenbosch. Suráfrica.

Newton, D.P. (2013). Moods, emotions and creative thinking: A framework for teaching Thinking. Skills and Creativity, 8, 34-44.

Nilsson, P. (2003).Empathy and emotions: On the notion of empathy as emotional sharing. Umea, Suecia: Umea University Print \&Media.

Norman, D.A. (2004). Emotional design. Why we love (or hate) everyday things, USA: Basic Books.

Northouse, P.G. (2010). Leadership: Theory and practice Thousand Oaks, CA: Sage Publications.

Nygren, T. E., Isen, A.M., Taylor, P. J, y Dulin, J. (1996). The influence of positive affect 
on the decision rule in risk situations: Focus on outcome (and especially avoidance of loss) rather than probability. Organizational Behavior and Human Decision Process, 66, 59-72.

Ochsner, K.N. (2000). Are affective events richly "remembered" or simply familiar? The experience and process of recognizing feelings past. Journal of Experimental Psychology General, 129, 242-261.

Öhman, A., Flykt, A., y Esteves, F. (2001). Emotion drives attention: detecting the snake in the grass. Journal of experimental Psychology general, 130, 466.

Oros, L. B., Manucci, V., y Richaud de Minzi, M. C. (2011). Desarrollo de las emociones positivas en la niñez. Lineamientos para la intervención escolar. Educación y Educadores, 14, 493-509.

Osborn, R. N. y Hunt, J. G. (1975). An adaptive-reactive theory of leadership: The role of macro variables in leadership research. En: HUNT, J. G. y LARSON, L.L. (Eds.). Leadership frontiers. Kent, OH. Kent State University Press

Palmero, F. (1996). Aproximación biológica al estudio de la emoción. Anales de Psicología, 12, 61-86.

Palmero, F. y Fernández-Abascal, E. G. (1998): Emociones y adaptación. Barcelona: Ariel Palmero, F., Martínez-Sánchez, F., y Fernández-Abascal, E. G. (2002). El proceso motivacional. En: F. Palmero, E. Fernández-Abascal, F. Martínez, y M. Choriz (Eds.). Psicología de la motivación y la emoción, (pp. 35-55) Madrid: McGraw Hill/Interamericana de España.

Palmero, F. (2003). La emoción desde el modelo biológico. Revista Electrónica de Motivación y Emoción, 6, 13. 
Palmero, F., Guerrero, C., Gómez, C., y Carpi, A. (2006). Certezas y controversias en el estudio de la emoción. Revista Electrónica de Motivación y Emoción, 9, 23-24

Palomo, M.T. (2013). Liderazgo y motivación de equipos de trabajo. Madrid: ESIC

Pan, W., Wang, T., Wang, X., Hitchman, G., Wang, L., y Chen, A. (2014). Identifiying the Core Components of Emotional Intelligence: Evidence from Amplitude of LowFrequency Fluctuations during Resting State. PLoS One, 9,111435.

Panksepp, J. (1982). Toward a general psychobiological theory of emotions. Behavioral and Brain sciences, 5, 407-422.

Papanicolaou, C. (2004). Schacter y Singer y el enfoque cognitivo. Revista Española de Neuropsicología, 6, 53-73.

Papez, J. W. (1937). A proposed mechanism of emotion. Archives of Neurology and Psychiatry, 38, 725-743.

Patlán, J., Navarrete, Z., García, V., (2010). Comportamiento Organizacional, positivo vs negativo: análisis y confrontación. V encuentro de investigación en ciencias económico administrativas y primer encuentro de integración y articulación de la investigación. México

Pearce, C. L., Gallagher, C. A. y Ensley, M. D. (2002). Confidence at the group level of analysis: A longitudinal investigation of the relationship between potency and team effectiveness. Journal of Occupational and Organizational Psychology, 75, 115119.

Pedhazur, E. J., Schmelkin, L. P. (1991). Measurement, Design, and Analysis: An Integrated Approach. Hillsdale, NJ: Erlbaum. 
Pena, M. y Extremera, N. (2012). Inteligencia emocional percibida en profesorado de primaria y su relación con los niveles de burnout e ilusión por el trabajo (engagement). Revista de Educación, 359, 604-627.

Pérez, M.A. y Redondo, M. (2006). Procesos de valoración procesos de valoración y emoción: características, desarrollo, clasificación y estado actual. Revista Electrónica de Motivación y Emoción, 9, 8.

Petrides, K. V., y Furnham, A. (2000). On the dimensional structure of emotional intelligence. Personality and Individual Differences, 29, 313-320.

Petrides, K. V., y Furnham, A. (2001). Trait emotional intelligence: Psychometric investigation with reference to established trait taxonomies. European Journal of Personality, 15, 425-448.

Petrides, K. V., Frederickson, N., y Furnham, A. (2004). The role of trait emotional intelligence in academic performance and deviant behavior at school. Personality and individual differences, 36, 277-293.

Petrides, K. V, Pérez-González, J.C, y Furnham, A. (2007). On the criterion and incremental validity of trait emotional intelligence. Cognition \& Emotion 21, 26-55.

Pham, M. T. (1998). Representativeness, relevance and the use of feelings in decision making. Journal of Consumer Research, 25, 144-159.

Phillips, M. L., Drevets, W.C., Rauch, S.L., y Lane, R. (2003). Neurobiology of emotion perception I: The neural basis of normal emotion perception. Biological psychiatry, $54,504-514$.

Phelps, E. A. (2006). Emotion and cognition: Insights from studies of the human amygdala. Annual Review of Psychology, 57, 27-53 
Piaget, J. (1974). La prise de conscience. Paris: PUF

Pillai, R., Schriesheim, C., y Williams, E. (1999). Fairness perceptions and trust as mediators for transformational and transactional leadership: A two-sample study. Journal of Management, 25, 897-933.

Pinel, J. P. J (2001) .Biopsicología. Madrid. Prentice Hall.

Plutcnick, R. (1980). Emotion: A Psychoevolutionary synthesis. Nueva York: Harper Row.

Posner, M. I. y Boies, S.J. (1971). Components of attention. Psychological Review, 78, $391-408$.

Posner, M. I., Snyder, C. R., y Davidson, B.J. (1980). Attention and the detection of signals. Journal of experimental psychology General, 109, 160.

Posner, M. I. (1993). Interactions of arousal and selection in the posterior attention network En A. Baddeley y M.L. Weiskrantz (Eds.), Attention, Selection, Awareness and Control. A tribute to Donald Broadbent, (pp. 390-405). New York: Oxford University Press.

Posner, M. I., y Dehaene, S. (1994). Attentional networks. Trends in neurosciences, 17, 7579.

Posner, M. I. (1996). Attention in Cognitive Neuroscience: An Overview. En M. S. Gazzaniga. (Ed.), The Cognitive Neurosciences. (pp. 615-624). London. MIT. Press.

Posner, J., Russell, J. A., y Peterson, B. S. (2005). The circumplex model of affect: An integrative approach to affective neuroscience, cognitive development, and psychopathology. Development and psychopathology, 17, 715-734. 
Power, M. J., y Dalgleish, T. (1999). Two routes to emotion: Some implications of multilevel theories of emotion for therapeutic practice. Behavioural and Cognitive Psychotherapy, 27, 129-14.

Premack, D., y Woodruff, G. (1978). Does the chimpanzee have a theory of mind? Behavioral and brain sciences, 1, 515-526.

Preston, S. y Waal, F. (2002). The communication of emotions and the possibility of empathy in animals. En S. Post, L.Underwood, J. Schloss \& W. Hurlburt (Eds.), Altruistic love: Science, philosophy, and religion in dialogue (pp 284-308). NuevaYork: Oxford University Press.

Pucic, J. (2015). Do as I Say: Ethical Leadership Through the Eyes of Lower Ranks. Journal of Business Ethics, 129, 655-671.

Pylyshyn, Z. W. (1984). Computation and cognition. Cambridge, MA: MIT press.

Quaas, C. (2006). Diagnóstico de Burnout y Técnicas de Afrontamiento al Estrés en Profesores Universitarios de la Quinta Región de Chile. Psicoperspectivas, 1, 6575.

Ravichandran, K., Arasu, R., y Kumar, S. A. (2011). The impact of emotional intelligence on employee engagement behavior: An empirical study. International. Journal of Business and Management, 6, 157-169.

Reddy, V. (2008). Experiencing others: A second-person approach to other-awareness. En: U. Müller., J.I.M. Carpendale., N. Budwing y B. Sokol (Eds.), Social Life and Social Knowledge, pp. 123-144. New York, EE. UU: Lawrence Erlbaum Associates 
Rego, A., Sousa, F., Marques, C., y Cunha, M. (2012). Authentic leadership promoting employees 'psychological capital and creative. Journal of Business Research, 65, 429-437.

Remo, N. (2012). Comparing Two Models of Employee Engagement: An Examination of Antecedents and Outcome Variables. Electronic Theses and Dissertations. Paper 4838.Reise, S. P., y Duan, N. (2003). Design issues in multilevel studies. In S. P. Reise \& N.Duan (Eds.), Multilevel modeling: Methodological advances, issues, and applications (pp. 285-298). Mahwah, NJ: Lawrence Erlbaum

Rico, P. G., y Barona, E. G. (2013). Bienestar laboral: diferencias de género en el personal docente e investigador. Proceedings del X Foro Internacional sobre Evaluación de la Calidad de la Investigación y la Educación Superior (25-28 junio 2013, GranadaEspaña), pp 41-44.

Richard, L. (1984). On the primacy of cognition. American Psychologist, 46, 124-129.

Richard, L. (1991). Emotion and adaptation. New York: Oxford University Press.

Rizzolatti, G., Fadiga, L., Gallese, V., y Fogassi, L. (1996). Premotor cortex and the recognition of motor actions. Cognitive brain research, 3, 131-141.

Rizzolatti, G., Fogassi, L., y Gallese, V. (2001). Neurophysiological mechanisms underlying the understanding and imitation of action. Nature Reviews Neuroscience, 2, 661-670.

Rizzolatti, G., Craighero, L. (2004). The Mirror-Neuron System. Annual Rewiew of Neuroscience, 27, 169-192.

Rizzolatti, G., y Sinigaglia, C. (2006). So quel che fai: il cervello che agisce ei neuroni specchio. Milán: Raffaello Cortina 
Robbins, S. P. y Judge, T. A. (2009).Comportamiento organizacional. México: Pearson Educación.

Robinson, J. E., y L. Z. McArthur (1982). Impact of salient vocal qualities on causal attribution for a speaker's behavior. Journal of Personality and Social Psychology, 43, 236-247.

Robinson, J. P., Shaver, P. R., y Wrightsman, L. S. (1991). Criteria for scale selection and evaluation. Measures of personality and social psychological attitudes, 1, 1-16.

Robinson, S., y Bennett, R. (1995). A typology of deviant workplace behaviors: A multidimensional scaling study. Academy of Management Journal, 38, 555-72.

Rodríguez-Sánchez, A. y Cifre, E. (2012).Guías de Optimización: Experiencias óptimas (Flow) y bienestar subjetivo en el trabajo. Madrid: Síntesis.

Rodríguez-Muñoz, A., y Bakker, A. B. (2013). El engagement en el trabajo. En B. MorenoJiménez \& E. Garrosa Hernández (Eds.), Salud laboral: Riesgos laborales psicosociales y bienestar laboral (pp. 437-452). Madrid: Pirámide

Rolls, E. T. (1986). Neural systems involved in emotion in primates. Emotion. Theory, Research, and Experience, Biological Foundations of Emotion, 3, 125-143.

Rosas, A., Caviedes, E., Arciniegas, A., y Arciniegas, A. (2013). ¿Decisión utilitarista o decisión aleatoria? Crítica a una tesis atrincherada en la neurociencia cognitiva. Ideas y Valores. 62, 179-199.

Rosenzweig, M., y Leiman, A. (1992). Psicología Fisiológica. México: Mc-Graw Hill. Rosete, D., y Ciarrochi, J. (2005). Emotional intelligence and its relationship to workplace performance outcomes of leadership effectiveness. Leadership \& Organization Development Journal, 26, 388-399. 
Rosselli, M., Jurado, M. y Matute, E. (2008) Las funciones ejecutivas a través de la vida. Revista de Neuropsicología, Neuropsiquiatría y Neurociencias, 8, 23-46.

Rosselló, J. (1996). Psicología del sentimiento: Motivación y emoción. Palma: SPIC, Universitat de les Illes Balears.

Rosselló, J. y X. Revert (2008). Modelos teóricos en el estudio científico de la emoción, en F. Palmero y F. Martínez Sánchez (eds.), Motivación y Emoción (pp. 95-138). McGraw-Hill, Madrid.

Rueda, B. y Pérez-García (2007). Estado de la Alexitimia y de los Procesos Emocionales negativos en el ámbito de los factores de riesgo y la sintomatología cardiovascular. Revista de Psicopatología y Psicología Clínica, 12, 105-116.

Ruggieri V. L. (2013). Empatía, cognición social y trastornos del espectro autista. Revista de Neurología, 56, 13-21.

Rusell, J. A. (1980). A circumplex model of affect. Journal of Personality and Social Psychology, 39, 1161-1178.

Russell, J. A. (2003). Core affect and the psychological construction of emotion. Psychological review, 110, 145-172.

Russell, R. F., y Stone, A.G. (2002). A review of servant leadership attributes: developing a mith practical model. Leadership \& Organization Development Journal, 23, 145157.

Sacharin, V. (2009). The Influence of Emotions on Cognitive Flexibility (Tesis Doctoral), The University of Michigan.

Sandoval, C., Gonzalez, P., Sanhueza, L., Borjas, R. y Odgers, C. (2006). Síndrome De 
Burnout En El Personal Profesional Del Hospital De Yumbel. Cuadernos Médicos Sociales, 46, 268-273.

Salanova, M., Peiró, J. M., y Schaufeli, W. B. (2002). Self-efficacy specificity and burnout among information technology workers: An extension of the Job Demands-Control Model. European Journal on Work and Organizational Psychology, 11, 1-25

Salanova, M. y Schaufeli, W. B. (2004): El engagement de los empleados: Un reto emergente para la dirección de los recursos humanos. Estudios Financieros, 261, 109-138.

Salanova, M., Agut, S., y Peiró, J. M. (2005). Linking organizational resources and work Engagement to employee performance and customer loyalty: The mediating role of service climate. Journal of Applied Psychology, 90, 1217-1227

Salanova, M., Cifre, E., Martinez, I. M. y LLorens, S. (2007). Caso a caso en la prevención de riesgos psicosociales. Metodología WONT para una organización saludable. Bilbao: Lettera Publicaciones.

Salanova, M. (2008). Organizaciones saludables: una aproximación desde la Psicología Positiva. En Psicología positiva aplicada (pp. 403-428). Desclée de Brouwer Salanova, M., Llorens, S. y Rodríguez, A. (2009). Hacia una psicología de la salud ocupacional más positiva. En M. Salanova (Dir.), Psicología de la Salud Ocupacional (pp. 247-284). Madrid: Editorial Síntesis.

Salanova, M. (2009). Psicología de la salud ocupacional. Madrid: Editorial Síntesis

Salanova, M., Cifre, E., Martínez, I. M., Llorens, S., y Lorente, L. (2011). Psychosocial risks and positive factors among construction workers. En S. Clarke, C. Cooper, y 
R. Burke (Eds.), Occupational health and safety: Psychological and behavioral challenges (pp. 295-320). UK: Gower.

Salanova, M., Llorens, S., Cifre, E. y Martínez, I. M. (2012). We need a HERO! Towards a validation of the Healthy \& Resilient Organization (HERO). Model. Group \& Organization Management, 37, 785-822.

Salanova, M., Llorens, S., Torrente, P. y Acosta, H. (2013). Intervenciones para promover organizaciones saludables y resilientes (HERO) desde la Psicología Positiva. En F. Palací (Ed.), Psicología de las Organizaciones (en prensa). Madrid: UNED.

Salanova, M., Martínez, I. y Llorens, S. (2014). Una mirada más "positiva" a la salud ocupacional desde la psicología organizacional positiva en tiempos de crisis: aportaciones desde el equipo de investigación WoNT. Papeles del Psicólogo. 35, 22-30.

Salovey, P., y Mayer, J.D. (1990). Emotional intelligence. Imagination, Cognition, and Personality, 9, 185-211.

Salovey, P., Mayer, J.D., y Caruso, D. (2002). The positive psychology of emotional intelligence. En C.R. Snyder \& S.J. Lopez (Eds.), The handbook of positive psychology (pp. 159-171). New York: Oxford University Press.

Salovey, P. (2006). Applied emotional intelligence: Regulating emotions to become healthy, wealthy, and wise. En J. Ciarrochi, J. Forgas, \& J.D. Mayer (Eds.), Emotional intelligence in everyday life: A scientific inquiry (2nd edition, pp. 229248). Philadelphia, PA: Psychology Press.

Salvador, J., Mestas, L., Gordillo, F., Arana, J. M., Meilán, J. J. G., Pérez, E. y Carro, J. (2010). Toma de decisiones en la anorexia nerviosa. Revista de 
Neurología, 50, 703-704.

Schachter, S., Singer, J. (1962). Cognitive, Social, and Physiological Determinants of Emotional State. Psychological Review, 69, 379-399.

Schaufeli, W. B., Salanova, M., González-Roma, V., y Bakker, A. B. (2002). The measurement of engagement and burnout: A two sample confirmation factor analytic approach. Journal of Happiness Studies, 3, 71-92.

Schaufeli, W.B., y Bakker, A.B. (2003).Test manual for the Utrecht Work Engagement Scale .Un published manuscript, Utrecht University, the Netherlands. Recuperado el 31 de octubre de 2014 de http://www.schaufeli.com.

Schaufeli, W. B. y Bakker, A. B. (2004). Job Demands, job resources, and their relationship with burnout and engagement a multi-sample study. Journal of Organizational Behavior, 25, 293-315.

Schaufeli, W .B. Bakker, A. B., y Salanova, M. (2006). The measurement of work engagement with a brief questionnaire: A cross-national study. Educational and Psychological Measurement, 66, 701-716.

Schaufeli, W. B., Taris, T. W., y Van Rhenen, W. (2008). Workaholism, burnout, and work engagement: Three of a kind or three different kinds of employee well-being? Applied Psychology: An International Review, 57, 173-203.

Schaufeli, W. B., y Bakker, A. B. (2010). The conceptualization and measurement of work engagement: A review. En A.B. Bakker y M.P. Leiter (Eds.), Work engagement: A handbook of essential theory and research. New York: Psychology Press.

Scherer, K. R. (2000). Emotions as episodes of subsystem synchronization driven bay non linear appraisal processes. En M.D. Lewis e I. Granic (Eds.), Emotion, 
development and self-organization: Dynamic systems approaches to emotional development (pp. 70-99). Cambridge, UK: Cambridge University Press.

Scherer, K. R. (2001). Appraisal considered as a process of multilevel sequential checking. En K.R. Scherer, A. Schorr y T. Johnstone (Eds.), Appraisal processes in emotion: Theory, methods, research. (pp. 92-120). New York: Oxford University Press.

Schriesheim, C. A., Castro, S. L., y Cogliser, C. C. (1999). Leader-member exchange (LMX) research: A comprehensive review of theory, measurement, and dataanalytic practices. The Leadership Quarterly, 10, 63-113.

Schutte, N. S., Malouff, J. M., Hall, L. E., Haggerty, D. J., Cooper, J. T., Golden, C. J., y Dornheim, L. L. (1998). Development and validation of a measure of emotional intelligence. Personality and Individual Differences, 25, 167-177.

Schwabe, L., Nader, K., \& Pruessner, J. (2013). $\beta$-Adrenergic blockade during reactivation reduces the subjective feeling of remembering associated with emotional episodic memories. Biological Psychology, 92, 227-232.

Schwarz, N. (2000). Emotion, cognition and decision making. Cognition and emotion, 14 433-440.

Sergio, R. P. (2001). Emotional intelligence and mental ability as determinants of job performance among plant supervisors in selected manufacturing firms. Tesis No Publicada. Universidad-Dasmarinas, Behavioral Sciences Department, Philippines.

Smith, B. N., Montagno, R. V., y Kuzmenko, T. N. (2004). Transformational and servant leadership: Content and contextual comparisons. Journal of Leadership and Organizational Studies, 10, 80-91. 
Sendjaya, S., Sarros, J. C. (2002). Servant leadership: its origins, development, and application in organizations. Journal of Leadership and Organization Studies, 9, 5764.

Seligman, M E. P. y Csikszentmihalyi, M. (2000). Positive Psychology: An Introduction. American Psychologist, 55, 5-14.

Seligman, M. E. P. (2002). Authentic Happiness: Using the New Positive Psychology to Realize Your Potential for Lasting Fulfillment. New York: Free Press/Simon and Schuster.

Seligman, M. E. P. (2011). La vida que florece. Barcelona: Ediciones B

Seo, M. G., y Barrett, L. F. (2007). Being emotional during decision making good or bad? An empirical investigation. Academy of Management Journal, 50, 923-940.

Sevinc, L. (2001). The effect of emotional intelligence on career success: Research on the 1990 graduates of Business Administration. Tesis No Publicada. Faculty of Istanbul University.

Schaefer, A., y Philippot, P. (2005). Selective effects of emotion on the phenomenal characteristics of autobiographical memories. Memory, 13, 148-160.

Schaefer, H. S., Larson, C. L., Davidson, R. J., y Coan, J. A. (2014). Brain, body, and cognition: Neural, physiological and self-report correlates of phobic and normative fear. Biological psychology, 98, 59-69.

Sheldon O. J, Ames, D.R, Dunning, D. (2013). Unskilled, Unaware, \& Uninterested in Learning More: Reactions to Emotional Intelligence Feedback. En Academy of Management Proceedings (Eds), (Vol. 2013, No. 1, p. 11901). Academy of Management. 
Scholl, B. J., y Leslie, A. M. (2001). Minds, modules, and meta-analysis. Child development, 72, 696-701.

Shirom, A. (2004). Feeling vigorous at work? The construct of vigor and the study of positive affect in organizations. En D. Ganster \& P. L. Perrewe (Eds.), Research in organizational stress and well-being (Vol. 3, pp. 135-165). Greenwich, CN: JAI.

Shirom, A., Toker, S., Jacobson, O., y Balicer, R. (2010). Feeling vigorous and the risks of all-cause mortality, ischemic heart disease and diabetes: A 20-years follow-up of apparently healthy employees. Psychosomatic Medicine, 72, 727-733.

Shirom, A. (2011). Vigor as a positive affect at work: Conceptualizing vigor, its relations with related constructs, and its antecedents and consequences. Review of General Psychology, 15, 50-64.

Shraga, O., y Shirom, A. (2009). The construct validity of vigor and its antecedents: A qualitative study. Human Relations, 62, 271-291.

Singer, T., y Lamm, C. (2009). The social neuroscience of empathy. Annals of the New York Academy of Sciences, 1156, 81-96.

Siegel, D. J. (2015). The developing mind: How relationships and the brain interact to shape who we are. New York: Guilford Publications.

Sifneos, P. E. (1973). The prevalence of 'alexithymic'characteristics in psychosomatic patients. Psychotherapy and psychosomatics, 22, 255-262.

Silva, J. (2008). Neuroanatomía funcional de las emociones. En Labos E, Slachevsky A, Fuentes P, Manes F. (Eds), Tratado de neuropsicología y neuropsiquiatría clínica. (pp. 271-307). Buenos Aires: Akadia, 
Sivasubramaniam, N., Murry, W. D., Avolio, B. J. y Jung, D. I. (2002). A longitudinal model of the effects of team leadership and group potency on group performance. Group \& Organization Management, 27, 66-96.

Slovic, P., Finucane, M. L., Peters, E., y MacGregor, D. G. (2007). The affect heuristic. European Journal of Operational Research, 177, 1333-1352.

Solís, H., y López-Hernández, E. (2009). Neuroanatomía funcional de la memoria. Arch Neurocien (Mex), 14, 176-187.

Solomon, R. C. (2000). Nuevas reflexiones acerca de las organizaciones de negocios. El éxito basado en la integridad de las personas. Oxford: University Press.

Sohlberg, M. M., y Mateer, C. A. (2001). Cognitive rehabilitation: All integrated neuropsychological approach. New York: Guilford Publications

Sonnenfeld, A. (2010). Liderazgo ético. La sabiduría de decidir bien. Madrid: Ediciones Encuentro, S. A. y Nueva Revista.

Sonnentag, S., Dormann, C., y Demerouti, E. (2010). Not all days are created equal: The concept of state work engagement. En A. B. Bakker y M. P. Leiter (Eds.), Work engagement: Recent developments in theory and research (pp. 25-38). New York, NY: Psychology Press

Spears, L.C., y Lawrence, M. (2004). Practicing servant-leadership: succeeding through trust, bravery and forgiveness. San Francisco: Jossey-Bass.

Stam, D., van Knippenberg, D., y Wisse, B. (2010). The role of regulatory focus in visionary leadership. Journal of Organizational Behavior, 31, 499-518. 
Stajkovic, A.D.; Lee, D., Nyberg, A.J. (2009). Collective efficacy, group potency, and group performance: Meta-analyses of their relationships, and test of a mediation model. Journal of applied Psychology, 94, 814-828.

Staw, B. M., y Barsade, S. G. (1993). Affect and managerial performance: A test of the sadder-but-wiser vs. happier-and-smarter hypothesis. Administrative Science Quarterly, 38, 304-331.

Sternberg, R. J. (1985). Beyond IQ: A Triarchic Theory of Intelligence. Cambridge: Cambridge University Press.

Stone, A.G., Russell, R.F., y Patterson, K. (2003). Transformational versus servant leadership: a difference in leader focus. Leadership \& Organization Development Journal, 25, 349-361.

Stogdill, R. M. (1948). Personal factors associated with leadership: A survey of the literature. The Journal of psychology, 25, 35-71.

Stogdill, R.M. (1974). Handbook of leadership: A survey of the literature. New York: Free Press.

Stogdill, R. M. y Coons, A. E. (1957). Leader behavior: Its description and measurement. Columbus, OH: Bureau of Business Research: The Ohio State University

Storbeck, J., y Clore, G. L. (2005). With sadness comes accuracy; with happiness, false memory: mood and the false memory effect. Psychological Science, 16,785791. 
Stubbs- Koman, E., y Wolff, S. B. (2008). Emotional intelligence competencies in the team and team leader: A multi-level examination of the impact of emotional intelligence on team performance. Journal of Management Development, 27, 55-75.

Stewart, R. (1976). Contrast in management. Maidenhead. Berkshire. UK: McGraw-Hill

Stewart, R. (1982). Choices for the manager: A guide to understanding managerial work. Englewood Cliffs, NJ: Prentice-Hall.

Sy, T., Côté, S., y Saavedra, R. (2005). The contagious leader: Impact of the leader's mood on the mood of group members, group affective tone, and group processes. Journal of Applied Psychology, 90, 295-305.

Tamietto, M., Latini, L., De Gelder, B. y Geminiani, G. (2005). Functional asymmetry and interhemispheric cooperation in the perception of Emotions form facial expressions. Experimental Brain Research, 171, 389-404.

Taris, T. W., Schaufeli, W. B., y Shimazu, A. (2010). The push and pull of work: About the difference between workaholism and work engagement. Work engagement: A handbook of essential theory and research, 39-53.

Taylor, G. J., Bagby, R. M., y Parker, J. D .A. (1997). Disorders of Affect Regulation: Alexithymia. Medical and Psychiatric Illness. Cambridge: Cambridge University Press.

Ten Brummelhuis, L. L., Bakker, A. B., Hetland, J., y Keulemans, L. (2012). Do new ways of working foster work engagement? Psicothema, 24, 113-120.

Thomas, W.H., y Feldman, D. C. (2015). Ethical leadership: Meta-analytic evidence of criterion-related and incremental validity. Journal of Applied Psychology, 100, 948965. 
Thorndike, E. L. (1920). Intelligence and its use. Harper's Magazine, 140, 227-235.

Tims, M., Bakker, A. B., y Xanthopoulou, D. (2011). Do transformational leaders enhance their followers' daily work engagement? The Leadership Quarterly, 22, 121-131.

Tirapu-Ustárroz, J., Muñoz J. M., y Pelegrín-Valero, C. (2002). Funciones ejecutivas: necesidad de una integración conceptual. Revista de Neurología, 34, 673-685.

Tirapu-Ustárroz, J., Molina, y A. Lario P., (2008). Modelos de funciones y control ejecutivo (I). Revista de Neurología, 46, 684-921.

Tirapu-Ustárroz, J., Pérez-Sayes, G., Erekatxo-Bilbao, M. y Peligrín-Valero, C. (2007) ¿Qué es la teoría de la mente? Revista de Neurología, 44,479-489

Tortosa, F., y Mayor, L. (1992). Watson y la Psicología de las emociones: Evolución de una idea. Psicothema, 4, 297-315.

Treviño, L. K, Brown, M. E. y Pincus, L. (2003). A qualitative investigation of perceived executive ethical leadership: perceptions from inside and outside the executive suite”. Human relations, 56, 5-37.

Treviño, L. K, Brown, M. E. y Harrison, D. A. (2005). Ethical Leadership: A social learning perspective for construct development and testing. Organizational Behavior and Human decision Process, 97, 117-134.

Treviño, L. K. y Brown, M. E. (2006). Ethical Leadership: a review and future directions. The leadership Quarterly, 17, 595-616.

Trógolo, M., Pereyra A, Sontón C. (2013). Impacto de Diferentes Estilos de Liderazgo Sobre el Engagement y Burnout: Evidencia en una Muestra de Trabajadores Argentinos. Ciencia \& Trabajo. 15, 152-157.

Tucker, D., M., Watson R.T. y Heilman., K.M. (1977). Discrimination and evocation of 
effectively intoned speech in patients with right parietal disease. Neurology, 27, 947-950.

Tuckey, M. R., Bakker, A. B., y Dollard, M. F. (2012). Empowering leaders optimize working conditions for engagement: a multilevel study. Journal of Occupational Health Psychology, 17, 15.

Tudela, P. (1992). Atención. En J. L. Trespalacios y P. Tudela (Eds.), Atención y Percepción. (pp.119-162). Madrid. Alhambra: Longman

Unda, S. (2013). Estudio sobre la autopercepción del ejercicio de liderazgo ético de dirigentes universitarios en España. Modelo multidimensional y concéntrico de liderazgo ético (MOMUCLE). Tesis Doctoral No Publicada. Universidad Autónoma de Madrid.

Vacharkulksemsuk, T., Sekerka, L. E., y Fredrickson, B. L. (2011). Establishing a Positive Emotional Climate to Create Twenty-first Century Organizational Change. En N. M. Ashkanasy, C. P. M. Wilderom, \& M. F. Peterson (Eds.) Handbook of Organizational Culture and Climate, 2nd Edition (pp. 101-118). Thousand Oaks, CA: Sage.

Valins, S. (1966). Cognitive effects of false heart-rate feedback. Journal of Personality and Social Psychology, 4, 400-408.

Valsania, S. E. (2014). Influencia del liderazgo auténtico en las conductas extra-rol de los empleados. Tesis Doctoral Universidad Nacional de Educación a Distancia. España

Van den Broeck, A., Vander Elst, T., Dikkers, J., De Lange, A., y De Witte, H. (2012). This is funny: On the beneficial role of self-enhancing and affiliative humor in job design. Psicothema, 24, 87-93. 
Van Kleef, G. A., De Dreu, C. K. W., y Manstead, A. S. R. (2004). The interpersonal effects of anger and happiness in negotiations. Journal of Personality and Social Psychology, 86, 57-76.

Van Kleef, G. A., De Dreu, C. K. W., y Manstead, A. S. R. (2006a). Supplication and appeasement in conflict and negotiation: The interpersonal effects of is appointment, worry, guilt, and regret. Journal of Personality and Social Psychology, 91, 124-142.

Van Kleef, G. A., De Dreu, C. K. W., Pietroni, D., y Manstead, A. S. R. (2006b). Power and emotion in negotiation: Power moderates the interpersonal effects of anger and happiness on concession making. European Journal of Social Psychology, 36, 557581.

Van Kleef, G. A., y Côté, S. (2007). Expressing anger in conflict: When it helps and when it hurts. Journal of Applied Psychology, 92, 1557-1569. Academy of Management Journal, 52, 562-580.

Van Kleef, G. A., Oveis, C., Van der Löwe, I., LuoKogan, A., Goetz, J., y Keltner, D. (2008). Power, distress, and compassion: Turning a blind eye to the suffering of others. Psychological Science, 19, 1315-1322.

Van Kleef, G. A., y Van Lange, P. A. M. (2008). What other's disappointment may do to selfish people: Emotion and social value orientation in a negotiation context. Personality and Social Psychology Bulletin, 34, 1084-1095.

Van Kleef, G. A. (2008). Emotion in conflict and negotiation. En N. M. Ashkanasy y C. L. Cooper (Eds.), Research companion to emotion in organizations (pp. 392-404). London: Edward Elgar. 
Van Kleef, G. A. (2009). How emotions regulate social life. Current Directions in Psychological Science, 18, 184-188.

Van Kleef, G., De Dreu, C., y Manstead, A. (2010). An interpersonal approach to emotion in social decision making: The emotions as social information model. Advances in Experimental Social Psychology 42, 45-96.

Van Kleef, G. A., Anastasopoulou, C., y Nijstad, B. A. (2010). Can expressions of anger enhance creativity? A test of the emotions as social information (EASI) model. Journal of Experimental Social Psychology, 46, 1042-1048.

Van Kleef, G. A., Homan, A.C., Beersma, B., y van Knippenberg, D. (2010). On Angry Leaders and Agreeable Followers: How Leaders' Emotions and Followers' Personalities Shape Motivation and Team Performance. Psychological Science, 21 pp 1827-1824.

Van Kleef, G. A., Van Doorn, E. A., Heerdink, M. W., y Koning, L. F. (2011). Emotion is for influence. European Review of Social Psychology, 22, 114-163.

Van Kleef, G. A., Homan, A. C., y Cheshin, A. (2012). Emotional influence at work: Take it EASI. Organizational Psychology Review, 2, 311-339.

Vallejo, M.A. (2006) Atención plena. Mindfulness. EduPsykhe , 5, 231-53

Van Veldhoven, M., y Meijman, T. (1994). Het meten van psychosociale arbeidsbelasting met een vragenlijst: de Vragenlijst Beleving en Beoordeling van de Arbeid (VVBA). Measurement of psychosocial job demands with a questionnaire: The questionnaire experience and evaluation of work(VBBA)]. Ámsterdam: NIA Verdejo-García A., Bechara A. (2010). Neuropsicología de las funciones ejecutivas. Psicothema, 20, 227-235. 
Vijayalakshmi, V. y Bhattacharyya, S. (2012). Emotional contagion and its relevance to individual behavior and organizational Processes: A position paper. Journal of Business Psychology, 27, 363-374.

Visser, V. A., van Knippenberg, D., Van Kleef, G. A., y Wisse, B. (2013). How leader displays of happiness and sadness influence follower performance: Emotional contagion and creative versus analytical performance. The Leadership Quarterly, $24,172-188$.

Volmer, J. (2012). Catching leaders' mood: Contagion effects in teams. Administrative Sciences, 2, 203-220.

Vosburg, S. K. (1998). Mood and the quantity and quality of ideas. Creativity Research Journal, 11, 315-324.

Vuilleumier, P. (2005). How brains beware: neural mechanisms of emotional attention. Trends in cognitive sciences, 9, 585-594.

Vuilleumier, P., y Brosch, T. (2009). Interactions of emotion and attention. The cognitive neurosciences $I V, 925-934$.

Wagner, J. A., y Hollenbeck, J. R. (2004).Comportamiento organizativo: Consiguiendo la ventaja competitiva. Madrid: Thomson.

Walumbwa, F.O., Avolio, B.J., Gardner, W.L., Wernsing, T.S. y Peterson, S.J. (2008). Authentic leadership: Development and validation of a theory-based measure. Journal of Management, 34, 89-126.

Walumbwa, F. O., Wang, P., Wang, H., Schaubroeck, J., y Avolio, B. J. (2010). Psychological processes linking authentic leadership to follower behaviors. The Leadership Quarterly, 21, 901-914. 
Walumbwa, F.O., Luthans, F., Avey, J.B., y Oke, A. (2011). Authentically leading groups: The mediating role of collective psychological capital and trust. Journal of Organizational Behavior, 32, 4-24.

Walumbwa, F. O., Mayer, D. M., Wang, P., Wang, H., Workman, K., y Christensen, A. L. (2011). Linking ethical leadership to employee performance: The roles of leadermember exchange, self-efficacy, and organizational identification. Organizational Behavior and Human Decision Processes, 115, 204-213.

Warr, P. (1987). Work, Unemployment and Mental Health. Clarendon Press: Oxford.

Watson, J.B. (1928). The Heart or the Intellect? Harper's Monthly Magazine, 156, 245-352.

Wechsler, D. (1958). The measurement and appraisal of adult intelligence. (4th Ed.). Baltimore, MD: The Williams \& Wilkins Company.

Wefald, A. J.; Mills, M. J, Smith, M. R., Downey, R. G. (2012). A comparison of three job engagement measures: Examining their factorial and criterion-related validity. Applied Psychology: Health and Wellbeing, 4, 67-90.

Wefald, A. J., y Downey, R. G. (2009). The construct dimensionality of engagement and its relationship with satisfaction. Journal of Psychology: Interdisciplinary and Applied, 143, 91-111.

Weiner, B., Graham, S., y Chandler, C. (1982) Pity, anger and guilt: An attributional analysis. Personality and Social Psychology Bulletin, 8, 226-232.

Wicht, H. (2012). Circuitos en el sistema límbico. Cuadernos Mente y Cerebro, 1, 48-50. 
Wild, B., Erb, M.y Bartels, M. (2001). Are emotions contagious? Evoked emotions while view-ing emotionally expressive faces: Quality, quantity, time course and gender differences. Psychiatry Research, 102, 109-124.

Wilderom, C. P., Hur, Y., Wiersma, U. J., Berg, P. T. V., y Lee, J. (2015). From manager's emotional intelligence to objective store performance: Through store cohesiveness and sales-directed employee behavior. Journal of Organizational Behavior. 6, 825844.

Wilson, K. S., Sin, H. P., y Conlon, D. E. (2010). What about the leader in leader-member exchange? The impact of resource exchanges and substitutability on the leader. Academy of Management Review, 35, 358-372

Wilson, M. G., DeJoy, D. M., Vandenberg, R. J., Richardson, H., y McGrath, A. L. (2004). Work characteristics and employee health and well-being: Test of a model of healthy work organization. Journal of Organizational and Occupational Psychology, 77, 565-588.

Wolff, S. B. (2008). Emotional and social competency inventory: Technical manual updated ESCI research titles and abstracts. Boston, MA: The Hay Group.

Wolfe, J. M., y Horowitz, T. S. (2004). What attributes guide the deployment of visual attention and how do they do it? Nature Reviews Neuroscience, 5, 495-501.

Wong, C., y Law, K. (2002). The effects of leader and follower emotional intelligence on performance and attitude: An exploratory study. The Leadership Quarterly, 13, 243274.

Wright, W. F., y Bower, G. H. (1992). Mood effects on subjective probability assessment. Organizational behavior and human decision processes, 52, 276-291. 
Vroom, V.H. (1964). Work and motivation. New York: Wiley

Vroom, V. H. y Yetton, P. W. (1973). Leadership and decision making. London: University of Pittsburg Press.

Vroom, V. H. y Jago, A. G. (1988). The New leadership: Managing participation in organizations. Englewood Cliffs, NJ. Prentice-Hall

Wundt, W. (1920). Grundiss der Psychologie. Stuttgart: Alfred Kröner.

Xanthopoulou, D., Bakker, A.B., Heuven, E., Demerouti, E., y Schaufeli, W.B. (2008). Working in the sky: A diary study on work engagement among cabin attendants. Journal of Occupational Health Psychology, 13, 345-356.

Xanthopoulou, D., Bakker, A.B, Demerouti, E., Schaufeli, W.B. (2011). Work engagement and financial returns: A diary study on the role of job and personal resources. Journal of Occupational and Organizational Psychology 82, 183-200.

Yerkes, R. M., y Dodson, J.D. (1908). The relation of strength of stimulus to rapidity of habit formation. Journal of comparative and neurological psychology, 18, 459-482.

Yukl, G. (1981). Leadership in organizations. Englewood Cliffs, NJ. Prentice- Hall.

Yukl, G. (1989). Managerial leadership: A review of theory and research. Journal of management, 15, 251-289.

Yukl, G, y Tracey, J. B. (1992). Consequences of influence tactics used with subordinates, peers, and the boss. Journal of Applied Psychology, 77, 525535.

Yukl, G., Kim, H., y Falbe, C.M. (1996). Antecedents of influence outcome. Journal of Applied Psychology, 81, 309-417. 
Yukl, G., Gordon, A. y Taber, T. (2002). A hierarchical taxonomy of leadership behavior: integrating a half century of behavior research. Journal of Leadership and Organizational Studies, 9, 15-32

Yukl, G. (2010). Leadership in organizations (7th ed.). Upper Saddle River, NJ: Prentice Hall.

Yammarino, F., Dionne, S., Schriesheim, C., y Dansereau, F. (2008). Authentic leadership and positive organizational behavior: A meso, multi-level perspective. The Leadership Quarterly, 19, 693-707.

Ying, C. Y., y Ting, S. K. T. (2010). The Relationship between Emotional Intelligence and Effective Leadership among Academic Heads in Higher Learning Educational Institutions. Conferencia Internacional de Business and Economía Research (ICBER). Marzo de 2010 (pp.15-16).

Zajonc, R. B, Pietromanaco, P., y Bargh, J. (1982). Independence and interaction of afecct and cognition. En M.S. Clark y S.T. Fiske (Eds). Affect and cognition. The 17th Annual Carnegie Symposium on Cognition (pp.211-228). Hillsdale, NJ: Erbaulm.

Zajonc, R. B. (1984). On the primacy of emotion. American Psychologist, 39, 117-123.

Zhu, W., Avolio, B. J., y Walumbwa, F. O. (2009). Moderating role of follower characteristics with transformational leadership and follower work engagement. Group \& Organization Management, 34, 590-619. 